
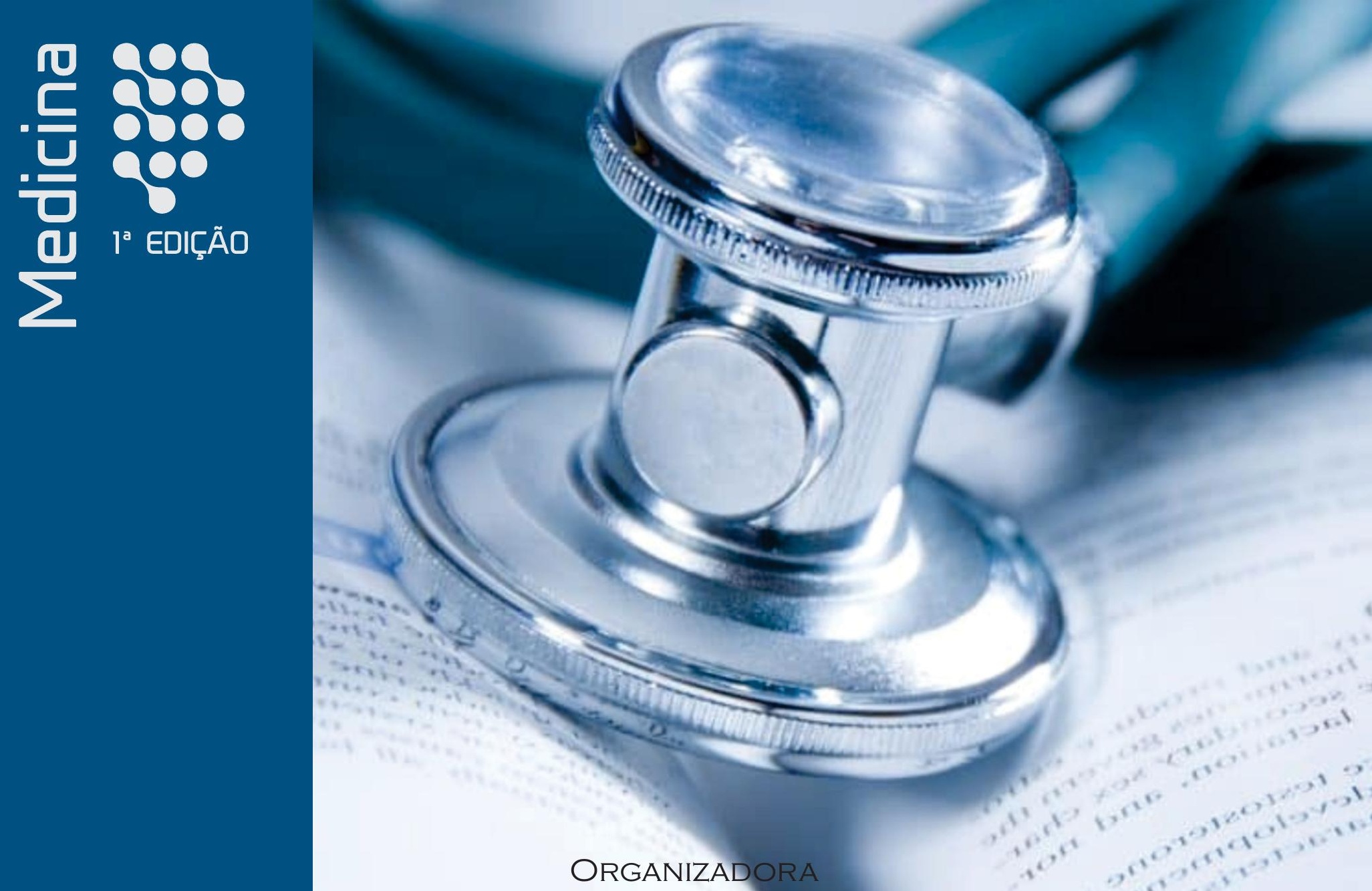
MARIA EMÍLIA DE ABR्SEU CHAVES
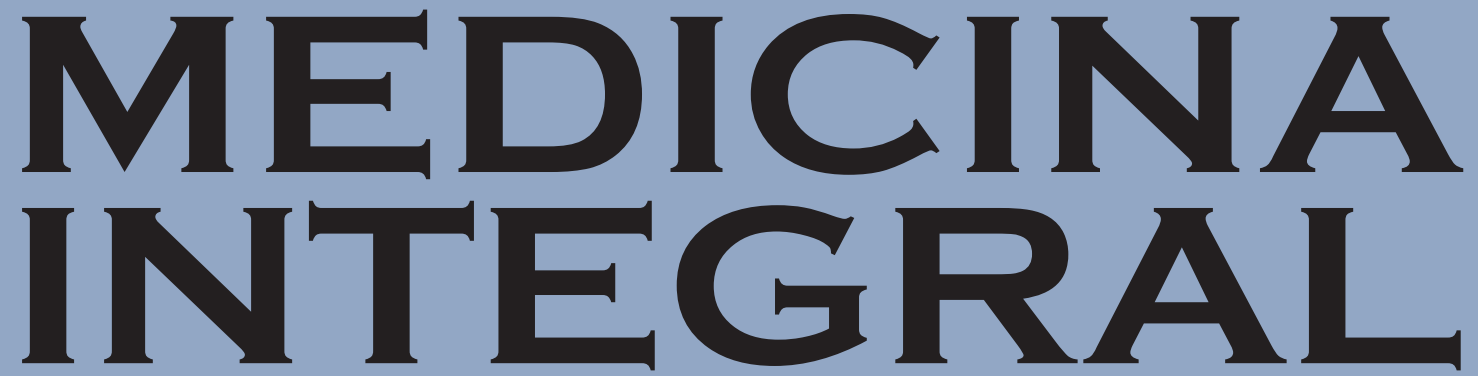

DESAFIOS ENFRENTADOS NO AMBIENTE HOSPITALAR
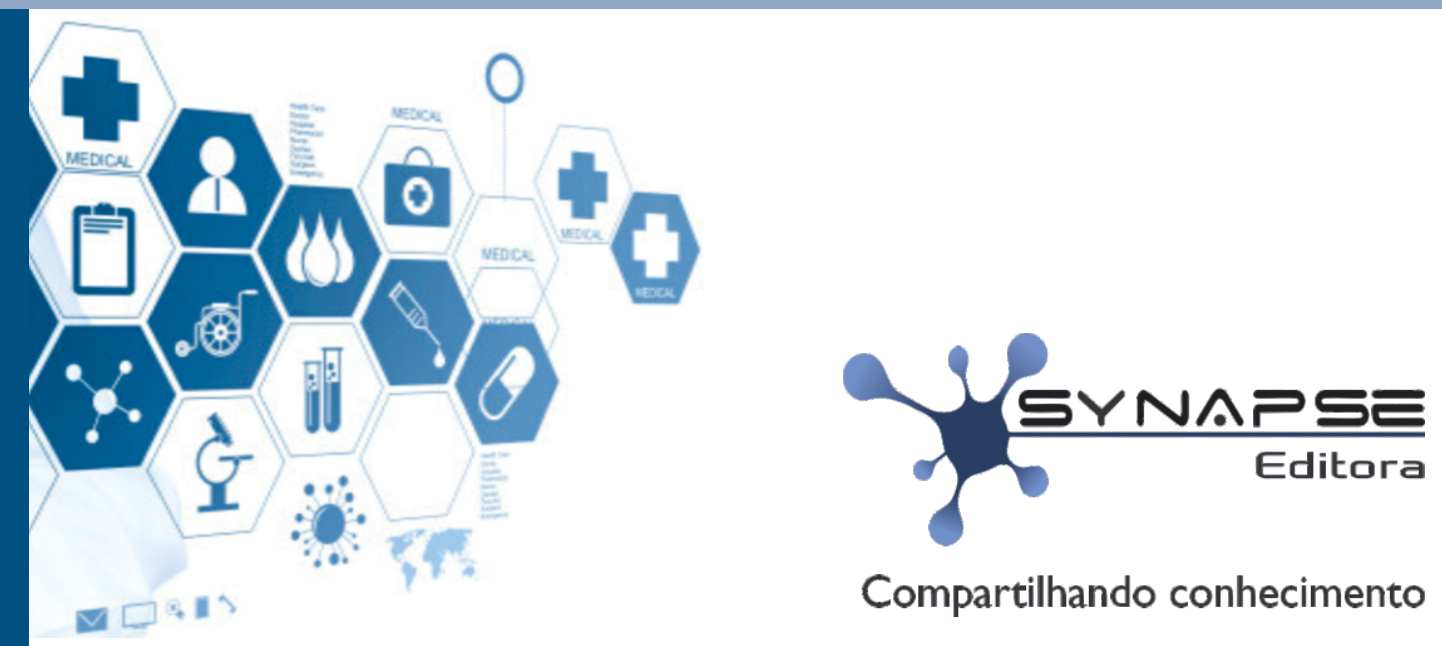

Compartilhando conhecimento 

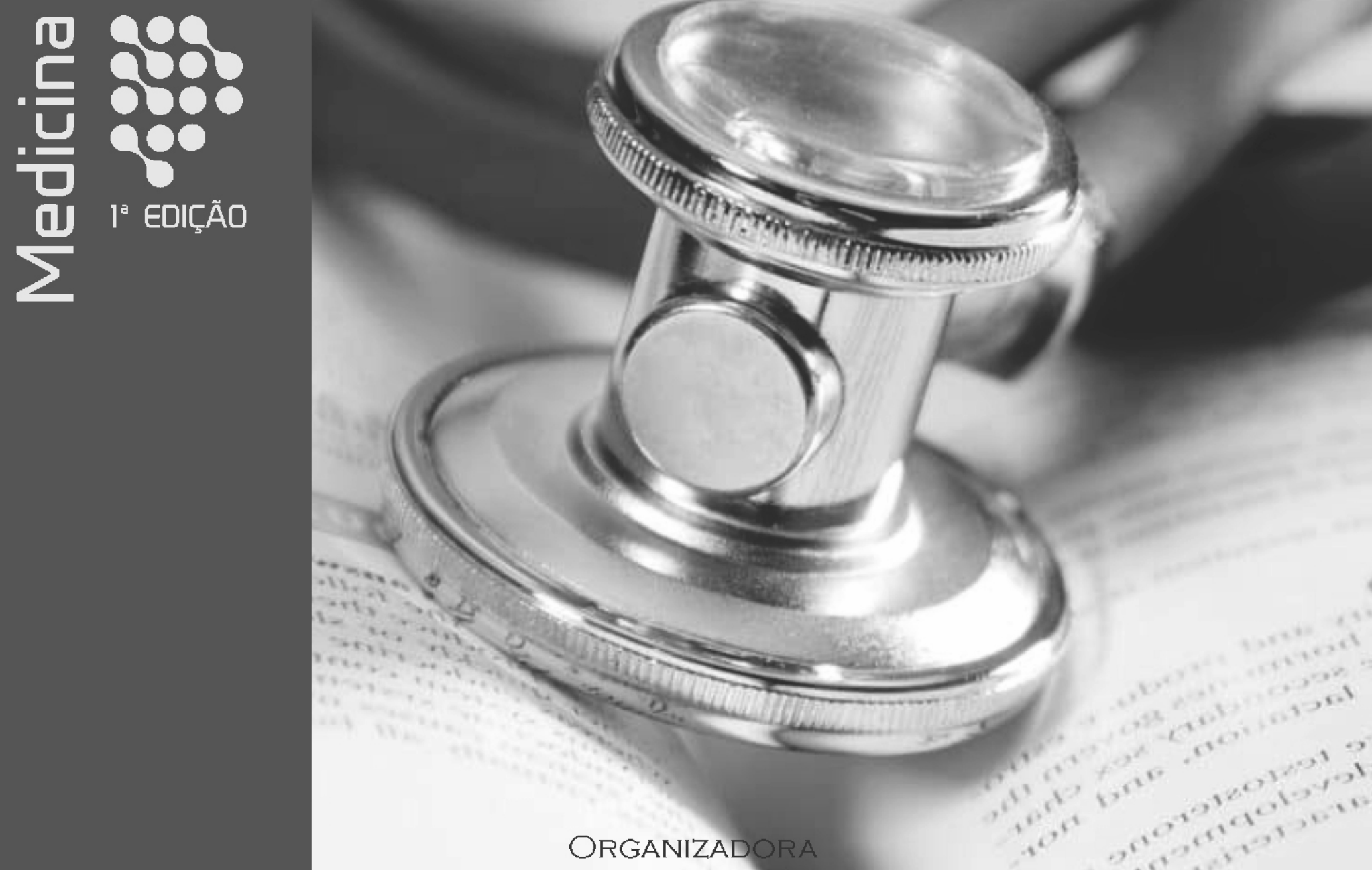

MARIA EMÍLIA DE ABREU ChAVES
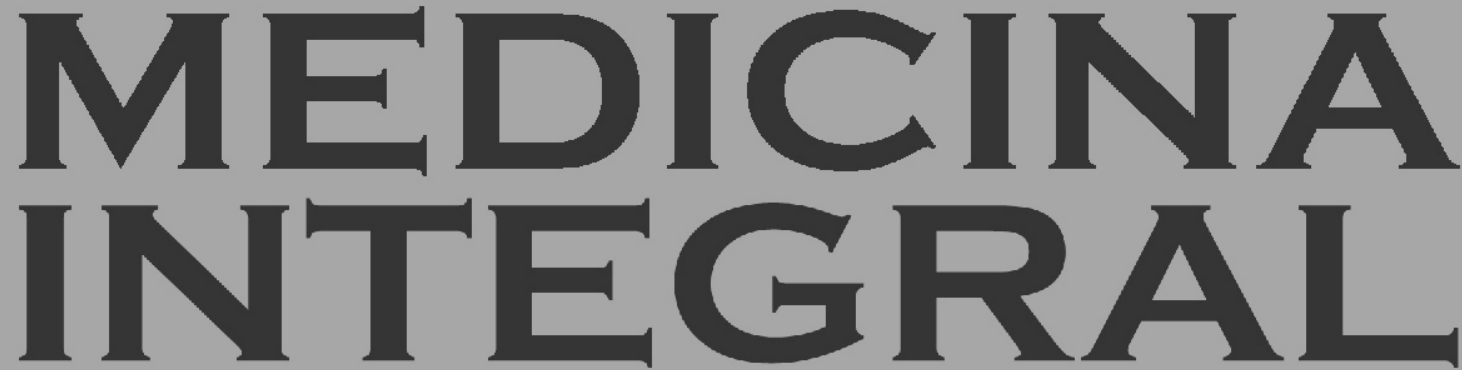

\section{DESAFIOS ENFRENTADOS NO AMBIENTE HOSPITALAR}
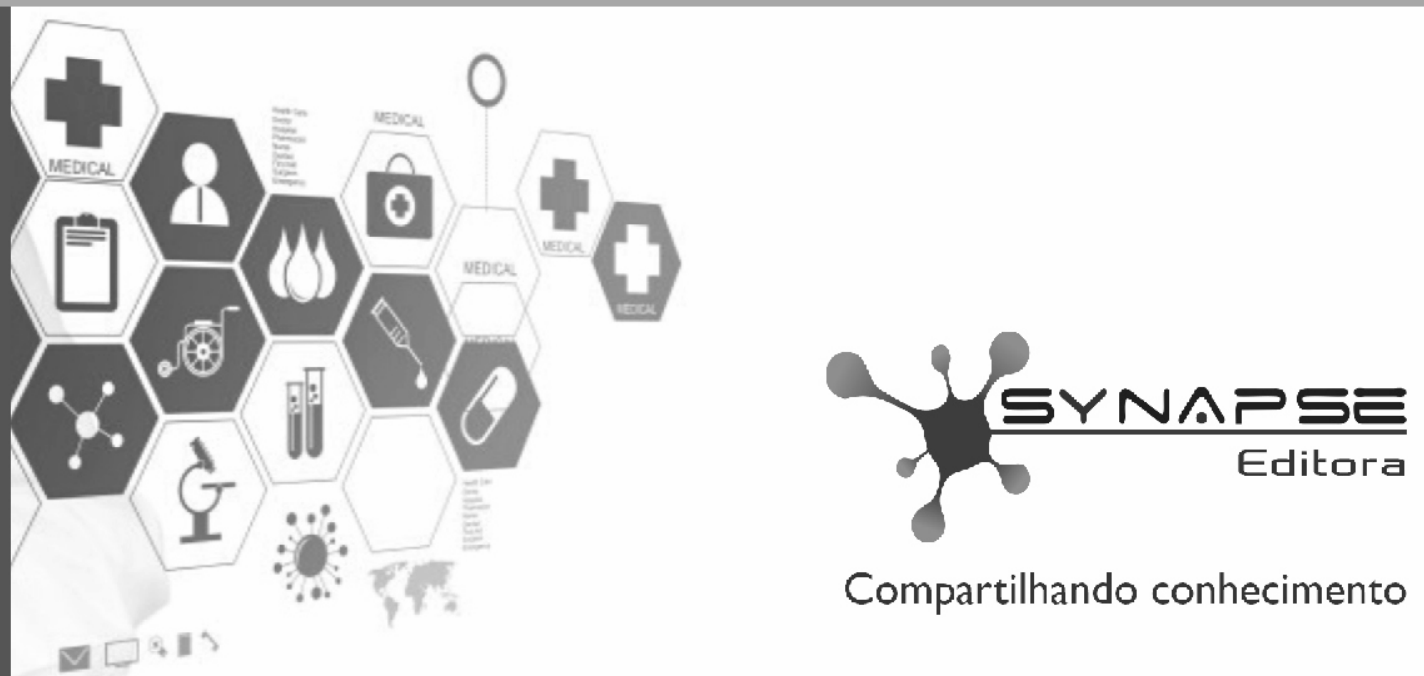

Compartilhando conhecimento

vom 
Editor Chefe

Msc Washington Moreira Cavalcanti

Organizadora

Dra Maria Emília de Abreu Chaves

Conselho Editorial

Msc Lais Brito Cangussu

Msc Rômulo Maziero

Msc Jorge dos Santos Mariano

Dr Jean Canestri

Projeto Gráfico e Diagramação

Departamento de arte Synapse Editora

Edição de Arte

Maria Aparecida Fernandes

Revisão

Os Autores
2021 by Synapse Editora

Copyright (C) Synapse Editora

Copyright do Texto (c) 2021 Os autores

Copyright da Edição (c) 2021 Synapse Editora

Direitos para esta edição cedidos à

Synapse Editora pelos autores.

O conteúdo dos artigos e seus dados em sua forma, correção e confiabilidade são de responsabilidade exclusiva dos autores, inclusive não representam necessariamente a posição oficial da Synapse Editora.

Permitido o download da obra e o compartilhamento desde que sejam atribuídos créditos aos autores, mas sem a possibilidade de alterá-la de alguma forma ou utilizá-la para fins comerciais.

A Synapse Editora não se responsabiliza por eventuais mudanças ocorridas nos endereços convencionais ou eletrônicos citados nesta obra.

Todos os manuscritos foram previamente submetidos à avaliação por parte dos membros do Conselho Editorial desta Editora e pareceristas convidados, tendo sido aprovados para a publicação.

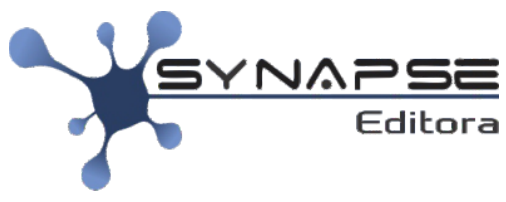

Compartilhando conhecimento 
C512m Chaves, Maria Emília de Abreu

Medicina Integral: Desafios enfrentados no ambiente hospitalar Organizadora: Maria Emília de Abreu Chaves

Belo Horizonte, MG: Synapse Editora, 2021, 178 p.

Formato: PDF

Modo de acesso: World Wide Web.

Inclui bibliografia

ISBN: 978-65-88890-05-9

DOI: doi.org/10.36599/editpa-2021_mint

1. Medicina, 2.Saúde e Sociedade, 3. Saúde pública,

4. Saúde do integral, 5.Ambiente hospitalar.

I. Medicina Integral: Desafios enfrentados no ambiente hospitalar

CDD: $610-610.7$

CDU: $61-616.08$

SYNAPSE EDITORA

Belo Horizonte - Minas Gerais

CNPJ: 20.874.438/0001-06

Tel: + 5531 98264-1586

www.editorasynapse.org

editorasynapse@gmail.com

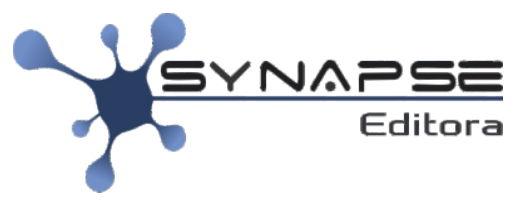

Compartilhando conhecimento

2021 


\section{Apresentação}

Nos últimos anos, a área da saúde foi aprimorada na busca por diagnósticos e tratamentos mais precisos. Com a evolução da tecnologia, tornou-se necessário melhorar a comunicação entre o profissional de saúde e o paciente. Por meio do atendimento humanizado, é possível proporcionar uma melhor forma de cuidado.

Métodos mais eficientes são exigidos pelos pacientes em relação aos profissionais da saúde. Atualizar os conhecimentos sobre o tratamento do paciente de forma integrada e humanizada levou à elaboração do presente livro. Na área da saúde, a humanização é fundamental para aumentar a eficácia do tratamento e a satisfação dos pacientes.

Este livro procurou valorizar estudos recentes de diversos setores da saúde com foco na humanização. Foram selecionados artigos como o papel desempenhado pelos microrganismos orais nas doenças sistêmicas, abordagem terapêutica da obesidade e do hipotireoidismo, atenção à saúde da criança, do idoso e dos homossexuais, tratamento de pacientes com câncer e lesões por pressão, além da promoção da saúde mental de pacientes hospitalizados e dos trabalhadores de saúde envolvidos.

Dra. Maria Emília de Abreu Chaves

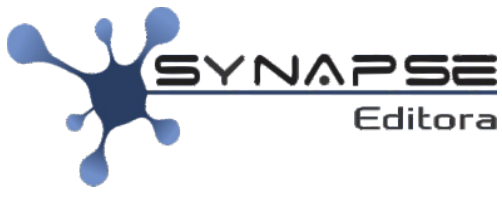

Compartilhando conhecimento

202) 


\title{
Sumário
}

CAPÍTULO 1

FATORES RELACIONADOS ÀS LESÕES POR PRESSÃO NO ÂMBITO HOSPITALAR E O PAPEL DO ENFERMEIRO: REVISÃO INTEGRATIVA

\author{
Barbara Beatriz Lira da Silva \\ Ana Klara Rodrigues Alves \\ Raquel de Brito Pereira \\ Ana Kamila Rodrigues Alves \\ Ana Karla Rodrigues Alves \\ Fábio Dias Nogueira \\ Danielle Souza Silva Varela \\ doi.org/10.36599/editpa-2021_mint-0001
}

CAPÍTULO 2.

O EFEITO DO MINDFULNESS E MINDFUL EATING COMO SUPORTE AO

TRATAMENTO DA OBESIDADE

Érica Vanessa da Silva Retrão

Liejy Agnes dos Santos Raposo Landim

doi.org/10.36599/editpa-2021_mint-0002

\section{CAPÍTULO 3}

PERFIL CLÍNICO-EPIDEMIOLÓGICO E OS PRINCIPAIS DIAGNÓSTICOS DE CRIANÇAS INTERNADAS EM UM HOSPITAL PEDIÁTRICO

Fernanda Maria Melo Pereira

Joseneide Teixeira Câmara

Diellison Layson dos Santos Lima

Amanda Silva Oliveira

Hayla Nunes Conceição

Magnólia de Jesus Sousa Magalhães

doi.org/10.36599/editpa-2021_mint-0003

\section{CAPÍTULO 4}

A ENFERMAGEM FRENTE AO CÂNCER DO COLO DE ÚTERO

Thayane Steinbach Campos Maia

Claudia Tchmola Garcia

Allan Carlos Mazzoni Lemos

Icsor Almeida Araujo

doi.org/10.36599/editpa-2021_mint-0004

\section{CAPÍTULO 5}

REDE DE APOIO AOS HOMOSSEXUAIS VIVENDO COM HIV/AIDS: UMA REVISÃO INTEGRATIVA

Anderson Marcos Vieira do Nascimento

Carlus Alberto Oliveira

Lais Nicolly Ribeiro da Silva

Mirelly dos Santos Matos

Daylâne Danielly dos Santos Silva

Layla Maria da silva Feitosa

Ana Luiza Gonçalves Souza

Diana Dantas Santos

Luana Vilas Boas Dos Santos Chaves

Tatiane Nascimento de Menezes

Márjory de Almeida Silva

Ysabely de Aguiar Pontes Pamplona

Guilia Rivele Souza Fagundes 


\section{Sumário}

\section{CAPÍTULO 6}

PRODUTO EDUCACIONAL PARA ACOMPANHANTE IDOSO: O LÚDICO E A HEUTAGOGIA

Samara Caram Aniceto

Lucrecia Helena Loureiro

doi.org/10.36599/editpa-2021_mint-0006

\section{CAPÍTULO 7}

HIPOTIREOIDISMO NO DESENVOLVIMENTO DA CRIANÇA E DO ADOLESCENTE

Pablo de Matos Monteiro

Pedro da Silva Gerônimo Neto

Mariele Borges Ferreira

Rafael Arouche

Cibelly de Fátima Vieira Ferreira

Lucas Daylor Aguiar da Silva

Kaytlhen Kayllen Carvalho de Menezes

Mirla de Jesus Santos Brasil

Maria Madalena Corrêa Melo

Flavia Castello Branco Vidal

doi.org/10.36599/editpa-2021_mint-0007

\section{CAPÍTULO 8}

81

NEUROPATIA PERIFÉRICA INDUZIDA POR QUIMIOTERAPIA: DESAFIOS NO CUIDADO A

LONGO PRAZO DE PACIENTES ONCOLÓGICOS

Nathalie da Costa Nascimento

Morgana dos Santos Machado

Suélly Krein Heuert

Thamara Graziela Flores

Miriam Cabrera Corvelo Delboni

doi.org/10.36599/editpa-2021_mint-0008

\section{CAPÍTULO 9}

UM OLHAR FENOMENOLÓGICO SOBRE A ANGÚSTIA EXISTENCIAL EM

PACIENTES HOSPITALIZADOS E A PSICOLOGIA HOSPITALAR

Ágnes Cristina da Silva Pala

Rose Mary Costa Rosa Andrade Silva

Eliane Ramos Pereira

Isadora Pinto Flores

Vanessa Carine Gil de Alcântara

Vilza Aparecida Handan de Deus

doi.org/10.36599/editpa-2021_mint-0009

CAPÍTULO 10

MECANISMOS DE ENFRENTAMENTO NA SAÚDE MENTAL DOS TRABALHADORES DO CTI ONCOPEDIÁTRICO: REVISÃO INTEGRATIVA

Elida Gabriela Serra Valença Abrantes

Geilsa Soraia Cavalcanti Valente

Claudia Maria Messias

Elaine Antunes Cortez

Vanessa Teles Luz Stephan Galvão

Jéssica do Nascimento Rezende

doi.org/10.36599/editpa-2021_mint-0010 


\section{Sumário}

CAPÍTULO 11

NARRATIVA DOS IMPACTOS E REPERCUSSÕES DA PANDEMIA DA COVID-19

NA PERSPECTIVA DO ENFERMEIRO EMERGENCISTA:

A ÓTICA NÃO ROMÂNTICA DA LINHA DE FRENTE DO CUIDADO

Denilson da Silva Evangelista

Thiago Valentim de Oliveira Marins

Cristiano Gomes Crispim

Keila do Carmo Neves

Bruna Porath Azevedo Fassarella

Wanderson Alves Ribeiro

Jully Camara Guinancio

Júlio Gabriel Mendonça de Sousa

Bianca Lemos de Carvalho

Ana Beatriz Teodoro de Souza

Amanda de Araújo Franco

Amanda de Almeida Floriano

doi.org/10.36599/editpa-2021_mint-0011

\section{CAPÍTULO 12}

INTER-RELAÇÃO: MICROBIOTA ORAL E DOENÇAS SISTÊMCIAS,

COM FOCO À ABORDAGEM MULTIDISCIPLINAR EM ODONTOLOGIA

Natália Franco Brum

Patrícia Kolling Marquezan

doi.org/10.36599/editpa-2021_mint-0012

CAPÍTULO 13

ATIVIDADE ANTIMICROBIANA E ANTIBIOFILME DA IMUNOGLOBULINA Y:

UMA REVISÃO DE LITERATURA

Fernanda Haboski da Silva

Gabriela da Luz Machado

Patricia Kolling Marquezan

doi.org/10.36599/editpa-2021_mint-0013

PANDEMIC METAPHORS: BIBLIOMETRIC STUDY OF THE COVID-19 (CO)LLATERAL EFFECTS

Priscilla Chantal Duarte Silva

doi.org/10.36599/editpa-2021_mint-0014 


\section{FATORES RELACIONADOS ÀS LESÕES POR PRESSÃO NO ÂMBITO HOSPITALAR E O PAPEL DO ENFERMEIRO: REVISÃO INTEGRATIVA}

\author{
Barbara Beatriz Lira da Silva \\ Universidade Estadual do Piauí - UESPI \\ brbeatriz16@gmail.com \\ Ana Klara Rodrigues Alves \\ Universidade Estadual do Piauí - UESPI \\ Raquel de Brito Pereira \\ Universidade Estadual do Piauí - UESPI
}

\author{
Ana Kamila Rodrigues Alves \\ Universidade Federal do Piauí - UFPI \\ Ana Karla Rodrigues Alves \\ Universidade Federal do Piauí - UFPI \\ Fábio Dias Nogueira \\ Instituto de Educação Superior do Vale do Parnaíba \\ FAHESP/IESVAP \\ Danielle Souza Silva Varela \\ Universidade Federal do Piauí - UFPI
}

\begin{abstract}
RESUMO
INTRODUÇÃO: A lesão por pressão (LPP) desenvolve-se a partir da pressão prolongada sobre a superfície da pele ou tecidos moles, dificultando ou impedindo a perfusão tissular, ocasionando um dano subjacente em tecidos e, principalmente, em proeminências ósseas. A finalidade do presente estudo foi levantar fatores de riscos associados à ocorrência de lesão por pressão e a possibilidade de atuação do enfermeiro frente à prevenção dessas de acordo com a literatura. DESENVOLVIMENTO: O presente estudo utilizou como método a revisão integrativa da literatura, realizado através de uma busca na Biblioteca Virtual de Saúde (BVS) nas bases de dados do Lilacs, Medline e Scielo (Scientific Electronic Library Online) usando os cruzamentos dos descritores "Lesão por pressão", "Incidência" e "Hospital". Para a construção deste artigo, aplicou-se o seguinte questionamento: quais os fatores de risco para a ocorrência de LPP no ambiente hospitalar e o papel do enfermeiro frente a esse agravo?
\end{abstract}

Dentre os principais fatores associados à ocorrência de LPP descritos nos estudos analisados estiveram: a exposição da pele, umidade excessiva, pressão sobre proeminência, perda de sensibilidade, imobilidade, friç̧ão e cisalhamento. Além disso, estudos evidenciaram que a incidência de LPP ocorre principalmente em pacientes homens, em estado crítico, com idade acima de 60 anos e em internações mais prolongadas. CONCLUSÃO: Este estudo apresentou os fatores de riscos para a ocorrência de LPP, colaborando no entendimento sobre a multicausalidade no surgimento desse agravo. Verificouse que alguns cuidados se tomados, podem diminuir o aparecimento das lesões, sobretudo, quando direcionados ao ambiente, aos fatores extrínsecos.

Palavras-chave:

Lesão por pressão; Incidência; Hospital.

\section{ABSTRACT}

INTRODUCTION: Pressure injury develops from prolonged pressure on the surface of the skin or soft tissues, making it difficult or impeding tissue perfusion, causing underlying tissue damage and especially bone prominence. The purpose of the present study was to raise risk factors associated with the occurrence of pressure injury and the possibility of nurses acting on their prevention according to the literature. DEVELOPMENT: The present study uses as integrative literature review method, performed through a search in the Virtual Health Library (VHL) in the databases of Lilacs and Medline and Scielo (Scientific Electronic Library Online) using the intersections of the descriptors "Pressure Injury", "Incidence", "Hospital". For the construction of this article, the following question was applied: what are the risk factors for the occurrence of pressure injury in the hospital environment and the nurse's role in relation to this problem? Among the main factors associated with the occurrence of pressure injury described in the analyzed studies were: skin exposure, excessive humidity, pressure on prominence, loss of sensation, immobility, friction and shear. In addition, studies have shown that the incidence of such injuries occurs mainly in critically ill male patients over the age of 60 and in longer hospitalizations. CONCLUSION: This study presented the risk factors for the occurrence of pressure injury, contributing to the understanding of the multicausality in the onset of this condition. It was found that some care can reduce the appearance of lesions, especially when directed to the environment, to extrinsic factors.

\section{Keywords:}

Pressure Injury; Incidence; Hospital. 


\section{INTRODUÇÃO}

No ambiente hospitalar, um dos maiores desafios dos gestores é garantir a segurança do paciente, sendo esse um critério de qualidade da assistência prestada. Nesse contexto, um dos indicadores que expressam a qualidade da assistência é a investigação dos Eventos Adversos (EA). A ocorrência de EA é considerado um aspecto que impacta negativamente na segurança do paciente, a exemplo do surgimento de lesão por pressão (LPP) em pacientes hospitalizados (OLIVEIRA et al., 2016).

A LPP desenvolve-se a partir da pressão prolongada sobre a superfície da pele ou tecidos moles, dificultando ou impedindo a perfusão tissular, ocasionando um dano subjacente em tecidos e, principalmente, em proeminências ósseas. A gravidade da LPP está associada à intensidade da lesão, à duração da pressão exercida e à tolerância dos tecidos. Alguns fatores como a imobilidade, deficiência nutricional, envelhecimento da pele, umidade, fricção, incontinência, pressão, cirurgias e doenças crônicas levam a um estado de vulnerabilidade à LPP, principalmente nos idosos. $O$ envelhecimento da pele é um dos aspectos que influenciam na propensão ao desenvolvimento de lesões por pressão, pois a pele é o órgão mais exposto a agressões externas (SOUZA et al., 2017).

Sua etiologia é multifatorial, vários são os fatores associados ao desenvolvimento das LPP e, dentre esses, especialmente para os pacientes críticos destacam-se a pressão extrínseca associada à idade avançada, o déficit nutricional, a umidade, a imobilidade no leito, a perfusão tecidual diminuída, o uso de drogas vasoativas, a sedação e as comorbidades como diabetes mellitus e doença vascular (CAMPANILI et al., 2015). A frequência de LPP é influenciada por múltiplas condições, incluindo os relacionados aos pacientes e sua gravidade, perfil e complexidade da unidade e características da equipe de profissionais de saúde (GONÇALVES et al., 2012); (PAGNAMENTA et al., 2012).

A ocorrência de LPP é particularmente preocupante, pois possuem perfil de gravidade clínica, maior demanda de medicamentos, necessidade de procedimentos e dispositivos invasivos que resulta em maior risco ao paciente, e deste modo, podem ocasionar aumento de mortalidade e maior permanência hospitalar dos pacientes (ORTEGA et al., 2017). Além disso, provocam dor física, estigma, preconceito, reduz o convívio social e produz impactos negativos na qualidade de vida dessas pessoas, como se observa no cotidiano assistencial (BORGES et al., 2015).

Pesquisadores têm apontado que a prevalência e incidência de LPP têm aumentado nos mais diversos espaços que prestam cuidados de saúde, sejam em instituições de longa permanência, hospitais, unidades de terapia intensiva e domicílios, a doença acomete em pacientes que estejam em estado de risco (SOUSA et al., 2016).

Sabendo disto, considerando que a LPP torna-se um grave problema de saúde pública, destaca-se que a equipe de enfermagem possui uma importante função na prevenção de ocorrências, diminuindo suas consequências, visto que pode atuar na manutenção da integridade da pele, hidratação, estado nutricional, mudança de decúbito, entre outros (SOUZA et al., 2017).

A finalidade do presente estudo foi levantar fatores de riscos associados à ocorrência de lesão por pressão e a possibilidade de atuação do enfermeiro frente à prevenção dessas de acordo com a literatura. 


\section{DESENVOLVIMENTO}

O presente estudo utilizou como método a revisão integrativa da literatura, realizado através de uma busca na Biblioteca Virtual de Saúde (BVS) nas bases de dados do Lilacs, Medline e Scielo (Scientific Electronic Library Online) usando os cruzamentos dos descritores "Lesão por pressão", "Incidência" e "Hospital". Para a construção deste artigo, aplicou-se o seguinte questionamento: quais os fatores de risco para a ocorrência de LPP no ambiente hospitalar e o papel do enfermeiro frente a esse agravo?

Quanto aos critérios de inclusão, introduziram-se artigos escritos nas línguas portuguesa e inglesa; publicados entre os anos 2008 a 2018 e que retrataram os fatores de riscos relacionados a incidência das LPP nos hospitais e o papel do enfermeiro no contexto da prevenção. No que diz respeito aos critérios de exclusão, dispensaram-se artigos que se distanciavam da temática central desta revisão e trabalhos que não apresentavam resumos na íntegra nas bases de dados pesquisadas. Após a préleitura e leitura seletiva dos textos, foram selecionados 22 artigos (Quadro 1), nos quais realizou-se uma leitura interpretativa buscando responder a pergunta de pesquisa desta revisão.

Quadro 1. Distribuição dos artigos utilizados nesta revisão segundo o nome da publicação, autores, revista e ano.

\begin{tabular}{|l|}
\hline \multicolumn{1}{|c|}{ ARTIGOS } \\
\hline $\begin{array}{l}\text { Ocorrência e fatores de risco para lesões } \\
\text { por pressão em centros de terapia intensiva }\end{array}$ \\
\hline $\begin{array}{l}\text { O enfermeiro frente à prevenção de lesão } \\
\text { por pressão: revisão integrativa }\end{array}$ \\
\hline
\end{tabular}

Gerenciamento de riscos em ambiente hospitalar: incidência e fatores de riscos associados à queda e lesão por pressão em unidade clínica

Eventos adversos em Unidades de Terapia Intensiva: estudo bibliométrico

Conhecimentos da equipe de enfermagem sobre prevenção de úlceras por pressão

Assistência de enfermagem na prevenção de lesão por pressão em idosos em ambiente hospitalar: um relato de experiência

Análise de eventos adversos em pacientes internados em unidade de terapia intensiva

Ações de enfermagem antes e após um protocolo de prevenção de lesões por pressão em terapia intensiva

Úlcera por pressão em pacientes criticos: incidência $\mathrm{e}$ fatores associados

Fatores relacionados à ocorrência de eventos adversos em pacientes idosos críticos

Carga de trabalho de enfermagem e ocorrência de eventos adversos na terapia intensiva: revisão sistemática*

Análise da prevalência de desbridamento cirúrgico de úlcera por pressão em um hospital municipal

AUTORES
Paula Knoch Mendonça, Marisa Dias Rolan Loureiro,
Marcos Antônio Ferreira Júnior, Albert Schiaveto de
Souza.
Gabriel Marcos Gomes Santos, Rodrigo Rammony dos
Santos Rocha, Ana Fátima Souza de Melo, Taciana
Silveira Passos.
Rayane Oliveira Cedraz Cristiane Helena Gallasch Eugenio
Fuentes Pérez Júnior Helena Ferraz Gomes, Ronilson
Gonçalves Rocha, Vivian Aline Mininel.
Dariele Dias Dutra, Marcella Costa Souto Duarte, Karla
Fernandes de Albuquerque, Jiovana de Souza Santos,
Kaliny Monteiro Simões, Patrícia da Cruz Araruna.
Nariani Souza Galvão, Maria Alice Barbosa Seriquei, Vera
Lúcia Conceição de Gouveia Santos, Paula Cristina
Nogueira.
Kézia Eunice Costa de Souza, Jonatha Douglas dos Santos
Rocha, Bianca Maria Vieira de Vasconcelos, Paulo Sérgio
Gomes da Silva.
Daniela Benevides Ortega, Maria D'innocenzo, Lucia
Marta Giunta da Silva, Elena Bohomol.
Josilene de Melo Buriti Vasconcelo, Maria Helena Larcher
Caliri.
Andressa Tomazini Borghardt, Thiago Nascimento do
Prado, Sheilla Diniz Silveira BicudoI, Denise Silveira de
CastroI, Maria Edla de Oliveira Bringuente.
Maria Cecilia Toffolettoi, Ricardo Luis Barbosaii, Rafaela
Andolhe, Elaine Machado de Oliveira, Adriana Janzantte
ducc, Katia Grillo Padilha.
Andrea Carvalho de Oliveira, Paulo Carlos Garcia, Lilia de
Souza Nogueira.
Laelson Rochelle Milanês Sousa, Sandra Marina
Gonçalves Bezerra, Rafael Fernandes de Mesquita, Maria
Helena Barros Araújo Luz, Maria Eliete Batista Moura.

\section{Rev}

Escola Anna Nery

REVISTA

ANO DE PUBLICAÇÃO

Rev enferm UFPE on line

Journal of health

connections

2018

Rev Fund Care Online

Ver Bras Enferm

Anais V CIEH

Acta Paul Enferm

Escola Anna Nery

Rev Bras Enferm

2016

Rev Bras Enferm

2016

Rev Esc Enferm USP

2016

Journal of Research

Fundamental Care Online

Continua 


\begin{tabular}{|c|c|c|c|}
\hline ARTIGOS & AUTORES & REVISTA & $\begin{array}{l}\text { ANO DE } \\
\text { PUBLICAÇÃO }\end{array}$ \\
\hline $\begin{array}{l}\text { Incidência de úlceras por pressão em } \\
\text { pacientes de Unidade de Terapia Intensiva } \\
\text { Cardiopneumológica }\end{array}$ & $\begin{array}{l}\text { Ticiane Carolina Gonçalves Faustino Campanili, Vera } \\
\text { Lúcia Conceição de Gouveia Santos, Kelly Cristina } \\
\text { Strazzieri-Pulido, Priscilla de Brito Mendes Thomaz, Paula } \\
\text { Cristina Nogueira. }\end{array}$ & Rev Esc Enferm USP & 2015 \\
\hline $\begin{array}{l}\text { Evaluation of the two-component } \\
\text { compression system for treatment of } \\
\text { varicose ulcer }\end{array}$ & $\begin{array}{l}\text { Eline Lima Borges ,Aidê Ferreira Ferraz, Selme Silqueira } \\
\text { de Matos „José Ferreira Pires Junior ,Andréia Felipe de } \\
\text { Oliveira Nascente. }\end{array}$ & Rev Min Enferm & 2015 \\
\hline $\begin{array}{l}\text { Estresse, coping e burnout da Equipe de } \\
\text { Enfermagem de Unidades de Terapia } \\
\text { Intensiva: fatores associados* }\end{array}$ & $\begin{array}{l}\text { Rafaela Andolhe, Ricardo Luis Barbosa, Elaine Machado } \\
\text { de Oliveira, Ana Lúcia Siqueira Costa, Katia Grillo } \\
\text { Padilha. }\end{array}$ & Rev Esc Enferm USP & 2015 \\
\hline $\begin{array}{l}\text { Úlcera por pressão: um desafio para a } \\
\text { enfermagem }\end{array}$ & $\begin{array}{l}\text { Rosana amora Ascari, Juliana Veloso, Olvani Martins da } \\
\text { Silva, Marciane Kessler, Aline Mara Jacoby, Gabriela } \\
\text { Schwaab. }\end{array}$ & $\begin{array}{l}\text { Brazilian Journal of } \\
\text { Surgery and Clinical } \\
\text { Research }\end{array}$ & 2014 \\
\hline $\begin{array}{l}\text { Prática do enfermeiro intensivista no } \\
\text { tratamento de úlceras por pressão }\end{array}$ & $\begin{array}{l}\text { Anna Livia de Medeiros Dantas ,Patricia Cabral Ferreira, } \\
\text { Késsya Dantas Diniz, Ana Beatriz de Almeida Medeiros, } \\
\text { Ana Luisa Brandão de Carvalho Lira. }\end{array}$ & J.res.: fundam care. online & 2014 \\
\hline $\begin{array}{l}\text { Caracterização e fatores de risco para } \\
\text { úlceras por pressão na pessoa idosa } \\
\text { hospitalizada }\end{array}$ & $\begin{array}{l}\text { Chrystiany Plácido de Brito Vieira, Mirtes Sousa Sá, Maria } \\
\text { Zélia de Araújo Madeira, Maria Helena Barros. }\end{array}$ & Rev Rene & 2014 \\
\hline $\begin{array}{l}\text { Evaluation of the risk for pressure ulcers in } \\
\text { bedridden elderly at home }\end{array}$ & $\begin{array}{l}\text { Geridice Lorna de Andrade Moraes, Thiago Moura de } \\
\text { Araújo, Joselany Áfio Caetano, Marcos Venícios de } \\
\text { Oliveira Lopes, Maria Josefina da Silva }\end{array}$ & Acta Paul Enferm & 2012 \\
\hline $\begin{array}{l}\text { Alocação da equipe de enfermagem e } \\
\text { ocorrência de eventos adversos/incidentes } \\
\text { em unidade de terapia intensiva* }\end{array}$ & $\begin{array}{l}\text { Leilane Andrade Gonçalves, Rafaela Andolhe, Elaine } \\
\text { Machado de Oliveira, Ricardo Luís Barbosa, Ana Cristina } \\
\text { Mancussi e Faro, Renata Mahfuz Daud Gallotti, Katia } \\
\text { Grillo Padilha. }\end{array}$ & Rev Esc Enferm USP & 2012 \\
\hline Úlceras de pressão & $\begin{array}{l}\text { Sheila Rampazzo Luz, André Cleocir Lopacinski, Rogério } \\
\text { de Fraga, Cícero de Andrade Urban. }\end{array}$ & $\begin{array}{l}\text { Ver Geriatria \& } \\
\text { Gerontologia }\end{array}$ & 2010 \\
\hline $\begin{array}{l}\text { Uso da escala de braden e de glasgow para } \\
\text { identificação do risco para úlceras de } \\
\text { pressão em pacientes internados em centro } \\
\text { de terapia intensiva }\end{array}$ & Luciana Magnani Fernandes, Maria Helena Larcher Caliri. & $\begin{array}{l}\text { Rev Latino-am } \\
\text { Enfermagem }\end{array}$ & 2008 \\
\hline
\end{tabular}

Fonte: Autores (2020)

Foi realizada uma análise ampla da literatura com passos pré-definidos, buscando responder o questionamento, descritores, e seus critérios de inclusão e exclusão. Foram encontrados 683 artigos, sendo selecionados 22, destes 3 foram encontrados na Scielo, 6 na base de dados Lilacs e o restante encontrado na base de dados Medline.

Dentre os resultados, os fatores associados à ocorrência de LPP descritos nos estudos analisados estiveram: a exposição da pele, umidade excessiva, pressão sobre proeminência, perda de sensibilidade, imobilidade, fricção e cisalhamento (VIEIRA et al., 2014; CAMPANILI et al., 2015; BORGES et al., 2015; ROQUE et al., 2016; MATOZINHOS et al., 2017; ASCARI et al., 2014; SOUSA et al., 2016); CEDRAZ et al., 2018).

O estudo de Mendonça et al. (2018), por exemplo, no campo da pressão, friç̧ão e cisalhamento, destacou a influência do tipo do colchão utilizado pelos clientes na ocorrência de LPP, sendo maior naqueles que faziam uso do colchão de espuma viscoelástica (51\%), quando comparado aos que utilizavam o colchão pneumático (49\%). Da mesma forma, atribuiu importância às condições dos lençóis, pois quando não conformes, representou uma ocorrência de LPP em $82,4 \%$ dos clientes, enquanto que nos clientes que usaram lençóis conformes, apenas 17,6\% apresentaram LPP. 
Para Ascari et al. (2014), a debilidade, ou seja, a dependência por terceiros para realizar as necessidades do dia-a-dia foi considerado um fator determinante para LPP. Segundo os autores, toda pessoa debilitada se torna mais suscetível e, sobretudo, o decúbito prolongado em mesma posição leva a um risco aumentado de desenvolver esse agravo.

Ademais, a perda de massa muscular, a diminuição de resposta inflamatória, dos níveis de albumina e da tela subcutânea associada à redução na adesão derme e epiderme proporciona maior risco de ruptura da integridade da pele, que já não tem adequada capacidade para redistribuir a carga mecânica a ela imposta, constituindo um item de importante representação para a estratificação de risco (CAMPANILI et al., 2015).

O desenvolvimento de LPP está diretamente relacionado à duração da imobilidade, quando a pressão é prolongada ocorre necrose tissular e a trombose de pequenos vasos. As regiões de proeminências ósseas são mais suscetíveis ao desenvolvimento por serem cobertas apenas por pele e pequenas quantidades de tecido subcutâneo. Pacientes com perda sensorial, níveis comprometidos da consciência ou paralisia podem não estar atentos ao desconforto associado à pressão prolongada sobre a pele. Assim, não ocorre mudança espontânea de posição para aliviar a pressão. A pressão prolongada impede o adequado fluxo sanguíneo, reduzindo a nutrição da pele, levando ao rápido desenvolvimento da lesão (ASCARI et al., 2014)

De acordo com Luz et al. (2010), a umidade é outro importante fator no desenvolvimento de lesões, pois seu excesso torna a pele mais suscetível à lesão, e o contato prolongado com urina gera irritação local, motivos pelo qual o paciente acamado demanda atenção especial. Dessa forma, é indicado o uso de fraldas, e a sua troca logo após cada eliminação vesical e/ou intestinal, higiene adequada da pele, e se possível o uso de cremes como barreira de proteção da pele. Apesar de ser constatado nesta pesquisa que a maioria faz uso de sonda vesical de demora.

Outros fatores importantes também foram levantados pelos estudos, de maneira especial, aqueles relacionados às condições do próprio paciente, tais como: idade avançada, deficiência nutricional, hidratação da pele, presença de distúrbios neurológicos, cânceres e outras comorbidades (diabetes, doença vascular, e edema), uso de drogas vasoativas, tabagismo e diminuição da pressão arteriolar (ANSELMI et al., 2009; CAMPANILI et al., 2015; BORGES et al., 2015; ROQUE et al., 2016; MATOZINHOS et al., 2017; ASCARI et al., 2014; SOUSA et al., 2016); CEDRAZ et al., 2018).

Sobre isso, foi verificado que fatores que interferem na tolerância do tecido à pressão, como a diabetes mellitus e o tabagismo, além de alterações no Índice de Massa Corporal (IMC), podem estar relacionadas a ocorrência de LPP, pois é sabido que, nos pacientes com redução de massa corporal, há um comprometimento da proteção nas regiões de proeminência óssea (BORGHARDT et al., 2016).

Além disso, estudos evidenciaram que a incidência de LPP ocorre principalmente em pacientes homens, em estado crítico, com idade acima de 60 anos e em internações mais prolongadas (BORGHARDT et al., 2016; TOFFOLETTO et al., 2016; ORTEGA et al., 2017; CEDRAZ et al., 2018; MENDONÇA et al., 2018). Para autores, a população idosa é mais propensa ao desenvolvimento de LPP, devido à diminuição da elasticidade da pele, à hidratação cutânea insuficiente e à alteração na sensibilidade, além de outros fatores que podem ser agravados quando em associação a doenças crônicas (MORAES et a.l, 2012).

Marcadores nutricionais, comumente, estão associados entre pacientes subnutridos e em dieta zero, devido aos jejuns prolongados, aos estados catabólicos e hipercatabólicos, a cirurgias e à alteração da 
ingestão alimentar ou à perda de peso, fatores alterados muitas vezes desde a admissão. Contribuindo para redução da tolerância tecidual à pressão devido a alteração no transporte de oxigênio e alterações metabólicas (BORGHARDT et al., 2016).

O uso de vasodilatadores, como a noradrenalina, podem interferir na circulação periférica e na perfusão do tecido, tornando-se um preditor significante para LPP (MORAES et al,, 2012; CAMPANILI et al,, 2015; BORGHARDT et al,, 2016).

Desse modo, ao considerar que a LPP torna-se um grave problema de saúde pública, é consenso que deve-se prevenir através de uma assistência adequada, onde a equipe de enfermagem tem uma importante missão na manutenção da integridade da pele, hidratação, estado nutricional e mudanças de decúbito (STEIN et al., 2012). Para tanto, é necessário compreender que a prática do cuidar só é possível a partir de uma profunda visão holística (SANTOS et al., 2018).

A ação do enfermeiro na prevenção da LPP baseia-se em quatro pilares: avaliação do potencial de risco, os cuidados com a pele e tratamento premeditado, diminuição da carga mecânica e uso de superfícies de suporte, e, por fim, educação dos pacientes e acompanhantes (ASCARI et al., 2014). Rolim et al. (2013) afirmam que é necessário o envolvimento da equipe na busca do conhecimento através da educação permanente pode contribuir para melhorias contínuas e, consequentemente, para a redução de custos e do tempo de internação, ocasionando assim o conforto do paciente e qualidade na assistência.

A determinação do risco do paciente para o desenvolvimento da LPP é a primeira medida a ser adotada para a prevenção desse agravo. Deve ser realizada na admissão do paciente e pelo menos a cada 48 horas, ou quando ocorrer alteração em suas condições de saúde, principalmente em pacientes criticamente enfermos que apresentam grande número de fatores de risco. $O$ instrumento de avaliação do risco mais extensivamente testado e utilizado é a Escala de Braden, pois permite a padronização da avaliação e a documentação do risco para LPP. A escala apresenta linguagem comum e deve ser compartilhada pelos profissionais para todos terem conhecimento e saberem identificar os fatores de risco, auxiliando na elaboração da prescrição das intervenções de enfermagem e multiprofissionais de forma individualizada (FERNANDES et al., 2008).

Em um estudo realizado por Stein et al. (2012), observou-se que em pacientes com risco de desenvolver LPP, a inspeção da pele deve ser realizada diariamente pela equipe de enfermagem, priorizando as regiões de proeminências ósseas. No entanto, Galvão et al. (2017) ressaltam uma ausência do conhecimento dos enfermeiros quanto ao estadiamento e classificação da LPP. Esta classificação inadequada pode levar a uma dificuldade para a uniformização dos registros e, consequentemente, no planejamento dos cuidados de enfermagem (SANTOS et al., 2018). Em vista disso, o enfermeiro deve conhecer os fatores de riscos, complicações e saber o grau de dependência do paciente e prescrever os cuidados necessários para a prevenção do desenvolvimento dessas lesões (VIEIRA et al., 2014).

Para Dantas et al. (2014), há necessidade de uma assistência mais sistematizada que contemple aspectos da mudança de decúbito, pois melhora o fluxo sanguíneo e evita morte tecidual, e são técnicas simples de se realizar, como por exemplo: posicionar o paciente com decúbito de 30 graus em quaisquer posições que permaneça; realizar mudança de decúbito a cada duas horas; reforçar a utilização das superfícies de apoio para o alívio da pressão das proeminências ósseas; o exercício e mobilidade do paciente, mesmo que movimentos passivos; a utilização de técnicas de posicionamento adequadas que evitem a fricção e o cisalhamento. 
Fernandes e Caliri (2008) e Dantas et al. (2014) reforçam que os enfermeiros relataram a preocupação relativa quanto mudança de decúbito, afirmando que o reposicionamento deve ser realizado em todos os pacientes, visto que grandes pressões sobre as proeminências ósseas por tempo prolongado é um fator de risco para o desenvolvimento de LPP.

No estudo de Vasconcelos et al. (2017) a aplicação do hidratante corporal nas diferentes regiões corporais foi mais frequente após avaliação do risco para LPP. O uso do hidratante é recomendado após o banho e quando a pele do paciente estiver seca. Embora o produto mais apropriado ainda não tenha sido encontrado, existem resultados promissores em relação aos ácidos graxos hiperoxigenados.

Vasconcelos e Caliri (2017) identificaram que apesar de ter sido constatada mudança no comportamento dos profissionais, com maior frequência de registros em prontuários, identificou-se que existe necessidade de incrementar a adoção dessa prática tanto na admissão do paciente, quanto nos dias subsequentes. A partir dessa avaliação inicial e frequente é que o enfermeiro, por meio do raciocínio clínico, pode estabelecer as condutas para individualizar a assistência centrada no paciente, com a colaboração deste, de sua família e dos profissionais de saúde.

A identificação da incidência das LPP é imprescindível para demonstrar a relevância desse evento adverso nas instituições hospitalares e um desafio para a enfermagem, à beira do leito, durante a prestação dos cuidados, bem como aos gestores dos serviços, como indicador de qualidade da assistência. A obtenção sistemática desses indicadores nos serviços de saúde está intimamente ligada às metodologias de avaliação dos processos assistenciais e àquelas relacionadas à segurança do paciente (BORGHARDT et al., 2016).

\section{CONCLUSÃO}

Este estudo apresentou os fatores de riscos para a ocorrência de LPP, colaborando no entendimento sobre a multicausalidade no surgimento desse agravo. Verificou-se que alguns cuidados, se tomados, podem diminuir o aparecimento das lesões, sobretudo, quando direcionados ao ambiente, aos fatores extrínsecos. Nesse contexto, faz-se uma alerta sobre a importância de orientar os acompanhantes ou familiares acerca dos fatores de risco e dos cuidados a serem realizados, seja na internação ou no domicílio, para tornarem-se parceiros da enfermagem. Para isso, os profissionais precisam ter esse conhecimento.

Com relação às condições do paciente, entende-se que conhecer o perfil de maior risco é essencial para desenvolver um plano de cuidados individualizado, com ações multiprofissionais e uma atenção mais direcionada. O conhecimento desses fatores, por todos envolvidos no cuidado, permite uma intervenção mais precisa e eficaz, reduzindo a incidência e complicações associadas a LPP.

Assim, a presente revisão torna-se relevante ao evidenciar as circunstâncias que influenciam o surgimento das LPP, de forma a fornecer subsídios para a construção de estratégias de prevenção. De modo especial, defende-se a implementação de protocolos não apenas nas instituições de saúde, mais também como proposta de política pública nacional, tendo como pilar a qualificação profissional.

Investigações com essa temática podem promover a discussão no meio acadêmico e científico de forma a ampliar o conhecimento das tecnologias em enfermagem voltadas para a prevenção da LPP e habilidades para a prática clínica. 


\section{REFERÊNCIAS}

ANSELMI, M. L. et al. Incidência de úlcera por pressão e açõıes de enfermagem. Acta Paul Enferm., v.22, n.3, p.257-64, 2009.

ASCARI, R. A. et al. Úlcera por pressão: um desafio para a enfermagem. Braz. J. Surg. Clin. Res. V.6, n.1, p.1116 (Mar - Mai 2014).

BORGES, E.L. et al. Avaliação do sistema de compressão de dois componentes no tratamento de úlcera varicosa. Revista da Rede de Enfermagem do Nordeste, Minas Gerais, v.19, n. 4, p. 934-942, out./dez. 2015.

BORGHARDT, A. T.; PRADO, T. N.; BICUDO, S. D. S. et al. Úlcera por pressão em pacientes críticos: incidência e fatores associados. Rev Bras Enferm [Internet], v. 69, n. 3, p.431-8, 2016.

CAMPANILI, T. C. G. F.; SANTOS, V. L. C. G.; STRAZZIERI-PULIDO, K. C. et al. Incidência de úlceras por pressão em pacientes de Unidade de Terapia Intensiva Cardiopneumológica. Rev Esc Enferm USP, v. 49, p. 7-14, 2015.

CEDRAZ, R. O.; GALLASCH, C. H.; PÉREZ JÚNIOR, E. F. et al. Gerenciamento de riscos em ambiente hospitalar: incidência e fatores de riscos associados à queda e lesão por pressão em unidade clínica. Esc Anna Nery, v. 22, n. 1, 2018.

DANTAS, A.L.D.M. et al. Prática do enfermeiro intensivista no tratamento de úlceras por pressão. Revista de pesquisa cuidado é fundamental, Rio Grande do Norte, v. 6, n. 2, p. 716-724, abr. 2014

FERNANDES, L.M. et al. Uso da escala de Braden e de Glasgow para identificação do risco para úlceras de pressão em pacientes internados em centro de terapia intensiva. Revista Latino Americana de Enfermagem, Paraná, v. 16, n. 6, p. 973-978, out./dez. 2008.

GALVÃO, N. S.; SERIQUE, M. A. B.; SANTOS, V. L. C. G. et al. Conhecimentos da equipe de enfermagem sobre prevenção de úlceras por pressão. Rev Bras Enferm [Internet], v. 70, n. 2, p.294-300, 2017.

GONÇALVES. L. A.; ANDOLHE, R.; OLIVEIRA, E. M.; BARBOSA, R. L.; FARO, A. C.; GALLOTTI, R. M. et al. Nursing allocation and adverse events/incidents in intensive care units. Rev Esc Enferm USP, v. 46, p.71-7, 2012.

LUZ, S. R.; LOPACINSKI, A. C.; FRAGA, R. et al. Úlceras de pressão. Rev. Geriatria \& Gerontologia, v. 4, n. 1, p. 36-43, 2010.

MATOZINHOS, F. P., VELASQUEZ-MELENDEZ. G., TIENSOLI, S. D. et al. Fatores associados à incidência de úlcera por pressão durante a internação hospitalar. Rev Esc Enferm USP, v.51, p.1-7, 2017.

MENDONÇA, P. K.; LOUREIRO, M. D. R.; FERREIRA JÚNIOR, M. A. et al. Ocorrência e fatores de risco para lesões por pressão em centros de terapia intensiva. Rev enferm UFPE on line., Recife, v.12, n. 2, p.303-11, fev., 2018.

MORAES, G. L. A.; ARAÚJO T. M.,; CAETANO, J. A. et al. Evaluation of the risk for pressure ulcers in bedridden elderly at home. Acta Paul Enferm [Internet], v. 25, p.7-12, 2012.

OLIVEIRA, A. C.; GARCIA, P. C.; NOGUEIRA, L. S. Nursing workload and occurrence of adverse events in intensive care: a systematic review. Rev Esc Enferm USP, v. 50, n. 4, p.679-689, 2016.

ORTEGA, D. B.; D'INNOCENZO, M.; SILVA, L. M. G. et al. Análise de eventos adversos em pacientes internados em unidade de terapia intensiva. Acta Paul Enferm., v. 30, n. 2, p.168-73, 2017. 
PAGNAMENTA, A.; RABITO, G.; AROSIO, A.; PERREN, A.; MALACRIDA. R.; BARAZZONI, F. et al. Adverse event reporting in adult intensive care units and the impact of a multifaceted intervention on drug-related adverse events. Ann Intensive Care, v. 2, n. 1, p.47, 2012.

ROLIM, J. A.; VASCONCELOS, J. M. B.; CALIRI, M. H. L.; SANTOS, I. B. C. Prevenção e tratamento de úlceras por pressão no cotidiano de enfermeiros intensivistas. Revista da Rede de Enfermagem do Nordeste, Fortaleza, v.4, n.1, p.148-57, set./out., 2013.

ROQUE, K. E. et al. Eventos adversos na unidade de terapia intensiva: impacto na mortalidade e no tempo de internação em um estudo prospectivo. Cad. Saúde Pública, Rio de Janeiro, v.32, n.10, p,1-15, out, 2016.

SANTOS, G. M.G.; ROCHA, R. S.; MELO, A. F. S. et al. O enfermeiro frente à prevenção de lesão por pressão: revisão integrativa. Journal of Health Connections, v. 3, n. 2, p.60-71. 2018.

SOUSA, L. R. M. et al. Análise da prevalência de desbridamento cirúrgico de úlcera por pressão em um hospital municipal. Revista de enfermagem cuidado é fundamental, Rio de Janeiro, v. 8, n. 2, p. 4186-4196, abr./jun. 2016.

SOUZA, K. E. C.; ROCHA, J. D. SANTOS.; VASCONCELOS, B. M. V. et al. Assistência de enfermagem na prevenção de lesão por pressão em idosos em ambiente hospitalar: um relato de experiência. In: $V$ Congresso Internacional de Envelhecimento Humano. Anais V CIEH , Campina Grande. , 2017, v. 1.

STEIN, E. A. et al. Nurses' actions in care management for the prevention of pressure ulcers in intensive care unit. Revista de Pesquisa: Cuidado é Fundamental Online, [S.I.], v. 4, n. 3, p. 2605-2612, aug. 2012.

TOFFOLETTO, M. C.; BARBOSA, R. L.; ANDOLHE, R. et al. Fatores relacionados à ocorrência de eventos adversos em pacientes idosos críticos. Rev Bras Enferm [Internet], v. 69, n. 6, p.1039-45, 2016 nov-dez.

VASCONCELOS, J. M. B. et al. Ações de enfermagem antes e após um protocolo de prevenção de lesões por pressão em terapia intensiva. Escola Anna Nery, v. 21, n. 1, 2017.

VIEIRA, C. P. B.; SÁ, M. S.; MADEIRA, M. Z. A. et al. Caracterização e fatores de risco para úlceras por pressão na pessoa idosa hospitalizada. Rev Rene, v. 15, n. 4, p.650-8, 2014 jul-ago. 


\title{
O EFEITO DO MINDFULNESS E MINDFUL EATING COMO SUPORTE AO TRATAMENTO DA OBESIDADE.
}

\author{
Érica Vanessa da Silva Retrão \\ Centro Universitário Santo Agostinho - UNIFSA \\ ericaretrao@gmail.com
}

Liejy Agnes dos Santos Raposo Landim

Centro Universitário Santo Agostinho - UNIFSA

\section{RESUMO}

Introdução: O Mindfulness ou atenção plena é uma prática consolidada na cultura oriental, que data de milhares de anos, comum a cultura do Budismo e vem demonstrado efeitos benéficos à saúde, bem-estar e felicidade. A Consciência Alimentar Baseada em Atenção Plena ou Mindful Eating é orientada para o manejo de sobrepeso, obesidade e compulsão alimentar. Indivíduos com obesidade podem apresentar estresse psicológico e estratégias de enfrentamento à sua disposição podem ajudar a conduzir e reduzir emoções negativas. A obesidade é um desafio para o Brasil e para o mundo. Essa pesquisa tem como objetivo demonstrar a influência dessas práticas como uma estratégia de suporte ao tratamento desta doença. Metodologia: Este trabalho é uma revisão integrativa de literatura, que teve como questão norteadora: “Quais os efeitos da prática de Mindfulness e Mindful Eating para o tratamento de obesidade?" A base de dados utilizada foi a PubMed e os termos utilizados para busca foram "Mindfulness and obesity" e "Mindful eating and obesity", teve como termos Decritores de Ciências da Saúde (Mindfulness, Obesity, public health e mental health). E de acordo com os critérios de elegibilidade foram escolhidos 11 artigos. Resultados e Discussão: Nos estudos explorados foi possível verificar relevância no uso das práticas para o tratamento de obesidade, sendo considerada uma estratégia de enfrentamento capaz de gerar benefícios significativos na vida dos indivíduos acometidos pela obesidade, através do desenvolvimento de uma postura mais atenta, consciente em relação aos alimentos e com melhor manejo das emoções, acarretando menos impulsividade, menor sensibilidade à recompensa alimentar, diminuição do comer emocional, diminuição do estresse, mais autocontrole, redução da ingestão de doces, redução dos níveis de glicose de jejum, redução da proporção cintura-quadril, melhora no colesterol de lipoproteína de baixo densidade, aumento do consumo de vegetais e perda ou manutenção de peso. Considerações finais: Esse estudo apontou efeitos promissores em relação a manutenção ou perda de peso e necessidade de maiores estudos com trabalhos desenvolvidos a longo prazo a fim de avaliar de maneira mais aprofundada os efeitos dessa ferramenta.

\section{Palavras-chave:}

Mindfulness; Obesidade; Saúde coletiva; Saúde mental.

\section{ABSTRACT}

Introduction: Mindfulness or mindfulness is a consolidated practice in Eastern culture, which dates back thousands of years, common to the culture of Buddhism and has been showing beneficial effects on health, wellbeing and happiness. Food Consciousness Based on Mindfulness or Mindful Eating is oriented towards the management of overweight, obesity and binge eating. Individuals with obesity may experience psychological stress and cope strategies at their disposal can help to drive and reduce negative emotions. Obesity is a challenge for Brazil and the world. This research aims to demonstrate the influence of these practices as a strategy to support the treatment of this disease. Methodology: This work is an integrative literature review, whose guiding question was: "What are the effects of Mindfulness and Mindful Eating for the treatment of obesity?" The database used was PubMed and the search terms used were "Mindfulness and obesity" and "Mindful eating and obesity", with the terms Health Science Decriters (Mindfulness, Obesity, public health and mental health). And according to the eligibility criteria, 11 articles were chosen. Results and Discussion: In the studies explored, it was possible to verify relevance in the use of practices for the treatment of obesity, being considered a coping strategy capable of generating significant benefits in the lives of individuals affected by obesity, through the development of a more attentive, conscious posture. in relation to food and with better handling of emotions, leading to less impulsivity, less sensitivity to food reward, decreased emotional eating, decreased stress, more selfcontrol, reduced sweets intake, reduced fasting glucose levels, reduced proportion waist-to-hip, improvement in low-density lipoprotein cholesterol, increased consumption of vegetables and weight loss or maintenance. Final considerations: This study pointed out promising effects in relation to maintenance or weight loss and the need for further studies with works developed in the long term in order to evaluate in more depth the effects of this tool.

\section{Keywords:}

Mindfulness; Obesity; Public health; Mental health. 


\section{INTRODUÇÃO}

Mindfulness, isto é, atenção plena, é uma prática, um estilo de vida. É um conceito que data de milhares de anos e costuma ser citado como "o coração da meditação budista", embora sua essência seja universal. Ela tem grande poder sobre a saúde, o bem-estar e a felicidade, entretanto, o seu cultivo é um processo que se desenrola e se torna profundo com o tempo. Sendo mais eficaz quando se assume um compromisso sério consigo mesmo, o que exige disciplina, persistência, despreocupação e leveza (KABAT-ZINN, 2010).

A aplicação de mindfulness no campo da saúde e na atenção primária à saúde tem grande potencial para melhorar o estado de saúde e o bem-estar da população em geral e de pacientes, especialmente aos portadores de condições crônicas, associadas a sintomas de ansiedade e depressão, como no caso da obesidade (DEMARZO, 2017).

O Mindfulness ou atenção plena e o Mindful Eating ou alimentação consciente têm o potencial de abordar comportamentos alimentares problemáticos e os desafios que muitos enfrentam para controlar a ingestão de alimentos (WARREN, SMITH, ASHWELL, 2017).

A Consciência Alimentar Baseada em Atenção Plena (Mindfulness-based Eating Awareness Training, em inglês, MB-EAT) é dirigida para o manejo de sobrepeso, obesidade e compulsão alimentar (MASON, 2015).

A obesidade resulta do excesso prolongado de ingestão energética em relação ao gasto energético, onde fatores genéticos, fisiológicos, comportamentais e ambientais podem influenciar e variar entre os indivíduos, contribuindo para o seu desenvolvimento, dessa forma, ela não é considerada um transtorno mental e não está inclusa no Manual Diagnóstico e Estatístico de Transtornos Mentais (DSM-5), mas existem associações robustas entre obesidade e uma série de transtornos mentais como transtorno de compulsão alimentar, transtornos depressivo e bipolar, assim como esquizofrenia (American Psychiatric Association, 2014).

Em 2016, mais de 1,9 bilhão de adultos com idade igual ou maior a 18 anos tinham sobrepeso no mundo, onde mais de 650 milhões de adultos estavam obesos. No geral, cerca de 13\% da população adulta mundial (11\% dos homens e $15 \%$ das mulheres) era obesa em 2016. A prevalência mundial da obesidade quase triplicou entre 1975 e 2016. Em 2019, cerca de 38,2 milhões de crianças com menos de 5 anos estavam com sobrepeso ou obesas. O sobrepeso e a obesidade estão aumentando atualmente em países de baixa e média renda, especialmente em áreas urbanas. O sobrepeso e a obesidade estão associados a mais mortes em todo o mundo do que o baixo peso (WHO, 2020). No Brasil, essa doença crônica aumentou 67,8\% nos últimos treze anos, saindo de 11,8\% em 2006 para 19,8\% em 2018. E o sobrepeso ao nascer parece ser um preditor de risco de obesidade em adultos (ABESO, 2020).

A obesidade constitui um desafio para o Brasil e para o mundo. Os caminhos são múltiplos, e ações isoladas não são capazes de endereçar adequadamente o problema. Apenas políticas integradas e articuladas dão conta de um enfrentamento efetivo (MARTINS, 2018). 
Novas descobertas destacam a importância da alimentação consciente para o tratamento de pessoas obesas, assim como a inclusão de técnicas que possam reduzir a desregulação emocional e o afeto negativo (CZEPCZOR-BERNAT, 2020). O estresse psicológico está entre os fatores que mais podem comprometer a perda de peso (DALLMAN, 2010). Indivíduos com obesidade que endossam maior estresse psicológico e que têm poucas estratégias de enfrentamento à sua disposição podem estar mais propensos a usar alimentos para reduzir emoções negativas, como aquelas associadas ao estresse (BYRNE, 2002; ELFHAG \& RÖSSNER, 2005).

O presente artigo tem como objetivo demonstrar a influência do Mindfulness e Mindful eating como uma das estratégias no tratamento da obesidade.

\section{METODOLOGIA}

Este trabalho trata-se de uma revisão integrativa de literatura que teve como questão norteadora: "Quais os efeitos da prática de Mindfulness e Mindful Eating para o tratamento de obesidade?". A base de dados utilizada foi a PubMed e os termos utilizados para busca foram "Mindfulness and obesity" e "Mindful eating and obesity", e teve como termos Descritores em Ciências da Saúde (Mindfulness, Obesity, public health e mental health). O banco de dados utilizado foi o PubMed e a triagem do material bibliográfico respeitou os seguintes critérios de inclusão:

I-Ser ensaio clínico randomizado

II-Apresentar relação direta com a temática e com a questão norteadora do mesmo,

III-Não apresentar conflitos de interesse.

IV-Ter no máximo 11 anos de publicação

A seleção final dos artigos se deu pela leitura do título, resumo e em casos de dúvida, leitura completa do periódico. Os artigos eleitos eram então confrontados com fatos levantados pelos pesquisadores.

E como critérios de exclusão:

I-Artigos repetidos

II-Artigos que apresentassem protocolo de ensaio randomizado

III - Artigos que não tinha relação direta com a temática

IV-Artigos que citavam a temática, mas não apresentavam resultado direto sobre o tema.

Não foram encontrados artigos produzidos antes do ano de 2009 referente a temática abordada, o que sugere que esse seja um tema inovador e que vem atraindo interesse e atenção de pesquisadores recentemente.

\section{RESULTADOS E DISCUSSÃO}

Conforme a combinação das palavras-chave selecionadas no DeCS e os filtros de busca préestabelecidos, o levantamento da pesquisa resultou-se em 87 artigos no PubMed onde as palavras "mindfulness and obesity" apresentaram 54 artigos ao todo e as palavras "mindful eating and obesity" apresentaram um total de 33 artigos. Após a leitura do título, do objetivo, da metodologia, dos resultados, da conclusão e da aplicação dos critérios de elegibilidade e de inelegibilidade, restaram 11 artigos aptos para responder à pergunta norteadora desta revisão. 


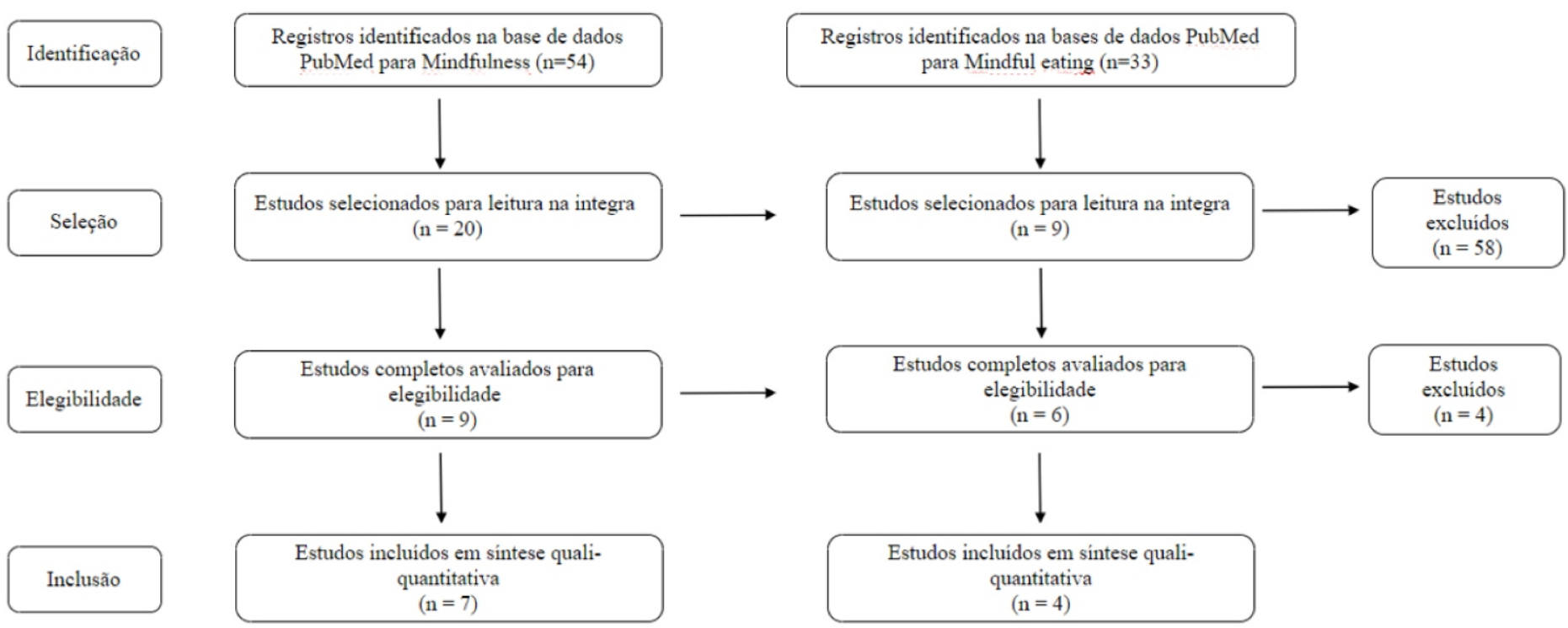

Figura 1: Fluxograma de seleção dos estudos revisados. Teresina, Piauí, Brasil. 2020. Fonte: Autores (2020)

Durante o processo de leitura integral dos artigos selecionados para esta revisão, foram extraídos, de forma sintetizada, os principais resultados que estão agrupados no quadro 1 abaixo, segundo título, autor, ano de publicação, objetivo do estudo e principais resultados.

\section{Quadro 1: Os efeitos do uso da prática de Mindfulness e Mindful eating no tratamento de obesidade segundo artigo publicos entre 2009 e 2020.}

\section{TíTULO}

Effects of a mindfulness-based intervention on mindful eating, sweets consumption, and fasting glucose levels in obese adults: data from the SHINE randomized controlled trial

Reduced reward-driven eating accounts for the impact of a mindfulness-based diet and exercise intervention on w eight loss: Data from the SHINE randomized controlled trial.

Mindful eating reduces impulsive food choice in adolescents and adults.
Effects of a mindfulness-based weight loss intervention in adults with obesity: A randomized clinical trial.

\section{ANO/AUTOR}

Mason et al, 2015.

Mason et al, 2016.

Hendrickson, et al, 2016.

\section{OBJETIVOS}

Avaliar as mudanças em mindful eating como um mecanismo potencial subjacente aos efeitos de uma intervenção baseada na Mindfulness para perda de peso na ing estão de alimentos doces e nos níveis de glicose en jejum.

Verificar os efeitos da Mindful em relação a reduções maiores na alimentação orientada por recompensas e no estresse psicológico.

Testar até que ponto a idade e a obesidade previam escolhas impulsivas para comportamentos alimentares e com o uso de dinheiro, testou como um breve treinamento de Mindfulness alteraria o atraso no desconto para escolhas alimentares e relação com o dinheiro em comparação com grupos de controle.

Determinar se a adição de práticas

Daubenmier et al, 2016. alimentares baseadas na atenção plena e de controle do estresse a um programa de exercícios com dieta melhora a perda de peso e os componentes da síndrome metabólica.

\section{PRINCIPAIS RESULTADOS}

A inclusão de componentes do mindful eating em programas de controle de peso com dieta e exercício padrão pode promover a estabilização a longo prazo da redução da ingestão de doces e a manutenção dos níveis de glicose em jejum em adultos obesos sem diabetes.

Os participantes da atenção plena (em relação ao controle) tiveram reduções significativas na alimentação baseada em recompensas em 6 meses (pós-intervenção), que, por sua vez, previu perda de peso em 12 meses.

Os participantes com alto percentual de gordura corporal (APGC) foram mais impulsivos para a alimentação do que aqueles com baixo percentual de gordura corporal (BPGC). Adultos com APGC também eram mais impulsivos na sua relação com dinheiro em comparação com adultos com BPGC, não foram encontradas diferenças relacionadas ao APGC para adolescentes. Os participantes do grupo de Mindful eating exibiram escolhas mais autocontroladas de comida, mas não da relação com dinheiro. As condições de controle não apresentaram alterações.

Os efeitos estimados comparando a atenção plena com o grupo controle favoreceram a atenção plena em perda de peso em 12 meses, e 18 meses, embora não seja estatisticamente significativo e mudanças na glicose de jejum em 12 meses, alterações na proporção de triglicerídeos/HDL em 12 meses e 18 meses. As estimativas para outros fatores de risco m etabólicos não foram estatisticamente significativas, incluindo circunferência da cintura, pressão arterial e proteína C reativa. 


TÍTULO
Mindfulness-Based Stress Reduction in
Women with Overweight or Obesity: A
Randomized Clinical Trial

Women's Health and Mindfulness (WHAM): A Randomized Intervention Among Older Lesbian/Bisexual Women.

Ingraham, et al, 2017.

Descreve os efeitos da saúde de mulheres em Mindfulness, uma intervenção piloto de 12 semanas que aborda mindfulness, alimentação saudável e atividade física, nos resultados associados ao risco de doença crônica entre mulheres com sobrepeso e obesidade lésbicas e bissexuais com mais de 40 anos.

\section{Explorar o efeito da}

Effect of mindfulness meditation on short-term weight loss and eating behaviors in overweight and obese adults: A randomized controlled trial.

Preventing Childhood Obesity Through a Mindfulness-Based Parent Stress Intervention: A Randomized Pilot Study.
Spadaro, et al, 2017. um programa de perda de peso comportamental padrão (SBWP) na perda de peso em adultos com sobrepeso e obesidade.
Mindfulness-based group intervention in adolescents at-risk for excess weight gain: A randomized controlled pilot study
Avaliar a viabilidade de envolver pais estressados e de baixa renda com obesidade em uma nova intervenção de estresse parental baseada na atenção plena, com o objetivo de diminuir o risco de obesidade infantil.
Shomaker et al, 2019. abordagem baseada na atenção plena para a prevenção do excesso de peso em adolescentes com risco de ganho de peso excessivo. Para testar a eficácia de uma intervenção baseada em mindfulness para melhorar a sensibilidade de recompensa alimentar, alimentação sob estresse, função executiva (FE) e IMC / adiposidade.
A combined mindfulness-prolonged chewing intervention reduces body weight, food craving, and emotional eating.
Investigar a eficácia do Mindfulness em 4 Schnepper, et al, 2019. sessões e intervenção prolongada de mastigação.
Pilot randomized controlled trial of a mindfulness-based group intervention in adolescent girls at risk for type 2 diabetes with depressive symptoms.

Thomas, et al, 2019.

Estabelecer a viabilidade de combinar o Aprimoramento de recuperação orientada em Minfulness (AROM) com exercícios e nutrição para sobreviventes de câncer com sobrepeso e obesos, identificar potenciais mecanismos terapêuticos da interv enção AROM e obter tamanhos de efeito para alimentar um ensaio subsequente de Estágio II.
Foram observadas melhorias clinicamente significativas no colesterol de lipoproteína de baixa densidade, $\mathrm{m}$ क nenhuma alteração na hemoglobina A1c. Encontramos evidências de efeitos de interv enção na melhora dos escores de mindfulness e alimentação consciente e na nutrição (melhora na ingestão de vegetais).

A taxa de retenção de participantes que com pletaram o programa foi de $76,1 \%(n=35)$. Ambos os programas tiveram uma perda de peso média significativa com a perda de peso favorecendo PAS (Programa de perda de peso comportamental padrão clínico) + MM (Meditação Mindfulness) $(-6,9 \mathrm{~kg} \pm 2,9)$ em relação a somente PAS $(-4,1 \mathrm{~kg} \pm 2,8)$. O comportamento alimentar $(p=0,02)$ e a restrição alimentar $(\mathrm{p}=0,02)$ melhoraram

significativamente na PAS + MM, em comparação com a PAS. O MMaumentou a perda de peso em $2,8 \mathrm{~kg}$, potencialmente por meio de maiores melhorias nos comportamentos alimentares e restrição alimentar.

Após estabelecer a viabilidade em 20 duplas paisfilhos, na fase 1,42 duplas foram randomizadas para o programa Parenting Mindfully for Health plus com orientação nutricional e aconselhamento de atividade física (PMH +

$\mathrm{N})$ versos Orientação nutricional e ativ idade física $(\mathrm{C}+\mathrm{N})$ na fase 2. Comparado com o grupo $\mathrm{C}+\mathrm{N}$, o grupo $\mathrm{PMH}$ $+\mathrm{N}$ demonstrou comparecimento ao grupo significativamente melhor $(P<0,015)$, maior envolvimento $(p<0,05)$ e diminuição do comer emocional dos pais $(p<0,011)$. Além disso, $\mathrm{C}+\mathrm{N}$, foi associado a aumentos significativos no percentil do índice de massa corporal da criança durante o tratam ento $(p$ $<0,03$ ) ao contabilizar a tarefa Toy Wait Task(TWT) antes e depois das mudanças nas pontuações dos pais.

A assistência média às sessões foi de 6 sessões em ambas as condições, as classificações de aceitabilidade do programa estavam acima da média. Em comparação com a educação em saúde, os adolescentes em Mindfulness tiveram menor sensibilidade a recompensa alimentar aos seis meses $(\mathrm{d}$ de Cohen $=0,64, \mathrm{p}=0,01)$. Não houve diferenças entre as condições no IMC (Mindfulness vs. educação para a saúde ${ }_{\Delta \text { seis meses }}$ CI 95\% $0,20,1,52 \mathrm{~kg} / \mathrm{m}^{2}$ vs. $\left.0,21,1,62 \mathrm{~kg} / \mathrm{m}^{2}\right)$ ou adiposidade $(-3,64,-0,61 \%$ vs. $-4,31,-1,04 \%)$

Ao longo das 8 semanas de intervenção, interações significativas Grupo vs Medição do tempo apontaram para diminuições no índice de massa corporal (IMC) e nos estilos de alimentação desajustados (desejos alimentares, comer emocional e comer social) com aumento na alimentação intuitiva no grupo de intervenção. A perda de peso no grupo de intervenção foi mantida após um acompanhamento de 4 semanas.

A viabilidade foi demonstrada por $82 \%$ dos participantes que iniciaram o AROM recebendo uma dose completa da intervenção. Modelos lineares mistos revelaram que a adição de AROM levou a aumentos significativamente maiores nos índices de consciência interoceptiv a, sabore e responsividade de recompensa natural e, diminuições significativamente maiores em comportamentos alimentares sociais e viés de consciência alimentar- o último dos quais foi significativamente associado a diminuições na proporção cintura-quadril.

Fonte: Autores (2020). 
Para Mason et al. (2015), sintonizar a atenção dos indivíduos para a consciência plena da fome física e observar as experiências de querer (e não querer) comer alimentos doces prontamente disponíveis pode reduzir a ingestão estúpida de comer nesses contextos. Dessa forma, o estudo feito em Mindful Eating contribui para a compreensão de mudanças específicas na ingestão de alimentos doces.

Em Mason et al. (2016), as suas análises sugerem que a integração dos componentes de Mindfulness em uma intervenção com dieta e exercícios para perda de peso leva a maiores reduções na alimentação baseada em recompensas. Essas reduções na alimentação orientada por recompensas, por sua vez, estão associadas a uma maior perda de peso, sugerindo que diminuições na alimentação orientada por recompensas são um mecanismo pelo qual as intervenções afetam a mudança de peso e sugere que as intervenções futuras devem visar reduções na alimentação orientada por recompensas, de modo a melhorar os resultados da perda de peso.

No estudo de Hendrickson et al. (2017), ele sugere que indivíduos com APGC fazem escolhas alimentares mais impulsivas do que aqueles com BPGC, o que pode aumentar o risco de obesidade ao longo do tempo. Também é o primeiro a demonstrar mudanças nos padrões de escolha de comida, usando um breve treinamento de alimentação consciente com adolescentes. O Mindful Eating é uma estratégia benéfica para reduzir a escolha alimentar impulsiva, pelo menos temporariamente, que pode impedir o ganho de peso.

De acordo com Daubenmier et al. (2016), o efeito da adição de componentes de atenção plena a programas de exercícios com dieta na perda de peso em indivíduos com obesidade não foi estatisticamente significativo. Foram encontradas algumas evidências de que a intervenção mindfulness pode levar à manutenção a longo prazo dos níveis de glicose em jejum e perfis lipídicos aterogênicos melhorados. Mais pesquisas são necessárias para determinar se os benefícios potenciais podem ser confirmados ou fortalecidos.

Em estudo desenvolvido por Raja-Khan et al. (2017), em mulheres com sobrepeso ou obesidade, o MBSR reduziu significativamente o estresse e demonstrou ter efeitos benéficos sobre a glicose. Estudos futuros são necessários para determinar se um aumento sustentado em mindfulness com uma intervenção mais longa baseada em Mindfulness resultaria em benefícios ainda melhores e mais duradouros, assim como, demonstrando os benefícios cardiometabólicos de longo prazo do MBSR para estabelecê-la como uma ferramenta eficaz no tratamento da obesidade.

Para Ingraham et al. (2017), a intervenção na saúde de mulheres em Mindfulness parece ter iniciado mudanças positivas de comportamento e saúde física nesta população, entretanto parece necessário o refinamento no modelo de intervenção, como extensão da duração da intervenção e acompanhamento de longo prazo para determinar os efeitos sustentados.

De acordo com Spadaro et al. (2017), dedicar tempo intencionalmente a si mesmo por meio do Mindfulness estabelece uma base para o comportamento de mudança. A atenção plena é uma ferramenta de baixo custo, extremamente acessível e uma estratégia facilmente adaptável. Prestar atenção, ouvir a si mesmo e tomar decisões conscientes sobre as escolhas alimentares, comportamentos alimentares e exercícios podem ajudar adultos com sobrepeso e obesos na perda de peso e outros comportamentos saudáveis. $O$ aumento da autorregulação reforçada pela prática da atenção plena pode ajudar os indivíduos adultos com sobrepeso e obesidade a aderir a um programa de perda de peso e manter um peso saudável ao longo do tempo. 
No estudo de Jastreboff et al. (2018), a intervenção foi significativamente associada com o percentil do IMC da criança após levar em conta as mudanças na parentalidade positiva e negativa. As mudanças de comportamento dos pais e consequentes efeitos percentuais do IMC da criança foram observados juntamente com melhorias na alimentação saudável em ambos os grupos, com reduções na alimentação emocional entre os pais no grupo de intervenção $\mathrm{PMH}+\mathrm{N}$ e melhorias não significativas nas habilidades de atenção plena nos pais, bem como na atividade vigorosa nas crianças do grupo $\mathrm{PMH}+\mathrm{N}$, usando estratégias comportamentais e Mindfulness bem estabelecidas adaptadas de Mindfulness-Based Stress Reduction (MBSR), mas sem diferenças significativas entre os grupos nos níveis de estresse dos pais como função de intervenção. Abordar o alto estresse em pais obesos de crianças pré-escolares para impactar a saúde e as escolhas alimentares pode ser uma forma de atenuar o risco de obesidade infantil em famílias de baixa renda cronicamente estressadas.

Segundo Shomaker et al. (2019), uma intervenção em grupo baseada em Mindfulness é viável entre adolescentes com risco de excesso de peso. Nesta amostra piloto, Mindfulness e educação em saúde foram ambíguas para os resultados de IMC / adiposidade. Ensaios futuros com uma amostra maior, alimentação adequada e acompanhamento de longo prazo são necessários para testar a eficácia de uma intervenção baseada em mindfulness para avaliar a sensibilidade à recompensa alimentar, alimentação sob estresse, função executiva e histórico de crescimento em jovens em risco de obesidade.

Para Schnepper et al. (2019), uma combinação de Mindfulness e um treinamento de mastigação específico que promova um aumento da consciência da saciedade impactou fortemente na ingestão energética e nos estilos alimentares. Essas intervenções influenciam na redução de calorias orientada para a perda e promovem o prazer e a degustação focada nos alimentos. As dietas convencionais para perda de peso podem incorporar essas intervenções breves em programas de dieta de longo prazo.

Segundo Thomas et al. (2019), embora adicionar AROM a um programa de exercícios e nutrição não tenha melhorado significativamente a perda de peso entre os sobreviventes do câncer, a atenção plena, a reavaliação e as habilidades de saborear ensinadas nesta intervenção integrativa podem modular mecanismos implicados em comportamentos obesogênicos, incluindo consciência interoceptiva, viés de atenção e resposta natural de recompensa. Ainda não se sabe se as mudanças nesses mecanismos são necessárias ou suficientes para a perda de peso clinicamente significativa nessa população. AROM pode ser promissor para direcionar a desregulação do apetite subjacente à perda de controle sobre a alimentação e ao excesso de adiposidade, o que pode reduzir o risco de morbidade e mortalidade relacionadas ao câncer.

O Minfulness também pode ser relevante no combate à obesidade e aos transtornos alimentares, reduzindo os episódios de compulsão alimentar - em parte responsável pela recuperação do peso para um grande número de pessoas - e aumentando a consciência de fatores emocionais e outros desencadeadores de comer demais (SALVO, 2018).

\section{CONSIDERAÇÕES FINAIS}

A utilização do Mindfulness e do Mindful Eating como estratégia de enfrentamento no tratamento da obesidade, tem demonstrado ser eficaz, tendo em vista a redução do comer emocional, o comer por recompensa alimentar, o comer por impulso, e a consequente redução de consumo exagerado de alimentos ou de comportamento alimentares inadequados, pois demonstra ter influência na 
estimulação e manifestação de uma atitude mais consciente dos indivíduos, proporcionando mais autoconhecimento, estimulando mudanças do comportamento, gerando mais qualidade de vida, com a redução dos níveis de estresse na sua vida e diminuindo os riscos de ganho de peso, mesmo que a perda de peso não aconteça, entre outros fatores também observados em comorbidade. Existindo ainda a necessidade de mais estudos, especialmente a longo prazo, a fim de verificar com maior rigor a sua utilidade e os efeitos sustentados. 


\section{REFERÊNCIAS}

ABESO. Obesidade e sindrome metabólica. Disponível em: <https://abeso.org.br/obesidade-e-sindromemetabolica/mapa-da-obesidade/>. Acesso em: 04 de dez de 2020.

AMERICAN PSYCHIATRIC ASSOCIATION. Manual diagnóstico e estatístico de transtornos mentais: DSM-5. (5a ed.; M. I. C. Nascimento, Trad.). Porto Alegre, RS: Artmed. 2014.

BYRNE, S.M. Psychological aspects of weight maintenance and relapse in obesity. J Psychosom Res, Nedlands, Austrália, v.53, n.5, p.1029-36, nov, 2002. Doi: 10.1016/s0022-3999(02)00487-7.

CZEPCZOR-BERNAT, K. et al. The moderating effects of mindful eating on the relationship between emotional functioning and eating styles in overweight and obese women. Eat Weight Disord, Wrocław, Polônia, v.25, n.4, p.841-849, agos, 2020. Doi: 10.1007/s40519-019-00740-6.

DALLMAN, M.F. Stress-induced obesity and the emotional nervous system. Trends Endocrinol Metab, Califórnia, EUA, v.21, n.3, p.159-65, mar, 2010. Doi: 10.1016/j.tem.2009.10.004.

DAUBENMIER, J. et al. Effects of a mindfulness-based weight loss intervention in adults with obesity: A randomized clinical trial. Obesity (Silver Spring), Califórnia, EUA, v.24, n.4, p.794-804, abr, 2016. Doi: 10.1002/oby.21396.

DEMARZO, M.A; GARCIA-CAMPAYO, J.A. Mindfulness Aplicado à Saúde. in AUGUSTO, D.K; UMPIERRE, R.N. PROMEF-Programa de Atualização em Medicina de Família e Comunidade. Porto Alegre-RS: Artmed Panamericana, p.125-64, 2017.

ELFHAG, K; ROSSNER. S. Who succeeds in maintaining weight loss? A conceptual review of factors associated with weight loss maintenance and weight regain. Obes. Rev, Estocolmo, Suécia, v.6, n.1, p.67-85, fev, 2005. Doi: 10.1111/j.1467-789X.2005.00170.x.

HENDRICKSON, K.L; Rasmussen, E.B. Mindful eating reduces impulsive food choice in adolescents and adults. Health Psychol, Pocatello, EUA, v.36, n.3, p.226-235, mar, 2017. Doi: 10.1037/hea0000440.

INGRAHAM, N. et al. Women's Health and Mindfulness (WHAM): A Randomized Intervention Among Older Lesbian/Bisexual Women. Health Promot. Pract, Califórnia, EUA, v.18, n.3, p.348-357, mai, 2017. Doi: $10.1177 / 1524839916670874$.

JASTREBOFF, A.M. et al. Preventing Childhood Obesity Through a Mindfulness-Based Parent Stress Intervention: A Randomized Pilot Study. J. Pediatr, New Haven, EUA, v.202, n.1, p.136-142, nov, 2018. Doi: 10.1016/j.jpeds.2018.07.011.

KABAT-ZINN, J. in WILLIAMS. M; PENMAN D. Atenção plena-Mindfulness. Rio de Janeiro: Sextante, 2015.

MARTINS, A.P. É preciso tratar a obesidade como um problema de saúde pública. Revista de Administração de Empresas, São Paulo, v.58, n.3, p.337-41, jun, 2018.

MASON, A.E. et al. Effects of a mindfulness-based intervention on mindful eating, sweets consumption, and fasting glucose levels in obese adults: data from the SHINE randomized controlled trial. J. Behav Med [Internet] Springer, Califórnia, EUA, v.39, n.2, p.201-13, Abri, 2015. Doi: 10.1007/s10865-015-9692-8.

MASON, A.E. et al. Reduced reward-driven eating accounts for the impact of a mindfulness-based diet and exercise intervention on weight loss: Data from the SHINE randomized controlled trial. Appetite. Califórnia, EUA, v.100, n.1, p.86-93, mai, 2016. Doi: 10.1016/j.appet.2016.02.009.

RAJA-KHAN, N. et al. Mindfulness-Based Stress Reduction in Women with Overweight or Obesity: A Randomized Clinical Trial. Obesity (Silver Spring), Pensilvânia, EUA, v. 25, n.8, p.1349-1359, agos, 2017. Doi: 10.1002/oby.21910. 
SALVO, $V$. et al. Mindfulness as a complementary intervention in the treatment of overweight and obesity in primary health care: study protocol for a randomised controlled trial. Trials. São Paulo, v.19, n.1, p.277, dez, 2018. Doi: 10.1186/s13063-018-2639-y.

SHOMAKER, L.B. et al. Mindfulness-based group intervention in adolescents at-risk for excess weight gain: A randomized controlled pilot study. Appetite. Colorado, EUA, v.140, n.1, p.213-222, set, 2019. Doi: 10.1016/j.appet.2019.05.022.

SCHNEPPER, R. et al. A combined mindfulness-prolonged chewing intervention reduces body weight, food craving, and emotional eating. J. Consult. Clin. Psychol. Salzburg, Áustria, v.87, n.1, p.106-111, jan, 2019. Doi: $10.1037 /$ ccp0000361.

SPADARO, K.C. et al. Effect of mindfulness meditation on short-term weight loss and eating behaviors in overweight and obese adults: A randomized controlled trial. J. Complement. Integr. Med., Pensilvânia, EUA, v.15, n.2, dez, 2017. doi: 10.1515/jcim-2016-0048.

THOMAS, E.A. et al. Mindfulness-Oriented Recovery Enhancement Restructures Reward Processing and Promotes Interoceptive Awareness in Overweight Cancer Survivors: Mechanistic Results From a Stage 1 Randomized Controlled Trial. Integr. Cancer Ther. Knoxville , EUA, v.18:1534735419855138, jan-dez, 2019. Doi: 10.1177/1534735419855138.

WARREN, J.M; SMITH, N; ASHWELL, M. A structured literature review on the role of mindfulness, mindful eating and intuitive eating in changing eating behaviours: effectiveness and associated potential mechanisms. Nutrition research reviews. Oxford, Inglaterra, v.30, n.2, p.272-83, dez, 2017. Doi: 10.1017/\$0954422417000154.

WHO. Obesity and overweight. Disponível em: <https://www.who.int/en/news-room/factsheets/detail/obesity-and-overweight>. Acesso em: 04 de dez de 2020. 


\section{PERFIL CLÍNICO-EPIDEMIOLÓGICO E OS PRINCIPAIS DIAGNÓSTICOS DE CRIANÇAS INTERNADAS EM UM HOSPITAL PEDIÁTRICO}

\author{
Fernanda Maria Melo Pereira \\ Universidade Estadual do Maranhão - UEMA \\ fernanda.melo820@gmail.com \\ Joseneide Teixeira Câmara \\ Universidade Estadual do Maranhão - UEMA \\ josaeneide.tc@gmail.com \\ Diellison Layson dos Santos Lima \\ Universidade Federal do Piauí - UFPI \\ laysondih09@live.com
}

\author{
Amanda Silva Oliveira \\ Hospital Universitário Materno-Infantil - UFMA \\ enfaso@hotmail.com \\ Hayla Nunes Conceição \\ Universidade Estadual do Maranhão - UEMA \\ haylanunes_cx@hotmail.com \\ Magnólia de Jesus Sousa Magalhães \\ Universidade Estadual do Maranhão - UEMA \\ magmagalhaes2009@hotmail.com
}

\section{RESUMO}

Introdução: A criança é um ser que está em constante transformação, ou seja, crescendo e se desenvolvendo, o que contribui para apresentar um elevado risco no surgimento de patologias e possíveis necessidades de hospitalização. Objetivo: Descrever o perfil epidemiológico e os principais diagnósticos de crianças internadas no hospital pediátrico municipal da cidade de Caxias - MA. Metodologia: Trata-se de um estudo transversal, de caráter descritivo e com uma abordagem quantitativa. O cenário da pesquisa foi o Hospital Infantil municipal. A amostra foi composta por 170 crianças e os dados foram coletados no período de abril a agosto de 2019 através da aplicação de um formulário e dos prontuários de cada paciente. Os dados foram processados e analisados por meio da análise exploratória-descritiva no Statistical Package for the Social Sciences - SPSS. Resultados: A amostra foi majoritariamente de crianças do sexo masculino 97 (57\%), com idade entre seis meses a um ano 63 (37\%), da raça/cor parda 122 (71,7\%), com pais solteiros 70 (41,1\%), sendo o nível de escolaridade dos seus progenitores o ensino fundamental incompleto 55 (32,3\%) mãe e 49 (28,8\%) pai, possuindo moradia própria 134 (78,8\%) com um número de 3-5 residentes 99 (58,2\%) e renda inferior a um salário mínimo 95 (55,8). Em relação a clínica, 118 (69,4\%) estavam na 1a internação, com maior frequência de nascidos "A termo" 137 (80,5\%), sem patologia de base 142 (83,5\%),não necessitando fazer uso diário de medicamentos $152(89,4 \%)$, ficando internados no período de até 10 dias 162 (95,2\%), com uma frequência significativa da prática do aleitamento materno exclusivo 120 (82,7\%). E os principais diagnósticos foram das doenças do aparelho respiratório. Conclusão: Sendo assim, a realização desse estudo foi de grande relevância para o meio social e científico e com base nessas informações, a gestão pública e as equipes de saúde terão condições de desenvolver estratégias para uma melhor assistência dessa clientela.

\section{Palavras-chave:}

Criança Hospitalizada; Saúde da Criança; Perfil de Saúde.

\section{ABSTRACT}

Introduction: The child is a being that is constantly changing, that is, growing and developing, which contributes to presenting a high risk in the appearance of pathologies and possible hospitalization needs. Objective: To describe the epidemiological profile and the main diagnoses of children admitted to the Municipal pediatric hospital in the city of Caxias - MA. Methodology: This is a cross-sectional, descriptive study with a quantitative approach. The research scenario was the Municipal Children's Hospital. The sample consisted of 170 children and data were collected from April to August 2019 through the application of a form and the records of each patient. The data were processed and analyzed using exploratory-descriptive analysis in the Statistical Package for the Social Sciences - SPSS. Results: The sample consisted mainly of 97 male children (57\%), aged between six months and one year old 63 (37\%), brown / brown 122 (71.7\%), with single parents $70(41,1 \%)$, with the level of education of their parents the incomplete elementary education 55 (32.3\%) mother and 49 (28.8\%) father, having their own home 134 (78.8\%) with a number of $3-5$ residents 99 (58.2\%) and income below the minimum wage 95 (55.8). Regarding the clinic, 118 (69.4\%) were in their 1st hospitalization, with a higher frequency of "full term" births 137 (80.5\%), without basic pathology 142 (83.5\%), not needing to use medication diary 152 (89.4\%), staying in the period of up to 10 days 162 (95.2\%), with a significant frequency of exclusive breastfeeding 120 (82.7\%). And the main diagnoses were diseases of the respiratory system. Conclusion: Therefore, the realization of this study was of great relevance for the social and scientific environment and based on this information, public management and health teams will be able to develop strategies to better assist this clientele.

\section{Keywords:}

Hospitalized Child; Child Health; Health Profile. 


\section{INTRODUÇÃO}

Considera-se como um hospital pediátrico, o estabelecimento de saúde que possuem setores específicos para o atendimento de crianças, iniciando por ambientes que perpassam pela a assistência à sintomatologia, seja urgência ou emergência até a internação. Os serviços da urgência e emergência irão focar na assistência médica rápida, descontínua e objetiva, enquanto que na internação, a criança fica reclusa no hospital por um período maior a depender das suas necessidades e sob os cuidados de uma equipe de saúde multiprofissional (FLÔR, 2016).

A criança é um ser que está em constante transformação, ou seja, crescendo e se desenvolvendo, o que contribui para apresentar um elevado risco no surgimento de patologias e possíveis necessidades de hospitalização (OLÍMPIO et al., 2018).

Além disso, quando comparado a outras faixas etárias, elas possuem particularidades e mais necessidades de uma assistência qualificada, uma vez que são mais suscetíveis ao agravamento do seu quadro clínico e ao aparecimento de infecções virais, bacterianas e parasitárias, em decorrência da sua anatomia e fisiologia, bem como do sistema imunológico imaturo (ESCOBAR et al., 2013).

As crianças com maior risco de internação hospitalar são aquelas com menor idade (recém-nascidos ou lactentes) e que apresentam baixo peso ao nascer. Além disso, o nível socioeconômico e demográfico da família também constitui um fator de risco para hospitalização. Outro agravo é a avaliação nutricional inadequada da criança durante o processo de internação, dificultando o diagnóstico e o tratamento dos agravos (HUBER; VINHOLES, 2015).

A elaboração de políticas públicas para a saúde das crianças deve ser uma prioridade, haja vista que se trata de um grupo com maior vulnerabilidade a diversos agravos, doenças e riscos de sequelas, o que interfere na qualidade de vida desses menores. Portanto, para concretizar essa prioridade, é essencial conhecer, avaliar e intervir em indicadores (SILVA; TEIXEIRA, 2016).

Nesta perspectiva, visando conhecer melhor a realidade de crianças internadas por meio de evidências científicas, elaborou-se a seguinte problemática: Qual o perfil clínico-epidemiológico e os principais diagnósticos de crianças internadas no hospital pediátrico municipal da cidade de CaxiasMA? Visando resposta para essa inquietação, o objetivo desse estudo foi descrever o perfil clínicoepidemiológico e os principais diagnósticos de crianças internadas no hospital pediátrico municipal da cidade de Caxias - MA.

\section{METODOLOGIA}

Trata-se de um estudo observacional do tipo transversal, de caráter descritivo e com uma abordagem quantitativa. O cenário da pesquisa foi o município de Caxias - MA, considerada atualmente como a 5a maior cidade do estado. Contudo, o ambiente de coleta dos dados foi no Hospital Infantil municipal, sendo esse o único estabelecimento público de saúde específico para a criança. 
Assim, a amostra do estudo foi composta por crianças internadas no hospital pediátrico de ambos os sexos, levando-se em consideração para o cálculo amostral, o universo de 1098 pacientes internados em 2017, no qual resultou em uma amostra de 170 menores. Entretanto, para compor a amostra, a criança precisava ter o tempo mínimo de internação de $48 \mathrm{~h}$ e estar hemodinamicamente estáveis. Sendo excluído aquelas acamadas sem mobilidade ou sem condições clínicas para realização de todo o processo da pesquisa.

A coleta ocorreu no período de abril a agosto de 2019 e os dados foram obtidos por meio da aplicação de um formulário contendo perguntas sobre o perfil sociodemográfico, econômico, condições de vida e características clínicas, sendo aplicado junto aos pais ou responsáveis, além dos prontuários de cada participante.

Após todo o processo de coleta, os dados foram digitados em uma planilha eletrônica elaborada no Microsoft Excel, versão 2016, posteriormente transferidos para o programa Statistical Package for the Social Sciences - SPSS, onde ocorreu o processamento e análise dos dados por meio da análise exploratória-descritiva.

O estudo seguiu as recomendações da Resolução 466/2012 sob pesquisas com seres humanos, sendo aprovado pelo Comitê de Ética em Pesquisa da Universidade Estadual do Maranhão, com o seguinte Parecer: 3.235.492. Antes da coleta dos dados era repassado para os participantes e responsáveis todo o processo do estudo e esclarecidas todas as dúvidas, assim os sujeitos eram convidados a assinarem os termos de assentimento (responsáveis) e consentimento (crianças que sabiam ler e escrever) livre e esclarecido-TALE e TCLE.

\section{RESULTADOS E DISCUSSÃO}

A amostra foi composta por 170 crianças internadas no hospital pediátrico. O perfil epidemiológico dos sujeitos está apresentado na tabela 1.

Tabela 1 - Distribuição das internações pediátricas, de acordo com características sociodemográficas e econômicas. Caxias - MA, 2019. ( $n=170)$.

\begin{tabular}{|l|c|}
\hline \multicolumn{2}{|c|}{ Características Sociodemográficas e Econômicas } \\
\hline \multicolumn{1}{|c|}{ Sexo } & $\mathbf{n}(\%)$ \\
\hline Masculino & $97(57,0)$ \\
\hline Feminino & $73(42,9)$ \\
\hline & \\
\hline Até 6 meses & $20(11,7)$ \\
\hline De 6 meses a 1 ano & $63(37,0)$ \\
\hline De 1 a 2 anos & $14(8,2)$ \\
\hline De 2 a 4 anos & $28(16,4)$ \\
\hline Acima de 4 anos & $45(26,4)$ \\
\hline
\end{tabular}


continuação

\section{Características Sociodemográficas e Econômicas}

Raça/Cor

\section{Preta}

Branca

Parda

Amarela

Estado civil dos pais

\section{Casados}

Separados /Solteiros

União Estável

Viúvo

\section{Escolaridade do pai}

Não Alfabetizado

Ensino médio completo

Ensino médio incompleto

Ensino Fundamental completo

Ensino fundamental incompleto

Ensino superior completo

Ensino superior incompleto

Escolaridade da mãe

\begin{tabular}{|l|c|}
\hline Não Alfabetizado & $6(3,5)$ \\
\hline Ensino médio completo & $44(25,8)$ \\
\hline Ensino médio incompleto & $30(17,6)$ \\
\hline Ensino Fundamental completo & $33(19,4)$ \\
\hline Ensino fundamental incompleto & $49(28,8)$ \\
\hline Ensino superior completo & $5(2,9)$ \\
\hline Ensino superior incompleto & $3(1,7)$ \\
\hline Moradia & \\
\hline Própria & $134(78,8)$ \\
\hline Alugada & $19(11,1)$ \\
\hline Cedida & $16(9,4)$ \\
\hline Financiada & $1(0,5)$ \\
\hline Localização & \\
\hline Urbana & $115(67,6)$ \\
\hline Rural & $55(32,3)$ \\
\hline
\end{tabular}

$16(9,4)$

$24(14,1)$

$122(71,7)$

$6(3,5)$

$2(1,1)$

$37(21,7)$

$70(41,1)$

$62(36,4)$

$1(0,5)$

$7(4,1)$

$46(27,0)$

$24(14,1)$

$36(21,1)$

$55(32,3)$

$2(1,1)$

$0(0,0)$

$6(3,5)$

$44(25,8)$

$30(17,6)$

$33(19,4)$

$5(2,9)$

$3(1,7)$

$134(78,8)$

$9(11,1)$

$6(9,4)$

$(0,5)$

$55(32,3)$ 


\begin{tabular}{|l|c|}
\hline \multicolumn{2}{|c|}{ Características Sociodemográficas e Econômicas } \\
\hline \multicolumn{1}{|c|}{$N^{0}$ de pessoas na residência } \\
\hline 1 a 2 pessoas & $21(12,3)$ \\
\hline 3 a 5 pessoas & $99(58,2)$ \\
\hline 6 a 9 pessoas & $38(22,3)$ \\
\hline 10 ou mais pessoas & $12(7,0)$ \\
\hline \multicolumn{1}{|c|}{ Renda } & \\
\hline Menor que 1 SM & $95(55,8)$ \\
\hline De 1 a 2 SM & $72(42,3)$ \\
\hline 3 ou mais SM & $3(1,7)$ \\
\hline
\end{tabular}

Fonte: Autor

Observou-se neste estudo que 97 (57,6 \%) das crianças internadas eram do sexo masculino, achado que corrobora com uma pesquisa realizada em uma unidade pediátrica em um Hospital Geral, a qual verificou que $56,5 \%$ das internações aconteceram majoritariamente por esse sexo biológico (MAISEL et. al., 2016).

Sugere-se que um dos fatores que contribuem para esse resultado está relacionado à maior exposição a agentes infecciosos e a traumas, pois há maior liberdade de ações e brincadeiras em comparação ao gênero feminino por razões socioculturais em nosso meio (SILVA, TIENGO; 2014). Essa visão social desencadeia mais cuidados das famílias para com as meninas e propiciam que os meninos realizem atividades que os expõem mais a patógenos desde a infância (OLíMPIO et al., 2018).

A faixa etária de 6 meses a 1 ano obteve 63 (37\%), em seguida acima de 4 anos com 45 (26,4\%). Esses dados corroboram com a maioria dos estudos na literatura, (RIBEIRO, M. et al., 2019; TEIXEIRA, 2016; OLIVEIRA, NISHIMURA, BARBOSA, 2015). No estudo de Olímpio et al. (2018), prevaleceu a faixa etária entre um a três anos. O número de internações de crianças menores de cinco anos pode ser usado como parâmetro para o desenvolvimento de estratégias no setor de saúde coletiva, na prevenção de doenças e na educação para a saúde das famílias, tendo em vista que vários são os fatores de risco para que as internações aconteçam em crianças de pouca idade (JOVENTINO et al., 2019).

Com relação à raça/cor, houve predomínio da parda 122 (71,7\%), logo em seguida a cor branca com 24 $(14,1 \%)$. Em um estudo realizado em um hospital pediátrico do Rio Grande do Sul houve maior prevalência na cor branca com 69,4\% e a parda apresentou apenas 20,5\% (CAMPOS et al., 2015). No entanto, vale ressaltar que o Brasil é um país miscigenado, portanto, dependendo da região, estado e/ou cidade que a pesquisa foi desenvolvida, essa variável pode distinguir bastante.

As crianças entrevistadas apresentam $70(41,1 \%)$ dos pais separados ou solteiros, sendo um percentual elevado em relação ao estudo realizado em uma Unidade Básica de Saúde (UBS) do município de Cuiabá, Mato Grosso, onde encontrou que 13,8\% das mães entrevistadas não possuem companheiro (SOARES et al., 2019) e um percentual menor ao encontrado em outro estudo 43,7\% da amostra tinham pais solteiros (PEREIRA et al., 2018). O elevado número de pais separados encontrados neste estudo pode ser justificado pelo cenário cultural ao qual a pesquisa foi desenvolvida, tratando-se de um município do interior do Maranhão, onde ainda, o 
tradicionalismo/conservadorismo é bastante presente na sociedade. Em que algumas situações como a mulher engravidar é o suficiente para a família obrigá-la a se casar, principalmente na se a gravidez ocorrer na adolescência, culminando em uma união precoce, sem ambas as partes se sentirem preparadas, resultando em uma relação com pouca duração. Betelho (2018) reforça que "casar cedo" pode apresentar problemas financeiros, uso de álcool e outras drogas e de violência, são fatores que culminam na separação conjugal.

Tanto a escolaridade da mãe quanto a do pai apresentaram maior frequência na categoria fundamental incompleto com $49(28,8 \%)$ e 55 (32,3\%) respectivamente. Em relação ao grau de escolaridade da mãe houve uma concordância com Pereira et al. (2018) que encontraram o ensino fundamental incompleto e ensino médio completo com $31 \%$ e $25 \%$, respectivamente.

Quanto à habitação das crianças, 134 (78,8\%) da amostra tem casa própria e 99 (58,2\%) dos lares dos sujeitos eram compostos de 3-5 pessoas. A casa própria foi mais prevalente e corrobora com o estudo de Pereira et al. (2018) com prevalência de 75\%. Quanto a localização, a maioria da amostra são residentes da zona urbana com 115 (67,6\%) e 55 (32,3\%) zona rural, havendo consenso com Lima et al. (2018) e Silva et al. (2018). Esses resultados podem estar relacionados pelo fato que este Hospital Municipal atender uma regional de saúde composta por sete municípios.

Considerando a renda familiar, $95(55,8 \%)$ dos pais possuem renda menor que 1 salário mínimo e 72 $(42,3 \%)$ recebem entre 1 a 3 salários e apenas $3(1,7 \%)$ recebem 3 ou mais salários mínimo. Esse achado foi similar ao estudo realizado por Olímpio et al. (2018) sobre o perfil clínico-epidemiológico de crianças de um hospital cearense, onde $50 \%$ dos responsáveis dos menores recebiam menos de 1 salário e $9 \%$ sem renda.

Em contrapartida, no estudo de Pereira et al. (2018), 50\% da amostra recebia até 1 salário mínimo. A renda inferior a um salário mínimo consiste em um fator de risco para a ocorrência de futuros problemas no estado de saúde da criança, uma vez que prejudica o acesso rápido aos serviços de saúde, à adesão de medidas preventivas contra diversos agravos e ao diagnóstico e tratamento precoce de doença (OLÍMPIO et al., 2018).

Na tabela 2 apresenta-se as características clínica dos participantes e chama-se atenção que 118 $(69,4 \%)$ das crianças estavam internadas pela primeira vez.

Tabela 2: Distribuição das internações pediátricas de acordo com características clínicas. Caxias - MA. 2019 ( $n=170)$

\begin{tabular}{|c|c|}
\hline \multicolumn{2}{|c|}{ Características Clínicas } \\
\hline & $\mathrm{n}(\%)$ \\
\hline \multicolumn{2}{|l|}{ Internaçăo Anterior } \\
\hline Não & $118(69,4 \%)$ \\
\hline Sim & $52(30,5 \%)$ \\
\hline \multicolumn{2}{|l|}{ Gestação } \\
\hline A termo & $137(80,5 \%)$ \\
\hline Pré-termo & $21(12,3 \%)$ \\
\hline Pós-termo & $12(7,0 \%)$ \\
\hline \multicolumn{2}{|l|}{ Patologia } \\
\hline Não & $142(83,5 \%)$ \\
\hline Sim & $28(16,4 \%)$ \\
\hline
\end{tabular}




\begin{tabular}{|c|c|}
\hline \multicolumn{2}{|l|}{ Medicamentos diários } \\
\hline Não & $152(89,4 \%)$ \\
\hline Sim & $18(10,5 \%)$ \\
\hline \multicolumn{2}{|c|}{ Tempo de Intemação Características Clínicas } \\
\hline Até 10 dias & $162(95,2 \%)$ \\
\hline De 10 a 20 dias & $5(2,9 \%)$ \\
\hline Acima de 20 dias & $3(1,7 \%)$ \\
\hline \multicolumn{2}{|c|}{ Aleitamento materno exclusivo } \\
\hline Não & $50(17,2 \%)$ \\
\hline Sim & $120(82,7 \%)$ \\
\hline
\end{tabular}

Fonte: Autor.

Nota-se que a grande maioria das crianças não apresentam nenhuma internação anterior 118 (69,4\%). No estudo de Silva et al. (2018) verificou-se que 153 (22,8\%) das crianças estudadas registravam internações prévias, sendo $77,2 \%$ sua primeira internação, o que corrobora com nossos achados. Vale ressaltar que é importante se investigar também a saúde emocional desses indivíduos, para que a assistência multiprofissional seja de forma holística, principalmente quando se trata da primeira internação da criança.

O tipo de gestação mais frequente foi a classificação "A termo" 137 (80,5\%), seguida da "Pré-termo" com 21 (12,3\%) e "Pós-termo" com 12 (7,0\%). Além disso, 142 (83,5\%) das crianças não apresentam patologias de base e não fazem o uso de medicamentos diários $152(89,4)$. Esses dados podem ser considerados como fator de proteção para as crianças, pois o menor que faz uso de medicamento constante e que detém de uma doença de base fica mais vulnerável a ter um prognóstico ruim diante de casos de internação.

O tempo de internação teve maior frequência de até 10 dias 162 (95,2\%), com tempo mínimo de 2 e máximo de 99 dias, enquanto que no estudo de Teixeira (2016) houve um maior percentual entre 0 a 3 dias. A média de internação foi 4,6 dias, aproximando assim dos dados encontrados por Campos et al. (2015), com média de 6 dias e Silva et al. (2018) com 7, 1 dias.

E a prática do aleitamento materno exclusivo ocorreu ou estava ocorrendo em 120 (82,7\%) da amostra analisada e $50(17,2 \%)$ não receberam ou completaram os 6 meses como preconizado pela Organização Mundial da Saúde. No estudo de Pereira et al. (2018) ao perguntar sobre experiências anteriores de amamentação, mais de $50 \%$ das mães afirmaram que as crianças se alimentaram somente do leite oriundo dos seus seios.

Portanto, as chances de uma criança crescer e se desenvolver com mais êxito, não precisando ser internada é maior naquelas que consumiram o leite materno exclusivo até o sexto mês de vida. Em uma revisão da literatura, evidenciou-se que as pesquisas destacam a importância do leite materno para o binômio mãe-bebê, influenciando na prevenção de doenças como o câncer de mama e ovário nas mães, diminuindo o sangramento pós parto e involução uterina. E para o bebê contribui na prevenção contra a mortalidade infantil, promovendo um bom desenvolvimento: musculatura bucal, face e diminuindo doenças futuras (SANTOS; SCHEID, 2019).

Os principais diagnósticos são apresentados na figura 1. Observa-se que o diagnóstico mais frequente na amostra foi a pneumonia, atingindo $36,4 \%$ das crianças entrevistadas, e a bronquiolite com $10 \%$, caracterizando uma maior frequência de doenças do trato respiratório. A gastrenterite difusa aguda 
foi o terceiro diagnóstico mais prevalente com 5,8\%. Logo em seguida, a Anemia falciforme e Glomerulonefrite difusa aguda (GNDA) apresentaram ambas taxas de 5,2\%. Outros diagnósticos foram compostos por: Infecção bacteriana, síndrome febril, mão pé boca, Chinkungunya, Escabiose, Infecção Urinária, Crise alérgica, Anemia, Leishmaniose Visceral, Politrauma, Síndrome Nefrótica, Adenite Séptica, Celulite em MMSS e MMII e foram responsáveis por 25,8\%.

Figura 1: Principais diagnósticos. Caxias - MA. 2019 ( $n=170)$.

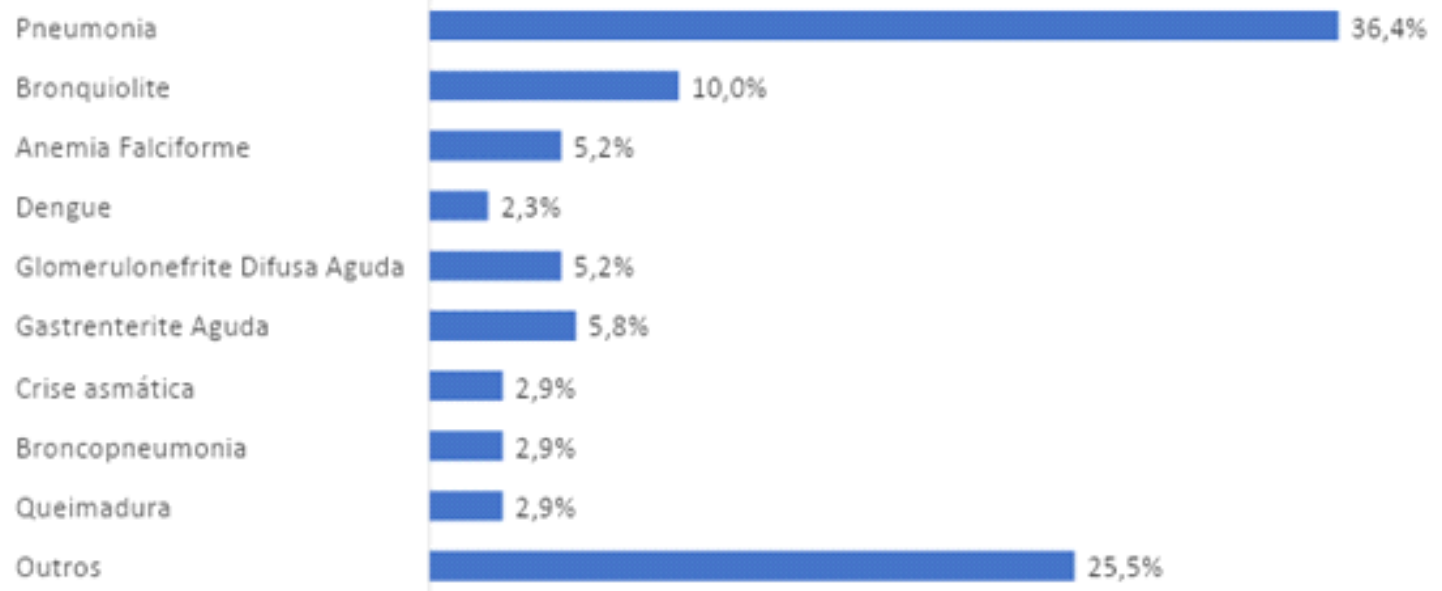

Fonte: Autor

Estudos mostram que a complicação mais comum em crianças hospitalizadas está relacionada a doenças do trato respiratório, sendo a pneumonia a mais frequente (SILVA et al., 2018; DESTERRO et al., 2018; SOUZA et al., 2019; SANTOS et al., 2018; CAMPOS et al., 2016). A maior causa de internação estar relacionada com o trato respiratório nesse estudo foi um fato esperado, tendo em vista que a população estudada em sua maioria era composta de menores de cinco anos, demonstrando a vulnerabilidade às doenças infecciosas.

A imaturidade do sistema imunológico dessas crianças, principalmente das que não são exclusivamente amamentadas ou que apresentam precário estado de saúde, associada às limitadas coberturas vacinais, coloca este grupo em condição de vulnerabilidade frente às infecções que podem resultar em pneumonia (CALDART et al., 2016). Estudos presentes na literatura apontam evidências científicas de que o aleitamento materno promove um efeito protetor para o crescimento saudável (SOARES, 2019).

Dentre os fatores de risco para internação por pneumonia estão: o estado nutricional da criança, a falta do aleitamento materno, baixo peso ao nascer, baixa idade materna, baixo nível educacional dos pais, pouco ganho de peso na gestação, presença de fumantes na casa e aglomerados (SANTOS; SANTOS, 2018). 


\section{CONCLUSÃO}

O estudo constatou que as crianças internadas no hospital pediátrico municipal em Caxias - MA foi em sua maioria do sexo masculino, com idade entre seis meses a um ano, da raça/cor parda, com pais solteiros, sendo o nível de escolaridade dos seus progenitores o ensino fundamental incompleto, possuindo moradia própria com um número de 3-5 residentes e renda inferior a um salário mínimo.

Em sua maioria, os sujeitos do estudo estavam passando pela sua primeira experiência na internação hospitalar, sendo a maior frequência daqueles que nasceram "A termo", sem patologia de base, não necessitando fazer uso diário de medicamentos, ficando internados no período de até 10 dias, com uma frequência significativa de indivíduos que vivenciaram ou vivenciam a prática do aleitamento materno exclusivo. E os principais diagnósticos foram: pneumonia, bronquiolite, anemia falciforme e gastrenterite aguda.

Sendo assim, a realização desse estudo foi de grande relevância para o meio social e científico, uma vez que foram traçados o perfil clínico-epidemiológico e os principais diagnósticos de crianças internadas em um hospital pediátrico. E com base nessas informações, os gestores públicos do município e as equipes de saúde terão condições de desenvolver estratégias para uma melhor assistência dessa clientela.

Destaca-se como limitação desse estudo a ausência de informação quanto a naturalidade das crianças, haja vista que o hospital pediátrico que serviu como cenário da investigação recebe crianças de outros municípios. 


\section{REFERÊNCIAS}

BOTELHO, Patrícia Alexandra Peixoto. Percepção dos fatores desencadeadores de separação conjugal. 2018. Dissertação (Mestrado Integrado em Psicologia) - Faculdade de Psicologia e de Ciências da Educação da Universidade do Porto. Portugal. 2018.

BRASIL. Resolução no 466, de 12 de dezembro de 2012. Dispõe sobre diretrizes e normas regulamentadoras de pesquisas envolvendo seres humanos. Diário Oficial da República Federativa do Brasil, Brasília, DF. 2012.

CALDART, R. V. et al. Fatores associados à pneumonia em crianças Yanomami internadas por condições sensíveis à atenção primária na região norte do Brasil. Ciência \& Saúde Coletiva, v. 21, p. 1597-1606, 2016.

CAMPOS, L. S. et al. Avaliação do risco nutricional em crianças hospitalizadas: uma comparação da avaliação subjetiva global pediátrica e triagem nutricional STRONGkids com os indicadores antropométricos. Sci Med, $\mathrm{v}$. 25, p. 1-8, 2015.

CAMPOS, S. B. G. et al. Déficit estatural em crianças do povo karapotó, Sao Sebastiao, Alagoas, Brasil. Revista Paulista de Pediatria, v. 34, n. 2, p. 197-203, 2016.

DESTERRO, R. C. et al. Condições sensíveis à atenção primária em hospital de referência pediátrica no maranhão/ambulatory care sensitive conditions in a pediatric referral hospital in Maranhão. Revista de Pesquisa em Saúde, v. 18, n. 2, 2018.

ESCOBAR, E. M. et al. O uso de recursos lúdicos na assistência a criança hospitalizada. Rev Ciênc Ext. 2013.

FLÔR, P. CS. Perfil das internações de crianças em um hospital infantil do alto sertão paraibano. 2016. Trabalho de Conclusão de Curso (Bacharelado em Enfermagem) - Universidade Federal de Campina Grande. Cajazeiras. 2016.

HUBER, Elisa; VINHOLES, Daniele Botelho. Estado nutricional de crianças internadas na pediatria de um hospital terciário. Arq.Saúde. Ciênc 91-95 22(3) jul-set; 2015.

JOVENTINO, E. S. et al. Influência de condições socioeconômicas e de saúde em crianças na ocorrência de diarreia infantil. Revista de Enfermagem e Atenção à Saúde, v. 8, n. 1, 2019.

LIMA, M. E. S. et al. Perfil epidemiológico de crianças internadas com leishmaniose visceral em um Hospital Universitário do Maranhão. Rev. Soc. Bras. Enferm. Ped, v. 18, n. 1, p. 15-20, 2018.

MAISEL, B. A. et al. Perfil epidemiológico das internações em uma unidade pediátrica do Sistema Único de Saúde. Fisioterapia Brasil, v. 16, n. 1, p. 14-18, 2016.

OLÍMPIO, A. C. S. et al. Perfil clínico-epidemiológico de internamentos na unidade pediátrica de um hospital público cearense. Rev Min Enferm, 2018.

OLIVEIRA, E. N; NISHIMURA, L. N. S; BARBOSA, L. G. A importância da avaliação nutricional em crianças internadas na enfermaria pediátrica em hospitais municipais de São Paulo. Rev Bras Nutr Clin, v. 30, n. 1, p. 71-5, 2015.

PEREIRA, I. C. et al. Sociodemographic profile and food habit of children with pneumonia. ReonFacema. 2018 Out-Dez 4(4): 1317-1323.

RIBEIRO, M. G. C. et al. Hospitalizações por condições sensíveis à atenção primária em crianças do Nordeste Brasileiro. Revista Brasileira de Saúde Materno Infantil, v. 19, n. 2, p. 491-498, 2019.

SANTOS, A. S. et al. Comparação de métodos subjetivos de avaliação nutricional em crianças hospitalizadas. Nutrición clínica y dietética hospitalaria, v. 32, n. 2, p. 39-42, 2018. 
SANTOS, D. S. S; SANTOS, M. E. F. Mortalidade por pneumonia em crianças menores de 5 anos no brasil de 2009 a 2012. Revista Brasileira de Saúde Funcional, v. 5, n. 2, p. 18, 2018.

SANTOS, P. P; SCHEID, M. M. A. Importância do aleitamento materno exclusivo nos primeiros seis meses de vida para a promoção da saúde da mãe e bebê. 2019.

SILVA, E. P; TIENGO, A. Perfil nutricional de crianças hospitalizadas e sua relação com o período de internação em um hospital de ensino no sul de Minas Gerais. Revista Ciências em Saúde v4, n 4, out-dez 2014.

SILVA, H. F; TEIXEIRA, A. C. S. Caracterização das Internações Pediátricas na Região Sul no Estado do Tocantins. Revista Cereus, Gurupi-TO, v. 8, n. 3, p. 83-95, set./dez. 2016.

SILVA, J. et al. Prevalência de internações hospitalares por desnutrição e anemia em bebês menores de um ano/Prevalence of hospital admissions due to malnutrition and anemia in infants less than one year old. Brazilian Journal of Health Review, v. 2, n. 1, p. 91-98, 2018.

SILVA, W. B. et al. Crianças internadas em hospital universitário: caracterização sociodemográfica e epidemiológica. Renome, v. 6, n. 1, p. 18-31, 2018.

SOARES, A. K. F. et al. Associação entre variáveis sociodemográficas e do estado nutricional infantil com o tipo de aleitamento materno. 2019.

SOUZA, L. A. et al. Associação da Ferramenta de Triagem Nutricional Strongkids com Parâmetros Antropométricos em Crianças. Revista Portal: Saúde e Sociedade, v. 4, n. 1, p. 975-984, 2019.

TEIXEIRA, A. F; VIANA, K. D. L. Triagem nutricional em pacientes pediátricos hospitalizados: uma revisão sistemática. Jornal de pediatria, v. 92, n. 4, p. 343-352, 2016. 


\section{A ENFERMAGEM FRENTE AO CÂNCER DO COLO DE ÚTERO}

Thayane Steinbach Campos Maia

Centro Universitário IBMR - Brasil

thayanecompos@gmail.com

Claudia Tchmola Garcia

Centro Universitário IBMR - Brasil

claudinha.hmcl@gmail.com

\author{
Allan Carlos Mazzoni Lemos \\ Centro Universitário IBMR - Brasil \\ allan.lemos@ibmr.br \\ Icsor Almeida Araujo \\ Centro Universitário IBMR - Brasil \\ icsor20@gmail.com
}

\section{RESUMO}

Devidos às taxas elevadas de prevalência e mortalidade do câncer cérvicouterino, é imprescindível que seja adotada de forma efetiva, estratégias para a adesão do rastreamento da doença através do exame Papanicolau, sendo o enfermeiro de suma importância neste processo de prevenção e promoção de saúde, trazendo uma assistência integralizada e humanizada durante a realização do exame citopatológico. Esse artigo tem por premissa, promover uma revisão integrativa-qualitativa, sendo estabelecidas as coletas de dados da seguinte forma: seleção da base de dados, filtragem dos textos, critérios de inclusão e exclusão, categorização dos estudos e avaliação dos trabalhos selecionados, tendo por objetivo: Analisar os fatores que impedem a adesão aos programas de prevenção e rastreamento, bem como identificar as abordagens dos profissionais que vêm sendo formados para atuar nesse contexto. O estudo demonstrou desinformação por parte das mulheres, desconforto, medo do exame preventivo e o despreparo da equipe em acolher, orientar $e$ atender estas de forma humanizada. Assim, sugere-se a elaboração de outros estudos a respeito do tema, que identifique as estratégias e esforços que estão sendo reunidos para que as taxas de incidência diminuam, e ainda, que as instituições responsáveis por formar profissionais de Enfermagem, reforcem as disciplinas que abordem o tema em questão.

\section{Palavras-chave:}

Neoplasias do colo do útero; Colo do útero;

Neoplasias uterinas.

\begin{abstract}
Due to the high prevalence and mortality rates of cervical cancer, it is essential that strategies for the adhering to disease screening through the Pap smear are effectively adopted, and nurses are of paramount importance in this process of prevention and health promotion, bringing comprehensive and humanized care during the cytopathological examination. This article has as premise, to promote an integrative-qualitative review, being established the data collection as follows: selection of the database, filtering of texts, inclusion and exclusion criteria, categorization of studies and evaluation of selected studies, aiming to: Analyze the factors that prevent the access to prevention and screening programs, as well as identify the approaches of professionals who
\end{abstract}

have been trained to act in this context. The study demonstrated disinformation on the part of women, discomfort, fear of preventive examination and the lack of preparation of the team in welcoming, guiding and attending them in a humanized way. Thus, it is suggested the elaboration of other studies on the subject, which identifies the strategies and efforts that are being gathered so that incidence rates decrease, and also, that the institutions responsible for training nursing professionals, reinforce the disciplines that address the theme in question.

\section{Keywords:}

Cervical neoplasms; Cervix; Uterine neoplasms. 
INTRODUÇÃO

Cada vez mais a enfemagem se insere em um ambiente de grande importância no que tange a prevenção do câncer do colo do útero (CCU), pois é responsável pela promoção à saúde, prevenção de doenças e qualidade de vida da mulher. Sendo assim, é necessária a atuação dos enfermeiros na Estratégia da Saúde da Família (ESF) e na realização de ações para a diminuição da incidência do CCU, conforme afirma Mistura et al (2011).

Entende-se que o profissional enfermeiro é o principal responsável dentro da atenção primária, por ser capaz de analisar as dificuldades encontradas para a realização do exame citopatológico, dessa forma ele pode encontrar soluções adequadas através de uma postura crítico-reflexiva para a busca de uma assistência mais humanizada (Amaral, Gonçalves \& Silveira, 2017).

Corroborando com a citação acima, as diretrizes brasileiras para o rastreamento do câncer do colo do útero define, o rastreamento como uma tecnologia da atenção primária e os profissionais atuantes nesse nível de atenção devem conhecer o método, a periodicidade e a população-alvo recomendada, sabendo ainda orientar e encaminhar para tratamento as mulheres de acordo com os resultados dos exames e garantir seu seguimento (Inca, 2016).

No cenário da prevenção do CCU, a atuação do enfermeiro nas equipes da ESF se revelou de importância fundamental, uma vez que suas atividades são desenvolvidas em múltiplas dimensões, entre elas: realização das consultas de enfermagem e do exame de papanicolau, ações educativas diversas junto à equipe de saúde e comunidade, gerenciamento e contatos para o provimento de recursos materiais e técnicos, controle da qualidade dos exames, verificação, comunicação dos resultados e encaminhamentos para os devidos procedimentos quando necessário, favorecendo a saúde da mulher (Melo, Vilela, Salimena \& Souza, 2012).

Todavia, ressalta-se a importância do impacto psicológico que o diagnóstico de uma infecção sexualmente transmissível (IST) e precursora do câncer terá na vida das mulheres, sobretudo na autoimagem e na própria sexualidade. Principalmente nos casos de mulheres mais jovens, com vida sexual ativa, devendo ser orientadas pelos profissionais da ESF sobre a anticoncepção, infecções sexualmente transmissíveis e práticas de sexo seguro, com uso de preservativo (Inca, 2016).

Para que ocorra de forma adequada a orientação por parte dos profissionais, torna-se fundamental compreender que o câncer são células mutadas, conhecidas como células cancerosas que não morrem e ao invés disso, dão-se em crescimento anormal e desordenado, replicando-se de maneira a gerar novas células alteradas de forma rápida, agressiva e incontrolável, espalhando-se para outras regiões do corpo - acarretando transtornos funcionais como o câncer (Inca, 2020).

Além disso, é necessário entender que o câncer do colo uterino é caracterizado pela divisão desordenada das células epiteliais anormais que revestem o órgão, comprometendo o estroma (tecido subjacente), podendo por vez invadir os tecidos contíguos ou à distância, formando as chamadas metástases. São duas as principais categorias de câncer do colo do útero, dependendo do tecido comprometido: o carcinoma epidermóide, que conta com o maior número de incidências e 
acomete o epitélio escamoso (cerca de $90 \%$ dos casos) e o adenocarcinoma que é um tipo raro, acometendo assim o epitélio glandular ( $10 \%$ dos casos). O agente etiológico de ambos os carcinomas apresentados é o Papiloma Vírus Humano (HPV) (Inca, 2007).

O HPV é um vírus de DNA que infecta primariamente o epitélio, podendo induzir lesões benignas/malignas na pele e na mucosa. Alguns HPVs são considerados de alto risco, responsáveis pela progressão das lesões precursoras até o CCU, especialmente o HPV-16 e o HPV-18, responsáveis por cerca de 70\% dos cânceres uterinos (Rosa et al., 2009; WHO, 2020).

Avalia-se que os números de casos novos de câncer do colo do útero esperados para o Brasil indicados pelo INCA (2019), em cada ano do triênio 2020-2022, será de 6.540, com um risco estimado de 6,07 casos a cada 100 mil mulheres. Em relação à mortalidade no Brasil, em 2017, ocorreram 1.827 óbitos e a taxa bruta de mortalidade por câncer do colo do útero foi de 1,77/100 mil, já de acordo com dados apresentados pelo Instituto Nacional de Saúde da Mulher, da Criança e do Adolescente Fernandes Figueira IFF/Fiocruz 2017, existem cerca de 530 mil novos casos de CCU anualmente, sendo este o quarto câncer mais comum em mulheres e a quarta causa mais frequente de óbitos entre a população feminina, tendo em média 265 mil mortes associadas por ano.

Dessa forma, esse trabalho apresenta razões que intensificam estudos sobre a enfermagem e sua atuação no processo de prevenção do câncer do colo do útero, visto que, de acordo com o Instituto Nacional de Câncer José Alencar Gomes da Silva, o câncer do colo do útero é o quarto tipo oncológico que mais acomete a população feminina no mundo e no Brasil, é a terceira localização primária de incidência e a quarta de mortalidade por câncer em mulheres no país.

Com base na importância de engrandecer os estudos dos profissionais de enfermagem, diretamente ligados a saúde da mulher, propõe-se agregar conhecimentos em seu desempenho frente ao câncer do colo do útero, numa abrangência melhor e mais direcionada de sua atuação, viabilizando o enriquecimento de referencial teórico sobre o tema.

Dessa maneira, emerge a questão norteadora: Como se apresentam os estudos diante do tema câncer do colo do útero, sobre a perspectiva dos profissionais de enfermagem? Tendo por objetivo: Analisar os fatores que impedem a adesão aos programas de prevenção e rastreamento; identificar as abordagens dos profissionais que vêm sendo formados para atuar nesse meio; descrever a abordagem dos profissionais atuantes nesse contexto.

\section{Metodologia}

Esse artigo tem por premissa promover uma revisão integrativa. De acordo com Mendes, Silveira \& Galvão (2008), a revisão integrativa é um método de pesquisa incipiente na enfermagem nacional, porém a sua contribuição na melhoria do cuidado prestado ao paciente e familiar é inegável. A síntese dos resultados de pesquisas relevantes e reconhecidas mundialmente facilita a incorporação de evidências, ou seja, agiliza a transferência de conhecimento novo para a prática.

Este tipo de pesquisa é vital para se delimitar um problema, criar-se um protótipo de pesquisa e conseguir um cenário preciso sobre o estado atual dos conhecimentos sobre o assunto, bem como as suas lacunas e sobre a contribuição do levantamento de informações para desenvolver o conhecimento (Lakatos \& Marconi, 2003). 
A metodologia utilizada neste artigo é de natureza qualitativa e segundo Pereira, Shitsuka, Parreira \& Shitsuka (2018), este tipo de pesquisa ocorre tendo o pesquisador como seu principal instrumento para coletar os dados de maneira direta, sendo preferencialmente descritivos, com foco no "significado" que as pessoas dão às coisas.

Foram estabelecidas as coletas de dados da seguinte forma: Seleção da base de dados, filtragem dos textos, critérios de inclusão e exclusão, categorização dos estudos e avaliação dos trabalhos selecionados.

A busca dos textos foram realizadas entre setembro e novembro de 2020, sem estabelecimento de filtro temporal nas bases de dados virtuais Scentific Eletronic Library Online (SCIELO) e Biblioteca Virtual de Saúde (BVS), desse modo, ao realizar a busca foi necessário estabelecer filtros criteriosos, sendo eles na plataforma BVS refinados em: Texto completo e Base de Dados em Enfermagem (BDENF) e na SCIELO refinados em: Citável e Texto e Contexto - Enfermagem. Logo, foram encontrados 28 artigos na BVS ao utilizar "(Neoplasias do colo do útero) OR (Prevenção do colo uterino) OR (câncer do colo uterino)" e na SCIELO foram encontrados 15 artigos ao utilizar "(Neoplasias do colo do útero) OR (Prevenção do colo uterino) OR (câncer do colo uterino)", totalizando 43 artigos sendo selecionados destes, 21 artigos. Após a filtragem dos textos foi iniciada a leitura exploratória e analítica, com isso foram excluídos 2 artigos, sendo selecionados 19 estudos para permitir a realização da discussão. Sucederam-se como critérios de exclusão as dissertações, teses, resumos e artigos repetidos, assim como aqueles que não foram pertinentes ao estudo. As palavras chaves utilizadas foram: Neoplasias do colo do útero; Colo do Útero; Neoplasias Uterinas.

Ao final, foram realizadas a leitura e a análise dos artigos e publicações elegidos para fazerem parte do estudo, sendo construídos quadros que contemplam as principais características dos artigos que foram utilizados na pesquisa, posteriormente foi feita a leitura analítica dos textos, para que assim, fosse elaborado um conteúdo que permitisse identificar evidências da atuação da enfermagem frente ao câncer do colo uterino.

Imagem 1 - Seleção dos artigos.

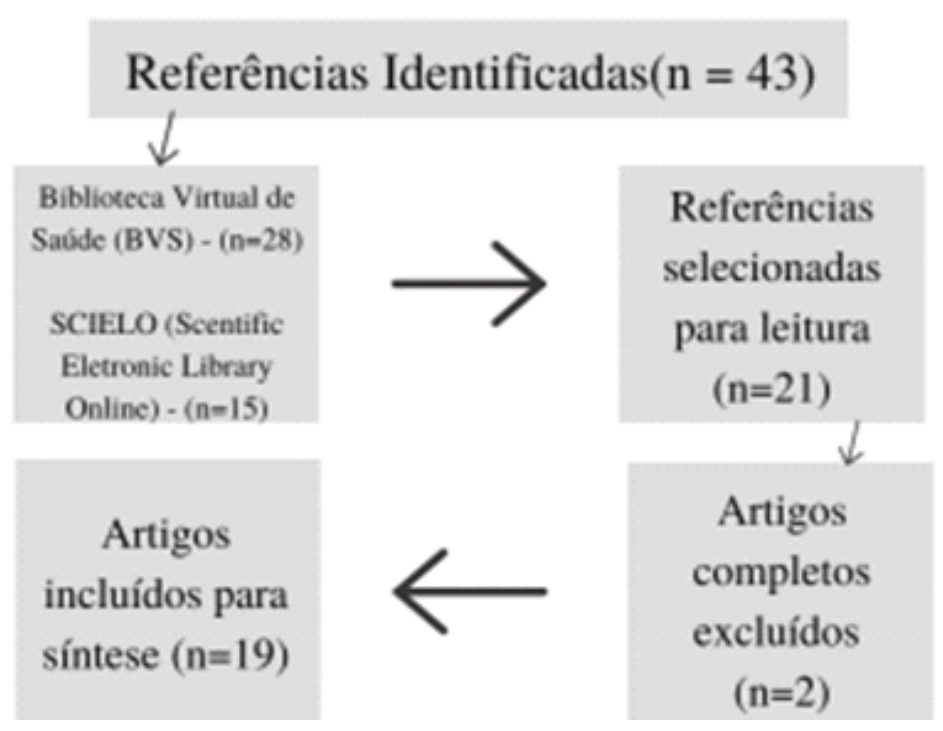

Fonte: Autores. 


\section{A Imagem 1 tem o propósito de esclarecer como foram selecionados os artigos e para sustentar o nosso referencial teórico, encontramos 19 artigos que foram descritos no quadro abaixo.}

Quadro 1 - Informações dos artigos selecionados.

\begin{tabular}{|c|c|c|c|c|c|}
\hline \multicolumn{6}{|c|}{ N TíTULO AUTOR ANO RESULTADO CONCLUSÃO } \\
\hline 1 & $\begin{array}{l}\text { Exclusividade na coleta de } \\
\text { material para exame de } \\
\text { colpocitologia oncótica: } \\
\text { percepção dos enfermeiros }\end{array}$ & $\begin{array}{l}\text { Letícia Lima de Oliveira; } \\
\text { Marllon Rodrigo Sousa } \\
\text { Santos; Ivaneide Leal } \\
\text { Ataíde Rodrigues; Suzana } \\
\text { Rosa André; Ingrid Fabiane } \\
\text { Santos da Silva; Laura } \\
\text { Maria Vidal Nogueira. }\end{array}$ & 2020 & $\begin{array}{l}\text { Os dados correspondem a percepções sobre a coleta do } \\
\text { exame de colpocitologia oncótica, subdivididas em } \\
\text { percepções sobre a coleta realizada pelo enfermeiro e } \\
\text { técnico de enfermagem, facilidades e dificuldades na coleta } \\
\text { e alterações na rotina dos enfermeiros. }\end{array}$ & $\begin{array}{l}\text { As percepções dos enfermeiros são } \\
\text { heterogêneas, porém convergem ao } \\
\text { reconhecerem a necessidade de agregar } \\
\text { conhecimento técnico e cientifico para } \\
\text { realização da coleta de material para } \\
\text { colpocitologia oncótica, em razão da alta } \\
\text { complexidade da técnica. }\end{array}$ \\
\hline 2 & $\begin{array}{l}\text { Atividades educativas } \\
\text { estimulando o auto-cuidado e } \\
\text { prevenção do câncerfeminino }\end{array}$ & $\begin{array}{l}\text { Lorena Campos Mendes; } \\
\text { Thais Cristina Elias; Taciana } \\
\text { Nunes dos Santos; Erika } \\
\text { Mendes Tayar;Sueli da } \\
\text { Silva Riul. }\end{array}$ & 2017 & $\begin{array}{l}\text { Foi beneficiado um grupo de aproximadamente } 1040 \\
\text { estudantes. Notoutse que, de um modo geral, as mulheres } \\
\text { eram carentes de informações relacionadas à temática e que } \\
\text { possuíam um déficit de conhecimento maior referente à } \\
\text { Auto-palpação das Mamas em relação ao exame } \\
\text { Papanicolaou. }\end{array}$ & $\begin{array}{l}\text { Observou-se que a transmissão de } \\
\text { informações neste contexto é de extrema } \\
\text { importância, e apresentase como uma } \\
\text { ferramenta fundamental na assistência de } \\
\text { Enfermagem. }\end{array}$ \\
\hline 3 & $\begin{array}{l}\text { Intervenções de } \\
\text { enfermagem na prevenção } \\
\text { do câncer cérvico uterino: } \\
\text { perspectivas das clientes }\end{array}$ & $\begin{array}{l}\text { Jorge Luis Tavares de } \\
\text { Oliveira; Betânia Maria } \\
\text { Fernandes. }\end{array}$ & 2017 & $\begin{array}{l}\text { Emergiram três categorias: intervençõescomportamentais, } \\
\text { intervençōes cognitivas e intervenções sociais }\end{array}$ & $\begin{array}{l}\text { Os enfermeiros devem combinar } \\
\text { intervenções comportamentais, cognitivas } \\
\text { e sociais, conjuntamente, com demais } \\
\text { profissionais da equipe, visando efetivar } \\
\text { ações preventivas para câncer cérvico- } \\
\text { uterino e promover a saúde das mulheres. }\end{array}$ \\
\hline 4 & $\begin{array}{l}\text { Percepção de mulheres } \\
\text { sobre o teste de } \\
\text { papanicolaou }\end{array}$ & $\begin{array}{l}\text { Carla Marins Silva; Daniela } \\
\text { Soares de Oliveira; Octavio } \\
\text { Muniz da Costa Vargens. }\end{array}$ & 2016 & $\begin{array}{l}\text { Os dados foram sistematizados em duascategorias: } \\
\text { "Percebendo o procedimento como desconfortável" que se } \\
\text { subdivide em três subcategorias: "relacionando o desconforto } \\
\text { ao procedimento propriamente dito", "relacionando o } \\
\text { desconforto com a sensação de constrangimento e vergonha" } \\
\text { e "percebendo o vínculo com o profissional como forma de } \\
\text { diminuição do desconforto" e; "Percebendo o exame } \\
\text { Papanicolaou como forma de cuidado à saúde". }\end{array}$ & $\begin{array}{l}\text { As mulheres percebem o exame } \\
\text { Papanicolaou como desconfortável, mas } \\
\text { entendem a necessidade e a importância } \\
\text { do cuidado à saúde. }\end{array}$ \\
\hline 5 & $\begin{array}{l}\text { Atividades educativas no } \\
\text { controle do câncer de colo do } \\
\text { útero: relato de experiência }\end{array}$ & $\begin{array}{l}\text { Carolina Amancio Valente; } \\
\text { Viviane Andrade;Mauricia } \\
\text { Brochado Oliveira } \\
\text { Soares;Sueli Riul da Silva. }\end{array}$ & 2015 & $\begin{array}{l}\text { Durante a realização da atividade educativa obtivemos } \\
\text { grande participação do público alvo com levantamento de } \\
\text { dúvidas sobre o câncer de colo do útero, exame de } \\
\text { Papanicolau e também sobre questões relacionadas à } \\
\text { sexualidade e ao corpo feminino. }\end{array}$ & $\begin{array}{l}\text { A atividade extensionista foi de grande } \\
\text { valor tanto para o ensino/aprendizagem } \\
\text { das acadêmicas como para a população } \\
\text { alvo. }\end{array}$ \\
\hline 6 & $\begin{array}{l}\text { Fatores associados a não } \\
\text { realização periódica do } \\
\text { exame papanicolaou }\end{array}$ & $\begin{array}{l}\text { Roberta Jeane Bezerra } \\
\text { Jorge; Luis Rafael Leite } \\
\text { Sampaio; Maria Albertina } \\
\text { Rocha Diógenes; Francisco } \\
\text { Antonio da Cruz } \\
\text { Mendonça;Lucijane Leite } \\
\text { Sampaio }\end{array}$ & 2011 & $\begin{array}{l}\text { Os fatores relacionados pelas entrevistadas para a não } \\
\text { observação da periodicidade do exame dizem respeito à } \\
\text { preferência por ervas medicinais ao invés de terapia } \\
\text { convencional e aos aspectos sociais e individuais das } \\
\text { mulheres. Estas mulheres percebem o exame como um } \\
\text { processo agressivo, físico e que as afeta emocionalmente. }\end{array}$ & $\begin{array}{l}\text { Sugere-se melhor preparação dos } \\
\text { profissionais de saúde, para compreensão } \\
\text { dos contextos sociais e individuais } \\
\text { dessas mulheres que podem contribuir } \\
\text { negativamente para adesão ao exame } \\
\text { citológico. }\end{array}$ \\
\hline 7 & $\begin{array}{l}\text { Prática inadequada de } \\
\text { mulheres acerca do } \\
\text { papanicolaou }\end{array}$ & $\begin{array}{l}\text { Elainy Fabríia Galdino } \\
\text { Dantas Malta; Fabiane do } \\
\text { Amara Gubert; Camila } \\
\text { Teixeira Moreira } \\
\text { Vasconcelos; Emília Soares } \\
\text { Chaves; João Marcos } \\
\text { Ferreira de Lima Silva; } \\
\text { Eveline Pinheiro Beserra. }\end{array}$ & 2017 & $\begin{array}{l}\text { Observaram-se inadequações, principalmente no } \\
\text { conhecimento, pois, apesar de possuírem informações sobre } \\
\text { o exame, utilizavam-no apenas para detectar doenças } \\
\text { sexualmente transmissiveis. No quesito prática, percebeutse } \\
\text { que mulheres solteiras de até } 29 \text { anos apresentam maiores } \\
\text { chances de prática inadequada do que aquelas com } \\
\text { maioridade/casadas, aumentando a probabilidade de } \\
\text { desenvolver câncer do colo do útero. A maior dificuldade para } \\
\text { a realização do exame foi devido à falta de material }(68,1 \% \text {. }\end{array}$ & $\begin{array}{l}\text { O esclarecimento às mulheres acerca do } \\
\text { exame necessita de comunicação efetiva } \\
\text { entre usuárias e equipe de saúde, além } \\
\text { da garantia e suporte à continuidade do } \\
\text { cuidado dos gestores. }\end{array}$ \\
\hline 8 & $\begin{array}{l}\text { A percepção da } \\
\text { vulnerabilidad e entre } \\
\text { mulheres com diagnóstico } \\
\text { avançado do câncer do colo } \\
\text { do útero }\end{array}$ & $\begin{array}{l}\text { Angela Vieira } \\
\text { Pimentel;:Marislei Sanches } \\
\text { Panobianco; Ana Maria de } \\
\text { Almeida; lácara Santos } \\
\text { Barbosa Oliveira. }\end{array}$ & 2011 & $\begin{array}{l}\text { Emergiram duas categorias temáticas: Percebendose } \\
\text { vulnerável na descoberta da doença e vulnerável na } \\
\text { realização do tratamento. Fatores relacionados à cliente, } \\
\text { profissionais, serviços, entre outros, tornaram a mulher } \\
\text { suscetivel aos problemas e danos de saúde, relativos ao } \\
\text { câncer cérvico-uterino, exacerbando sua vulnerabilidade à } \\
\text { doença. }\end{array}$ & $\begin{array}{l}\text { É necessário superar deficiências no } \\
\text { modelo de assistência e humanização do } \\
\text { atendimento, no grau de compromisso e } \\
\text { qualidade das instituições, dos recursos, } \\
\text { gerenciamento e monitoramento dos } \\
\text { programas de prevenção e detecção do } \\
\text { câncer do colo do útero, nos diferentes } \\
\text { níveis de atenção. }\end{array}$ \\
\hline 9 & $\begin{array}{l}\text { Análise da influência do } \\
\text { acondicionam ento } \\
\text { diferenciado de lâminas para } \\
\text { colpocitologia no resultado } \\
\text { laboratorial }\end{array}$ & $\begin{array}{l}\text { Camila Félix Américo; Ana } \\
\text { Carolina Maria Araújo } \\
\text { Chagas; Emeline Moura } \\
\text { Lopes;Levânia Maria } \\
\text { Benevides Dias;Thaís } \\
\text { Marques Lima;Escolástica } \\
\text { Rejane Ferreira Moura; Ana } \\
\text { Karina Bezerra Pinheiro. }\end{array}$ & 2010 & $\begin{array}{l}\text { Os resultados das duas lâminas foram comparados } \\
\text { verificando discordâncias nos diferentes armazenamentos. } \\
\text { Houve discordância de } 58,3 \% \text { em relação aos Epitélios } \\
\text { Representativos da Amostra e } 48,2 \% \text { com relaçãa às } \\
\text { Alteraçỗes Celulares Benignas. }\end{array}$ & $\begin{array}{l}\text { Os resultados sugerem novos estudos } \\
\text { sobre formas de acondicionamento, } \\
\text { controle da intra subjetividade do técnico } \\
\text { responsável pela leitura e ordem de coleta } \\
\text { das lâminas caso e controle. }\end{array}$ \\
\hline
\end{tabular}


Continuação

N TÍTULO AUTOR ANO R ESULTADO CONCLUSÃO

\begin{tabular}{|c|c|c|c|c|c|}
\hline 10 & $\begin{array}{l}\text { Adesão das acadêmicas de } \\
\text { enfermagem à prevenção do } \\
\text { câncer ginecológico: Da } \\
\text { teoria à prática }\end{array}$ & $\begin{array}{l}\text { Alessandra Bonato Beghini; } \\
\text { Anna Maria de Oliveira } \\
\text { Salimena; Maria Carmen } \\
\text { Simões Cardoso de Melo; } \\
\text { Ívis Emília de Oliveira } \\
\text { Souza. }\end{array}$ & 2006 & $\begin{array}{l}\text { A análise de suas falas, apontou três categorias: } \\
\text { conhecimento, atitude e prática; a dicotomia entre o saber e } \\
\text { o fazer incorretamente; a dicotomia entre o saber e o não } \\
\text { fazer. }\end{array}$ & $\begin{array}{l}\text { Revelou-se que a preconização do Ministério } \\
\text { da Saúde quanto a este auto cuidado é } \\
\text { implementada corretamente por algumas das } \\
\text { participantes, porém não o é por outras. } \\
\text { Observou-se que o conhecimento adquirido } \\
\text { no decurso das disciplinas não impõe nas } \\
\text { acadêmicas a aderência de na prática, cuidar } \\
\text { da própria prevenção. O tema mostrou-se } \\
\text { bastante amplo e passivel de reflexões, } \\
\text { apresentando subsídios para novos } \\
\text { questionamentos }\end{array}$ \\
\hline 11 & $\begin{array}{l}\text { Conhecimento, atitude e } \\
\text { prática de acadêmicas de } \\
\text { enfermagem sobre o exame } \\
\text { de papanicolaou }\end{array}$ & $\begin{array}{l}\text { Kellyane Feitosa Carvalho } \\
\text { Ribeiro; Maria Sauanna } \\
\text { Sany de Moura;Rosianne } \\
\text { Gomes Cipriano Brandão; } \\
\text { Ana Izabel Oliveira Nicolau; } \\
\text { Priscila de Souza Aquino; } \\
\text { Ana Karina Bezerra } \\
\text { Pinheiro. }\end{array}$ & 2013 & $\begin{array}{l}\text { A coleta de dados ocorreu de agosto a outubro de } 2010 \text {, } \\
\text { perfazendo } 143 \text { acadêmicas de enfermagem. Quanto ao } \\
\text { conhecimento sobre o exame, apenas } 40(28 \%) \text { foram } \\
\text { classificadas com um conhecimento adequado. Já em } \\
\text { relação à atitude e à prática, o percentual foi } 106(74,1 \%) \text { e } \\
75(52,4 \%) \text { respectivamente. }\end{array}$ & $\begin{array}{l}\text { Conclui que mesmo se tratando de uma } \\
\text { população do curso da área da saúde, o } \\
\text { conhecimento acerca do exame necessita } \\
\text { ser revisto, com mais atividades de } \\
\text { promoção da saúde dentro do ambiente } \\
\text { universitário. }\end{array}$ \\
\hline 12 & $\begin{array}{l}\text { Análise espacial dos } \\
\text { indicadores pactuados para o } \\
\text { rastreamento do câncer do } \\
\text { colo do útero no Brasil }\end{array}$ & $\begin{array}{l}\text { Raila de Souza Santos; } \\
\text { Enirtes Caetano Prates } \\
\text { Melo;Keitt Martins Santos. }\end{array}$ & 2012 & $\begin{array}{l}\text { Apesar de estruturado e com melhoras nos indicadores, o } \\
\text { programa ainda se encontra abaixo das metas pactuadas em } \\
\text { alguns Estados, configurando um padrão desigual de } \\
\text { desempenho dos indicadores no território brasileiro. }\end{array}$ & $\begin{array}{l}\text { As diferenças regionais mostraram falhas } \\
\text { na captação de mulheres, na cobertura } \\
\text { populacional, na qualidade das amostras } \\
\text { do exame citológico e estabilidade da taxa } \\
\text { de mortalidade. Estados que se } \\
\text { encontram abaixo das metas pactuadas } \\
\text { precisam otimizar os recursos e promover } \\
\text { acesso às mulheres que não estão } \\
\text { inseridas no programa de rastreamento. }\end{array}$ \\
\hline 13 & $\begin{array}{l}\text { Abordagem fenomenológic a } \\
\text { do câncer do colo do útero } \\
\text { em gestantes: aspectos da } \\
\text { prevenção }\end{array}$ & $\begin{array}{l}\text { Rita de Cássia Rocha } \\
\text { Moreira; Regina Lúcia } \\
\text { Mendonça Lopes; Elaine de } \\
\text { Carvalho Santana } \\
\text { Peñarrieta; Ramaiana de } \\
\text { Jesus Gonzaga; Maria } \\
\text { Lúcia Silva Servo; Maria } \\
\text { Angela Alves do } \\
\text { Nascimento. }\end{array}$ & 2017 & $\begin{array}{l}\text { O sentido da prevenção do câncer do colo do útero para as } \\
\text { gestantes desvelou as possibilidades de vivenciar a } \\
\text { ambigüidade na convivência conjugal e ainautenticidade nas } \\
\text { relações entre profissional de saúde e cliente }\end{array}$ & $\begin{array}{l}\text { Necessário se faz, enfrentar o desafio de } \\
\text { reconhecer a fragilidade da cultura do } \\
\text { desenho biomédico para cuidar da saúde } \\
\text { das mulheres, na perspectiva de } \\
\text { desenvolver um cuidado comprensivo. }\end{array}$ \\
\hline 14 & $\begin{array}{l}\text { Conhecimento de mulheres } \\
\text { acerca do papiloma vírus } \\
\text { humano e sua relação com o } \\
\text { câncer de colo uterino. }\end{array}$ & $\begin{array}{l}\text { Marisa de Castro Araújo } \\
\text { França; Michelle de Castro } \\
\text { Sampaio França; Samara } \\
\text { Dourado dos Santos } \\
\text { Moraes. }\end{array}$ & 2013 & $\begin{array}{l}\text { Observou-se que } 71,4 \% \text { conhecem o papiloma vírus } \\
\text { humano, mas } 63,5 \% \text { desconhecem sua forma de } \\
\text { transmissão e prevenção e } 89,7 \% \text { desconhecem o que este } \\
\text { provoca no organismo; } 96,8 \% \text { das entrevistadas referiram } \\
\text { conhecer o câncer do colo do útero, mas } 88,9 \% \text { não sabem } \\
\text { qual a relação deste com o papiloma vírus humano. }\end{array}$ & $\begin{array}{l}\text { Conclui-se que há deficiência no } \\
\text { conhecimento dessas mulheres sobre o } \\
\text { papiloma vírus humano, sua forma de } \\
\text { prevenção, transmissão e sua relação } \\
\text { com o câncer cervical. }\end{array}$ \\
\hline 15 & $\begin{array}{l}\text { Atividades educativas na área } \\
\text { da saúde da mulher: Um } \\
\text { relato de experiência }\end{array}$ & $\begin{array}{l}\text { Sueli Riul da Silva; } \\
\text { Fernanda Coimbra } \\
\text { Lício;Lívia Valentino Borges; } \\
\text { Lorena Campos } \\
\text { Mendes;Natália Gomes } \\
\text { Vicente;Nathália Silva } \\
\text { Gomes. }\end{array}$ & 2012 & $\begin{array}{l}\text { As participantes demonstraram grande interesse sobre a } \\
\text { temática, manifestado através da interação com œs } \\
\text { palestrantes, por meio de dúvidas, do relato de suas } \\
\text { vivências e das respostas aos questionamentos } \\
\text { apresentados. }\end{array}$ & $\begin{array}{l}\text { Apesar das mulheres não saberem do } \\
\text { que se trata, a maioria conhecia o } \\
\text { autoexame de mamas. Notourse também } \\
\text { desconhecimento da relação entre o } \\
\text { câncer de colo de útero e o Papiloma } \\
\text { Vírus Humano. }\end{array}$ \\
\hline 16 & $\begin{array}{l}\text { A atuação da enfermagem na } \\
\text { prevenção do câncer na } \\
\text { mulher: } \\
\text { questões culturais e de } \\
\text { gênero. }\end{array}$ & $\begin{array}{l}\text { Maria Elisa Wotzasek } \\
\text { Cestari; Márcia Maria } \\
\text { Fontão Zago }\end{array}$ & 2012 & $\begin{array}{l}\text { Como resultado, encontramos que o fato de o profissional } \\
\text { que realiza o exame ginecológico ser homem ou mulher } \\
\text { interfere na adesão às práticas de prevenção. }\end{array}$ & $\begin{array}{l}\text { Assim, ressaltamos que a inclusão da } \\
\text { discussão de gênero nos programas de } \\
\text { prevenção é essencial para garantir a } \\
\text { adesão das mulheres a programas de } \\
\text { prevenção do câncer cérvico-uterino e de } \\
\text { mamas. }\end{array}$ \\
\hline 17 & $\begin{array}{l}\text { Coleta de citopatológico de } \\
\text { colo uterino: } \\
\text { Saberes e percepções de } \\
\text { Mulheres que realizam o } \\
\text { exame. }\end{array}$ & $\begin{array}{l}\text { Simone Wünsch; Stefanie } \\
\text { Griebeler Oliveira;Raquel } \\
\text { Pötter Garcia;Izaura } \\
\text { BicaDomingues. }\end{array}$ & 2011 & $\begin{array}{l}\text { Realizou-se a coleta de dados por meio de entrevistas e, } \\
\text { posteriormente, análise temática. }\end{array}$ & $\begin{array}{l}\text { As mulheres apresentam conhecimento } \\
\text { acerca do objetivo do exame. Além disso, } \\
\text { afloraram sentimentos como vergonha e } \\
\text { constrangimento, os quais são } \\
\text { construídos culturalmente e se constituem } \\
\text { barreiras para a realização da coleta do } \\
\text { citopatológico de colo uterino. }\end{array}$ \\
\hline 18 & $\begin{array}{l}\text { Conhecimento de mulheres } \\
\text { de } 40 \text { a } 60 \text { anos sobre o } \\
\text { Papiloma vírus Humano }\end{array}$ & $\begin{array}{l}\text { Caroline Freitas Silveira; } \\
\text { Mariana Martins de Melo; } \\
\text { Leiner Resende Rodrigues; } \\
\text { Bibiane Dias Miranda } \\
\text { Parreira. }\end{array}$ & 2011 & $\begin{array}{l}\text { A média de idade foi de } 48,7 \text { anos. Quanto ao exame de } \\
\text { Papanicolaou, } 96,7 \% \text { relataram ter realizado o procedimento } \\
\text { alguma vez e } 40 \% \text { citaram que o exame previne o câncer do } \\
\text { colo uterino. Sobre o HPV, } 86,7 \% \text { das mulheres conheciam a } \\
\text { sigla, mas } 53,3 \% \text { não sabiam o que era HPV. }\end{array}$ & $\begin{array}{l}\text { Concluiu-se uma deficiência do } \\
\text { conhecimento dessas mulheres sobre o } \\
\text { exame de Papanicolaou e o HPV. Desta } \\
\text { forma, é necessário o desenvolvimento de } \\
\text { estratégias educativas para essa faixa } \\
\text { etária específica. }\end{array}$ \\
\hline
\end{tabular}


Continuação

\begin{tabular}{|c|c|c|c|c|c|}
\hline \multicolumn{6}{|c|}{ № TíTULO AUTOR ANO R ESULTADO CONCLUSÃO } \\
\hline 19 & $\begin{array}{l}\text { Prevenção do câncer de colo } \\
\text { uterino: Adesão de } \\
\text { enfermeiros e usuárias da } \\
\text { atenção primária }\end{array}$ & $\begin{array}{l}\text { Francisco Antonio da Cruz } \\
\text { Mendonça; Luis Rafael } \\
\text { Leite Sampaio; Roberta } \\
\text { Jeane Bezerra } \\
\text { Jorge;Raimunda } \\
\text { Magalhães da Silva; Andrea } \\
\text { Gomes Linard; Neiva } \\
\text { Francenely Cunha Vieira. }\end{array}$ & 2011 & $\begin{array}{l}\text { Os resultados do estudo apontam para a importância da } \\
\text { prevenção como recurso importante para manutenção da } \\
\text { saúde feminina, embora encontrem entraves para realização } \\
\text { destas ações. }\end{array}$ & $\begin{array}{l}\text { Observou-se a adesão dos enfermeiros e } \\
\text { das usuárias relacionada ao auto-cuidado } \\
\text { com o motivo para busca da prevenção. } \\
\text { Os enfermeiros apontaram deficiência na } \\
\text { organização, do suprimento de insumos e } \\
\text { da manutenção de materiais na atenção } \\
\text { primária, como fatores que dificultavam a } \\
\text { realizaçãão do exame, enquanto que para } \\
\text { as usuárias, a vergonha, medo e } \\
\text { nervosismo eram variáveis que } \\
\text { retardavam a procura pelo atendimento. }\end{array}$ \\
\hline
\end{tabular}

Fonte: Autores.

Pode-se observar de acordo com o Quadro 1 que em relação ao ano de publicação, as mesmas ocorreram entre 2006 e 2020, sendo que os anos de 2017 e 2011 se destacaram nas publicações.

\section{Resultados e Discussões}

De acordo com os estudos levantados, o Instituto Nacional do Câncer (INCA) traz dados alarmantes a respeito do câncer cérvicouterino. A taxa de incidência de novos casos de câncer de colo de útero para 2020 foi de 16.710 casos, possuindo um risco estimado de 15,38 casos a cada 100 mil mulheres brasileiras. Este é o terceiro tipo de câncer mais comum na população feminina, atrás apenas do câncer de mama e do câncer colorretal; entrando no ranking como a quarta causa de óbitos por câncer na população feminina. Nota-se então, um grande avanço do país em relação à capacidade de realizar diagnóstico precoce, já que na década de 1990, 70\% dos casos diagnosticados eram da doença invasiva (Inca, 2020).

O Ministério da Saúde estipula que mulheres com a vida sexual ativa ou que já tenham iniciado a vida sexual, devem realizar periodicamente o exame preventivo. A faixa indicada está entre os 25 aos 59 anos de idade. De início, o exame é realizado anualmente e após dois exames consecutivos negativos (no intervalo de um ano cada), o preventivo pode ser realizado a cada três anos (Brasil, 2015).

Porém, mesmo com a indicação divulgada pelo Ministério da Saúde, as mulheres costumam buscar atendimento ginecológico para realização do exame apenas quando já há algum processo patogênico instalado, o que reforça o hábito de busca pelos serviços de saúde na ótica curativa e não de prevenção como seria o adequado (Jorge, Sampaio, Diógenes \& Sampaio, 2011; Pimentel, Panobianco, Almeida \& Oliveira, 2011).

O mais alarmante se apresenta nos artigos, indicando que acadêmicos de Enfermagem ainda demonstram grandes falhas com relação ao seu conhecimento sobre o papanicolau, seu objetivo, frequência e formas corretas de realizá-lo. A desinformação por parte desses futuros profissionais é um dado preocupante, uma vez que, estes passarão as informações para as usuárias do sistema de saúde. Essa lacuna nos faz pensar que um dos motivos aos quais tornam as usuárias afastadas da prevenção seja a falta de compreensão do próprio profissional, alinhado à ausência de comunicação e empatia com as usuárias (Pimentel et al., 2011; Cestari \& Zago, 2012; Ribeiro et al., 2013; Beghini, Salimena, Melo \& Souza, 2006). 
Dentro desse contexto acadêmico, o saber ou o não saber estão diretamente relacionados ao fazer com frequência, se há o hábito da prática rotineira, dificilmente esquecerá a técnica recomendada. $A$ não execução poderá prejudicar a incorporação deste conhecimento e interferir na melhoria da sua qualidade de vida e futuramente na assistência prestada aos seus pacientes (Pimentel et al., 2011).

As mulheres deixam de aderir ao exame preventivo por diversos motivos como desconforto em relação ao procedimento propriamente dito e ao sentimento de vergonha, dor e medo do profissional machucá-las durante a realização do procedimento. Nesses casos o vínculo com o profissional pode amenizar essa sensação, bem como o constrangimento na realização do exame, uma vez que se torna imprescindível a exposição do órgão genital ao examinador. Normalmente estes sentimentos mencionados surgem quando se referem a profissionais com quem a paciente não se encontra familiarizada ou do sexo masculino realizando o exame. No entanto, essa mesma percepção aparece em diversas pesquisas cujos resultados apontam que esse desconforto influência na não adesão ao preventivo (França, França \& Moraes, 2013; Silva, Oliveira \& Vargens, 2016).

Além disso, as mulheres podem estar retardando a procura pelo serviço de saúde por não terem obtido adequadamente informações sobre a importância da realização de exames preventivos, ou ainda, se as receberam, tiveram dificuldade para elaborá-las e incorporá-las ao seu cotidiano ou até mesmo a associação do exame à violência contra a mulher (França et al., 2013; Silva et al., 2012).

Todavia no aspecto social, há artigos que demonstram que mulheres com o ensino fundamental incompleto estão mais vulneráveis ao câncer do colo do útero, visto que essas usuárias possuem informações limitadas diante dessas perspectivas e muitas vezes também têm o acesso ineficaz ao exame de prevenção (Pimentel et al., 2011; Santos, Melo \& Santos, 2012; Mendes, Elias, Santos, Tayar \& Riul, 2017).

Acredita-se que as vivências armazenadas pelas pessoas levam outras a confiarem plenamente naquilo que está dando certo, no caso, a medicação caseira, principalmente, pela resolubilidade observada e pelo seu fácil acesso às mesmas. Logo, tende-se a desconsiderar as práticas preventivas nos serviços de saúde (Jorge et al., 2011).

Este cenário mostra a necessidade de ações de educação em saúde para a população e o amplo acesso das mulheres a informações claras, consistentes e culturalmente apropriadas para cada região, que deve ser uma iniciativa dos serviços de saúde em todos os níveis de atendimento. A equipe da Estratégia Saúde da Família (ESF) precisa atentar para essa realidade, despertando a partir de discussões e orientações acerca do assunto, a iniciativa do autocuidado, incentivando as mulheres a procurarem voluntariamente os serviços de saúde para se submeter ao exame citológico (Malta etal., 2017)

Sabe-se que os Enfermeiros são um importante elo entre os usuários do sistema de saúde, porém, segundo estudos muitas mulheres já se depararam com profissionais que não agiram de maneira humanizada, alegando que já foram machucadas na hora do exame e ficaram com medo de sentir dor novamente, deixando de realizar o exame por anos (Silva et al., 2016).

Questões como o medo e ansiedade somados ao desconhecimento sobre a realização do exame, além de considerá-lo invasivo e violento são fatores de grande relevância para o distanciamento das mulheres desse processo (Pimentel et al., 2011).

Porém, para incentivar a adesão do exame às mulheres, deve-se utilizar estratégias comportamentais e cognitivas, que eduquem sobre a importância do exame e que não as deixem esquecer destes. Utilizar lembretes, cartas, telefonemas e cartazes são métodos de alta eficácia, que permite a maior adesão das 
mulheres ao exame papanicolau, também elevando o número de retorno de mulheres com resultados alterados. Tais intervenções partem do pressuposto de que as mulheres necessitam apenas de um estímulo para adotar uma conduta que promova a sua saúde (Oliveira \& Fernandes, 2017).

A educação em saúde é uma estratégia imprescindível para se abordar questões referentes à prevenção CCU, todavia, necessita ser desenvolvida de forma sistemática na vida das mulheres. Logo, educar, ensinar e informá-las quanto às medidas de prevenção dos agravos, é também conscientizálas de seu papel de sujeitos responsáveis por sua saúde e bem-estar (Jorge et al., 2011).

Observa-se que nos serviços de saúde, os enfermeiros assumem a posição de liderança da equipe multiprofissional e da comunidade, sendo responsáveis por ações como: treinamento e capacitação da equipe de enfermagem, além de avaliar, sistematizar e promover a conduta mais apropriada para cada indivíduo assistido, colocando em prática habilidades de gestão e gerenciamento de recursos, profissionais e informação em saúde (Oliveira et al., 2020).

O enfermeiro também age com estratégias cognitivas através da educação das mulheres durante a consulta de enfermagem, onde deveriam mantê-las completamente informadas à respeito dos meios de prevenção, como a prática do sexo seguro (com preservativos) e a vacinação contra o HPV, além de outras informações relevantes. Durante a consulta de enfermagem, é possível aumentar o vínculo do profissional com o paciente, trazendo conforto e segurança para a realização do exame (Oliveira \& Fernandes, 2017).

Sendo assim, o enfermeiro atua através da realização de diversas atividades que abordem a prevenção do CCU e o exame preventivo (Papanicolau), proporcionando uma realidade diferente, aumentando a adesão da população feminina ao exame cérvicouterino como prática de prevenção e assim, reduzindo a morbimortalidade por este tipo de câncer (Valente, Andrade, Soares \& Silva, 2015).

O conhecimento dos saberes e das percepções da mulher acerca da coleta do exame citopatológico de colo uterino aproxima os enfermeiros à realidade das usuárias do sistema de saúde, conduzindoos para novas posturas práticas frente ao atendimento a essa parcela da população. Essa maior aproximação poderá permitir ações de educação em saúde mais eficazes, favorecendo um diálogo de compreensão entre os profissionais e usuárias, bem como o atendimento às demandas locais (Cestari \& Zago, 2012).

Sendo assim, para que os programas de educação em saúde e de rastreamento precoce tenham sucesso é necessário haver cobertura mais efetiva e direcionada à população de risco, bem como, treinamento específico para os profissionais de saúde capaz de torná-los aptos a fornecerem todas as informações a respeito do Papiloma Vírus Humano (HPV) e do câncer do colo uterino para depois realizar o Papanicolaou com as mulheres melhor esclarecidas, havendo a necessidade de boa qualidade, tanto na coleta, quanto na interpretação do material, tratamento e acompanhamento adequado (Mendonça et al., 2011; Américo et al., 2010).

Contudo, é urgente a adoção de propostas inovadoras nas rotinas assistenciais de saúde no sentido de se objetivar o fortalecimento do trabalho do enfermeiro e dos processos de acolhimento às mulheres que buscam apoio na prevenção do câncer do colo uterino (Moreira, Lopes \& Diniz, 2013).

Fundamenta-se a importância de manter a população esclarecida sobre os fatores de risco associados ao HPV para diminuir a incidência da infecção. Portanto, é necessário a implantação, por parte do governo, de programas com métodos de educação em saúde que atinjam toda a população (Wünsch, Oliveira, Garcia \& Domingues, 2011). 
Uma vez que o problema já existe, o profissional de saúde tem a incumbência de promover a saúde, de rastreá-la precocemente, por meio das consultas comunitárias e ginecológicas e tratá-la, evitando a progressão das lesões para danos mais complexos que demandem atenção mais especializada e mais onerosa para o SUS (Silveira, Melo, Rodrigues

\& Parreira, 2011).

É imprescindível que as mulheres sejam melhor instruídas, para que não cometam o erro de pressupor que um cuidado seja mais importante que o outro, sem que tenham conhecimento da existência de diversos cuidados que devem ser adotados antes da realização de tal procedimento e dessa forma estejam cientes que a eficácia desse exame só é possível quando todos estes são incorporados (Ribeiro et al., 2013).

Entende-se ainda que a cultura organiza o mundo social e provê uma visão relativa às pessoas que a compartilham, orientando dessa forma os seus conhecimentos, práticas e atitudes que envolvem a questão da saúde e da doença. Pode-se dizer que muitos foram os avanços na área da saúde, porém, é necessário empreender ações mais efetivas as quais devem estar relacionadas com os aspectos culturais imbricados no contexto em que as mulheres se encontram. Para que ocorra maior adesão de mulheres ao exame preventivo de câncer do colo uterino, deve-se considerar a desmistificação da doença, bem como o da realização do exame preventivo (Wünsch et al., 2011).

\section{Considerações Finais}

Conclui-se que apesar das diversas campanhas elaboradas pelo Ministério da Saúde a respeito da importância da prevenção do câncer do colo do útero, ainda há um longo caminho a ser percorrido para que se reduza o número de incidência da doença. É preciso desmistificar diversos tabus e medos particulares das usuárias, e ainda, deve-se reunir esforços para que as usuárias se sintam seguras ao procurar o profissional para a prevenção.

Torna-se fundamental que os acadêmicos de enfermagem se dediquem a respeito do tema, visto que, eles serão os principais elos entre as usuárias e a prevenção da doença. As instituições precisam frisar com seus alunos as competências que os profissionais de Enfermagem precisam ter dentro dos aspectos de promoção e prevenção de saúde.

Assim, sugere-se a elaboração de outros estudos a respeito do tema, que identifique as estratégias e esforços que estão sendo reunidos para que as taxas de incidência diminuam, e ainda, que as instituições responsáveis por formar profissionais de Enfermagem, reforcem as disciplinas que abordem o tema em questão. 


\section{REFERÊNCIAS}

.Amaral, M. S., Gonçalves, A. G., \& Silveira, L. C. G. (2017). Prevenção do câncer de colo de útero: A atuação do profissional enfermeiro nas unidades básicas de saúde. Revista Científica FacMais, 8 (1), 198-223. Recuperado de: https://revistacientifica.facmais.com.br/wp content/uploads/2017/04/8-PREVEN\%C3\%87\%C3\%830-DOC\%C3\%82NCER-DE-COLO-DE-\%C3\%9ATERO-A-ATUA\%C3\%87\%C3\%830-DO-PROFISSIONAL-ENFERMEIRO NASUNIDADES-B\%C3\%81SICAS-DE-SA\%C3\%9ADE.pdf.

Américo, C. F., Chagas, A. C. M. A., Lopes, E. M., Dias, L. M. B., Lima, T. M., Moura, E. R. F., \& Pinheiro, A. K. B. (2010). Análise da influência do acondicionamento diferenciado de lâminas para colpocitologia no resultado laboratorial. Texto \& Contexto - Enfermagem, Florianópolis, 19 (2), 343-350. doi: 10.1590/S010407072010000200016.

Beghini, A. B., Salimena, A. M. de O., Melo, M. C. S. C de., \& Souza, Í. E. de O. (2006). Adesão das acadêmicas de enfermagem à prevenção do câncer ginecológico: da teoria à prática. Texto \& Contexto - Enfermagem, Florianópolis, 15 (4), 637-644. doi: 10.1590/S0104-07072006000400012.

Brasil, (2015). Papanicolau (exame presentivo de colo de útero). Biblioteca Virtual em Saúde -Ministério da Saúde (BVSMS). Recuperado de: https://bvsms.saude.gov.br/dicas-em saude/2069-papanicolau-examepreventivo-de-colo-de-uter.

Cestari, M. E. W., \& Zago, M. M. F. (2012). A atuação da enfermagem na prevenção do câncer na mulher:questões culturais e de gênero. Ciência, cuidado e saúde, Maringá, 11 (suplem.), 176-182. doi: 10.4025/cienccuidsaude.v11i5.17073.

França, M. de C. A., França, M. de C. S., \& Moraes, S. D. dos S.(2013). Conhecimento de mulheres acerca do papilomavírus humano e sua relação com o câncer de colo uterino. Cogitare enfermagem, Curitiba, 18 (3), 509514. Recuperado de: http://www.revenf.bvs.br/scielo.php?script=sci_arttext\&pid=S141485362013000300013.

IFF, FIOCRUZ. (2017). Saiba mais sobre câncer do colo do útero. Instituto Nacional de Saúde da Mulher, da Criança e do Adolescente Fernandes Figueira. Rio de Janeiro. Recuperado de: http://www.iff.fiocruz.br/index.php/8-noticias/390-cancer-colo-utero.

Inca, (2007). Programa Nacional de Controle do Câncer do Colo do Útero e Mama. Instituto Nacional de Câncer José Alencar Gomes da Silva. Recuperado de: https://www.inca.gov.br.

Inca, (2016). Diretrizes brasileiras para o rastreamento do câncer do colo do útero, (2a ed.), rev. atual, p. 114. Rio de Janeiro, Brasil, M. S. Recuperado de: http://portaldeboaspraticas.iff.fiocruz.br/wpcontent/uploads/2018/01/99-984-MS-Inca-2016- Diretrizes-para-o-Rastreamento-do-c\%C3\%B3ncer-do-colodo-\%C2\%A6tero.pdf.

Inca, (2019). Estimativa 2020: incidência de câncer no Brasil. Instituto Nacional de Câncer José Alencar Gomes da Silva, Brasil, M. S. Rio de Janeiro. Recuperado de: https://www.inca.gov.br/sites/ufu.sti.inca.local/ files/media/document/estimativa-2020-incidencia-de-cancer-no-brasil.pdf.

Inca, (2020). ABC do câncer: abordagens básicas para o controle do câncer; Instituto Nacional de Câncer José Alencar Gomes da Silva. (6a ed.), rev. atual. Rio de Janeiro. Recuperado de: https://www.inca.gov.br/publicacoes/livros/abc-do-cancer-abordagens basicas-para-o-controle-do-cancer.

Jorge, R. J. B., Sampaio, L. R. L., Diógenes, F. A. C. M., \& Sampaio, L. L. (2011). Fatores associados a não realização periódica do exame papanicolaou. Rev da Rede de Enfermagem do Nordeste, Fortaleza, 12 (3), p. 606-612. Recuperado de: https://pesquisa.bvsalud.org/bvsms/resource/pt/lil-682128. 
Lakatos, E. M., \& Marconi, M. de A. (2003). Fundamentos de Metodologia Científica. (5a ed.) - São Paulo: Atlas. Recuperado de: http://docente.ifrn.edu.br/olivianeta/dis ciplinas/copy_of_historia-i/historia-ii/china-eindia/view.

Malta, E. F. G. D., Gubert, F. A., Vasconcelos, C. T. M., Chaves, E. S., Silva, J. M. F. L., \& Beserra, E. P. (2017). Inadequate practice related of the papanicolaou test among women. Texto \& Contexto - Enfermagem, Florianópolis, 26 (1), e5050015. doi: 10.1590/0104-07072017005050015.

Melo, M. C. S. C., Vilela, F., Salimena, A. M. de O., \& Souza, I. E.de O. (2012). O Enfermeiro na Prevenção do Câncer do Colo do Útero: o Cotidiano da Atenção Primária. Revista Brasileira de Cancerologia, 58 (3), 389-398. R e c u p e r a d o

d e : https://rbc.inca.gov.br/site/arquivos/n_58/v03/pdf/08_artigo_enfermeiro_prevencao_cancer_colo_utero_cot idiano_atencao_primaria.pdf.

Mendes, L. C., Elias, T. C., Santos, T. N. dos., Tayar, E. M., \& Riul, S. da S. (2017). Atividades educativas estimulando o autocuidado e prevenção do câncer feminino. Rev Enferm Atenção Saúde; 6 (1), 140-147. Recuperado de: https://pesquisa. bvsalud.org/bvsms/resource/pt/biblio-1034661.

Mendes, K. D. S., Silveira, R. C. de C. P., \& Galvão, C. M. (2008). Revisão integrativa: método de pesquisa para a incorporação de evidências na saúde e na enfermagem. Texto \& Contexto - Enfermagem, 17 (4), 758-764. doi: 10.1590/S0104-07072008000400018.

Mendonça, F. A. da C., Sampaio, L. R. L., Jorge, R. J. B., Silva, R. M. da., Linard, A. G., \& Vieira, N. F. C.(2011). Prevenção do câncer de colo uterino: Adesão de enfermeiros e usuárias da atenção primária. RENE, 12 (2), 261270. Recuperado de: https://pesquisa.bvsalud.org/bvsms/resource/pt/lil-682111.

Mistura, C., Mistura, C., Silva, R. C. C., Sales, J. R. P. de., Melo, M. C. P. de., \& Sarmento, S. S. (2011). Papel do enfermeiro na prevenção do câncer de colo uterino na estratégia saúde da família. Revista Contexto \& Saúde, 10
( 200$)$,
$1161-1164$.
$\mathrm{R}$ e c u p e $\mathrm{r}$ a d o
d e :

https://www.revistas.unijui.edu.br/index.php/contextoesaude/article/view/1763/1467.

Moreira, R. de C. R., Lopes, R. L. M., \& Diniz, N. M. F. (2013). Prevention of cervical cancer in pregnant women: a phenomenological study. Online Brazilian Journal Of Nursing (OBJN), 12 (3), 511-520. doi: 10.5935/16764285.20134011.

Oliveira, L. L., Santos, M. R. S., Nogueira, L. M. V., Rodrigues, I. L. A., André, S. R., \& Silva, I. F. S. (2020). Exclusividade na coleta de material para exame de colpocitologia oncótica: percepção dos enfermeiros. Revista de Enfermagem da UFSM. 10 (15), 1-17. doi: 10.5902/2179769233721.

Oliveira, J. L. T. de, \& Fernandes, B. M. (2017). Intervenções de enfermagem na prevenção do câncer cérvicouterino: perspectivas das clientes. Revista de enfermagem UERJ, Rio de Janeiro, 25, e26242. Recuperado de: https://pesquisa.bvsalud.org/bvsms/resource/pt/biblio 915884.

Pereira, A. S., Shitsuka, D. M., Parreira, F. J., \& Shitsuka, R. (2018). Metodologia da pesquisa científica (pp. 67-68). Universidade Federal de Santa Maria, UAB/NTE/UFSM, 1. Recuperado de: https://repositorio.ufsm.br/bitstream/handle/1/15824/Lic_Computa cao_Metodologia-PesquisaCientifica.pdf?sequence $=1$.

Pimentel, A. V., Panobianco, M. S., Almeida, A. M. de., \& Oliveira, I. S. (2011). Percepção da vulnerabilidade entre mulheres com diagnóstico avançado do câncer do colo do útero. Texto \& Contexto - Enfermagem, Florianópolis, 20 (2), 255-262. doi: 10.1590/S0104-07072011000200006.

Ribeiro, K. F. C., Moura, M. S. S. de., Brandão, R. G. C., Nicolau, A. I. O., Aquino, P. de S., \& Pinheiro, A. K. B. (2013). Conhecimento, atitude e prática de acadêmicas de enfermagem sobre o exame de papanicolaou. Texto \& Contexto - Enfermagem, Florianópolis, 22 (2), 460- 467. doi: 10.1590/S0104-07072013000200023.

Rosa, M. I.da., Medeiros, L. R.., Rosa, D. D., Bozzeti, M. C., Silva, F. R., \& Silva, B. R. (2009). Papilomavírus humano e neoplasia cervical. Cadernos de Saúde Pública, 25 (5), 953- 964. doi: 10.1590/\$0102-311X2009000500002. 
Santos, R. de S., Melo, E. C. P., \& Santos, K. M. (2012). Análise espacial dos indicadores pactuados para o rastreamento do câncer do colo do útero no Brasil. Texto \& Contexto - Enfermagem, Florianóplis, 21 (4), 800-810. doi: 10.1590/S0104-07072012000400010.

Silva, C. M., Oliveira, D. S. de, \& Vargens, O. M. C. (2016). Percepção de mulheres sobre o teste de papanicolaou. Revista Baiana de Enfermagem, Salvador, 30 (2), 1-9. Recuperado de: https://portalseer.ufba.br/index.php/enfermagem/article/view/15239/pdf_45.

Silva, S. R., Lício, F. C., Borges, L. V., Mendes, L. C., Vicente, N. G., \& Gomes, N. S. (2012). Atividades educativas na área da saúde da mulher: Um relato de experiência. Revista de Enfermagem e Atenção à Saúde (REAS), Minas Gerais, 1 (1), 108-112. Recuperado de: https://pesquisa.bvsalud.org/enfermeria/resource/pt/biblio-1034539.

Silveira, C. F., Melo, M. M. de., Rodrigues, L. R., \& Parreira, B. D. M. (2011). Conhecimento de mulheres de 40 a 60 anos sobre o Papillomavirus Humano. RENE, Fortaleza, 12 (2), 309- 315. Recuperado de: https://pesquisa.bvsalud.org/bvsms/resource/pt/lil-682105.

Valente, C. A., Andrade, V., Soares, M. B. O., \& Silva, S. R. da. (2015). Atividades educativas no controle do câncer de colo do útero: relato de experiência. Revista de enfermagem e atenção à saúde. 5 (3), 1898-1904. Recuperado de: https://pesquisa.bvsalud.org/bvsms/resource/pt/lil-782572.

W.H.O, (2020). Human papillomavirus (HPV) and cervical cancers. World Health Organization, Recuperado de: https://www.who.int/news-room/fact-sheets/detail/human papillomavirus-(hpv)-and-cervical-cancer.

Wünsch, S., Oliveira, S. G., Garcia, R. P., \& Domingues, I. B. (2011). Coleta de citopatológico de colo uterino: Saberes e percepções de Mulheres que realizam o exame. Revista de enfermagem da UFSM, Santa Maria, 1 (3), 360-368. doi: 10.5902/217976922543. 


\title{
REDE DE APOIO AOS HOMOSSEXUAIS \\ VIVENDO COM HIV/AIDS: UMA REVISÃO INTEGRATIVA
}

Anderson Marcos Vieira do Nascimento

Universidade Estadual da Paraíba

Carlus Alberto Oliveira dos Santos

Universidade Estadual da Paraíba

Lais Nicolly Ribeiro da Silva

Universidade Federal de Alagoas

Mirelly dos Santos Matos

Centro Universitário Estácio de Sergipe

Daylâne Danielly dos Santos Silva

Escola de Saúde Pública de Pernambuco

Layla Maria da silva Feitosa

Faculdade de Integração do Sertão

Ana Luiza Gonçalves Souza

Faculdade Pitágoras - Ipatinga

\section{RESUMO}

Objetivo: O presente estudo tem como finalidade analisar na literatura quais os âmbitos de apoio social dispostos aos homossexuais que vivem com HIV/AIDS no Brasil, e de que forma essa rede de apoio é organizada na sociedade, a fim de atender todas as demandas essenciais para essa população no enfrentamento das dificuldades pósdiagnóstico e tratamento, visando à integralidade da assistência à saúde e a singularidade de cada sujeito. Métodos: Trata-se de uma revisão integrativa da literatura, definida como um estudo que sintetiza resultados de pesquisas que abordem as vias de acesso e apoio aos homossexuais portadores de HIV/AIDS. Para tanto, o levantamento bibliográfico foi realizado na Scientific Eletronic Library Online (SciELO) utilizando os
Diana Dantas Santos

Centro Universitário Estácio de Sergipe

Luana Vilas Boas Dos Santos Chaves Centro Universitário Una

Tatiane Nascimento de Menezes Universidade Federal de Sergipe

Márjory de Almeida Silva Universidade Paulista - UNIP

Ysabely de Aguiar Pontes Pamplona Universidade Católica de Santos

Guilia Rivele Souza Fagundes Universidade do Estado da Bahia

descritores: Homossexualidade, Rede de apoio, HIV/AIDS. Resultados: As redes de apoio foram descritas na literatura como: Rede de apoio familiar, profissional, instrumental, emocional, religioso e saberes populares. Evidenciando melhor adesão terapêutica e qualidade de vida, aos indivíduos que contam com uma rede de apoio fortalecida. Considerações finais: As redes de apoio a essa população, organizam-se de forma desarticulada, embora desempenhem papel fundamental na adesão ás terapias medicamentosas e na manutenção da qualidade de vida dessas pessoas.

\section{Palavras-chave:}

Homossexualidade; Rede de apoio; HIV/AIDS..

\begin{abstract}
Objective: The purpose of the present study is to analyze in the literature which areas of social support are available to homosexuals living with HIV / AIDS in Brazil, and how this support network is organized in society, in order to meet all essential demands for this population in facing post-diagnosis and treatment difficulties, aiming at comprehensive health care and the uniqueness of each subject. Methods: This is an integrative literature review, defined as a study that synthesizes research results that address the access and support routes for homosexuals with HIV / AIDS. For that, the bibliographic survey was carried out in the Scientific Eletronic Library Online (SCIELO) using the descriptors: Homosexuality, Support
\end{abstract}

network, HIV / AIDS. Results: Support networks have been described in the literature as: Family, professional, instrumental, emotional, religious and popular knowledge support network. Evidence of better therapeutic adherence and quality of life for individuals who have a strengthened support network. Final considerations: The support networks for this population are organized in a disjointed manner, although they play a fundamental role in adhering to drug therapies and in maintaining the quality of life of these people.

\section{Keywords:}

Homosexuality; Support network; HIV / AIDS. 


\section{INTRODUÇÃO}

A Síndrome da Imunodeficiência Adquirida (SIDA/AIDS) tornou-se uma doença crônica de grande relevância para o mundo devido a suas altas taxas de infectividade e letalidade, ocasionando alterações imunológicas relevantes. Atualmente, a doença tem tratamento efetivo que garante longevidade e qualidade de vida as pessoas com diagnóstico precoce e boa aceitação da terapia medicamentosa, sendo ofertada gratuitamente peloSistema Único de Saúde (SUS) (SANTOS et al., 2018).

O fenômeno da AIDS no mundo ocorreu no início da década de 80. Desde então, altos índices de infecção na comunidade LGBT eram evidenciados, sendo considerado empiricamente como "o câncer dos homossexuais". Ressalta-se, ainda, o preconceito social já existente nessa época, com maior enfoque nas mídias aos casos de infecções e mortes por HIV em pessoas assumidamente gays, o que culminou em estigmatização da doença, considerada por muitos até os dias de hoje, como castigo "divino", sobre aqueles que praticavam sexo sem fins de procriação ou com pessoas do mesmo sexo (BRITO et al., 2001;VILLARINHO, M. I. P et al., 2012).

As dificuldades atreladas ao preconceito social que impõem uma heteronormatividade à população, ainda se mostram como fatores que podem dificultar o acesso à assistência em saúde de pessoas homoafetivas. Estudos evidenciam o desconforto desse grupo de indivíduos em falar abertamente sobre sua sexualidade, tendo uma alta associação com prejulgamentos, não aceitação e repressão social, sendo então um fator contribuinte para o distanciamento por parte dessa comunidade aos serviços de saúde, repercutindo em um déficit no autocuidado (NEVES et al., 2018).

A efeito de crítica no que concerte a ultraje de que os homossexuais foram considerados por muito tempo como "grupo de risco" para o HIV, surgiu a denominação de comportamento de risco, objetivando universalizar a preocupação com a infecção passível a toda população que se encontra mais vulnerável, enquadrando assim todas as pessoas com maior exposição, dentre eles: profissionais do sexo, gays, pessoas que trabalham com material biológico, múltiplos parceiros e aqueles que praticam sexo desprotegido, independente da sua orientação sexual (SÁ; SANTOS, 2018).

O vírus da imunodeficiência adquirida (HIV) ataca principalmente as células responsáveis pelo sistema de defesa, e tem como característica principal a sua rápida replicação, fazendo com que o sistema imunológico não seja mais capaz de combater a infecção e esteja fortemente vulnerável a doenças oportunistas, caso o diagnóstico e o tratamento não sejam iniciados rapidamente. As células mais atingidas são as TCD4, que sofrem alteração em seu DNA, com rápida multiplicação de células alteradas e comprometidas pelo vírus (BRASIL, 2005).

De acordo com o último boletim epidemiológico, referente ao período de 2007 a 2019, foram registrados no Brasil 207.207 novos casos de HIV, sendo desse total, $69 \%$ representado por pessoas do sexo masculino e $31 \%$ do sexo feminino, resultando em uma razão de 26 homens infectados para cada dez mulheres. É importante ressaltar que do número total 207.207 (51,3\%) dos casos são de pessoas que se autodeclararam homossexual ou bissexual, evidenciando o número significativo desses indivíduos e da vulnerabilidade desse grupo social (BRASIL, 2020). 
Apesar de muitos avanços tecnológicos e do vasto acesso às informações sobre os riscos de transmissão e tratamento da AIDS, a descontextualização e o preconceito com pessoas HIV-positivo ainda se faz presente, o que configura uma barreira na interface entre a prevenção, diagnóstico e tratamento, e a integração desses indivíduos no acesso e busca aos serviços de saúde, bem como de sua inclusão no cotidiano social. Essa situação ocasiona além do sofrimento psicológico, sensação de insegurança, rejeição e má qualidade de vida (SANTOS et al., 2018).

Segundo a literatura, os sentimentos negativos, mediante a descoberta do diagnóstico positivo para HIV, estão presentes na maioria dos casos, comportamentos que demonstram reprovação, angústia, choro e pânico (VENDRAMINI et al., 2005).

Nesse sentido, grande parte dos indivíduos acometidos por essa doença prefere suportar as dificuldades se isolando da sociedade, agravando as consequências psicossociais negativas, excluindo-se do convívio coletivo e familiar, iniciando assim um grave ciclo de sofrimento psicológico, sobretudo fisiológico e sistêmico (VILLARINHO. M. I. P et al., 2012).

Nesse contexto, a necessidade do cuidado aos portadores de HIV/AIDS já era vista como fator positivo, desde o surgimento da epidemia, quando não havia disposição de tratamentos específicos, onde basicamente ocorria de forma paliativa proporcionando conforto às pessoas adoecidas. Dessa forma, é sabido que a rede de apoio disponibilizada para esses indivíduos pode influenciar diretamente na qualidade de vida e nas terapias propostas, tanto de forma positiva quanto de forma negativa (SANTOS et al., 2018).

De acordo com Santos e colaboradores (2018) os indivíduos que contavam com uma rede de apoio efetiva mostravam melhor resultado no que fere o tratamento medicamentoso e o alcance de metas planejadas para esses, logo também relatavam melhor aceitação e maior grau de comprometimento com a sua saúde, evidenciado por pontualidade em consultas e exames de rotina, sustentação de planos para a vida e melhor aceitação no seu contexto social, referindo não haver prejuízos frente a sua condição sorológica.

Conforme consta na carta de direitos das pessoas vivendo com HIV, fica explícito o direito à dignidade atrelada a diversos fatores, dentre eles, o acesso a trabalho e renda "Apoio instrumental", o direito ao sigilo, incluindo todos os aspectos referentes ao convívio social. Destarte, considera-se relevante o levantamento de demandas específicas dessa população, no que tange saúde e qualidade de vida, a fim de evidenciar possíveis lacunas essenciais na assistência à saúde de indivíduos convivendo com HIV/AIDS (BRASIL, 2020).

Nesse sentido, objetivou-se buscar na literatura quais os âmbitos de apoio social dispostos aos homossexuais que vivem com HIV/AIDS no Brasil e de que forma essa rede de apoio é organizada na sociedade, a fim de atender todas as demandas essenciais para essa população no enfrentamento das dificuldades pós-diagnóstico e tratamento, visando à integralidade da assistência à saúde e a singularidade de cada sujeito, com base nas necessidades evidenciadas por estudos científicos.

\section{Metodologia}

Trata-se de uma revisão integrativa da literatura, definida como um método que possibilita a sintetização do conhecimento sobre as mais diversas temáticas, possibilitando uma discussão expositiva assim como a avaliação dos resultados encontrados (SOARES et al., 2010). 
Para tanto, o levantamento bibliográfico foi realizado na Scientific Eletronic Library Online (SciELO) utilizando os descritores: Homossexualidade, Rede de apoio, HIV/AIDS, Rede social, Saúde, disponíveis na página eletrônica dos Descritores em Ciências da Saúde (DeCs). Para aumentar o alcance de buscas, utilizou-se o operador booleano AND, como segue: DeCs 1 AND DeCs 2 AND DeCs 3 AND DeCs 4 AND DeCs 5. A seleção dos manuscritos foi realizada por dois pesquisadores previamente calibrados, onde aplicou-se o teste Kappa para avaliar a concordância Interexaminadores e intraexaminadores, obtendo-se uma concordância de $80 \%$. Em caso de discordância entre os avaliadores, um terceiro pesquisador foi requisitado para decisão final. Foram considerados apenas os artigos identificados como sendo do ano de 2012 até 2020 . 0 tempo adotado para seleção dos estudos foi estipulado após análise do baixo índice de publicação sobre a temática abordada. A análise seguiu critérios de elegibilidade previamente determinados. Os critérios de inclusão foram: a) no idioma português; b) artigos sobre a temática em questão; c) pesquisas originais e revisões narrativas e integrativas; d) artigos disponíveis na íntegra; e) data de publicação entre os últimos nove anos.

Foram excluídas da amostra pesquisas ainda não publicadas, monografias, dissertações e teses. Após a realização da leitura criteriosa e amostra selecionada, os dados foram analisados, interpretados e apresentados descritivamente. O fluxograma na figura 01 , traz o detalhamento da estratégia utilizada na busca e na seleção dos artigos.

Figura 1. Fluxograma da estratégia de pesquisa, número de registros identificados e estudos incluídos e excluídos.

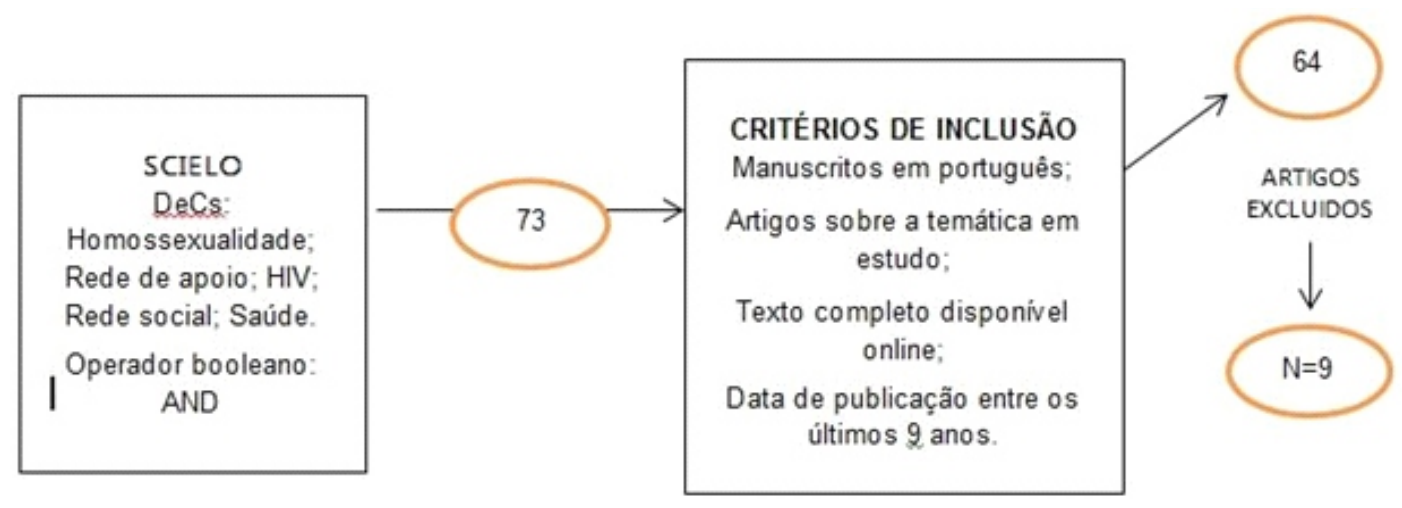

Fonte: Elaboração Própria.

\section{Resultados e Discussão}

Diante da literatura analisada é possível inferir que homossexuais vivendo com HIV/AIDS, que dispõe de uma boa rede de apoio, demonstraram maior adesão às terapias propostas, menor acometimento psicológico e mantiveram-se comprometidos com a sua saúde. Contudo a desconectividade dessa rede é notada pela maioria dos autores que diante disso, alocam a família como parte essencial dessa rede. O quadro 01, apresenta uma amarração teórica sintetizada dos estudos selecionados, proporcionando conhecer os conceitos de cada rede de apoio defendida pelos autores selecionados. 
Quadro 01. Síntese dos artigos selecionados para a revisão.

\begin{tabular}{|c|c|c|}
\hline AUTOR/ANO & TIPO DE APOIO & DESCRIÇÃO \\
\hline $\begin{array}{l}\text { (DA SILVA; CAMPOS TAVARES, 2015; FREITAS } \\
\text { et al., 2012; MARIANA VIEIRA VILLARINHO, } \\
\text { 2012; RODRIGUES; MAKSUD, 2017; ROSSETTO } \\
\text { et al., 2019; SILVA et al., 2015). }\end{array}$ & Familiar & $\begin{array}{l}\text { Descrito Como laço familiar e social fortalecido } \\
\text { incluindo familia, amigos e comunidade, como campo } \\
\text { efetivo nas estratégias de apoio. }\end{array}$ \\
\hline $\begin{array}{l}\text { (ALBUQUERQUE et al., 2013; RODRIGUES; } \\
\text { MAKSUD, 2017). }\end{array}$ & Apoio profissional & $\begin{array}{l}\text { Faz referência à importância da relação de confiança } \\
\text { entre paciente e profissional, associando a aumento dos } \\
\text { números de adesão terapêutica. }\end{array}$ \\
\hline (RODRIGUES; MAKSUD, 2017). & Apoio religioso e saberes populares & $\begin{array}{l}\text { Evidencia-se que pacientes que participam de } \\
\text { movimentos de fé, concomitante as terapias mostram-se } \\
\text { mais esperançosos e determinados ao autocuidado. }\end{array}$ \\
\hline $\begin{array}{l}\text { (DE SOUZA NEVES et al., 2018; PERDIGÃO et al., } \\
\text { 2020; RODRIGUES; MAKSUD, 2017; ROSSETTO } \\
\text { et al., 2019). }\end{array}$ & Apoio emocional & $\begin{array}{l}\text { Enfatizam que o pós-diagnóstico, desencadeia uma serie } \\
\text { de sentimentos e pensamentos que devem ser } \\
\text { considerados e direcionados ao devido suporte } \\
\text { necessários de modo singular a cada indivíduo. }\end{array}$ \\
\hline $\begin{array}{l}\text { (DA SILVA; CAMPOS TAVARES, 2015; FREITAS } \\
\text { et al., 2012; PERDIGÃO et al., 2020; RODRIGUES; } \\
\text { MAKSUD, 2017). }\end{array}$ & Apoio instrumental & $\begin{array}{l}\text { Considera o apoio financeiro, acesso a bens e serviços } \\
\text { essenciais, incluindo a sua atuação profissional com } \\
\text { remuneração. }\end{array}$ \\
\hline
\end{tabular}

Fonte: Elaboração Própria.

As redes de apoio aos homossexuais que vivem com HIV/AIDS vêm sendo tratadas como ferramentas essenciais no enfrentamento aos problemas advindos do diagnóstico da infecção, podendo ser um fator decisivo no modo de encarar o sucesso ou fracasso terapêutico (SILVA et al., 2015). Pacientes com redes sociais fortalecidas mostram-se mais otimistas, esperançosos e confiantes, e trazem melhores resultados nas terapias propostas e na autoaceitação do diagnóstico positivo para o HIV/AIDS.

Entretanto, outros estudos evidenciam que redes de apoio mal estruturadas estão diretamente associadas ao fracasso terapêutico, sofrimento psicossocial e a altas taxas de abandono dos pacientes, o que acarreta no declínio de estímulos fisiológicos e psicológicos inerentes à condição de saúde e, com isso, induz a queda das respostas imunológicas refletindo no surgimento de doenças oportunistas, que se não tratadas rapidamente, podem levar a óbito em um curto período de tempo (SILVA et al., 2015).

Conforme a literatura descreve, a família é a rede de apoio mais utilizada por homossexuais portadores de HIV/AIDS, caracterizado pelo acolhimento por parentes e amigos quanto ao suporte emocional e financeiro "instrumental", estando diretamente relacionados a elevadas taxas de sucesso terapêutico e bem-estar como um todo (SILVA et al., 2015).

Em contraponto, há trabalhos como descreve Rodrigues \& Maksud (2017), aos quais afirmam que o suporte familiar também pode influenciar negativamente na aceitação e acolhimento quando os portadores de HIV/AIDS são diagnosticados com a doença. Para esses casos, são observados a falta de boa convivência familiar, não aceitação religiosa, desrespeito ao sigilo e privacidade, bem como exclusão em grupo social (RODRIGUES \& MAKSUD, 2017).

Dentre as estratégias de fortalecimento de vínculo entre famílias e sociedade que convivem com pessoas portadoras de HIV, podem ser consideradas soluções viáveis, com a finalidade de garantir a melhora da comunicação e inclusão entre os envolvidos, medidas como: confecção e distribuição de cartilhas informativas, rodas de conversas participativas, consultas individualizadas e acolhimento realizado inicialmente pela atenção primária em saúde (NEVES et al., 2018). 
O apoio profissional é descrito como estratégia fundamental para o sucesso no tratamento dos indivíduos que convivem com HIV. São, portanto, fundamentais na formação de laços de confiança e vínculo, trazendo como ponto primordial, a importância da capacitação dos profissionais de saúde numa abordagem de inclusão multiprofissional na assistência em saúde ofertada à população, a fim de romper pormenores, hábitos e costumes excludentes e assegurar acolhimento e atendimento qualificado às demandas desses indivíduos de modo universal, integral e equânime (ALBUQUERQUE et al., 2013; RODRIGUES \& MAKSUD, 2017).

Sob uma cultura em grande parte, heteronormativa, ainda se faz presente no cotidiano da sociedade contemporânea, hábitos excludentes e discriminantes, que transcendem pontos de vista pouco flexíveis no que tange a diversidade de gênero, refletindo diretamente e indiretamente no modo como indivíduos acometidos por questões singulares, a exemplo dos portadores de HIV/AIDS recorrem aos serviços de saúde (ALBUQUERQUE et al., 2013).

Os saberes populares, juntamente com instituições religiosas, sempre foram ferramentas utilizadas no enfrentamento de causas difíceis por diferentes povos e culturas. No que tange aos homossexuais e as demais pessoas que vivem com HIV/AIDS (RODRIGUES et al., 2017), a associação de apoio espiritual e religioso paralelo aos tratamentos médicos são reportados pela literatura como um meio coadjuvante no apoio e acolhimento a indivíduos em situações de grave risco à saúde (FREITAS et al., 2012).

A deficiente oferta de vias de amparo emocional pode contribuir com o desencadeamento de comportamentos depressivos e suicidas, sendo perceptível a perda de estímulo no desempenho de atividades rotineiras atreladas ao comprometimento emocional e psicológico. Além desses fatores, ainda se percebe a falta de manejo profissional nas redes de atenção à saúde, incluindo educação. Frente a isso, as primeiras linhas de amparo a homossexuais portadores de HIV/AIDS ainda são em sua maioria, órgãos não regulamentados, ONGS não formalizadas e grupos de apoio sensibilizados com as causas LGBTs (PERDIGÃO et al., 2020; RODRIGUES \& MAKSUD, 2017; ROSSETTO et al., 2019).

As ONGS e casas de apoio a homossexuais portadores de HIV desempenham papel fundamental no enfrentamento dos problemas advindos do diagnóstico positivo, principalmente na assistência emocional e instrumental prestadas as pessoas em vulnerabilidade social, as quais incluem desde grupos e rodas de conversas, como assistência profissional e em alguns casos com incentivo governamental (LENZI et al., 2018; PERDIGÃO et al., 2020; ROSSETTO et al., 2019).

O apoio instrumental é caracterizado como aquele que provém as necessidades básicas de vida, como acesso a trabalho e renda. A prevalência do HIV no Brasil está mais incidente na população economicamente vulnerável. Embora o tratamento para HIV seja ofertado gratuitamente, algumas pessoas não conseguem mais estabelecer um vínculo empregatício, e outros afirmam pedir ou serem demitidos em virtude do diagnóstico que, normalmente, vem acompanhado de preconceito, exclusão ou o medo de sofrer exclusões. Salienta-se que o HIV não se caracteriza como uma patologia incapacitante e é previsto em lei que a pessoa soro positiva não tenha nenhum dos seus direitos humanos e sociais negados, embora o serviço de prestação continuada ou auxílio doença sejam ofertados exclusivamente aqueles que tiverem comprometimento grave da sua saúde, após seu diagnóstico (PERDIGÃO et al., 2020; RODRIGUES \& MAKSUD, 2017; ROSSETTO et al., 2019).

A dificuldade financeira é também um dos fatores negativos na vida das pessoas vivendo com HIV. Segundo a literatura, pacientes que trabalham apresentam maior chance de vinculação ao serviço de saúde, são menos acometidos por distúrbios psicológicos e tem maior incidência de adesão à terapia 
antirretroviral e as práticas de autocuidado em saúde. $\mathrm{O}$ apoio instrumental mais comum é fruto do próprio trabalho e em menor proporção, pelas famílias, amigos e instituições independentes, sendo revertido em moradia, alimentos e assistência à saúde de forma complementar (PERDIGÃO et al., 2020; RODRIGUES; MAKSUD, 2017; ROSSETTO et al., 2019).

\section{Considerações Finais}

As redes de apoio às pessoas, famílias e populações fragilizadas é uma das ferramentas essenciais para manutenção e recuperação da saúde, principalmente quando se trata de doenças e outros agravos à saúde, que são estigmatizados socialmente. No que fere a população homossexual vivendo com HIV, nota-se uma fragilização das políticas sociais e de saúde, que visam a integralidade da assistência. Contudo, a luz da literatura percebe-se a existência dessas redes, porém de forma desconectada. Ressalta-se o baixo volume de estudos que abordem a temática, e isso é fator prejudicial à formulação de políticas que visem criar, reestruturar e aprimorar as políticas de assistência já existentes. Sendo assim, enfatizamos a necessidade de estudos mais aprofundados sobre o tema. 


\section{REFERÊNCIAS}

.ALBUQUERQUE, G. A. et al. Homossexualidade e o direito à saúde: um desafio para as políticas públicas de saúde no Brasil Homosexuality and the right to health: a challenge for health policies in Brazil. Saúde debate, v. 37, n. 98, p. 516-524, 2013.

BRASIL (MINISTÉRIO DA SAÚDE). Plano Estratégico Programa Nacional de DST e Aids. Aids, p. 121, 2005.

BRASIL MINISTÉRIO DA SAÚDE. Protocolo Clínico e Diretrizes Terapeuticas para Atenção às Pessoas com Infecções Sexualmente Transmissíveis (IST). Secretaria de Vigilância em Saúde, Departamento de Doenças de Condições Crônicas e Infecções Sexualmente Transmissíveis, n. 0014125063, p. 1-248, 2020.

BRITO, A. M.; CASTILHO, E. A.; SZWARCWALD, C. L. AIDS and HIV infection in Brazil: a multifaceted epidemic. Revista da Sociedade Brasileira de Medicina Tropical, v. 34, n. 2, p. 207-217, 2001.

DA SILVA, L. M. S.; CAMPOS TAVARES, J. S. A família como rede de apoio às pessoas que vivem com HIV/AIDS: Uma revisão na literatura Brasileira. Ciencia e Saude Coletiva, v. 20, n. 4, p. 1109-1118, 2015.

NEVES, L. A. et al. Social support and quality of life of people with tuberculosis/HIV. Enfermeria Global, v. 17, n. 2, p. 21-29, 2018.

FREITAS, J. G. DE et al. Enfrentamentos experienciados por homens que vivem com HIV/Aids no ambiente de trabalho. Revista da Escola de Enfermagem da USP, v. 46, n. 3, p. 720-726, 2012.

LENZI, L. et al. Social support and HIV: Relationship between clinical and sociodemographic characteristics and treatment adherence. Psicologia: Teoria e Pesquisa, v. 34, p. 1-11, 2018.

MARIANA VIEIRA, VILLARINHO, M. I. P. Feelings Reported By Health Workers When Facing the Aids Sentimientos Relatados Por Los Trabajadores De Salud Frente a La Epidemia De Sida (1986-2006 ). v. 25, n. 1, p. 1-9, 2012.

PERDIGÃO, R. E. A. et al. Timely care linkage of people living with hiv in a reference health service, belo horizonte, minas gerais. Revista Brasileira de Epidemiologia, v. 23, 2020.

RODRIGUES, M.; MAKSUD, I. Abandono de tratamento: itinerários terapêuticos de pacientes com HIV/Aids. Saúde em Debate, v. 41, n. 113, p. 526-538, 2017.

ROSSETTO, M. et al. Coinfecção tuberculose/HIV/aids em Porto Alegre, RS - invisibilidade e silenciamento dos grupos mais afetados. Revista gaucha de enfermagem, v. 40, p. e20180033, 2019.

SÁ, A. A. M. DE; SANTOS, C. V. M. DOS. A Vivência da Sexualidade de Pessoas que Vivem com HIV/Aids. Psicologia: Ciência e Profissão, v. 38, n. 4, p. 773-786, 2018.

SANTOS, V. F. et al. Suporte social de pessoas com HIV/Aids : Modelo da Determinação Social da Saúde. Rev Bras Enferm, v. 71, n. supl 1, p. 670-675, 2018.

SILVA, J. A. G. et al. Factors associated with non-adherence to antiretroviral therapy in adults with AIDS in the first six months of treatment in Salvador, Bahia State, Brazil. Cadernos de Saude Publica, v. 31, n. 6, p. 1-11, 2015.

SOARES, C. B. et al. Revisão Integrativa versus Revisão Sistemática. Reme: Revista Mineira de Enfermagem, v. 8, n. 1, p. 102-106, 2010.

VENDRAMINI, S. H. F. et al. Tuberculose em município de porte médio do Sudeste do Brasil: indicadores de morbidade e mortalidade, de 1985 a 2003. Jornal Brasileiro de Pneumologia, v. 31, n. 3, p. 237-243, 2005. 


\title{
PRODUTO EDUCACIONAL PARA ACOMPANHANTE IDOSO: O LÚDICO E A HEUTAGOGIA
}

\author{
Samara Caram Aniceto \\ MECSMA/Unifoa \\ samaracaram@hotmail.com \\ Lucrecia Helena Loureiro \\ MECSMA/Unifoa \\ lucrecia.loureiro@foa.org.br
}

\section{RESUMO}

OBJETIVO: apresentar um instrumento lúdico de aprendizagem heutagógica para orientar os acompanhantes idosos em caso de internação hospitalar. METODOLOGIA: Estudo metodológico do tipo construção de um produto educacional denominado "Passatempo para Acompanhante", desenvolvido entre maio de 2019 e outubro de 2020. RESULTADOS: O passatempo foi composto de sete seções de orientações, nas quais foram destacadas normas, rotinas, direitos e deveres do acompanhante hospitalar. $\mathrm{O}$ produto aqui elencado contém um breve relato inicial sobre o Estatuto do Idoso e a Política Nacional de Humanização do Ministério da Saúde. As páginas seguintes foram compostas por jogos trazendo ou reforçando uma conduta correta para ser reproduzida ou compreendida pelo acompanhante dentro da enfermaria com seu idoso. CONCLUSÃO: Dentro do ambiente hospitalar, um material lúdico pode, além de distrair, envolver, amenizar o stress e trazer o aprendizado de rotinas e normas hospitalares, para público alvo da pesquisa, ajudando também na melhor assimilação destes.

\section{Palavras-chave:}

Idoso. Ensino. Autoaprendizagem; Hospitalização; Acompanhante de paciente.

\begin{abstract}
OBJECTIVE: to present a play full instrument of theutagogical learning to guide elderly companions in case of hospitalization. METHODOLOGY: methodological study of the type of construction of an educational product called "Pastime for Companions", developed between May 2019 and October 2020. RESULTS: The competition consisted of seven sections of guidelines, in which the rules, routines, rights and duties of the hospital companion were highlighted. The product listed here contains a brief initial account of the Elderly Statute and the National Humanization Policy of the Ministry of Health. The following pages were composed of games bringing or reinforcing a correct conduct to be reproduced
\end{abstract}

or understood by the companion inside the infirmary with his older person. CONCLUSION: Within the hospital environment, a playful material can, in addition to distract, involve, all evitate stress and bring the learning of hospital routines and norms, to the target audience of the research, also helping in their better assimilation.

\section{Keywords:}

Elderly; Teaching. Self-learning; Hospitalization; Patient companion. 


\section{INTRODUÇÃO}

O envelhecimento é inevitável, porém a incapacidade que traz consigo não recai da mesma forma em todos os idosos. É certo que as limitações acontecem e podem ser um fator negativo para a função de acompanhante, já que nem sempre as enfermarias são adequadas para receber um acompanhante idoso, e os locais disponíveis para sua permanência não são confortáveis, mas em muitas ocasiões são somente os acompanhantes idosos que estão disponíveis e dispostos a permanecerem no hospital.

A Política Nacional de Saúde da Pessoa Idosa estabelece como meta a atenção à saúde adequada e digna para os idosos brasileiros e considera que a condição de funcionalidade, as limitações físicas, cognitivas e sensoriais não são conseqüências inevitáveis do processo de envelhecimento, e que esse fator sozinho não prediz incapacidade, embora reconheça que a prevalência desta aumente com a idade (BRASIL, 2014).

Meneguin (2017) cita que as estimativas da Organização Mundial de Saúde (OMS) apontam que em 2025 aproximadamente 1,2 bilhões de pessoas terão mais de 60 anos no mundo, e o Brasil será o sexto país com maior número de idosos. Segundo dados do Instituto Brasileiro de Geografia e Estatística (IBGE), a população idosa (acima de 65 anos) representa quase 10\% da população existente hoje (sendo aproximadamente 220 milhões a população total). Em 2060, chegará a 26\% da população existente.

A equipe de enfermagem está à disposição para atuar junto ao paciente e auxiliar o acompanhante no que for necessário. Mas é importante enfatizar-se que o acompanhante não deve ser mais um paciente dentro da enfermaria, primeiro porque sua função de acompanhante é reduzida quando ele também precisa de ajuda, e depois porque o seu estado geral pode piorar as condições do paciente que se encontra internado, além do risco de contaminação.

Nesse sentido, cabe lembrar que acolher é reconhecer o que o outro traz como legítima e singular necessidade de saúde. Esse processo tem como objetivo a construção de relações de confiança, compromisso e vínculo entre as equipes e serviços, o trabalhador e as equipes e usuário com sua rede socioafetiva (BRASIL, 2013), sendo uma ferramenta importante para a qualidade da assistência ao acompanhante idoso. A escuta faz parte desse processo, garantindo à equipe a aplicabilidade de tecnologias necessárias para atendê-los.

A sistematização da assistência e o diálogo com o acompanhante podem ser considerados tecnologia, pois contribuem para o trabalho da equipe. Para Mehry (2016), a tecnologia moderna não só produz máquinas e ferramentas físicas, mas também organiza e sistematiza as atividades.

Visto isso, percebe-se a grande importância da presença do acompanhante durante a internação do paciente não somente na ajuda física, mas também no apoio mental e social. Ele ganha protagonismo como integrante do processo de cuidado. Portanto, faz-se necessário orientar acompanhantes de pacientes quanto a sua permanência em unidade de internação e participação na assistência ao cliente.

Corroborando com essa assertiva, Martins et. al. (2016) reforça a presença positiva desse acompanhante para o bem-estar físico, mental, social e espiritual do paciente, bem como seu papel no compartilhamento de algumas atividades de trabalho com a equipe de enfermagem. Acrescenta-se, ainda, que a permanência do acompanhante tem permitido a humanização do ambiente hospitalar. 
Em unidades hospitalares, verifica-se que o acompanhante de pacientes não se atenta para as atitudes que são condizentes com o ambiente assistencial de saúde. Muitas vezes, levando em consideração a experiência das autoras dessa pesquisa, o acompanhante precisa ser mais assistido que o doente. Alguns demandam muito à equipe, com tarefas que consomem tempo, o qual poderia ser melhor aproveitado no cuidado do enfermo. Além disso, observa-se com frequência vestimentas inadequadas, ações não harmônicas com o ambiente hospitalar, situações de incapacidade de auxílio por problemas da própria saúde, entre outros.

Há alta prevalência de cuidadores sem preparo adequado para o cuidado, e parte do cuidado também advém da responsabilização social, por isso nem sempre os acompanhantes estão em condições saudáveis para exercer tal tarefa (SOUZA ET. AL., 2014).

As normas e rotinas têm sido utilizadas como instrumento de poder sobre os acompanhantes, e esse poder tem como justificativa uma ordem moral, social, política e normativa. Por meio delas, obtém-se o controle e impõe-se uma relação docilidade-utilidade. Vale ressaltar que a organização do processo de trabalho exige a existência de normas e rotinas que possibilitem a convivência pacífica entre acompanhantes, pacientes e profissionais, sem resistências e conflitos (MODERNEL XAVIER ET. AL., 2014).

Ter atuado junto a essa clientela por quase duas décadas reforça para as autoras desta pesquisa a percepção de que familiares e/ou acompanhantes necessitam de orientação tanto no que se refere ao seu próprio comportamento em uma unidade hospitalar, quanto à possibilidade de participar com ações de apoio a esses pacientes.

Dentro deste contexto, Andrade et. al. (2017) defendem que as equipes de saúde ainda não fortaleceram a idéia de que o acompanhante possui necessidades e demandas no ambiente hospitalar, as quais, quando não atendidas, deixam-no sem suporte, desamparado, sem entender políticas, rotinas e procedimentos hospitalares direcionadas à equipe.

No que se refere à identificação da possibilidade de se utilizar ferramentas que facilitem a orientação do acompanhante de forma lúdica, a literatura se mostra ainda incipiente. Diante do exposto, pretende-se, com este artigo, apresentar um instrumento lúdico de aprendizagem heutagógica, para orientar os acompanhantes idosos em caso de internação hospitalar.

De acordo com o dicionário Aurélio, o termo lúdico vem do latim "ludos", que remete a jogos e divertimento. Surgida no século XVI, na Grécia e em Roma, essa noção tinha como objetivo o ensino de letras, mas não era utilizada para isso, sendo o lúdico visto apenas como uma brincadeira para distrair (COVOS, 2018).

Huizinga (2019) descreve que o jogo é uma realidade originária, uma noção primitiva na realidade humana, onde nasce a cultura sob forma de ritual e sagrado, linguagem e poesia, pois o jogo já existe antes da cultura humana. Endossando essa concepção de jogo, Vander (2019) retoma o conceito de "círculo mágico" de Huizinga, e o define como o momento em que alguém participa de alguma atividade de entretenimento, deixando para trás os problemas, preocupações e aflições do cotidiano, mergulhando em outro universo.

É indiscutível a importância do lúdico para o ser humano, pois ao brincar, jogar, desenhar, dramatizar e, contar histórias, revelam-se muitas dificuldades, a maioria inconsciente, e tais instrumentos, por revelarem dimensões psíquicas profundas, podem facilitar intervenções nesse indivíduo (BARRETO, 2013). 
O lúdico passa a ter uma grande importância no processo de educação em saúde, em sua totalidade, quando aprender brincando retira a carga pesada do aprendizado por obrigação e facilita o processo de ensino de situações hospitalares.

Em complementação à ludicidade no ensino ao idoso acompanhante, tem-se a teoria heutagógica de aprendizagem. Esta teoria facilita o ensino no ambiente hospitalar, fazendo com que o aprendizado, além de divertido, seja realizado de forma que o interlocutor entenda, no seu momento, a sua importância no contexto do cuidado, utilizando o lúdico como ferramenta.

A Heutagogia (heuta - auto, próprio, e agogus - guiar) trata de um conceito que reconhece as experiências cotidianas como fonte de saber e incorpora a autodireção da aprendizagem com foco nas experiências. Envolve estudo de autoaprendizagem autodirigida, que pode acontecer no ensino à distância. Os alunos podem definir, além de "como", também "quando e onde" aprender (COELHO, 2016).

Do olhar heutagógico faz-se a provisão de fontes de consulta diversas, em vez de conteúdo programático. Nesse sentido, o aluno tenta avaliar os assuntos e tira suas próprias conclusões sobre ele, em uma experiência de aprendizagem. Desta forma, surge a fase da aprendizagem dirigida ou autodeterminada, em que cada um se garante e, realiza, arquitetando seu processo de construção do conhecimento (COELHO, 2016).

Percebe-se então a necessidade do ensino ao acompanhante idoso, pois o ato de aprender também é compartilhado. No contexto de uma enfermaria, por exemplo, ele sai da passividade e passa a ser ativo, à medida que vai orientar outros acompanhantes que ao lado dele estiverem, sendo um agente transformador no ambiente. Além disso, há o fator terapêutico, já que uma vez aprendida a conduta ideal, esse acompanhante irá acrescentar durante a internação.

\section{Metodologia}

A metodologia foi baseada na construção de um produto educacional denominado "Passatempo para Acompanhante", desenvolvido entre maio de 2019 e outubro de 2020. Tal estudo refere-se a uma estratégia de pesquisa com foco no desenvolvimento de um produto para o Mestrado Profissional.

O conteúdo do passatempo, selecionado por meio de revisão integrativa da literatura científica e levantamento bibliográfico, constituiu-se de uma breve apresentação, seguida de seções de orientações relacionadas às normas e rotinas e aos direitos e deveres do acompanhante dentro do ambiente hospitalar.

Esse produto contém, inicialmente, um breve relato em quadrinhos sobre o art. 16 da Lei 10.741/03, que trata do Estatuto do Idoso, o qual oferece a esse público o direito de permanecer no hospital com acompanhante; e a Política Nacional de Humanização, do Ministério da Saúde (PNH). As páginas seguintes serão compostas por: código secreto, caça-palavra, silabox, dominox, criptograma, jogo dos sete erros e cruzadinhas, trazendo ou reforçando em cada jogo uma conduta correta para ser reproduzida ou compreendida pelo acompanhante dentro da enfermaria. 


\section{Resultados}

O passatempo foi composto de sete seções de orientações, nas quais foram destacadas normas, rotinas, direitos e deveres do acompanhante hospitalar. A capa foi desenvolvida com base nas ilustrações contidas no interior dele, a fim de apresentar conteúdo e mensagem principal ao leitor. Vale ressaltar que o avatar (desenho criado à imagem e semelhança do criador) que se encontra em todas as secções do jogo foi denominado "Samy", nome escolhido em homenagem à idealizadora do desenho.

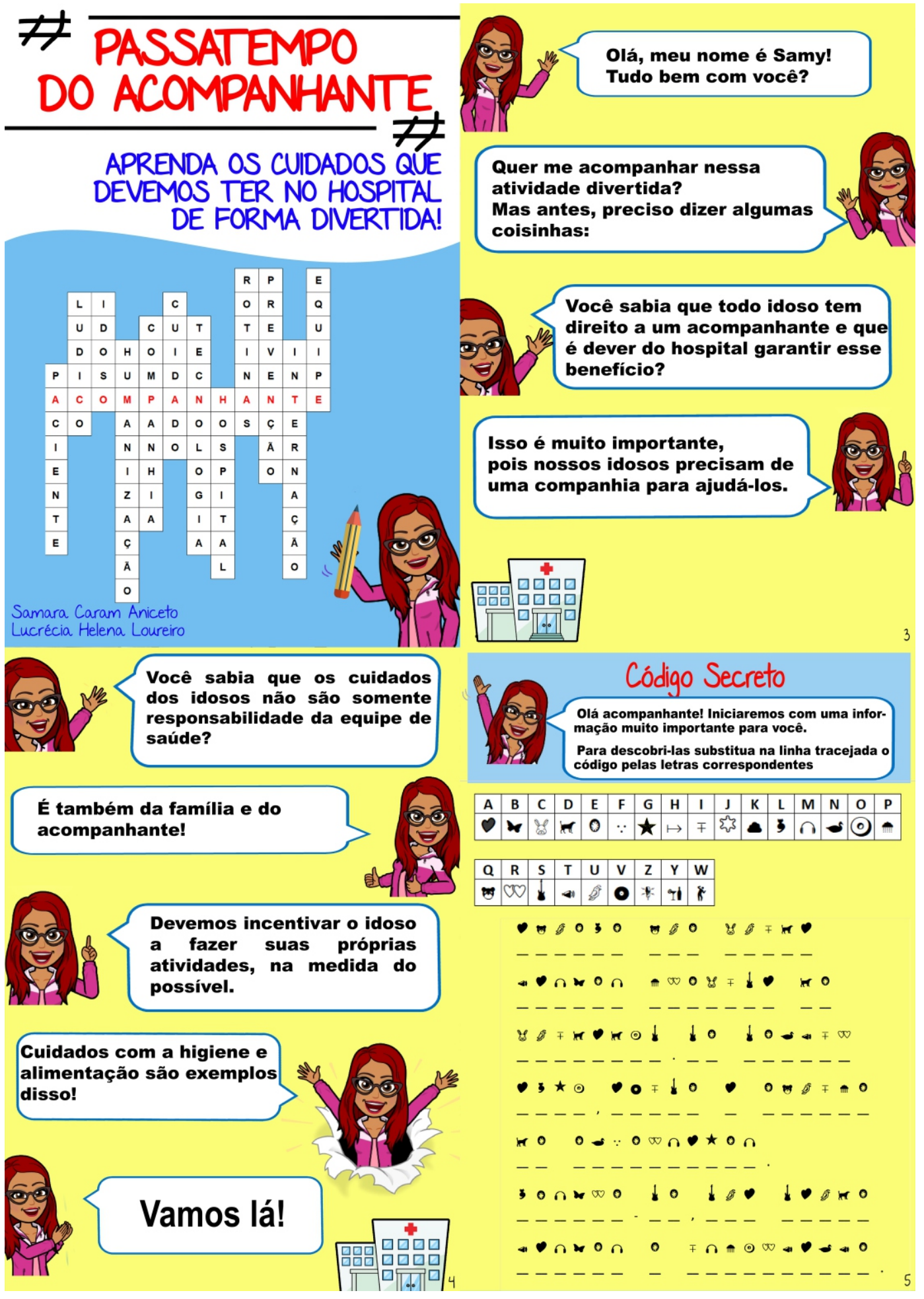

Figura 1

Fonte: Elaboração própria. 
Na Figura 1 são apresentados os quadrinhos do passatempo, com apresentação feita pela "Samy", que explicará, de forma resumida e bem didática, o art. 16 da Lei 10.741/03, o Estatuto do Idoso.

Art. 16. Ao idoso internado ou em observação é assegurado o direito a acompanhante, devendo o órgão de saúde proporcionar as condições adequadas para a sua permanência em tempo integral, segundo o critério médico.

Parágrafo único. Caberá ao profissional de saúde responsável pelo tratamento conceder autorização para o acompanhamento do idoso ou, no caso de impossibilidade, justificá-la por escrito (Lei 10.741/03).

A Política Nacional de Humanização do Ministério da Saúde (2013) abrange direitos também. A personagem irá abordar alguns assuntos provenientes dela:

O cuidado e a assistência em saúde não se restringem às responsabilidades da equipe de saúde. $O$ usuário e sua rede sócio familiar devem também se corresponsabilizar pelo cuidado de si nos tratamentos, assumindo posição protagonista com relação a sua saúde e a daqueles que lhes são caros.

Importante salientar o protagonismo, corresponsabilidade e autonomia dos sujeitos e coletivos do PNH:

Os usuários não são só pacientes, os trabalhadores não só cumprem ordens: as mudanças acontecem com o reconhecimento do papel de cada um. Um SUS humanizado reconhece cada pessoa como legítima cidadã de direitos $e$ valoriza e incentiva sua atuação na produção de saúde.

Ainda na Figura 1, tem-se também o código secreto, que aborda uma mensagem importante referente à atenção qualificada ao acompanhante idoso.

O acolhimento objetiva melhora nas relações e construções de vínculos de confiança entre profissionais e usuários (MINISTÉRIO DA SAÚDE, 2013). É uma ferramenta importante para a qualidade da assistência ao acompanhante idoso. Garantir uma aplicabilidade da tecnologia leve a esse usuário, o deixará menos ansioso.

Observa-se que o cuidador também precisa ser cuidado e esse assunto é muito abordado na área da saúde há décadas. Sabe-se que o acompanhante passa por um período de stress e ansiedade quando assume esse papel, pois sua rotina diária é modificada; por isso, caso este possua comorbidades, como hipertensão, diabetes ou outras doenças que podem ser alteradas pelo sistema emocional, torna-se paciente também, pois demandará cuidados da equipe.

É importante que este acompanhante se cuide e sinta-se confortável para permanecer no hospital. Sua presença é importante para o doente, mas é preciso que ele esteja bem para manter tal função, e, em caso de intercorrência pessoal, deve comunicar à equipe, para ser encaminhado ao pronto socorro para atendimento. 
Caça- Palavras - Vamos lavar nossas mãos! Trossas mãos são veículos de infecções, principalmente quando tocamos em algum lugar e no nosso paciente sem lavá-las antes.

Devemos lavar as mãos antes e depois do uso ao banheiro, após ter tocado superficies (mesa de cabeceira, grade da cama, cadeira do acompanhante, paredes, janelas, portas e maçanetas), antes e após tocar o paciente, antes da alimentação e no auxílio ao seu paciente.

Quando entramos no hospital também devemos lavar as mãos, pois tocamos em muitas coisas que estão sujas antes de chegar aqui. Podemos usar o álcool em gel se não tivermos como lavá-las e não estiverem com sujidades.

Usaremos as pias que estão no banheiro, ou na enfermaria, o sabão líquido, e para secar, o papel toalha.
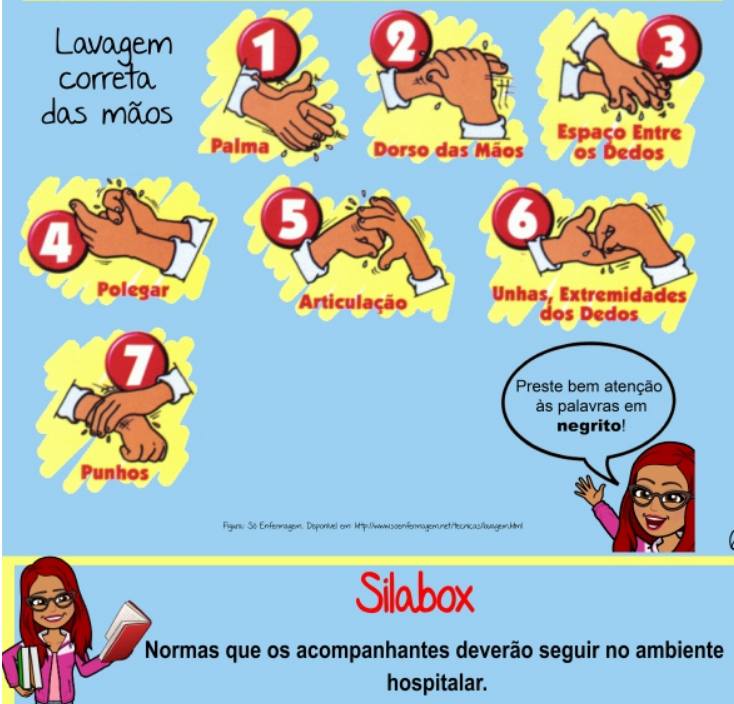

Dentro do hospital é importante seguirmos algumas normas para manter a segurança do paciente, do acompanhante e da equipe.

$\mathrm{Na}$ atividade abaixo estão algumas essenciais. Encontre as palavras escondidas para descobri-las.Cada quadradinho corresponde uma letra. Substitua letras iguais nos números iguais.

Dica: Local onde ficam internados os pacientes.

O acompanhante precisa dar apoio ao seu paciente, mas para manter-se no hospital é preciso vestir-se de forma

\section{[A|D|EIQQ'U|A|D|'A}

É preciso seguir as orientações da enfermagem quando aos cuidados pessoais, por isso é importante respeitar as

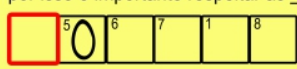

É proibido

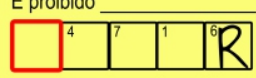

É imprescindivel o acompanhante ter mais de anos.

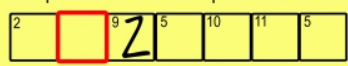

O acompanhante deve somente do seu paciente.

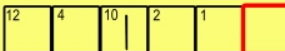

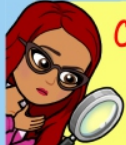

Caça- Palavras - Vamos lavar nossas mãos! Procure pelas palavras em negritos do texto anterior. Elas estão escondidas na vertical, horizontal e diagonal.

mão - infeccções - paciente - banheiro - acompanhante - paredes janelas - portas - maçanetas - alimentação - hospital - lavar - alcool em gel-pias - enfermarla-sabão-liquido-secar-papeltoalha O HOS P I T A L T SAEEÁOP P TOK T R R H A M S D F I E TOLEAS I PEEG $H T$ T A A MLN BOIACECLLAAOSP A Y LOOLE I A L AOW I T I NSPHNO TPOCSRA WNROCEHAMHIEEHR S CHURNOUHLWNONSEOGLLET I ETRA I NLEETSEMINOYTREA TTGETNFM I ETDOLPTNUORMS G TSLLTGBROOFMAEAITAEAT OLTRUERAOUETRVPÇNALR ÇE JANELASFAAYHBAA A WHHSA I FGSBHCN IESECARROAUABNA OETOERA I NFECÇÖESPCLNE I OS A B A OLI QU I DOTDLDTUHTA I DELHNAY I THENFERMAR I AE R B NEEELSREAEMFSCDSNWSR कह

\section{Silabox - Continuação}

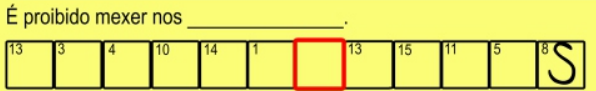

Se notarem alguma irregularidade, devem avisar a

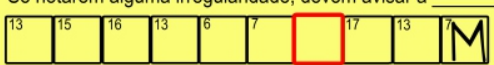

Os acompanhantes terão direito de 4 a 5 (café da manhã, almoço, lanche, jantar e ceia):

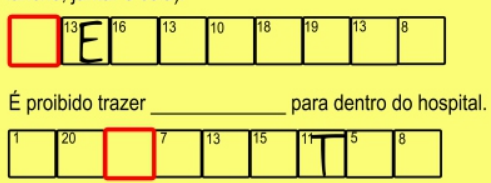

O acompanhante não deve ___ nem deitar no leito do paciente.

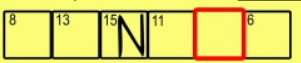

A palavra formada em destaque foi:

Figura 2

Fonte: Elaboração própria.

A parte superior da Figura 2 traz o caça-palavras. O conteúdo a ser fornecido nesse jogo será a orientação das lavagens das mãos, um ato tão importante na prevenção da disseminação de doenças dentro da enfermaria. 
As mãos são as maiores disseminadoras de infecções, e na área da saúde, durante a graduação e no campo de trabalho, muito é discutido sobre esse assunto, além da ênfase no treino da lavagem das mesmas para prevenir infecções hospitalares e contaminação cruzada.

Percebe-se no dia a dia que esse treinamento é feito para os profissionais, e os acompanhantes são somente orientados, não treinados. Os profissionais da saúde devem orientá-los quanto à forma correta de lavagem e os momentos de realização desta, o mínimo para a prevenção e a proteção do próprio acompanhante.

Na infraestrutura de um hospital, está preconizada na RDC 50 a disponibilização de pia dentro do banheiro e em uma área anterior à entrada das enfermarias ou dentro delas. O uso de sabão líquido, papel toalha e álcool em gel para higiene das mãos também está previsto.

Neri et. al. (2019) descreve os principais momentos para asseio das mãos, como depois do uso de banheiro, após ter tocado superfícies que pareciam sujas, após ter tocado uma pessoa doente, antes das alimentações do próprio acompanhante e no auxílio e preparo ao paciente. Ele também cita a lavagem durante visita (antes e após) a um paciente e após usar transporte público.

Na parte inferior da Figura 2, há o silabox. O assunto utilizado neste jogo são as regras do hospital mais utilizadas para acompanhante, pois nota-se que a inclusão de horários (troca de acompanhante, refeições e visitas), por exemplo, é utilizada em alguns hospitais.

Para algumas normas que os acompanhantes deverão seguir dentro do estabelecimento hospitalar, utilizamos como exemplo trechos de panfletos institucionais: dar apoio emocional ao seu paciente; vestir-se adequadamente (não vestir nada curto); seguir instruções da enfermagem no tocante aos cuidados pessoais; respeitar as normas e rotinas do hospital; ser maior de 18 anos; cuidar somente de seu paciente.

É proibido: mexer nos equipamentos da enfermaria; fumar nas dependências do hospital; trazer alimentos para o interior do hospital; sentar ou deitar no leito do paciente. E se notar alguma irregularidade, deve avisar imediatamente à enfermagem.

O acompanhante tem direito a 4 ou 5 refeições (café da manhã; almoço; lanche; jantar ou ceia), que dependerão do que está estabelecido na instituição hospitalar. Este item deverá ser observado atentamente pelo acompanhante.

A Figura 3, apresentada na próxima página, começa com o dominox. Nesta modalidade, aborda-se o uso do álcool em gel, já que em ambiente hospitalar torna-se imprescindível a higienização das mãos para evitar a contaminação do paciente e a própria. A lavagem das mãos é o melhor recurso para eliminar a sujeira. Caso as mãos não apresentem sujidade, pode-se utilizar do recurso do álcool gel. A orientação também serve para locais onde não há disposição de pias (como nos meios de transporte, na rua, entre outros).

O uso do álcool em gel aumentou desde o início da pandemia causada pelo coronavírus, nunca se ouviu tanto falar nesse antisséptico e seu uso como agora. Logo, reforçar seu uso correto é uma forma de manter o paciente protegido. Sendo assim, cabe lembrar que as mudanças diárias de protocolo no período de pandemia têm sido acompanhadas, mas a higienização das mãos mantém-se a mesma e é mais reforçada a cada dia.

O álcool em gel pode prevenir a transmissão de micro-organismos hospitalares. Quando as mãos estão contaminadas, friccioná-las com produto alcoólico pode prevenir a transmissão de patógenos com maior efetividade do que higienizar as mãos com água e sabonete comum (BRASIL, 2009). 
Dominox - Vamos usar álcool em gel nas mãos!

Pá citamos que lavar as mãos é importante para prevenir a transmissão de doenças para nosso paciente. Por isso, no hospital sempre devemos manter as mãos limpas. Caso não tenha sujeira visivel nas mãos, podemos usar 0 álcool em gel.

Também podemos utilizá-los em locais que não há pia, como nos meios de transporte, na rua, entre outros.

Importante lembrar que podemos usar o álcool em gel antes e após ter contato com o paciente e após ter contato com objetos e superfícies próximas ao paciente.

Devemos friccionar o álcool por 20 a 30 segundos até secar.
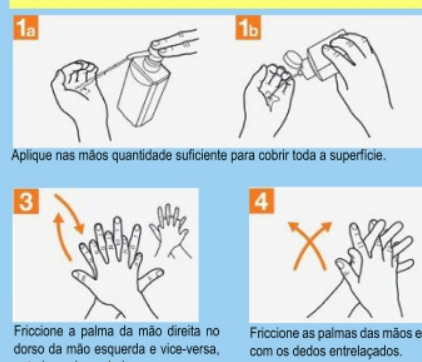

Friccione a palma da mầo direrta no
dorso da máo esquerda e vice-vers.
entrelą̧ando os dedos.

6.

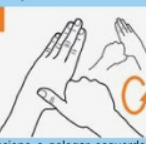

Friccione o polegar esquerdo com

auxilio da palma da mão direta
vice-versa) utilizando movimento

circular.
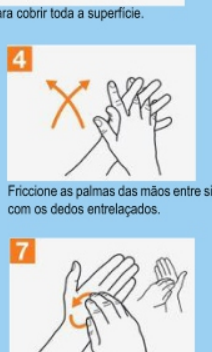

Friccione as polpas digtais e unhas da mäo direta contra a palma da mâo
esquerda(e vico-versa), fazendo um movimento circular.

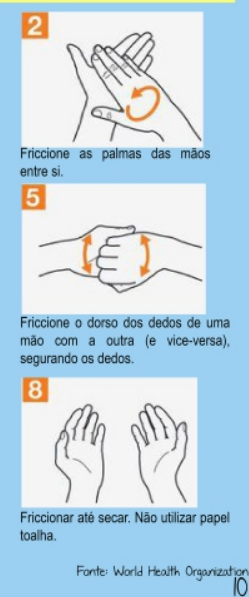

Criptograma

Acompanhante, sua participação é muito importante!

$\lim _{\pi}$

A participação do acompanhante torna a internação menos estressante ao paciente que acompanha. Outras vantagens podem ser percebidas com sua presença. Algumas estão escritas abaixo.

Descubra a palavra escondida. Lembre-se que cada quadradinho corresponde a uma letra. Simbolos iguais correspondem a letras iguais.

Em destaque formará uma palavra. Dica: Pessoa que você está cuidando A palavra em destaque é:

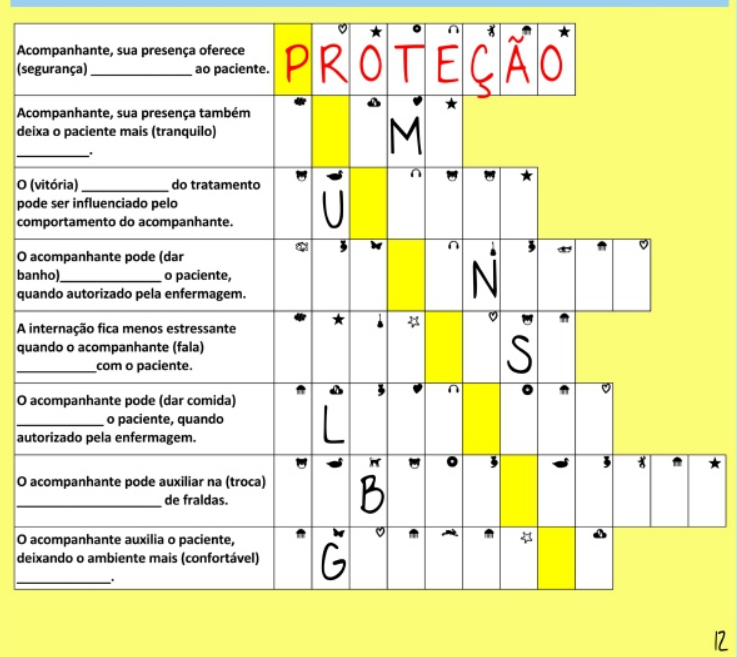

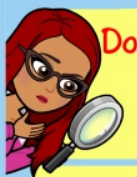

Dominox - Vamos usar álcool em gel nas mãos! Procure pelas palavras em negritos do texto anterior. Preencha os diagramas, respeitando os cruzamentos.

lavar - mãos - prevenir - trasmissão - paciente - hospital - limpas - sujeira - álcool pia - transporte - rua - gel - contato - objetos - superficies
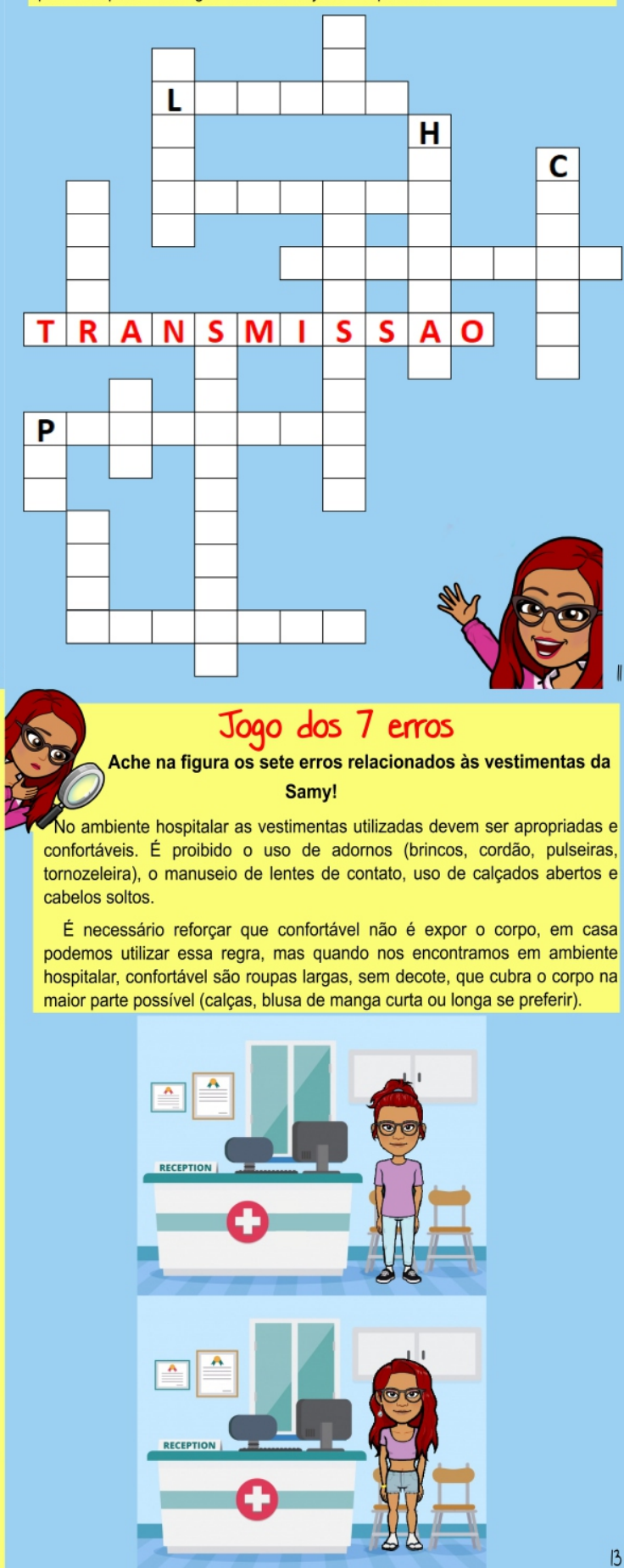

Figura 3

Fonte: Elaboração própria.

Para acompanhantes, cabe ressaltar que a higienização com álcool deve ocorrer antes e após de ter contato com o paciente; antes e após realizar procedimentos assistenciais que é permitido a eles; após ter contato com objetos inanimados e superfícies imediatamente próximas ao paciente e antes e após a remoção das luvas (BRASIL, 2009). 
Ainda na Figura 3, o criptograma aborda o papel e funções dos acompanhantes dentro da unidade hospitalar.

Os autores Andrade et. al. (2017) e Arcas et. al. (2016) apontam a importância do papel que o acompanhante exerce, auxiliando o paciente, oferecendo segurança, tranquilidade, apoio emocional e, no contexto biopsíquico, favorecendo a percepção de que a internação será superada em um espaço curto de tempo.

Corroborando com esta assertiva, apontamos as considerações dos autores Dahdah et. al. (2013), segundo as quais o familiar acompanhante necessita ter paciência e competência emocional para o cuidado e, mesmo inseguro, manter-se ao seu lado, para não o deixar sozinho. O familiar reduz o abatimento e ansiedade do paciente (ARCAS, 2016).

Cabe destacar que a presença física e emocional do acompanhante durante a internação também gera estresse a ele, pois há mudança de rotina. O mesmo pode participar dos cuidados dentro da enfermaria, mas é sempre importante tomar ciência de em que medida esse acompanhante deseja ajudar, visto que o ambiente hospitalar gera insegurança.

Por fim, na Figura 3 encontra-se o jogo dos sete erros, que abordará as vestimentas corretas que os acompanhantes devem utilizar quando estiverem em ambiente hospitalar. Ressalta-se que os cuidados com vestimentas não devem ser restritos aos profissionais de saúde.

A Norma Regulamentar - NR32 (2s005) determina que trabalhadores expostos a agentes biológicos devem utilizar vestimenta de trabalho adequada e em condições de conforto, proíbe o ato de fumar, o uso de adornos e o manuseio de lentes de contato nos postos de trabalho, além do consumo de alimentos e bebidas e o uso de calçados abertos. Entretanto, não se encontra nas recomendações nenhuma orientação aos acompanhantes, embora todas estas recomendações devam ser seguidas por eles também, já que, do mesmo modo, se encontram expostos a agentes biológicos.

A Norma cita o uso de adornos e calçados abertos como proibidos na Unidade Hospitalar, e o uso de roupas confortáveis como ideal. É necessário reforçar que quando se entra em um ambiente com exposição a risco biológico, confortável não é expor o corpo, mas usar roupas largas, sem decote, que cubram o corpo na maior parte possível (calças, blusas de manga curta ou longa, se preferir).

Na Figura 4, têm-se as cruzadas, um jogo bônus, em que se optou por selecionar manuais de acompanhantes de instituições hospitalares e abordar temas ainda não especificados nos jogos anteriores. Foram revisados dez manuais de forma aleatória, a partir da pesquisa realizada na internet, utilizando os indexadores "manual para acompanhante".

Verificou-se que a base dos manuais é muito semelhante, com diferenciação nas rotinas internas, como horários, números de visitantes, disponibilização das refeições, entrega de documentos e recolhimento de documentos para alta.

No manual do Grupo São Lucas (2020) está estabelecido que: no ato da internação hospitalar é importante que o acompanhante/familiar traga uma lista ou a receita de todas medicações que o paciente utiliza, bem como as alergias; trazer seus objetos para higiene pessoal; falar em voz baixa e manter o volume da televisão baixo também, para não incomodar outras pessoas; evitar andar nos corredores e não transitar em outros leitos; não cozinhar ou preparar o alimento no quarto; não lavar ou estender roupas no quarto; não trazer objetos de valor, o hospital não se responsabiliza pela perda; evitar trazer objetos como imagens, amuletos, flores, pois podem causar infecções pelas sujidades. 


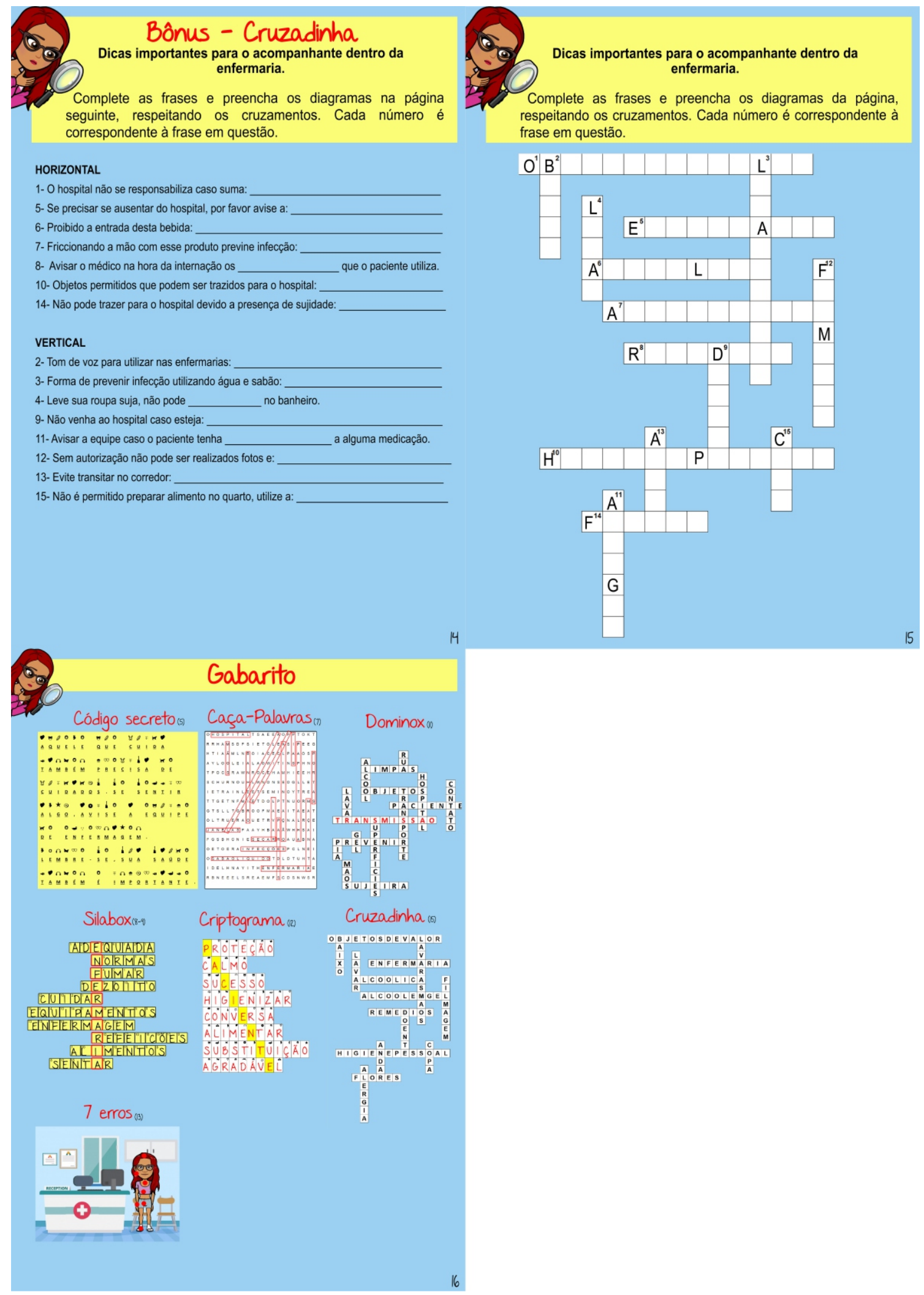

Figura 4

Fonte: Elaboração própria.

O manual de paciente do Hospital Português (2018) sugere que caso o acompanhante ou visitante tenha algum problema de saúde, opte por não ver o paciente; caso o acompanhante precise se 
ausentar, avise à equipe de enfermagem; e proíbe realizar filmagens ou fotos sem o consentimento da Direção.

A cartilha de orientação do Hospital do Câncer (s.d.) menciona como regras: não trazer bebidas alcoólicas; trazer somente itens necessários para os dias de internação e informa que o hospital não se responsabiliza pelos pertences deixados nas suas dependências.

Percebe-se nos demais manuais pesquisados, os mesmos temas já abordados no produto e nos manuais citados. Optou-se também em rever alguns assuntos já abordados, porém de extrema importância, principalmente nesse período de pandemia, como, por exemplo, lavagem das mãos e o uso do álcool em gel.

\section{Considerações Finais}

Dentro do ambiente hospitalar, trazer algo lúdico que possa, além de distrair, envolver, amenizar o estresse, trazendo o aprendizado de rotinas e normas hospitalares, pode facilitar a assimilação dessas pelo público alvo da pesquisa.

Nesse sentido, assinala-se também as vantagens da heutagogia aplicada, quando as pessoas de qualquer idade e condição podem aprender qualquer assunto de diversas áreas de conhecimento. Vale ressaltar que por ser autoaprendizagem, pode-se escolher o que deseja aprender, horário, local e ritmo, o que for melhor para seu conforto e necessidades.

Pretende-se com esse produto contribuir de forma educativa, elencando as orientações para o acompanhante compreender o seu papel dentro de uma unidade hospitalar, trazendo as principais orientações para que este possa ser "terapêutico".

Pode-se dizer que o acompanhante é "terapêutico" porque assume um papel fundamental em diminuir o tempo de internação hospitalar do paciente que assiste, visto que ele contribui de forma efetiva no tratamento. Este traz suporte emocional e cria um ambiente mais familiar, que o hospital não possui. 


\section{REFERÊNCIAS}

ANDRADE, Abigail de Paulo et al. Vivencia de acompanhantes e enfermeiros no cuidado de pacientes críticos . Revista Nursing, vol. 234, n.20, 2017. Disponível em http://www.cofen.gov.br/wpcontent/uploads/2017/11/Revista-Nursing_234-BAIXA.pdf. Acesso em 25/05/19.

ARCAS, Amaliane Bernardes et al. Significados do papel do acompanhante em unidade hospitalar: visão da pessoa hospitalizada com condição crônica. Revista Baiana de Enfermagem!́, v. 30, n. 4, 2016. Disponível em https://portalseer.ufba.br/index.php/enfermagem/article/view/16936. Acesso em: 25/05/19.

BARRETO, Ricardo Azavedo. O lúdico em odontopediatria: contribuições psicológicas. 2013. In: COTA, Ana Lídia Soares; COSTA, Bárbara Jéssica de Assunção. Atividades lúdicas como estratégia para a promoção da saúde bucal infantil. Saúde e Pesquisa, v. 10, n. 2, p. 365-371, 2017. Disponível em https://periodicos.unicesumar.edu.br/index.php/saudpesq/article/view/5963. Acesso em 18/02/20.

BRASIL. Lei 10.741/03 - Estatuto do Idoso. Disponível em http://www.planalto.gov.br/ccivil_03/ leis/2003/L10.741.htm. Acesso em 28/11/18.

BRASIL, Portaria MTE n.o 485, de 11 de Novembro de 2005. NR 32 - Segurança e saúde no trabalho em serviços de saúde. Disponível em http://www.guiatrabalhista.com.br/legislacao/nr/nr32.htm. Acesso em 06/07/20.

BRASIL, Ministério da Saúde. Secretaria de Atenção à Saúde. Humaniza SUS. Brasília, 2013. Disponível em http://www.saude.gov.br/bvs/humanizacao. Acesso em 26/12/19.

BRASIL, Ministério da Saúde. Secretaria de Atenção à Saúde. Departamento de Atenção Especializada e Temática / DAET. Coordenação Saúde da Pessoa Idosa / COSAPI .Diretrizes para o cuidado das pessoas idosas no SUS: proposta de modelo de atenção integral. XXX Congresso Nacional de Secretarias Municipais de Saúde. Brasilia, 2014. Disponível em http://www.saude.gov.br/idoso. Acesso em 19/12/19.

BRASIL. Agência Nacional de Vigilância Sanitária. Segurança do Paciente em Serviços de Saúde: Higienização das Mãos / Agência Nacional de Vigilância Sanitária. Brasília: Anvisa, 2009. Disponível em https://bvsms.saude.gov.br/bvs/publicacoes/seguranca_paciente_servicos_saude_higienizacao_maos.pdf. Acesso em 14/05/20.

BRASIL, Agencia Nacional de Vigilancia Sanitária. Higienização das mãos. 2020. Disponível em http://www.anvisa.gov.br/servicosaude/controle/higienizacao_simplesmao.pdf. Acesso em 05/04/20.

BRASIL. Ministério da Saúde.Agência Nacional de Vigilância Sanitária. Resolução-RDC no 50, de 21 de fevereiro de 2002. Disponível em https://bvsms.saude.gov.br/bvs/saudelegis/anvisa/2002/rdc0050_21_02_2002.html. Acesso em 03/05/20.

COELHO, Marcos Antônio; DUTRA, Lenise Ribeiro; MARIELI, Joane. Andragogia e heutagogia: práticas emergentes na educação. Revista Transformar, v. 8, n. 8, p. 97-107-107, 2016. Disponível em http://www.fsj.edu.br/transformar/index.php/transformar/article/view/87/83. Acesso em 10/10/19.

COVOS, Jacqueline Sardela, et al. O novo perfil de alunos no ensino superior, e a utilização de jogos lúdicos para facilitação do ensino aprendizagem. Revista Saúde em Foco, 2018. Disponível em http://portal.unisepe.com.br/unifia/wp-content/uploads/sites/10001/2018/06/ 007_O_NOVO_PERFIL_DE_ALUNOS_NO_ENSINO_SUPERIOR.pdf. Acesso em 31/01/20.

DAHDAH, Daniel Ferreira et al. Grupo de familiares acompanhantes de pacientes hospitalizados: estratégia de intervenção da Terapia Ocupacional em um hospital geral. Cadernos de Terapia Ocupacional da UFSCar, v. 21, n. 2, p. 399-404, 2013. Disponível em http://doi.editoracubo.com.br/10.4322/cto.2013.041. Acesso em 25/05/19. 
GRUPO SÃO LUCAS. Manual do Paciente. Grupo São Lucas. 2020. Disponível em http://www.gruposaolucas.com.br/orientacoes/manual-do-paciente/ . Acesso em 26/07/20.

HOSPITAL DO CÂNCER. Cartilha de orientação ao paciente e acompanhante para internação. S.d. Hospital do Câncer. Disponível em https://www.hcancer.com.br/wp-content/uploads/2017/02/ManualInterna\%C3\%A7\%C3\%A3o.pdf. Acesso em 27/07/20.

HOSPITAL PORTUGUÊS. Manual do paciente e do acompanhante. 2018. Disponível em https://www.hportugues.com.br/wp-content/uploads/2019/07/manual-paciente.pdf. Acesso em 26/07/20.

HUIZINGA, Johan. Homens ludens: o jogo como elemento da cultura. Traduzido por Monteiro JP. 1a. Ed. São Paulo: Perspectiva; 2019.

INSTITUTO BRASILEIRO DE GEOGRAFIA E ESTATISTICAS (IBGE). Projeção da população. Instituto Brasileiro de Geografia e Estatística. 2019. Disponível emhttps://www.ibge.gov.br/apps/populacao/ projecao/index.html?utm_source=portal\&utm_medium=popclock. Acesso em 28/10/19.

MARTINS, Maria Manuela; MONTEIRO, Maria Clara Duarte; GONÇALVES, Lucia Hisako Takase. Vivências de familiares cuidadores em internamento hospitalar: o início da dependência do idoso. Rev. enferm. UFPE online, $v$. 10, n. 3, p. 1109-1118, 2016. Disponível em https://periodicos.ufpe.br/revistas/revistaenfermagem/ article/download/11065/12491. Acesso em 26/05/19.

MERHY, Emerson Elias; FEUERWERKER, Laura Camargo Macruz. Novo olhar sobre as tecnologias de saúde: uma necessidade contemporânea. Avaliação compartilhada do cuidado em saúde: surpreendendo o instituído nas redes. Hexis, Rio de Janeiro, 1. ed., 2016. Disponível em: http://historico.redeunida.org.br/editora/bibliotecadigital/colecao-micropolitica-do-trabalho-e-o-cuidado-em-saude/politicas-e-cuidados-em-saude-livro-2avaliacao-compartilhada-do-cuidado-em-saude-surpreendendo-o-instituido-nas-redes . Acessado em 29/10/19.

MENEGUIN, Silmara; BANJA, Paula Fernanda Tieko; FERREIRA, Maria de Lourdes da Silva. Cuidado ao paciente idoso hospitalizado: implicações para a equipe de enfermagem. Revista Enfermagem UERJ, v. 25, n. 0, p. 16107, 2017. Disponível em https://www.e-publicacoes.uerj.br/index.php/enfermagemuerj/article/view/16107. Acesso em 25/05/19.

MODERNEL XAVIER, Daiani et. al. A família na Unidade de Pediatria: convivendo com normas e rotinas hospitalare s. Revista Brasileira de Enfermagem, Vol. 67, núm. 2, pp. 181-186, março-abril/2014. Disponível em: https://www.redalyc.org/pdf/2670/267030687002.pdf. Acesso em 28\10\19.

NERI, Maria Fabiana de Sena et. al. Comportamento sobre prática de higiene das mãos de acompanhantes em enfermarias de internação. Revista Rene, Ceará, 2019. Disponível em http://www.periodicos.ufc.br/rene/article/download/41015/99347. Acesso em 05/04/20.

SOUZA, Isabela Cata-Preta et. al. Perfil de pacientes dependentes hospitalizados e cuidadores familiares: conhecimento e preparo para as práticas do cuidado domiciliar. Revista Mineira de Enfermagem, v. 18, n. 1, p. 164-180, 2014. Disponível em http://www.reme.org.br/artigo/detalhes/916. Acesso em 26/05/19.

VANDER, Vince. Sobre Johan Huizinga, o Homo Ludens e a ideia de círculo mágico. Disponível em: https://www.updateordie.com/2017/03/05/sobre-johan-huizinga-o-homo-ludens-e-a-ideia-de-circulomagico/. Acesso em: 10/10/2019. 


\section{HIPOTIREOIDISMO NO DESENVOLVIMENTO DA CRIANÇA E DO ADOLESCENTE}

Pablo de Matos Monteiro

Universidade Federal do Maranhão

Pedro da Silva Gerônimo Neto

Universidade Federal do Maranhão

Mariele Borges Ferreira

Universidade Federal do Maranhão

Rafael Arouche

Universidade Federal do Maranhão

Cibelly de Fátima Vieira Ferreira

Universidade Federal do Maranhão
Lucas Daylor Aguiar da Silva

Universidade Federal do Maranhão

Kaytlhen Kayllen Carvalho de Menezes

Universidade Federal do Maranhão

Mirla de Jesus Santos Brasil

Universidade Federal do Maranhão

Maria Madalena Corrêa Melo

Faculdade Pitágoras de São Luís-MA

Flavia Castello Branco Vidal

Universidade Federal do Maranhão

\section{RESUMO}

O hipotireoidismo é uma doença que tem como característica a diminuição no processo de produção dos hormônios tireoidianos (HT), em que apresenta sintomas clínicos causados por efeitos inadequados desses hormônios em nível celular. OBJETIVO: Apresentar dados, conceitos e atualizações relacionados ao hipotireoidismo no desenvolvimento da criança e do adolescente. FONTES DOS DADOS: Artigos, revisões e livros contendo relevantes a temática abordada. DESENVOLVIMENTO: Esta revisão aborda dados sobre a fisiologia e quadros clínicos do hipotireoidismo. O hipotireoidismo é caracterizado por hipofunção da glândula tireoide e pode ocorrer como doença da própria glândula (hipotireoidismo). A triagem do hipotireoidismo é importante para o diagnóstico e tratamento precoce de crianças e adolescentes. Destaca- se que a clínica varia de acordo com a faixa etária em que ocorre a doença. As disfunções tireoidianas podem se apresentar de forma insidiosa e com manifestações clínicas sutis. CONCLUSÃO: A produção insuficiente da tireoide ou sua ação inadequada em nível celular ou molecular levam ao hipotireoidismo. Os hormônios tireoidianos são necessários para o desenvolvimento do cérebro na vida fetal e pós-natal. Aponta-se nesta revisão, o hipotireoidismo congênito $(\mathrm{HC})$ e adquirido.

\section{Palavras-chave:}

Hormônios tireoidianos; hipotireoidismo; criança; adolescência.

\begin{abstract}
Hypothyroidism is a disease characterized by a decrease in the production process of thyroid hormones (HT), in which it presents clinical symptoms caused by inadequate effects of these hormones at the cellular level. OBJECTIVE: To present data, concepts and updates related to hypothyroidism in the development of children and adolescents. DATA SOURCES: Articles, reviews and books containing relevant to the topic addressed. DEVELOPMENT: This review addresses data on the physiology and clinical features of hypothyroidism. Hypothyroidism is characterized by hypofunction of the thyroid gland and can occur as a disease of the gland itself (hypothyroidism). Screening for hypothyroidism is important for the early diagnosis and treatment of
\end{abstract}

children and adolescents. It is noteworthy that the clinic varies according to the age group in which the disease occurs. Thyroid dysfunctions can present in an insidious way and with subtle clinical manifestations. CONCLUSION: Insufficient production thyroid or its inadequate action at the cellular or molecular level leads to hypothyroidism. Thyroid hormones are necessary for brain development in fetal and postnatal life. In this review, the congenital and acquired hypothyroidism (HC) is pointed out.

\section{Keywords:}

Thyroid hormones; hypothyroidism; children; adolescence. 
INTRODUÇÃO

A diminuição no processo de produção dos hormônios tireoidianos (HT) é denominado de hipotireoidismo. Essa doença também pode ser caracterizada, mesmo que de forma rara, por sintomas clínicos causados por efeitos inadequados desses hormônios em nível celular. As alterações e modificações relacionadas ao estado clínico do paciente podem ser intensificadas ou amenizadas, contudo vai depender do aumento ou diminuição da produção desses hormônios. Os HT, durante todos os estágios de vida, possuem importante função de reguladores metabólicos, porém, o desempenho se torna fundamental para o desenvolvimento individual durante os primeiros estágios da vida (MATIAS, 2013).

Os sintomas clínicos causados pela deficiência dos hormônios tireoidianos irão depender de alguns fatores, tais como: a extensão da deficiência e a duração da doença, no qual irão afetar todos os tecidos sendo de menor ou maior proporção. No entanto, como a HT desempenha um papel importante no desenvolvimento normal do cérebro do feto, a falta de produção suficiente durante a vida no útero pode ocasionar consequências mais prejudiciais (MORREALE, 2001; SETIAN, 2007).

O hipotireoidismo pode ser classificado como: congênito, quando não há o desenvolvimento da glândula tireoide antes do nascimento, ou adquirido, normalmente causado pela tireoide de Hashimato numa etapa avançada da infância ou no início da adolescência; além disso, pode ser também esporádico ou familiar. Os defeitos causados pela função tireoidiana podem ser sintomáticos ou subclínicos, transitórios ou permanentes (AGUILÁ, 2013).

$\mathrm{Na}$ adolescência os distúrbios relacionados com a tireoide têm se tornado cada vez mais comuns, tendo sua prevalência aumentado. É possível encontrar duas situações clínicas durante uma consulta com adolescentes: um novo diagnóstico da doença ou a necessidade de seguimento de um processo diagnosticado precocemente (AGUILÁ, 2013).

A prevalência de doenças da tireoide varia na faixa etária de 11 a 18 anos de idade. Nos Estados Unidos, a prevalência de tireoidite autoimune em crianças com idade avançada varia de 0,08\% a $1,2 \%$, principalmente em meninas. Além disso, devido a alta prevalência do hipotireoidismo congênito, existem adolescentes que apresentam sequelas neuropsicológicas, apesar de terem sido corretamente diagnosticados no rastreio neonatal (AGUILÁ, 2013).

Para uma produção adequada do HT, é importante que o eixo hipotálamo-hipófise-tireoide esteja íntegro, garantindo a sequência das atuações do hormônio liberador hipotalâmico (TRH) sobre a hipófise, produzindo hormônio tireotrófico hipofisário (TSH), o qual, por sua vez, atua na tireoide, produzindo os HT. Deficiências nessas etapas levam a um hipotireoidismo terciário ou hipotalâmico, secundário ou hipofisário e primário ou tireoidiano (FOLEY, 1996; GRIFFIN, 2004; SETIAN, 2007). 


\section{FISIOLOGIA}

Os hormônios da tireoide, assim como os glicocorticóides, têm efeito de longo prazo no metabolismo. Porém, os HT diferem dos glicocorticóides devido não serem essenciais à vida, sendo essenciais para o crescimento e o desenvolvimento normal das crianças. Consoante a isso, recém nascidos que possuem deficiência na tireoide possuem um retardo no processo de desenvolvimento, exceto os casos em que haja tratamento inicial (SILVERTHORN, 2010).

Países da América do Norte, como os Estados Unidos e o Canadá realizam testes em recém nascidos para verificação da concentração dos hormônios da tireoide, por causa da importância desses hormônios nas crianças. Os hormônios da tireoide são aminas derivadas do aminoácido tirosina, e eles são incomuns porque contêm o elemento de iodo (SILVERTHORN, 2010).

O iodo é um componente exclusivo dos hormônios da tireoide, sendo essencial para as suas sínteses. As fontes de iodo na alimentação são o pão, o sal iodado e os laticínios. O iodo inorgânico presente na circulação é levado para o interior do folículo tireoidiano, onde será organificado. Este transporte depende do TSH e de um carregador sodium iodide symporter (NIS), que está localizado na membrana da célula acinar tireoidiana. O NIS humano já foi identificado na mama, cólon e ovário, e, por esta via, tecidos como glândulas salivares e mucosas gástrica são também capazes de concentrar o iodeto (DUNN, 2001; SETIAN, 2007).

Uma vez o iodo organificado, a tirosina vai dar lugar à formação das monoiodotirosinas (MIT) e diiodotirosinas (DIT) já incorporadas à tireoglobulina. Estes hormônios vão agora acoplar-se para dar lugar à formação dos dois principais HT: triiodotironina (T3) e tetraiodotironina (T4). Apenas três a quatro moléculas de T4 são formadas em cada molécula de tireoglobulina, e, normalmente, a glândula tireoide produz muito mais T4 do que T3. A relação T4 para T3 é de 15:1 na tireoglobulina normal. A formação de MIT e DIT pode ser inibida pelas sulfamidas (SETIAN, 2007).

\section{QUADRO CLÍNICO}

Reconhecer precocemente os sintomas clínicos em pacientes com situação de deficiência de hormônios tireoidianos é de suma importância, além de ser considerado uma emergência pediátrica entre os recém-nascidos. Os sinais mais precoces da doença são: icterícia prolongada ou recorrente, atraso na queda do funículo umbilical e hérnia umbilical. Outro aspecto a ser analisado é o choro rouco e a emissão de sons graves pela criança (SETIAN, 2007).

Nos primeiros meses de vida, outros sinais tornam-se presentes: dificuldade alimentar, ganho de peso insuficiente, respiração ruidosa, congestão nasal, distúrbios respiratórios, obstipação, letargia, pele seca, fria, pálida e com livedo reticularis (LR). Há ainda atraso do desenvolvimento neuropsicomotor (DNPM) e do crescimento, e suas proporções corpóreas são desarmônicas, além de os membros inferiores serem curtos se comparados ao tronco (SETIAN, 2007).

Quando o hipotireoidismo é adquirido, com início mais tardio, o retardo mental pode ser menos evidente, porém o crescimento será afetado e estas crianças terão atraso da maturação óssea, ou seja, atraso de idade óssea (IO) (SETIAN, 2002; SETIAN, 2007).

Nos adolescentes, podemos detectar, além da diminuição do desempenho escolar, fadiga e lentidão, labilidade emocional e humor deprimido ou alterado. Isso pode simular distúrbios de comportamento típicos da adolescência. Você também pode observar distúrbios menstruais, retardo puberal, pele seca, 
perda excessiva de cabelo, ganho de peso, bem como, com frequência parada pré-púber do crescimento, voz rouca, face inchada, pálpebras caídas, bradicardia e/ou bócio (AGUILÁ, 2013).

Outras alterações endócrinas podem acompanhar o hipotireoidismo. $\mathrm{O}$ adolescente pode apresentar infantilismo sexual. Paradoxalmente, alguns podem apresentar puberdade precoce. A longo prazo, pode haver hipertrofia dos tireotrofos, com aumento da hipófise e até da sela túrcica (ANASTI et al., 1995; SETIAN, 2007).

\section{HIPOTIREOIDISMO CONGÊNITO (HC)}

O hipotireoidismo congênito $(H C)$ primário tem uma incidência estimada de 1 para 2.600 a 4.000 nascimentos e entre 50.000 e 100.000 no secundário. O HC primário tem incidência bem mais elevada na síndrome de Down e pode associar-se com outras malformações e síndromes (SOUZA et al., 2013).

Em relação à sua etiologia, pode ocorrer por mutação de genes da glândula tireoide, da glândula hipofisária, das proteínas transportadoras ou dos receptores dos hormônios tireoidianos. Pode ser, ainda, consequente a problemas maternos (p. ex.: mãe com doença tireoidiana autoimune ou por ingestão de medicamentos) e ainda ser definitivo ou transitório. Apesar de na grande maioria dos casos os pacientes apresentarem etiologia indefinida, a causa descrita mais frequentemente é a disgenesia da tireoide ( $80 \%$ a $85 \%$ dos casos). O diagnóstico deve ser precoce através da triagem neonatal (SOUZA et al., 2013).

\section{Triagem neonatal}

O hipotireoidismo congênito é a causa principal de retardo mental, que pode ser prevenido com a instituição precoce do tratamento. A triagem neonatal é fundamental para o diagnóstico precoce, já que a maioria dos recém-nascidos com HC não apresenta sintomas ao nascimento e a detecção pela clínica pode atrasar o diagnóstico em 6 a 12 semanas (SOUZA et al., 2013).

Assim, o principal objetivo da triagem neonatal é prevenir o dano cerebral irreversível, através da deteç̧ão e tratamento precoce dos RN afetados. Estima-se que, atualmente, $25 \%$ da população mundial faze triagem neonatal para HC. Na América Latina em 2005 a cobertura era de aproximadamente 49\%. O Brasil em 2012 alcançou cobertura de 84\% (SOUZA et al., 2013).

\section{Diagnóstico}

O diagnóstico de HC é confirmado quando o valor de TSH está elevado e o de T4 total ou livre está baixo. Em programas que dosam inicialmente o T4 pode-se encontrar, no exame confirmatório, um TSH normal ou baixo com T4 total ou livre baixo. Isto sugere diagnóstico de hipotireoidismo secundário (hipofisário). Quando somente o T4 total é dosado e está baixo, mas com TSH normal, deve-se solicitar dosagens de T4 livre e da TBG (thyroxine binding globulin) para fazer o diagnóstico de deficiência desta proteína (SOUZA et al., 2013).

A deficiência de TBG é ligada ao cromossomo $X$ e ocorre em aproximadamente 1:4.000 recémnascidos. Os pacientes têm função tireoidiana normal e não necessitam de tratamento (ARES et al., 1997; SOUZA et al., 2013). 
Estudos têm demonstrado que o tratamento deve ser iniciado no máximo até o 14ㅇ dia de vida para evitar sequelas neurológicas, principalmente naqueles casos com HC grave (SOUZA et al., 2013).

\section{HIPOTIREOIDISMO ADQUIRIDO}

A tireoidite linfocítica crônica (TLC) ou tireoidite de Hashimoto é uma doença auto-imune, caracterizada por infiltrado linfo-plasmocitário do parênquima tireoidiano em regiões suficientes de iodo. A TLC ocorre pela incapacidade dos linfócitos T supressores em destruir clones de linfócitos sensibilizados por antígenos tireoidianos, com consequente citotoxicidade mediada por células "natural killer" e a comunicação de linfócitos T Helper com linfócitos B, gerando anticorpos contra componentes tireoidianos. Supõe que pode ser desencadeado pela alta ingestão de iodo, que supostamente demonstra o aumento da frequência de doença tireoidiana auto-imune (SZELIGA et al.,2002; SOUSA et a., 2013).

As células da tireoide de pacientes com tireoidite de Hashimoto apresentam alteração em seus genes como: ET/PTC, RAS e FAZ que são mediadores da morte das células apoptóticas, promovendo uma depleção dos folículos, no caso de hipotireoidismo (CAMANDAROBA et al., 2009).

A prevalência na criança é em torno de $0,15 \%$ e tem forte predileção para o sexo feminino, com uma relação de 2,8 meninas:1 menino. Cerca de $30 \%$ e $40 \%$ dos pacientes têm história familiar de doença tireoidiana autoimune. Essa patologia acontece com mais frequente na adolescência, mas pode ocorrer em qualquer idade. Um aumento da frequência de TLC ocorre em crianças com trissomia do cromossomo 21, síndrome de Turner, síndrome de Klinefelter e outras doenças autoimunes, incluindo diabetes mellitus tipo 1 . É importante ressaltar que nem todos os casos de TLC progridem para hipotireoidismo franco, mas esses pacientes podem apresentar um alto risco quando comparado com a população normal (SOUSA et al., 2013).

Os sinais de hipotireoidismo adquirido incluem: diminuição da velocidade de crescimento, bradicardia, obesidade leve, proporções corporais (relação segmento superior/inferior) imaturas, cabelo seco, rouquidão, atraso da dentição, desenvolvimento sexual precoce, pele fria e com impregnação carotenemia, unhas quebradiças e atraso na fase de relaxamento dos reflexos tendinosos profundos. O bócio pode ser secundário aos efeitos dos anticorpos estimuladores do receptor do TSH, a infiltração linfocítica inflamatória ou hiperplasia compensatória à diminuição das concentrações de T4 e aumento do TSH (SOUSA et al., 2013).

\section{Investigação laboratorial e por imagem}

Dosagem de TSH: é o teste de triagem mais sensível para estabelecer o diagnóstico de hipotireoidismo primário. Dosagem de TSH também é um ótimo parâmetro para orientar a dose de reposição de hormônio tireoidiano, exceto em pacientes com hipotireoidismo secundário. Dosagem de T4: está presente no soro nas formas livre (T4 livre) e ligado a TBG (T4 total). Ensaios para T4 total medem-no em ambos os estados e são úteis para estabelecer o diagnóstico de hipotireoidismo e avaliar a resposta ao tratamento. Os valores séricos de T4 total e T4 livre são baixos em pacientes com hipotireoidismo primário (SOUSA et al., 2013).

Medida da concentração sérica de T3, total ou livre, não é necessária para confirmar o diagnóstico de hipotireoidismo. Radiografia de mão e punho esquerdos: para avaliar idade óssea. A maturação óssea 
geralmente está atrasada em relação à idade cronológica e se correlaciona com a época de início do hipotireoidismo, exceto nos casos em que a presença de bócio chama a atenção para o diagnóstico mais rápido (menor tempo entre o início dos sinais e sintomas e o diagnóstico) (SOUSA et al., 2013).

\section{Tratamento}

As metas terapêuticas são normalização da função tireoidiana e eliminação dos sinais e sintomas de hipotireoidismo. A terapia no HC deve propiciar desenvolvimento normal e no hipotireoidismo adquirido, corrigir o crescimento, eliminar sinais de pseudopuberdade precoce e galactorreia (SOUSA et al., 2013).

No hipotireoidismo congênito o medicamento deve ser administrado de preferência entre as mamadas, principalmente se a criança fizer uso de fórmula com soja ou de ferro, que interferem com a absorção da levotiroxina. Os comprimidos de levotiroxina são facilmente triturados e podem ser administrados em uma colher com pequena quantidade de água, de fórmula ou cereal (SOUSA et al., 2013).

$\mathrm{Na}$ criança com diagnóstico de $\mathrm{HC}$, a partir dos três anos de idade, quando o cérebro já apresenta desenvolvimento adequado, assim como suas funções motoras, pode-se suspender a medicação por cerca de 30 dias para reavaliação com dosagens hormonais ou testes mais específicos (SOUSA et al., 2013).

Crianças com hipotireoidismo adquirido que recebem tratamento adequado pelo menos cinco anos antes do início da puberdade em geral atingem uma estatura final adulta compatível com seu potencial genético. Tratamento com dose excessiva de levotiroxina não melhora a recuperação do crescimento e pode comprometer a estatura final adulta, por avançar a maturação óssea (SOUSA et al., 2013).

\section{CONCLUSÃO}

Os hormônios da tireoide são necessários para o crescimento e o desenvolvimento normal das crianças, e bêbes que nascem com deficiência na tireoide terão o desenvolvimento atrasado, a não ser que sejam tratados rapidamente. O hipotireoidismo se caracteriza pela produção diminuída de hormônios tireoidianos (HT), ou raramente, como um estado clínico resultante da produção de uma ação inadequada destes hormônios em nível celular. Neonatologistas e pediatras deparam-se com problemas no desenvolvimento da criança, muitos dos quais já começam em vida intra-uterina. Portanto, a clínica varia de acordo com a faixa etária em que ocorre a doença. Atualmente, com a triagem neonatal, neonatologistas e pediatras podem evitar danos irreversíveis com tratamento precoce. 


\section{REFERÊNCIAS}

AGUILÁ, N. Curell. Hipotiroidismo en adolescentes. Pediatra. Unitat d'Adolescents. Institut Universitari Dexeus-Barcelona. Fecha de recepción: 17 febrero 2013. Fecha de publicación: 20 abril 2013. Adolescere 2013; XII(1):24-31. 24.

ANASTI JN, Flack MR, Froehlich J, Nelson LM, Nisula BC. A potential novel mechanism for precocious puberty in juvenile hypothyroidism. J Clin Endocrinol Metab. 1995;80:276-9

ARES S., Escobar-Morreale, HF, Quero J, Duran S, Presas MJ, Herruzo R, et al. Neonatal hypothyroxinemia: effects of iodine intake and premature birth. J Clin Endicrinol Metab. 1997;82:1704-12.

CAMANDAROBA, Marcos Pedro Guedes et al. Carcinoma papilífero da tireoide associado à tireoidite de Hashimoto: uma série de casos. Rev Bras Cancerol, v. 55, n. 3, p. 255-61, 2009.

DUNN JT. Endemic goiter and cretinism: an update on iodine status. J Pediatr Endocrinol Metab. 2001;14:1469-73.

FOLEY, TP. Disorders of the thyroid in children. In: Sperling MA, editor. Pediatric endocrinology. Philadelphia: W B Saunders; 1996. p. 171-94.

GRIFFIN, JE. The thyroid. In: Griffin JE, Ojeda SR, editors. Textbook of endocrine physiology. New York: Oxford University Press; 2004. p. 294-318.

MATIAS, Giovana Paola. Tcc-revisão de literatura:determinação dos níveis séricos de triiodotironina e tiroxina livre em obesos na cidade de renascença-pr: CASCAVEL: FACULDADE ASSIS GURGACZ, 2013.

MORREALE de Escobar G. The role of thyroid hormone in fetal neurodevelopment. J Pediatr Endocrinol Metab. 2001;14 Suppl 6:1453-62.

SETIAN N. Hipotireoidismo congênito. In: Setian N, editora. Endocrinologia pediátrica: aspectos físicos e metabólicos do recém-nascido ao adolescente. São Paulo: Sarvier; 2002. p. 259.

SETIAN N. Hypothyroidism in children: diagnosis and treatment. J Pediatr (Rio J). 2007;83(5 Suppl): S209-216. doi 10.2223/JPED.1716.

SILVERTHORN, Dee U.; Fisiologia Humana-Uma abordagem integrada. 5 ed. Porto Alegre: Artmed, 2010.

SOUZA, Micheline Abreu Rayol De; BESERRA, Izabel Calland Ricarte; GUIMARÃES, Marília Martins. Hipotireoidismo na criança. Moreira jr, Rio de janeiro, v. 49, n. 11, p.: 416-426, nov. 2013.

SZELIGA, DVM, et al. Tireoidite de Hashimoto na infância e na adolescência, estudo retrospectivo de 43 Casos. Arq Bras Endocrinol Metab 2002;46: 150-4. 


\section{NEUROPATIA PERIFÉRICA INDUZIDA POR QUIMIOTERAPIA: DESAFIOS NO CUIDADO A LONGO PRAZO DE PACIENTES ONCOLÓGICOS}

Nathalie da Costa Nascimento

Universidade Federal de Santa Maria - UFSM costtanathalie@gmail.com

Morgana dos Santos Machado

Universidade Federal de Santa Maria - UFSM momachado24@gmail.com

Suélly Krein Heuert

Universidade Federal de Santa Maria - UFSM suelly.heuert@gmail.com

\author{
Thamara Graziela Flores \\ Universidade Federal de Santa Maria - UFSM \\ thamaraflores_fisio@yahoo.com.br \\ Miriam Cabrera Corvelo Delboni \\ Universidade Federal de Santa Maria - UFSM \\ miriamdelboni@gmail.com
}

\section{RESUMO}

O câncer é uma das Doenças Crônicas Não Transmissíveis (DCNT) mais incidentes na população mundial e a quimioterapia é uma das mais importantes formas de tratamento. A quimioterapia além de destruir as células tumorais, destrói as células saudáveis dos demais tecidos, ocasionando efeitos adversos como a Neuropatia Periférica Induzida por Quimioterapia (NPIQ). A NPIQ é uma polineuropatia sensitivo-motora simétrica, bilateral, geralmente distal, de caráter progressivo, podendo ser aguda ou crônica. A presença desta neuropatia pode ocasionar alterações nos componentes sensoriais e cognitivos que possivelmente interferirão na capacidade dos pacientes realizarem suas atividades de vida diária (AVD). Estratégias farmacológicas e não-farmacológicas vêm sendo pesquisadas, porém, até o momento não se comprovou efeitos positivos na prevenção da NPIQ. Este capítulo apresentará uma breve revisão teórica sobre o tema, considerando que a NPIQ pode afetar potencialmente o desempenho ocupacional dos pacientes. Sugere-se que os profissionais estejam alertas para o relato de NPIQ, encaminhando os pacientes à equipe de reabilitação para avaliação, a fim de promover orientações e alívio dos sintomas, impactando positivamente na qualidade de vida.

\section{Palavras-chave:}

Neoplasias; Tratamento quimioterápico; Síndromes Neurotóxicas.

\begin{abstract}
Cancer is one of the most prevalent chronic noncommunicable diseases (NCDs) in the world population and chemotherapy is one of the most important forms of treatment. Chemotherapy, in addition to destroying tumor cells, destroys healthy cells in other tissues, causing adverse effects such as Chemotherapy-Induced Peripheral Neuropathy (NPIQ). CIPN is a symmetrical, sensitive, motor polyneuropathy, bilateral, usually distal, of progressive character, which may be acute or chronic. The presence of this neuropathy can cause changes in the sensory and cognitive components that will possibly interfere in the patients' ability to perform their activities of daily living (ADL). Pharmacological and non-
\end{abstract}

pharmacological strategies have been researched, however, to date, no positive effects on the prevention of CIPN have been proven. This chapter will present a brief theoretical review on the topic, considering that NPIQ can potentially affect patients' occupational performance. It is suggested that professionals be alert to the report of $N P I Q$, referring patients to the rehabilitation team for evaluation, in order to promote guidance and symptom relief, positively impacting quality of life.

\section{Keywords:}

Neoplasms; Drug Therapy; Neurotoxicity Syndromes. 


\section{INTRODUÇÃO}

Na atualidade, o câncer é uma das Doenças Crônicas Não Transmissíveis (DCNT) mais incidentes na população mundial, sendo considerado um problema de saúde pública, sobretudo nos países em desenvolvimento. Nestes países, nas próximas décadas, espera-se que o impacto na população seja o equivalente a $80 \%$ dos mais de 20 milhões de novos casos estimados para 2025 (OMS, 2015).

Com o avanço da idade, esperam-se proporções mais elevadas de casos de câncer, sendo que mais de $60 \%$ dos novos casos na população brasileira serão em idosos, visto que estes são mais suscetíveis ao seu desenvolvimento, pois além das alterações fisiológicas que o processo de envelhecimento ocasiona, apresentam maior período de exposição e acúmulo de fatores de risco ao longo da vida (INCA, 2020).

O tratamento do câncer envolve diversas modalidades, tais como cirurgia, radioterapia e quimioterapia. A quimioterapia é a utilização de substâncias químicas combinadas ou isoladas, agindo de modo sistêmico no organismo, sendo, portanto, uma das mais importantes formas de combater o câncer. Os quimioterápicos interferem nos processos de crescimento e divisão das células tumorais, impedindo a divisão e o crescimento do número celular ou bloqueando este processo. Em geral, não possuem especificidade, portanto não destroem exclusivamente as células tumorais, sendo tóxicos aos demais tecidos, ocasionando efeitos adversos (INCA, 2019).

Os principais efeitos adversos são náuseas, vômito, mucosite, alopecia, mielotoxicidade, diarreia e Neuropatia Periférica Induzida por Quimioterapia (NPIQ). A NPIQ é definida como uma complicação neurológica comum e potencialmente limitante no tratamento oncológico e é caracterizada como uma polineuropatia sensitivo-motora simétrica, bilateral, geralmente distal, de caráter progressivo, podendo ser aguda ou crônica (SIMÃO et al., 2015; CAPONERO, MONTARROYOS; TAHAMTANI, 2016).

A presença de NPIQ pode ocasionar alterações nos componentes sensoriais que possivelmente interferirão na capacidade em realizar as principais ações básicas do cotidiano, interferindo no desempenho ocupacional dessas ações e levando à privações ocupacionais para as atividades significativas dessas pessoas. Devido ao processo natural de envelhecimento, idosos submetidos à quimioterapia neurotóxica são mais suscetíveis a desenvolver os efeitos adversos da quimioterapia quando comparados aos adultos (INCA, 2019; HERSHMAN et al, 2016; CAVALETTI et al, 2019).

Além disso, atualmente não há estratégias farmacológicas e não farmacológicas cientificamente comprovadas na prevenção e controle da NPIQ, sendo, portanto, um desafio o manejo desses sintomas que podem impactar negativamente o cotidiano dessas pessoas (SCHLOSS, COLOSIMO, VITETTA, 2016). Diante do exposto, o objetivo deste capítulo é apresentar uma revisão teórica abrangente sobre o tema, visando abordar a temática e incentivar estudos futuros sobre o tema. 


\section{MÉTODOS}

O referencial teórico que compõem o presente capítulo foi realizado a partir de pesquisas nas bases de dados da Scielo, Medline, Lilacs e PUBMED. Foram incluídos artigos acerca da Neuropatia Periférica Induzida por Quimioterapia, visto que a proposta é apresentar uma atualização da revisão teórica o mais abrangente possível, sem pretensões de ser exaustiva, acerca da NPIQ e os impactos desse efeito adverso na vida das pessoas submetidas a protocolos quimioterápicos potencialmente neurotóxicos. Destaca-se que a revisão bibliográfica faz parte do projeto de pesquisa intitulado "Os efeitos da Neuropatia Periférica Induzida por Quimioterapia: Um estudo da Farmácia e Terapia Ocupacional", registrado sob o CEPE 2.699.922.

\section{RESULTADOS E DISCUSSÃO}

Estima-se para o Brasil, no biênio 2020-2022, a ocorrência de 625 mil casos novos de câncer a cada ano. Com exceção do câncer de pele não melanoma, os cânceres mais comuns em homens serão o câncer de próstata, cólon e reto, pulmão, estômago e cavidade oral. Já nas mulheres serão os cânceres de mama, cólon e reto, colo do útero, pulmão e tireoide (INCA, 2019).

As modalidades terapêuticas para o tratamento do câncer são a cirurgia, radioterapia, quimioterapia, hormonioterapia, imunoterapia, transplante de células-tronco hematopoiéticas e terapia alvo-molecular. A quimioterapia antineoplásica se sobressai por sua eficácia no combate ao câncer, devido a capacidade de tratar sistematicamente a doença com a utilização de substâncias químicas, isoladas ou em associação com outros medicamentos que intervêm em diferentes fases do ciclo celular. Por tratar-se de uma modalidade sistêmica de tratamento, isto é, atuando em diferentes regiões do corpo simultaneamente, a quimioterapia atualmente é a modalidade mais utilizada (COSTA, 2015; INCA, 2020).

A quimioterapia interfere nos processos de crescimento e divisão das células tumorais, entretanto não possui especificidade, ou seja, não destrói somente as células neoplásicas, afetando também as células saudáveis. Sendo assim, vários efeitos adversos causados pela quimioterapia costumam aparecer, como náusea, vômito, fadiga, alopecia, neurogenia, diarreia, constipação intestinal, alterações do sistema tegumentar, declínio cognitivo e neurotoxicidades (SELAMAT et al., 2014; COSTA, 2015).

Os Compostos de Coordenação de Platina (cisplatina, carboplatina e oxaliplatina) são a base do tratamento dos cânceres testiculares, ovarianos, bexiga, cabeça e pescoço, pulmão, esôfago e cólon. A oxaliplatina é usada de modo efetivo como primeira linha de tratamento no câncer colorretal tanto na forma adjuvante quanto na avançada. Os Taxanos (paclitaxel e docetaxel) exercem papel central no tratamento dos cânceres de mama, ovário, pulmão, esôfago, bexiga, cabeça e pescoço e células germinativas. Já os Alcalóides da Vinca, dentre eles a vincristina, são amplamente utilizados nas neoplasias pediátricas, como Leucemia Linfoide Aguda (LLA), Leucemia Mieloide Crônica (LMC) fase linfoblástica, linfomas não-Hodgkin e Hodgkin, tumor de Wilms, sarcomas de Ewing, neuroblastoma e rabdomiossarcoma (CAPONERO, MONTARROYOS; TAHAMTANI, 2016).

Essas classes de quimioterapia, pelos efeitos terapêuticos que possuem, embora causem efeitos adversos, como a NPIQ, dificilmente podem ser substituídas por outras classes sem que a eficácia terapêutica no controle e cura da doença não seja comprometida. A NPIQ é um efeito adverso 
relevante do ponto de vista clínico e epidemiológico, pois seus sintomas surgem logo nas primeiras infusões e se estendem durante e após o tratamento (CAPONERO, MONTARROYOS, TAHAMTANI, 2016; SIMÃO et al, 2015).

A NPIQ é a segunda complicação neurológica mais frequente ao tratamento antineoplásico, interferindo na condução dos estímulos sensoriais dos membros superiores e inferiores e região orofacial para o sistema nervoso central (SNC), na transferência de informações do SNC para o sistema nervoso periférico (SNP) e que, consequentemente, pode interferir na funcionalidade e na realização das atividades de vida diária (AVDs), comprometendo a qualidade de vida dos sujeitos (CAPONERO, MONTARROYOS, TAHAMTANI, 2016; SIMÃO et al, 2015).

Com a infusão desses quimioterápicos, estruturas do sistema nervoso são afetadas, desde as células sensoriais do Gânglio da Raiz Dorsal (GRD) até o axônio distal. No entanto, a exata fisiopatologia da NPIQ ainda não está clara e vários mecanismos têm sido estudados e propostos para as diferentes classes de quimioterápicos. O que se sabe é que, por ser menos protegido pela barreira hematoencefálica, o GRD está mais suscetível à neurotoxicidade, o que explica o quadro de alterações sensitivas que predomina nesses pacientes (HERSHMAN et al, 2016; SIMÃO et al, 2015).

A prevalência exata de NPIQ em sobreviventes de câncer é desconhecida, contudo, uma revisão sistemática e metanálise de 31 estudos com dados de 4179 pacientes resultou em uma prevalência de NPIQ de 68\% no primeiro mês após a quimioterapia, 60\% em 3 meses e 30\% aos 6 meses ou mais (SERETNY et al., 2014). Outro estudo apontou que pessoas submetidas a protocolos com Oxaliplatina relataram sintomas de NPIQ por até 11 anos após a conclusão da quimioterapia (PACHMAN et al., 2015).

A gravidade e a ocorrência da NPIQ estão diretamente relacionadas ao tipo de quimioterapia, posologia, tempo de tratamento, número de ciclos e tipo de fibra nervosa comprometida. Foi observada uma tendência para seu desenvolvimento em nervos previamente danificados devido ao uso prévio ou simultâneo de medicamentos neurotóxicos, neuropatia preexistente (neuropatia alcoólica ou diabética), uso de álcool, histórico de tabagismo e idade avançada (BREWER et al., 2015; SIMÃO et al., 2015).

Os sintomas relacionados à NPIQ são parestesia, fraqueza muscular, diminuição do feedback somatossensorial, alodinia, hiperalgesia e propriocepção reduzida, prejudicando o controle postural, equilíbrio e marcha, acarretando maior risco de quedas e mobilidade reduzida. Os sintomas afetam a região orofacial, membros superiores e inferiores numa progressão de distal para proximal e à medida que o tratamento quimioterápico tem continuidade, os sintomas tendem a piorar gradualmente (KERCKHOVE et al., 2017). A cognição também é uma das áreas afetadas pelo tratamento quimioterápico e termos como chermobrain ou brain fog são utilizados para descrever o comprometimento cognitivo de pacientes que experimentam os efeitos neurotóxicos da quimioterapia (SELAMAT et al., 2014; LANGE et al., 2019).

O Comprometimento Cognitivo Induzido por Quimioterapia (CICl) ou Comprometimento Cognitivo Relacionado ao Câncer ( $\mathrm{CRCl}$ ) é reconhecido como um dos efeitos adversos relativamente comuns dos agentes quimioterápicos, que podem ser observados pelo menos de 5 a 10 anos após a interrupção da quimioterapia. Na maioria dos casos, apresentam manifestações sutis que causam implicações a curto prazo. A incidência de $\mathrm{CICl}$ a longo prazo pode afetar uma proporção significativa de sobreviventes de câncer, com uma incidência que varia de $16 \%$ a $75 \%$. Ressaltando que estes fatores podem sofrer influências como idade, tipo e estádio da neoplasia, a dose do quimioterápico aplicado e fatores psicossociais (ARGYRIOU et al., 2012; GAMAN et al., 2016). 
O público que apresenta mais queixas relacionadas a déficits cognitivos é de sujeitos que realizaram tratamento antineoplásico para câncer de mama (SELAMAT et al., 2014). Um estudo com 53 mulheres que realizaram tratamento oncológico, com idades entre 21 a 65 anos, que tiveram diagnóstico de câncer em estágio inicial, foram acompanhadas desde o final do tratamento primário até 6 anos após sua conclusão. Ao final desse período, 14 das 53 mulheres relataram prejuízos cognitivos decorrentes da quimioterapia (VAN DYK, 2020).

Além disso, outro fator que pode acarretar déficit cognitivo são as internações recorrentes e de longo prazo que variam de acordo com o protocolo de tratamento adotado. Em conjunto, todos esses fatores impactam negativamente no cotidiano e qualidade de vida dos sujeitos (LANGE et al., 2019).

Quanto ao diagnóstico, a eletroneuromiografia (ENMG) é considerada o padrão ouro de avaliação da NPIQ, pois o comprometimento neuropático é definido pela detecção da alteração na condução nervosa, especialmente de fibras mielínicas. No entanto, esse método apresenta limitações, pois é incapaz de detectar neuropatia de fibras finas, bem como trata-se de um exame desconfortável, de alto custo e realizado por especialista em neurofisiologia clínica, raramente sendo utilizado no cenário da oncologia (SAAD et al., 2014; BREWER, 2015; MERKIES, FABER, LAURIA, 2015).

Na prática clínica diária, o diagnóstico da NPIQ é realizado mediante a exposição das queixas do paciente e da correlação direta com a administração da quimioterapia (CAPONERO, MONTARROYOS; TAHAMTANI, 2016). Com o intuito de favorecer a detecção da NPIQ, foi aplicado e validado no Brasil o QNIA-Questionário de Neurotoxicidade Induzida por Antineoplásicos - instrumento criado por Leonard e colaboradores para avaliar a neuropatia desencadeada pela oxaliplatina (LEONARD et al, 2005).

Já o diagnóstico do comprometimento cognitivo ainda é um desafio, devido à falta de instrumento padronizado e geralmente é considerado um fator binário, onde os sujeitos podem ou não ser prejudicados, o que dificilmente será preciso devido à complexidade da função cognitiva (KESSLER et al., 2020).

Considerando os dados apresentados ao longo deste capítulo, observa-se que a quimioterapia potencialmente acarreta alterações nos componentes sensoriais e cognitivos, interferindo diretamente no desempenho ocupacional. Tal situação também poderá interferir no desempenho das Atividades de Vida Diária, limitando a independência dos sujeitos no cotidiano, visto que os sintomas podem persistir durante meses e até anos após a conclusão do tratamento, sendo irreversíveis e levando a incapacidades de longa duração, podendo prejudicar significativamente a qualidade de vida.

Sendo assim, o impacto mais importante da NPIQ sobre o tratamento do câncer é o fato de esta ser uma síndrome dose limitante, isto é, os sintomas podem evoluir a tal ponto que o sujeito não consegue mais conviver com eles. Quando isso acontece, é necessário reduzir a dose do antineoplásico e, em alguns casos, a interrupção do tratamento, independente dos benefícios que se poderia ter no controle/cura da doença. Sendo assim, embora a quimioterapia seja a esperança de cura, ela pode acarretar efeitos adversos irreversíveis na vida dos sujeitos (DUREGON et al., 2018).

Portanto, a neurotoxicidade pode prejudicar o desempenho e o retorno de atividades significativas aos sujeitos, podendo gerar preocupações com a continuidade do cuidado consigo e com os familiares, principalmente quando o sujeito em questão é o provedor da família. Além disso, o trabalho também atende às necessidades mais complexas, como pertencer a um grupo, reconhecimento social e valorização pessoal (CAVALETTI et al., 2019). 
Pensando nestas alterações causadas pela NPIQ, estratégias farmacológicas e não-farmacológicas têm sido amplamente pesquisadas, buscando encontrar formas para amenizar, prevenir e tratar os sintomas. Dentre algumas das substâncias estudadas até o momento e que não apresentaram resultados que indiquem seu uso, estão o Cálcio e Magnésio, vitamina E, antidepressivo tricíclico, anticonvulsivante ou inibidores seletivos da recaptação da serotonina e da noradrenalina e Glutationa. Essas substâncias interferiram na ação terapêutica dos quimioterápicos e/ou causaram reações adversas. A duloxetina foi eficaz somente no tratamento da dor neuropática, sendo assim, atualmente nenhum agente farmacológico foi considerado benéfico na prevenção ou tratamento da NPIQ (SCHLOSS, COLOSIMO, VITETTA, 2016; SIMÃO et al., 2015).

Ademais, estratégias não farmacológicas têm sido utilizadas para amenizar os sintomas e educar os sujeitos para evitar lesões secundárias, tais como a Terapia Ocupacional, Acupuntura, Fisioterapia, massagens e atividade física, mas os benefícios precisam ser confirmados em estudos randomizados e controlados, pois o modo do exercício, a intensidade e a frequência ideais ainda são desconhecidos (DUREGON et al., 2018).

Tendo em vista o número crescente de sobreviventes a longo prazo do câncer, decorrentes do aprimoramento do tratamento, é de se considerar a avaliação da extensão da NPIQ e do declínio cognitivo, sendo necessário um acompanhamento constante dos sujeitos submetidos a protocolos neurotóxicos, pois a capacidade de realizar atividades funcionais com independência é fundamental para manter a qualidade de vida e evitar morbimortalidade prematura.

\section{CONSIDERAÇÕES FINAIS}

A avaliação dos componentes cognitivos, sensoriais e o desempenho ocupacional é de fundamental importância para o acompanhamento da saúde e qualidade de vida dos sujeitos, podendo assim detectar alterações nesses domínios previamente, visto que a saúde está mais relacionada a capacidade de realizar as ocupações com independência e de modo seguro do que com a ausência de doenças. Além disso, a presença de incapacidades é o principal preditor de mortalidade em idosos, o que a longo prazo pode ocasionar em hospitalização e institucionalização.

A NPIQ pode afetar potencialmente o desempenho ocupacional de adultos e idosos, visto as alterações cognitivas e de sensibilidade decorrentes da neurotoxicidade. Além disso, a NPIQ ainda apresenta aspectos não esclarecidos, que precisam ser abordados em pesquisas futuras, como as diferenças na incidência, os fatores de risco e tratamentos farmacológicos e não farmacológicos, inclusive a incidência da NPIQ anos após a conclusão do tratamento, de acordo com as diferentes classes de quimioterapia neurotóxica. Sugere-se que a equipe esteja alerta e sensível para esses sintomas relatados pelos pacientes e considerem encaminhamentos à equipe de reabilitação já citada anteriormente. A fim de promover melhor qualidade de vida no alívio dos sintomas e orientações ocupacionais específicas a cada caso, evitando a piora do quadro depressivo devido a impossibilidade de se fazer as atividades significativas para cada pessoa. 


\section{REFERÊNCIAS}

ARGYRIOU, A. A. et al. Peripheral neurotoxicity of oxaliplatin in combination with 5-fluorouracil (FOLFOX) or capecitabine (XELOX): a prospective evaluation of 150 colorectal cancer patients. Annals of Oncology. v. 23, n.12, p. 3116-22, 2012. DOI: https://doi.org/10.1093/annonc/mds208

BREWER, J. R.; MORRISON, G.; DOLAN, M. E.; FLEMING, G. F. Chemotherapy-induced peripheral neuropathy: Current status and progress. Gynecologic Oncology. v. 140. n.1. p.176-83, 2015. DOI: 10.1016/j.ygyno.2015.11.011.

CAPONERO, R.; MONTARROYOS, E. S.; TAHAMTANI, S. M. M. Post-chemotherapy neuropathy. Revista Dor. v.17, 2016. DOI 10.5935/1806-0013.20160049.

CAVALETTI, G. et al. Chemotherapy-induced peripheral neurotoxicity: A multifaceted, still unsolved issue. Journal of the Peripheral Nervous System. v. 24. n. 2. p. 6-12, 2019. DOI: 10.1111/jns.12337

COSTA, T. C.; LOPES, M.; ANJOS, A. C. Y. dos; ZAGO, M. M. F. Neuropatia periférica induzida pela quimioterapia: revisão integrativa da literatura. Revista da Escola de Enfermagem da USP, v.49, n.2, p. 335-345, 2015. DOI: 10.1590/S0080-623420150000200020

DUREGON, F. et al. Effects of exercise on cancer patients suffering chemotherapy-induced peripheral neuropathy undergoing treatment: A systematic review. Critical reviews in oncology/hematology. v. 121. p. 90-100, 2018. DOI: 10.1016/j.critrevonc.2017.11.002.

GAMAN, Amelia M. et al. The Role of Oxidative Stress in Etiopathogenesis of Chemotherapy Induced Cognitive Impairment (CICI) - "Chemobrain". Aging and Disease, v. 7, n. 3, p. 302-312, 2016. DOI: 10.14336/AD.2015.1022

HERSHMAN, D. L. et al. Comorbidities and Risk of Chemotherapy-Induced Peripheral Neuropathy Among Participants 65 Years or Older in Southwest Oncology Group Clinical Trials. Journal of Clinical Oncology. v. 34. n. 25. p. 3014-22, 2016. DOI: $10.1200 / J C O .2015 .66 .2346$

INSTITUTO NACIONAL DE CÂNCER JOSÉ ALENCAR GOMES DA SILVA, INCA. ABC do câncer: abordagens básicas para o controle do câncer/Instituto Nacional de Câncer José Alencar Gomes da Silva. Ministério da Saúde. 5 ed. Rio de Janeiro: INCA, 2020. Disponível em: < https://www.inca.gov.br/sites/ufu.sti.inca.local/ files//media/document//livro-abc-4-edicao.pdf>.

Estimativa 2020: Incidência de câncer no Brasil. Ministério da Saúde. 6 ed. Rio de Janeiro: INCA, 2019. Disponível em: <https://www.inca.gov.br/sites/ufu.sti.inca.local/files//media/document//livro-abc-6edicao-2020.pdf>.

KERCKHOVE N, Collin A, Condé S, Chaleteix C, Pezet D, Balayssac D. Long-Term Effects, Pathophysiological Mechanisms, and Risk Factors of Chemotherapy-Induced Peripheral Neuropathies: A Comprehensive Literature Review. Frontiers in pharmacology. v.8. n. 86. p.1-17, 2017. DOI: 10.3389/fphar.2017.00086

KESSLER, Sheli R. et al. Functional connectome biotypes of chemotherapy-related cognitive impairment. Journal of Cancer SurvivorShip. Journal of Cancer Survivorship. v. 14, p. 483-493, 2020. DOI: https://doi.org/10.1007/s11764-020-00863-1

LANGE, M. et al. Cancer-related cognitive impairment: an update on state of the art, detection, and management strategies in câncer survivors. Annals of Oncology, v. 30, n.12, p. 1925-1940, 2019. DOI: 10.1093/annonc/mdz410

LEONARD, G. D.; WRIGHT, M. A.; QUINN, M. G.; FIORAVANTI, S.; HAROLD, N.; SHULER, B.; THOMAS, R. R.; GREM, J.L. Survey of oxaliplatin-associated neurotoxicity using an interview-based questionnaire in patients with metastatic colorectal cancer. BMC Cancer, Oxford, v. 5, p. 116, 2005. DOI: 10.1186/1471-2407-5-116 
MERKIES, I. S. J. ; FABER, C.G.; LAURIA, G. Advances in diagnostics and outcome measures in peripheral neuropathies. Neuroscience Letters, Limerick, v. 596, p. 3-13, 2015. DOI: 10.1016/j.neulet.2015.02.038

ORGANIZAÇÃO MUNDIAL DA SAÚDE. Relatório mundial de envelhecimento e saúde. 2015. Disponível em: <https://sbgg.org.br/wp-content/uploads/2015/10/OMS-ENVELHECIMENTO-2015-port.pdf>.

PACHMAN DR et al. Clinical Course of Oxaliplatin-Induced Neuropathy: Results From the Randomized Phase III Trial N08CB (Alliance). Journal of clinical oncology. v.33. n.30. p. 3416-3422, 2015. DOI: 10.1200/JCO.2014.58.8533

SAAD, M.; TAFANI, C.; PSIMARAS, D.; RICARD, D. Chemotherapy-induced peripheral neuropathy in the adult. Current Opinion Oncology, v. 26, p. 634-641, 2014. DOI:10.1097/CCO.0000000000000139

SCHLOSS, J., COLOSIMO, M., VITETTA, L. New Insights into Potential Prevention and Management Options for Chemotherapy- Induced Peripheral Neuropathy. Asia Pacific Journal Oncology Nursing. v.3. n.1. p.73-85, 2016. DOI: $10.4103 / 2347-5625.170977$

SELAMAT, M.H., LOH, S.Y., MACKENZIE, L., VARDY, J. Chemobrain Experienced by Breast Cancer Survivors: A MetaEthnography Study Investigating Research and Care Implications. Plos One, v.9, n.9, 2014. DOI: 10.1371/journal.pone.0108002

SERETNY, M.; CURRIE, G. L.; SENA, E. S.; RAMNARINE, S.; GRANT, R.; MACLEOD, M. R., et al. Incidence, prevalence, and predictors of chemotherapy-induced peripheral neuropathy: A systematic review and meta-analysis. Pain. v.155, n.12, p. 2461-70, 2014. DOI: 10.1016/j.pain.2014.09.020

SIMÃO DA da S, Murad M, Martins C, Fernandes VC, Captein KM, Teixeira AL. Neuropatia Periférica induzida por quimioterápicos: revisão para a prática clínica. Revista Dor. v.16, n.3, p.215-220, 2015. DOI: https://doi.org/10.5935/1806-0013.20150043.

VAN DYK, K., CRESPI, C.M., PETERSEN, L.,GANZ, P.A. Identifying Cancer-Related Cognitive Impairment Using the FACT-Cog Perceived Cognitive Impairment. JNCI Cancer Spectrum, v.4, n.1, 2020. DOI: 10.1093/jncics/pkz099 


\section{UM OLHAR FENOMENOLÓGICO SOBRE A ANGÚSTIA EXISTENCIAL EM PACIENTES HOSPITALIZADOS E A PSICOLOGIA HOSPITALAR}

Ágnes Cristina da Silva Pala

Faculdade Maria Thereza - FAMATh; agnespala@gmail.com

Rose Mary Costa Rosa Andrade Silva

Escola de Enfermagem Aurora de Afonso Costa - UFF; roserosauff@gmail.com

Eliane Ramos Pereira

Escola de Enfermagem Aurora de Afonso Costa - UFF; elianeramos.uff@gmail.com

\author{
Isadora Pinto Flores \\ Universidade Federal Fluminense - UFF; isadoraflores@id.uff.br \\ Vanessa Carine Gil de Alcântara \\ Faculdade Maria Thereza - FAMATh; \\ vanessagilpsicologa@hotmail.com \\ Vilza Aparecida Handan de Deus \\ Universidade Estácio de Sá/RJ; vilzahandanbueno@gmail.com
}

\begin{abstract}
RESUMO
O presente artigo propõe identificar a vivência da angústia existencial em pacientes internados em instituições hospitalares e possíveis reflexões despertadas a partir da experiência da hospitalização. Através de pesquisa exploratória, utilizando o método fenomenológico e a pesquisa bibliográfica, são apresentados possíveis diálogos da noção de angústia pelo viés da Fenomenologia de Martin Heidegger (1889-1976) na prática da Psicologia Hospitalar. A compreensão da angústia, enquanto disposição afetiva fundamental, remete o homem à sua condição finita e, por isto, a necessidade de zelar pela realização de seu projeto existencial. A prática da Psicologia Hospitalar e
\end{abstract}

sua relevância para os cuidados em saúde são importantes de serem apresentados pelo caráter estratégico durante a internação do paciente e as consequências geradas e vivenciadas neste período. 0 psicólogo hospitalar pode utilizar o relato do paciente experienciando a angústia existencial para convidá-lo à meditação do que está sendo feito da Existência e recordá-lo de sua finitude, além de abrir caminhos para uma vida mais autêntica.

\section{Palavras-chave:}

Paciente; Psicologia Hospitalar; Angústia Existencial; Fenomenologia; Fenômenos Psicológicos.

\section{ABSTRACT \\ This article proposes to identify the experience of existential distress in patients hospitalized in hospital institutions and possible reflections aroused from the experience of hospitalization. Through exploratory research, using the phenomenological method and the bibliographic research, possible dialogues of the notion of anguish are presented through the bias of Martin Heidegger's Phenomenology (1889-1976) in the practice of Hospital Psychology. The understanding of anguish, as a fundamental affective disposition, brings man to his finite condition and, therefore, the need to ensure the realization of his existential project. The practice of Hospital Psychology and its relevance to}

health care are important to be presented due to the strategic character during the patient's hospitalization and the consequences generated and experienced in this period. The hospital psychologist can use the patient's report experiencing the existential anguish to invite him to meditate on what is being done in Existence and to remind him of his finitude, in addition to opening paths for a more authentic life.

\section{Keywords:}

Patient; Hospital Psychology; Existential Anguish; Phenomenology; Psychological Phenomena. 


\section{INTRODUÇÃO}

O movimento filosófico denominado Fenomenologia surge com contribuições e ensinamentos valiosos de Edmund Husserl (1859-1938): o método da redução eidética ou fenomenológica "método que elimina dos fenômenos suas características reais ou empíricas (supérfluas)" (Prado, 2005, p.46) - juntamente com a epoché - suspensão de juízo e idéias preconcebidas, sendo uma atitude contemplativa dos fenômenos - descobrindo a intencionalidade da consciência. " $A$ consciência é caracterizada pela intencionalidade porque é sempre a consciência de alguma coisa." (Prado, 2005, p. 46). A Fenomenologia é uma atitude de reflexão do fenômeno que se mostra para o Ser, na relação que estabelece com os outros, no mundo. É um constante desvelamento entre o manifesto e o não-manifesto. $O$ interesse para a Fenomenologia não é o mundo que existe, mas o modo como o conhecimento do mundo se realiza para cada pessoa.

O sentido conotativo para o vocábulo angústia é atrelado a "aperto no peito", a situação difícil. É, normalmente, vinculada a situações de extremo desgaste emocional de uma pessoa ou de um grupo, relacionado a um tensionamento, desassossego, uma ânsia ou agonia. Não é uma experiência considerada "positiva", agradável ou necessária. São vivências que buscam ser evitadas ou minimizadas.

Sillamy (1998) define angústia como "uma sensação penosa de profundo mal-estar, determinada pela impressão difusa de um perigo vago, iminente, diante do qual se está desarmado e impotente.... A angústia não é, em si mesma, um fenômeno patológico. Ela está ligada à condição humana." (p. 22) A angústia é compreendida como uma vivência penosa ao homem, por proporcionar a constatação de um perigo iminente - compreendido através de Heidegger (2002) e Medard Boss (1981) que toda angústia é, no fundo, angústia de morte. Tal constatação, normalmente, gera conflito e revolta por não poder realizar todos os planos para a Vida, além de reviver o sentimento de desamparo e abandono por perceber a morte como um fenômeno solitário. A angústia não é um fenômeno patológico e, portanto, passível de ser amenizado mas, não solucionado com medicação. Esta angústia é a existencial e auxilia no próprio transitar da vida, no movimento de trazer de volta o homem à refletir sobre seus projetos, planos e sonhos a serem realizados.

A Psicologia Hospitalar possui grande importância quanto à "minimização do sofrimento provocado pela hospitalização" (Angerami-Camon, 2002b, p.23). O enfoque no sofrimento ocasionado pela hospitalização e nas consequências da patologia em sua existência - desde sequelas físicas à decorrências emocionais da internação - é uma característica singular e diferencial do trabalho do psicólogo hospitalar em comparação ao psicólogo clínico, restrito ao consultório.

Abordar a angústia com a prática psi numa instituição hospitalar é, o tempo todo, apostar na possibilidade de fazer diferença no 'ambiente e casa do médico'. Trazer o tema da angústia num momento considerado caótico da Saúde é apostar que, apesar de tudo, consegue-se criar, abrir novos caminhos e novas formas de promoção de saúde e exigir melhores condições de trabalho dos profissionais de Saúde e de acolhimento aos pacientes e familiares. No movimento gerado pela angústia, vê-se também o comprometimento do profissional com a Ética profissional. 
Este estudo foi construído com pesquisa qualitativa que "busca uma compreensão particular daquilo que estuda" (Martins \& Bicudo, 1989), através de pesquisa bibliográfica definida por "uma coleta de material disponível e já existente, o qual pode ser selecionado a partir de livros, de revistas, de periódicos especializados e de documentos diversos" (Bastos, 2009). O método utilizado é o fenomenológico, compreendido como exercício da epoché - pôr o objeto de estudo ou o fenômeno, em suspensão, é a descrição de "como" o fenômeno se mostra, é desvelado pelo pesquisador. Este "orienta-se por um sentido, isto é, pelo conhecimento imediato, intuitivo e lógico que tem do fenômeno a ser investigado..." (Martins \& Bicudo, 1989).

A compreensão "está sempre sintonizada com o humor ... no modo possível de conhecimento entre outros, que se distingue, por exemplo, do esclarecimento." (Heidegger, 2002). "O verdadeiro caráter do método fenomenológico não pode ser explicitado fora do movimento e da dinâmica da própria análise do objeto." (Stein, 1973). A compreensão é fundamental à realização da pesquisa, pois o "método se determina a partir da coisa mesma." (Stein, 1973). A compreensão "está sempre sintonizada com o humor [...] no modo possível de conhecimento entre outros, que se distingue, por exemplo, do esclarecimento." (Heidegger, 2002). O sentido de verdade a ser compreendido neste método vem de aletheia-velamento e desvelamento de sentidos para os fenômenos observados.

\section{Algumas noções fenomenológicas heideggerianas}

Martin Heidegger (1889-1976), filósofo alemão, foi aluno e assistente de Husserl; é um dos expoentes da Fenomenologia. Em sua obra 'Ser e Tempo', publicada em 1927, é proposto outros modos de compreensão do mundo e dos entes que o compõe, para fazer um questionamento diferente, até então, no campo filosófico a respeito do homem. Ao invés de preocupar-se com "o que é o ser ?", "o que é o homem ?", Heidegger propôs "qual o sentido do ser?". Compreende-se que o sentido da existência humana não éúnico e, não há um padrão a ser seguido e/ou almejado. Com tal reflexão, percebe-se a mudança de o Ser não ter uma única essência que o define ao longo de toda a sua existência. Ao contrário, o Ser construirá suas essências ao longo de sua vida, através do convívio com outros entes no mundo.

Heidegger, em 'Ser e Tempo', apresentou considerações para o que seja fenômeno: originário do termo "phainomenon ... aquilo que se mostra por si mesmo" (Nunes, 2002) que aparece ao homem.

Mas, fenomenologicamente, o que deve ser chamado de fenômeno é aquilo que imediata e regularmente justo não se mostra, aquilo que, ao contrário, do que imediata e regularmente se mostra, está oculto, mas é algo que pertence por essência ao que imediata e regularmente se mostra, de tal sorte que constitui seu sentido e fundamento (Rodrigues, Barreiro, Garcez \& Pala, 2016, p. 683)

Neste caso, o sentido formal de Fenomenologia é permitir ver o que se mostra, tal como se mostra por si mesmo, efetivamente por si mesmo. A compreensão da noção de fenômeno desvela, indiretamente, outra noção fenomenológica: mundo.

"Mundo", primordialmente, não é uma caixa noética que contém tudo o que existe, nem mesmo um espaço homogêneo onde se encontra tudo o que existe.... O mundo, no qual o ser humano existe, é anterior ao mundo espacial, topográfico, interior (Spanoudis, 1981, p. 16, citado por, Pala, Fonseca, Rocha \& Aguiar, 2016, p. 509).

Mundo é o somatório de todos os entes - entes simplesmente-dados e entes existentes. É a estrutura de sentido dos entes existentes, sendo a tessitura mais ampla e complexa de sentidos. "O modo de ser dos entes não humanos é denominado 'ser simplesmente dado' porque o que eles são, o seu sentido, 
nunca está em jogo em seu devir temporal" (Sá, 2004, p. 325-326). Os entes simplesmente-dados são tudo que há no mundo: objetos, plantas, animais, materiais tecnológicos, etc. - com exceção ao homem. Suas características são fornecidas e criadas pelo ente existente-normalmente, é quem dará o nome e a(s) função(ões) ao(s) objeto(s) e, quem, em muitos casos, criará tais entes.

Os entes existentes são os que possuem o modo de ser em constante devir, sendo denominado por Heidegger (2002) de Dasein: "Esse ente que cada um de nós somos e que, entre outras, possui em seu ser a possibilidade de questionar, nós o designamos com o termo de presença." (p. 33). Na edição brasileira de Ser e Tempo, presença é a tradução para Dasein, também traduzido por pre-sença; Ser-aí; Sendo. Da- de Dasein, traduzido por 'aí', pode ser compreendido como mundo enquanto tessitura de sentidos. Por isto, Dasein também tem sentido de 'ser-no-mundo' e, somente pode ser ser-no-mundo se estiver em contato, em relação com outros entes. Dasein é, também, compreendido como 'ser-nomundo-com-outros' ou, simplesmente, 'ser-com'.

Heidegger (2002) apresenta o modo de Dasein relacionar-se com os entes simplesmente-dados e com outros Dasein nomeando-o como Sorge - palavra alemã traduzida para a Língua Portuguesa como cura ou cuidado. Cuidado Ocupação é o modo de relação de Dasein com os entes simplesmentedados. Cuidado Preocupação é o modo de relação de Dasein com outro Dasein. A partir das leituras de Heidegger (2002) e Sá (2004), Pala (2008) informa os dois modos do cuidado preocupação:

Substituição é o modo de preocupação em que o Dasein, ao relacionar-se com outro Dasein, tende a substituí-lo, livrando o outro do cuidado. É um colocar-se no lugar do outro, transpondo os obstáculos e dificuldades para ele... Já a anteposição é o modo de preocupação em que o Dasein, ao relacionar-se com outro Dasein, tende a antepor-se, colocando-se à frente do outro para, de lá, devolvê-lo ao cuidado de simesmo. (p. 78)

A substituição e a anteposição não são vivenciados de modo sequencial. Eles estão presentes no cotidiano de Dasein: substitui e é substituído em várias ações e, consequentemente, relações; anteposiciona-se e "proporciona" a anteposição aos outros. Em alguns momentos, a substituição pode ser vista como aprisionadora por não permitir que Dasein aproprie-se de seu próprio cuidado. Já a anteposição possui a característica libertadora, por devolver o exercício do cuidado ao Dasein, dispensando a substituição.

Ontologicamente, por ser cuidado, Dasein está em relação com o mundo. Quando algo não ocorre segundo as expectativas e o remete a revisitar seus projetos existenciais, pode-se estar experimentando a angústia existencial (Angst).

Na contribuição de Ferreira (1999), encontra-se o sentido denotativo de angústia: "Estreiteza, limite de espaço ou de tempo" (p. 142). Na pesquisa etimológica, encontra-se em Koehler (1957):

Angustiae: f. (angustus) passo ou lugar estreito: desfiladeiro; istmo; estreito do mar; brevidade do tempo; limitação; apuros, dificuldade, mesquinhez, estreiteza de vistas. Angustio (angustus) apertar, estreitar; atemorizar, angustiar, pôr em apuros; na v. p., serangustiado, atemorizar-se; angustiatum esse, estar em apuros.

Angusto (angustus) estreitar, restringir; o mesmo que angustio (v.) (p. 56)

Brevidade do tempo e limitação remetem à reflexão do sentido ontológico heideggeriano de angústia: ao ser acometido por ela, o homem é remetido à sua finitude, à brevidade do tempo da Existência - não se é imortal; é mortal sem saber quando será o momento final de sua própria vida. Estar em contato com a brevidade e limitação da Existência pode fazer com que o homem atente-se para a realização de seu projeto existencial. Estreitar a percepção para suas questões, para a pessoalidade e autenticidade ao invés de estar voltado para as questões da impessoalidade e da inautencidade. 
Segundo Kierkegaard, determinação que revela a condição espiritual do homem, caso se manifeste psicologicamente de maneira ambígua e o desperte para a possibilidade de ser livre. Segundo Heidegger, disposição afetiva pela qual se revela ao homem o nada absoluto sobre o qual se configura a existência (Ferreira, 1999, p.142).

Ferreira (1999) faz menção ao filósofo dinamarquês Sören Kierkegaard (1813-1855), precursor do Existencialismo, trazendo um sentido filosófico para angústia, enquanto condição facilitadora do homem vivenciar a possibilidade de ser livre. "A angústia é a realidade da liberdade como puro possível." (Kierkegaard, 1968). A angústia constitui o possível da liberdade; daí o homem pode reconhecer-se a partir dela, certo de sua finitude e conhecedor de suas ilusões.

O homem, na angústia, é constituído pelas possibilidades - ou seja, pelo caráter de indeterminação, por sua situação de abertura... Mobilizado pela angústia, o homem, prosseguindo seu caminho, pode enfrentar estes horrores sem desvios e de forma honesta consigo mesmo, abstendo-se de esconder-se nas possibilidades de êxito. (Calvo de Feijoo, Mattar, Lopez Feijoo, Lessa \& Protasio, 2013, p. 40-41)

Além de Kierkegaard, Ferreira (1999) também cita Heidegger, a respeito da angústia enquanto algo que revela a indeterminação e a finitude da Existência ao ser humano.

\section{A noção de angústia (Angst) segundo a Fenomenologia}

Ao retornar à tradução de Dasein por Ser-aí, o 'aí' pode ser compreendido como mundo, espaço de significação. Por estar em constante relação com o mundo - seja com entes simplesmente-dados ou existentes - observa-se que Dasein é cuidado, é relação, é ser-com. Ao estar em relação com o mundo e algo não funcionar como esperado, surge a possibilidade de desvelar novos sentidos; com isto, a ilusão de uma natureza dada é desfeita, surgindo o inesperado: o fenômeno da angústia (Angst). Comte-Sponville (1997) alerta a "angústia existencial não é uma doença.", assumindo um sentido diferenciado do que corriqueiramente o termo remete como uma experiência possível e crucial de ser evitada, aliviada ou abolida, associada a uma condição patológica.

A vida não é uma doença, nem a morte, nem, pois, a angústia que ambas inspiram, pelo menos esta angústia, que não impede de viver, que não impede pensar, mas nasce, ao contrário, do fato de que se vive e pensa como se pode, com todos os riscos, sem saber (se soubéssemos viver e pensar, que restaria para pensar e para viver ?), sem querer poder aprender verdadeiramente, ou tarde demais para que isso possa servir por muito tempo ou mudar o essencial (Comte-Sponville, 1997, p.18).

O fenômeno da angústia é a abertura para o desvelar de novos sentidos. "A angústia passa aqui a ser concebida como uma valiosa experiência que emerge quando tomamos consciência ou nos apropriamos da nossa condição humana, ou seja, a angústia nos defronta diante do 'nada' existencial." (Dantas, 2011, p. 63). Com esta apropriação, vivencia-se o surgimento da angústia angústia diante do nada, da falta de sentido, do vazio de significação já conhecido. É a disposição compreensiva na qual o Dasein está aberto para si mesmo.

Assim, entra-se em contato com a sua autenticidade, com o seu poder-ser mais próprio, a pura abertura de significações, retirando o Dasein de sua mesmice, ruína ou decadência por romper com a familiaridade cotidiana de resolução dos problemas. A angústia pode ser compreendida como uma "mola" que impulsiona Dasein a um movimento diferente de seu habitual. Surge o estranhamento: Dasein lembra-se de sua responsabilidade com suas escolhas, atitudes e de assumir a liberdade de poder-ser de diferentes modos. A angústia põe Dasein em contato com seu ser mais próprio, sendo 
angústia de morte. Ser-para-a-morte, outra noção heideggeriana, é a possibilidade mais própria do homem enquanto projeto. A existência humana é compreendida como projeto: não há nada certo, as vivências ocorrem com o passar dos atos e de escolhas, através do cuidado do Dasein com outros Dasein e entes simplesmente-dados.

Angústia leva Dasein a um constante movimento, desvelando a suposta máscara de totalidade e plenitude, de controle sobre o devir; é o "testemunho do fracasso de nossas certezas" (Arendt, 2008, p. 258), da incompletude do mundo e, consequentemente, das relações nele existentes. "A angústia faz parte de nossa vida. Abre-nos para o real, para o futuro, para a indistinta possibilidade de tudo." (Comte-Sponville, 1997, p.11). A angústia lança Dasein para encontro e reencontro com seus planos abandonados ou esquecidos pela impessoalidade do cotidiano da Existência e para a constatação da finitude enquanto delimitadora das inúmeras possibilidades passíveis de escolhas.

A angústia gera no Dasein um mundo inoportuno, exigindo dele (Dasein) uma abertura de sentido para ser e estar no mundo. "Acreditamos que a angústia a nos abrir para a indistinta possibilidade de tudo, revela uma abertura para uma existência mais singular" (Dantas, 2011, p. 66). A incerteza permeia a Existência e Arendt (2008) traz uma grande contribuição ao compreender a Existência com uma característica: a imprevisibilidade em viver em "pequenas ilhas de certeza num oceano de incertezas" (Arendt, 2008, p.256). Tais certezas auxiliam na construção do cotidiano impessoal mas, estão passíveis de modificações inesperadas por estarem cercadas das incertezas. Conscientizar-se das incertezas ameniza o sofrimento referente às expectativas não concretizadas.

A angústia auxilia ao retorno da Existência para o cumprimento de seu projeto, exatamente por lembrar de sua condição finita e não há "todo tempo". Porém, ao olhar para a finitude, não há o peso do entendimento da morte como término mas, "os homens, embora devam morrer, não nascem para morrer, mas para começar." (Arendt, 2008, p.258).

Constante e implícita, além de ocasional e explícita: são dois efeitos da angústia. No primeiro efeito, faz que Dasein tenha um modo-de-ser inautêntico, refugiando, acomodando-se em coisas familiares e, fechando-se ao mundo. No segundo efeito, sendo ocasional e explícita, faz que Dasein tenha um modo-de-ser autêntico, onde há um lançar-se ao desconhecido, experienciando e abrindo-se ao mundo. A angústia pode ser vista como fator importante para a existência do homem, pois a partir dela, ele posiciona-se no mundo sendo abertura e fechamento de sentido, segundo o evento que esteja experienciando, resgatando, reencontrando-se com seu projeto existencial.

O que está em jogo na angústia é o lançamento do Dasein perante a liberdade e responsabilidade de escolha de suas possibilidades próprias. Implica ao homem assumir seus atos e adaptar-se a novas situações/eventos. “... a vida é pegar ou largar, e é disso também que a angústia, dolorosamente, nos lembra. Que não há vida sem risco. Não há vida sem sofrimento. Não há vida sem morte. A angústia marca a nossa impotência..." (Comte-Sponville, 1997, p.12)

A angústia lança o homem ao encontro de seu projeto existencial, quase sempre velado pela impessoalidade do cotidiano. A vida é permeada de incertezas e, constantemente, constituída de escolhas realizadas: pegando e largando; arriscando-se e acomodando-se; sofrendo e alegrando-se com cada assumir-se, com cada apropriar-se de si. Propositalmente, utiliza-se e apontar-se para o estar-em-jogo da condição humana e sair da lógica dualista e cartesiana de um mundo binário, que exige uma escolha em detrimento da outra. A angústia remete à finitude do homem, a uma impotência de não poder realizar todas as possibilidades da Existência. 
Mas se alguém se mantém realmente aberto à essência total e não disfarçada da angústia, é aí justamente que ela abre aos seres humanos aquela dimensão de liberdade na qual, e só então, se possibilita o desdobrar das experiências do amor e da confiança. Pois a angústia... leva o estar-aí humano não só à possibilidade do maior e do mais rico, mas também, imediatamente, à possibilidade do totalmente diferente diante de tudo que, antes de mais nada é, e que como algo que é, tem, ainda assim, seus limites restritivos. Em outras palavras, ela ainda abre para a dimensão do "Não-Estar" do "Nada" que abriga tudo dentro de si, e de tal forma que ele tanto pode encobrir como também desvelar-nos e desvelar as coisas do nosso mundo (Boss, 1981, p.36).

A angústia existencial possibilita Dasein a ter experiências mais autênticas referentes ao seu projeto existencial. Ser fiel ao próprio projeto é proporcionar-se vivências de amor, confiança e liberdade isto não é sinônimo de ações e atitudes simplistas e aceitas por todas as pessoas que compõe o mundo desta Existência. Na maioria das vezes, uma atitude autêntica rompe com vínculos e laços caracterizados pela decadência ou ruína de Dasein através do que Heidegger (2002) explicita nos § 35 38 de Ser e Tempo como falatório, escritório, curiosidade e ambiguidade. A decadência, enquanto estrutura ontológica, é característica do Dasein mergulhado no cotidiano impessoal, afastando-se de seu projeto existencial. A angústia proporciona ao Dasein o desvelar de possibilidades; um olhar para a própria pessoalidade - um sair da cotidianidade e do velamento de seu Ser mais próprio em prol do resgate da realização de seu projeto e, também, do desvelamento de novos modos de ser e estar no mundo e do próprio mundo enquanto horizonte de sentido.

Medard Boss (1903-1990), psiquiatra suíço e colaborador de Heidegger, traz reflexões históricas da compreensão dos termos angústia e culpa. "Cada angústia humana tem um 'de quê', do qual ela tem 'medo' e um 'pelo quê', pelo qual ela teme.... Toda angústia é fundamentalmente medo da morte, do não-poder-mais-estar-aqui..." (Boss, 1981, p. 26;33) A angústia tem um de quê e pelo quê se tem medo. Inspirado em Heidegger, Boss explica que este medo é da morte, da finitude, do não-estarmais-no-mundo como ser-com. Deste modo, a angústia provoca algum tipo de movimento no indivíduo a voltar o seu olhar para a própria Existência e retomar e/ou realizar seu projeto existencial pois há o medo de não estar mais aqui e realizá-lo em função de se ser finito, mortal e não saber quando irá findar a própria vida. Conforme acima citada, Arendt (2008, p. 258) nos ensina “... os homens, embora devam morrer, não nascem para morrer, mas para começar", podendo ser compreendido como cada retomada de seu projeto existencial esquecido, abandonado e/ou adiado por outras atividades/ações da impessoalidade cotidiana.

Nas situações cotidianas de internação hospitalar, percebe-se a certeza desconstruída ou destruída dos pacientes - nenhum imaginava que seus modos-de-ser e estar no mundo pudessem gerar suas crises e mal-estares, culminando em internações emergenciais, exatamente naquele dia, naquela hora.

\section{A psicologia hospitalar no Brasil e a sua relevância}

A Psicologia Hospitalar é reconhecida enquanto especialidade pela Resolução do Conselho Federal de Psicologia no 014/2000. Porém, esta prática tem seu início no Brasil com Mathilde Neder, em 1954, na antiga Clínica Ortopédica e Traumatológica da Universidade de São Paulo (USP), hoje Instituto de Ortopedia e Traumatologia do Hospital das Clínicas da Faculdade de Medicina da USP. O trabalho era preparar os pacientes para cirurgia de coluna e acompanhá-los no pós-cirúrgico. Em 1974, Belkiss Wilma Romano foi convidada a organizar e implementar o Serviço de Psicologia do Instituto do Coração do Hospital das Clínicas da Faculdade de Medicina da USP (Angerami-Camon, 2002). 
O trabalho do psicólogo hospitalar é singular por fugir de certas características da Psicologia Clínica, imaginando consultório, ambulatório, Serviço de Psicologia Aplicada (SPA). Algumas das características relevantes: Demanda; Setting; Tempo de duração de atendimento; Atendimentos: temática, clientela atendida; Interconsultas.

A demanda é fabricada: o psicólogo aborda o paciente para avaliação e atendimento psicológico; porém, muitas vezes, o paciente não sabe o que é o trabalho de um psicólogo. O que ocorre, com frequência, são enfermeiros e/ou médicos solicitarem atendimento por perceberem "ansiedade", "depressão", "tristeza", "agressividade" e outros fenômenos no paciente. E, há casos de pacientes solicitarem atendimento.

Setting terapêutico indeterminado: o psicólogo pode atender em pé, à beira do leito ou em algum banco ou cadeiras, caso o paciente possa se locomover. Interrupção no atendimento é evento comum na prática da psicologia hospitalar, exatamente pela necessidade dos cuidados medicamentosos, intervenções médicas ou de enfermagem para algum procedimento e, não podendo esquecer de outros pacientes que, às vezes, resolvem "participar" do atendimento.

Tempo de duração de atendimento varia pelo estado de saúde do paciente, intervenções de emergência, saída de pacientes para exames ou cirurgias. Nesta característica, também, pode-se incluir tempo de permanência do paciente na instituição, permitindo ou não, trabalhar os temas que surgem em função do momento da internação.

O foco dos atendimentos é priorizar a internação hospitalar e suas consequências na existência deste paciente, mas, nada impede de serem trabalhados outros assuntos que, indiretamente, tem relação com a patologia e/ou internação. Além disso, o apoio psicológico aos familiares ajuda a esclarecer fatos sobre o paciente, além de auxilia-los a lidar com a ansiedade, muitas das vezes presente, por ver ou estar acompanhando a internação do familiar. Interconsultas com outros profissionais da instituição são possibilidades de interação com as outras especialidades que cuidam do paciente, podendo exercitar a Interdisciplinaridade ou, até mesmo, a Transdisciplinaridade.

Importante, também, é a possibilidade de serem abordados assuntos que não se restrinjam à internação, patologia e tratamentos necessários; muitos pacientes, ao longo dos atendimentos, trazem questões de suas existências. Nesta situação, há dois fatores a serem constantemente avaliados pelo psicólogo: previsão de alta do paciente e a impossibilidade de re-significar determinadas questões, acarretando um certo desconforto por ter iniciado um processo terapêutico e não ter a oportunidade de continuá-lo e; possibilidade de encaminhamento do paciente à psicoterapia após a alta hospitalar.

Dentre as enfermarias e áreas especializadas na maioria dos hospitais, abordar-se-á, brevemente, peculiaridades da Unidade Coronariana, desenvolvida para melhorar os cuidados cardiovasculares do paciente infartado.

Na segunda metade do século XX, introduzidas por Desmond Julian, na GrãBretanha, surgiram as unidades de cuidados coronarianos. Responsáveis por um dos maiores avanços isolados no tratamento do infarto, reduziram a mortalidade de $30 \%$ para 15\% nas primeiras horas de evolução, contribuindo para uma melhor apreciação no diagnóstico e manejo das arritmias, para advento da monitorização cardíaca contínua, para o desenvolvimento das manobras de ressuscitação cardiopulmonar e dos desfibriladores externos e para o melhor treinamento de médicos e enfermeiros. (Sarmento-Leite, Krepsky, Gottschall, 2001, p. 593)

Duas importantes características são o locus e os profissionais. É um setor da instituição hospitalar com 
poucos leitos, ao ser comparado com uma enfermaria; com equipamentos próprios para o tratamento das cardiopatias e das emergências que possam ocorrer ao longo da internação do paciente. A Unidade Coronariana prima por um ambiente calmo, com uma certa privacidade ao paciente, por exemplo, com divisórias entre os leitos. Quanto aos profissionais, espera-se a presença de equipes de enfermagem, de médicos cardiologistas, funcionários responsáveis pela limpeza e, a possibilidade de requisitar avaliação de outras especialidades médicas como Vascular, Oftalmologia e Ginecologia e, de outras áreas como Fisioterapia, Fonoaudiologia, Psicologia, Nutrição e Serviço Social.

De modo geral, os pacientes possuem idades diversas, englobando desde adolescentes à idosos. Por ser "área restrita à circulação principalmente de pessoas estranhas à equipe multiprofissional" (Romano, 2001, p.43) e onde os familiares têm pouco acesso - uma hora de visita por dia -, a presença do psicólogo faz-se necessária na Unidade Coronariana para minimizar o 'sofrimento' do paciente e de familiares, sendo necessário esclarecer que só há intervenção psicológica se houver abertura e aceitação do paciente e/ou familiares. Caso contrário, esta primeira abordagem serve de avaliação psicológica e tenta-se, em outro dia, uma nova abordagem ao paciente e, não havendo abertura para o atendimento é justificado à equipe o porquê da não continuidade do acompanhamento psicológico quando há pedido deste. Porém, quando há atendimento psicológico para o paciente e acompanhamento com os familiares, uma das "tarefas é ser o porta-voz do paciente junto à equipe e a seus familiares" (Romano, 2001, p.44).

Gerado pela hospitalização e pelas condições em que ocorreram a internação e o próprio ambiente hospitalar e toda a desinstitucionalização e despersonalização do indivíduo que torna-se paciente, o 'sofrimento' é constituído por outros sentimentos e comportamentos - agressividade, apatia, tristeza, euforia, medo, arrependimentos, culpas, ansiedade,... - que podem e são trabalhados ao longo da internação.

\section{Diálogos possíveis: a vivência da angústia existencial nos pacientes hospitalizados}

Ao pensar numa internação eletiva, compreende-se uma possibilidade de organização de tarefas a serem adiadas, canceladas, antecipadas e/ou transferidas a outrem. Já em uma internação emergencial, a única possibilidade vista é a de socorro e pronto-atendimento; depois as tarefas abandonadas vêm à lembrança, podendo gerar preocupação excessiva e, até atrapalhar o repouso e o tratamento proposto pela equipe de saúde da instituição hospitalar.

Ao refletir sobre isto, com base em experiência de atendimento psicológico em hospital universitário, comentar-se-á dois temas passíveis de desencadear a angústia existencial em pacientes internados em instituições hospitalares, não sendo exclusividades de unidades Coronarianas: trabalho e uso de substâncias lícita e ilícita.

Normalmente, os pacientes comentam de suas rotinas de trabalho e alguns relatam com euforia a grande quantidade de tarefas executadas mas, de agora em diante, veem que não poderão mais realizar por conta de seus quadros de saúde e novos hábitos que precisarão ser adquiridos. Alguns pacientes trazem também a questão de o local de trabalho ser mais agradável que suas residências, com isto fazem hora extra ou trocas de horários com colegas para ficarem o mínimo de tempo em casa e com seus familiares. Outros apontam a natureza de seu trabalho ir contra preceitos familiares e isso ser motivo de brigas e de um clima tenso.

Algumas reflexões desencadeadas nos pacientes por se verem longe de seus trabalhos, mais perto de si mesmos e, algumas vezes, com seus familiares nos horários de visita, foram o re-significar o sentido da palavra trabalho: diminuir esforço físico; solicitar ajuda em algumas tarefas; investir nos estudos. 
A compreensão do excesso de trabalho e da escassez de cuidado consigo mesmo pode ser difícil mas, torna-se necessária para a diminuição de atividades laborais. Neste sentido, o paciente pode constatar que trabalha em demasia para ficar o maior tempo possível ausente de casa para não conviver com a família, ou por não suportar a solidão - caso more sozinho. Este posicionamento pode gerar dois problemas: o surgimento de doenças por falta de repouso e cuidados e; o afastamento de pessoas importantes, por implicância, teimosia e dificuldade de respeitar a opinião do outro.

Ao refletir sobre as possibilidades desveladas para uma mudança de profissão, o indivíduo/paciente pode-se fazer algum curso que capacite para ter outra ocupação para se sustentar com um ofício que não vá contra a própria família. Neste momento, despertar a reflexão para as próprias habilidades e capacidades e atividades que se tenha domínio são válidas para um desvelar de horizonte de novos sentidos profissionais.

O uso de bebidas alcóolicas e cigarros, além de remédios sem prescrição médica, costumam ser relatados pelos pacientes como hábitos cotidianos. Por estar internado e, ter de suspender o uso destas substâncias sem um desmame ou redução progressiva, há uma grande dificuldade nos primeiros dias por atravessar a chamada fissura. Medicações poderão ser utilizadas para diminuir a vivência desagradável da falta da substância no organismo.

Pessoas que fumam entre 30 a 60 cigarros por dia, e que veem o cigarro como companhia, costumam sofrer a ausência da substância e do 'companheiro'. Costumam sentir-se protegidos por estar no hospital e não poderem ter acesso ao cigarro, mas sentem-se frágeis na alta hospitalar, com receio de não conseguirem manter-se sem o uso. Normalmente, estes pacientes recebem orientações para tratamento e acompanhamento para o uso do tabaco.

Ao dar entrada nas instituições hospitalares, pacientes relatam o uso de grande quantidade de substância ilícita, quase sempre cocaína, por causa de problemas existenciais envolvendo família, trabalho, religião, relacionamentos. Como tais questões geram tristeza e frustração e, sem o vislumbre de soluções para seus problemas, a saída momentânea era o alívio com a droga. É perceptível a necessidade de anestesiar uma "dor" da Existência que convoca para grandes mudanças. É comum os pacientes demonstrarem vontade e necessidade de parar de usar droga e ter interesse em fazer algum tratamento por reconhecerem que sozinhos não conseguem ficar sem usála. Este discurso possui a característica da promessa de mudanças de hábitos perante o susto da emergência clínica vivenciada. Mas o que pode ser apontado como possibilidade de vivência da angústia existencial é o fato do reconhecimento das dificuldades a serem percorridas e não desistir, verbalizando e questionando possíveis espaços de tratamento.

\section{CONSIDERAÇÕES FINAIS}

A angústia está presente em vários momentos da vida das pessoas e, pode ser perceptível em pacientes hospitalizados. Na maioria das vezes, estes pacientes estão privados de visitas familiares e de autonomia para realizar atividades cotidianas e costumeiras de higiene pessoal, por exemplo, sem esquecer o importante aspecto de uma interrupção brusca e, quase sempre, inesperada de sua vida cotidiana, acarretando preocupações e ansiedade quanto às obrigações, compromissos e outras vidas que dependem da presença do paciente para 'tudo sair na mais perfeita ordem'. Muitos pacientes constatam a impossibilidade da experiência de onipotência e controle de suas vidas e, percebem o constante o estado de incerteza. Neste momento, a angústia desvela-se, propondo ao indivíduo a 
possibilidade de um novo olhar, novo sentido para seu problema e a própria estadia no hospital é uma comprovação do fracasso do controle do devir e das certezas. A internação pode ser vista como um mergulho no "oceano de incertezas".

Ao atender os pacientes internados, além do fenômeno da angústia vivenciado por cada um, há o fenômeno da angústia no aspecto da 'não-garantia' deles realizarem os projetos desvelados na internação. Esta angústia é, de certa maneira, uma característica muito incômoda para quem inicia a prática psi em instituição hospitalar com pacientes internados, trazendo alguns questionamentos: se foram boas as repercussões das intervenções psi no paciente; se o paciente está lidando melhor com suas questões existenciais. Compreender a atividade do psicólogo hospitalar é perceber que tais perguntas não precisam de respostas. Uma das principais funções do psicólogo é tornar-se dispensável ao usuário e, no caso da Psicologia Hospitalar, esta prática é muito mais usual.

Sobre as intervenções do profissional psicólogo e seus efeitos, dois fatores imprescindíveis: psicoterapia e supervisão - ou pelo menos, espaço de troca de idéias e novos sentidos sobre o caso com outros profissionais. E sobre a prática psi e este necessário 'desprendimento' é importante recordar que o 'o psicólogo tem a função de ser dispensável', portanto está na essência - numa perspectiva fenomenológica-da profissão a incerteza, o não-controle do devir.

A angústia como caminho é um modo de refletir o quanto ela põe em movimento e devolve ao homem a condição de olhar para os próprios projetos e sentido da própria vida, sem predeterminar as ações a serem ou não realizadas. A meta de abertura para a prática do amor e da confiança e o próprio amadurecimento humano provém de vivências de angústia com retorno aos projetos existenciais esquecidos, abandonados ou interrompidos e/ou desvelamento de novos sentidos para o próprio existir. 


\section{REFERÊNCIAS}

Angerami-Camon, V. (org.), Chiattone, H. B. C. \& Nicoletti, E. A. (2002a). O doente, a psicologia e o hospital. São Paulo: Pioneira Thompson Learning.

Angerami-Camon, V. (org.), Knijnik, R., Sebastiani, R. \& Turcharte, F. (2002b). Psicologia Hospitalar: teoria e prática. São Paulo: Pioneira Thomson Learning.

Arendt, H. (2008). A condição humana. (10 ed.) Rio de Janeiro: Forense Universitária. (original: 1958)

Bastos, R. L. (2009). Ciências Humanas e Complexidades: projetos, métodos e técnicas de pesquisa - o Caos, a Nova Ciência. (1 ed.). Rio de Janeiro: e-pappers.

Boss, M. (1981). Angústia, culpa e libertação: ensaios de psicanálise existencial. Rio de Janeiro: Duas Cidades.

Calvo de Feijoo, A. M. L., Mattar, C. M., Lopez de Feijoo, E., Lessa, M. B. M. F. \& Protasio, M. M. (2013). O pensamento de Kierkegaard e a clínica psicológica. Rio de Janeiro, IFEN.

Comte-Sponville, A. (1997). Bom dia, Angústia! São Paulo: Martins Fontes.

Conselho Federal de Psicologia. Resolução CFP no 014/2000. Institui o título profissional de Especialista em Psicologia e dispõe sobre normas e procedimentos para seu registro. Brasília: Conselho Federal de Psicologia, 2000. Disponível: https://site.cfp.org.br/wp-content/uploads/2006/01/resolucao2000_14.pdf Acesso em: $10 \mathrm{abr} 2020$.

Dantas, J. B. (2011). Angústia, Existência na Contemporaneidade. Rio de Janeiro: Rubio.

Ferreira, A. B. H. (1999). Novo Dicionário Aurélio Século XXI. Rio de Janeiro: Nova Fronteira.

Heidegger, M. (2002). Ser e Tempo. Petrópolis: Vozes. (original: 1927)

Kierkegaard, S. (1968). O conceito de angústia. São Paulo: Hemus. (original: 1844)

Koehler, H. (1957). Dicionário escolar latino-português. Porto Alegre: Globo.

Martins, J. \& Bicudo, M. A. (1989). A pesquisa qualitativa em psicologia: fundamentos e recursos básicos (1 ed.). São Paulo: Moraes.

Nunes, B. (2002). Heidegger \& Ser e Tempo. Rio de Janeiro: Jorge Zahar.

Pala, A. C. S. . (2008). O cuidado psicológico com doentes crônicos em uma perspectiva fenomenológicaexistencial. 2008. Dissertação de Mestrado em Estudos da Subjetividade. Instituto de Ciências Sociais Humanas e Filosofia, Universidade Federal Fluminense, Niterói. Disponível em: https://app.uff.br/slab/uploads/2008_d_Agnes.pdf

Pala, Á. C. S, Fonseca, T. A., Rocha, S. C. \& Aguiar, R. P. (2016). O processo ensino-aprendizagem da Fenomenologia de Martin Heidegger em um curso de graduação em Psicologia: desencobrindo possibilidades. In Anais II Mostra Acadêmico-Científica de Niterói: Educação, Ciência e Tecnologia.; 2016; Niteroi. p. 506-513. Disponível em: https://pt.scribd.com/document/357509732/ANAIS-II-MOSTRAACADEMICO-CIENTIFICA-DE-NITEROI-2016-Atualizado

Prado, M. F. A. (2005). Fenomenologia e Daseinsanalyse. Daseinsanalyse-Revista da ABD/Associação Brasileira de Daseinsanalyse. $\mathrm{n} 014$. 
Rodrigues N. C. C. M., Barreiro, D. S. L., Garcez, M. R. L. \& Pala, Á. C. S. (2016). Estudos Introdutórios da abordagem psicoterápica fenomenológica-existencial: compreendendo a noção de fenômeno. Anais II Mostra Acadêmico-Científica de Niterói: Educação, Ciência, Tecnologia e Inovação, Niterói, RJ, Brasil. Disponível em: https://pt.scribd.com/document/357509732/ANAIS-II-MOSTRA-ACADEMICO-CIENTIFICADE-NITEROI-2016-Atualizado

Romano, B. W. (2001). Psicologia e cardiologia: encontros possíveis. São Paulo: Casa do Psicólogo.

Sá, R. N. (2004). As influências da Fenomenologia e do Existencialismo na Psicologia. In: Jacó-Vilela, Ana Maria; Leal, Arthur Ferreira; Portugal, Francisco Teixeira (org.). História da Psicologia - rumos e percursos. Rio de Janeiro: Nau Editora.

Sarmento-Leite, R., Krepsky, A. M., Gottschall, C. A. M. (2001). Infarto Agudo do Miocárdio. Um Século de História. Arq Bras Cardiol, (Arquivo Brasileiro de Cardiologia) volume 77 (no 6), 593-601, 2001. Recuperado em http://publicacoes.cardiol.br/abc/2001/7706/7706011.pdf

Sillamy, N. (1998). Dicionário de Psicologia Larousse. Porto Alegre: Artmed.

Stein, E. (1973). A questão do método na filosofia \& Um estudo do modelo heideggeriano. São Paulo: Duas Cidades. 


\title{
MECANISMOS DE ENFRENTAMENTO NA SAÚDE MENTAL DOS TRABALHADORES DO CTI ONCOPEDIÁTRICO: REVISÃO INTEGRATIVA
}

\author{
Elida Gabriela Serra Valença Abrantes \\ Universidade Federal Fluminense - UFF \\ elidagabriela2018@gmail.com \\ Geilsa Soraia Cavalcanti Valente \\ Universidade Federal Fluminense - UFF \\ geilsavalente@gmail.com \\ Claudia Maria Messias \\ Universidade Federal Fluminense - UFF \\ marimessi1512@gmail.com
}

\author{
Elaine Antunes Cortez \\ Universidade Federal Fluminense - UFF \\ nicortez@hotmail.com \\ Vanessa Teles Luz Stephan Galvão \\ Universidade Federal Fluminense - UFF \\ vanessatluz@gmail.com \\ Jéssica do Nascimento Rezende \\ Universidade Federal Fluminense - UFF \\ jessiiica_rezende@hotmail.com
}

\section{RESUMO}

Os riscos psicossociais entre os trabalhadores de saúde têm sido alvo de pesquisas nacionais e internacionais. Os trabalhadores de terapia intensiva oncopediátrica lidam constantemente com situações-limite, tornando-os vulneráveis ao esgotamento emocional e a possíveis mecanismos de enfrentamento. Objetivo: Identificar produções que visam a valorização da qualidade de vida do trabalhador de terapia intensiva oncopediátrica, assim como intervenções que promovem sua saúde mental. Metodologia: Revisão integrativa realizada em agosto de 2019 através da busca por artigos originais e disponíveis, publicados nos últimos cinco anos, e que tenham como tema a valorização da qualidade de vida de trabalhadores de saúde com alta demanda emocional no ambiente de terapia intensiva oncopediátrica. Realizou-se pesquisa online no portal BVS e bases de dados: PubMed e CAPES. Resultados: A amostra resultou em nove publicações das quais apenas uma avalia o risco ocupacional sofrido em terapia intensiva pediátrica, enquanto as demais relatam a presença de sentimentos de carga emocional negativa e mecanismos de enfrentamento adotados pelos profissionais de saúde. São destacadas inúmeras estratégias como espiritualidade, resiliência, técnicas de apoio individual e coletivo. Conclusão: A assistência contínua aos que estão em sofrimento suscita sentimentos que influenciam a vida dos profissionais como um todo, tornando-os vulneráveis aos riscos psicossociais. Aprimorar a capacitação do trabalhador em lidar com situações de sofrimento de alto impacto emocional com equanimidade e compaixão é uma iniciativa que promove a saúde mental e, também, favorece o cuidado humanizado eficaz.

\section{Palavras-chave:}

Educação Continuada; Unidades de Terapia Intensiva Pediátrica; Saúde do Trabalhador; Fadiga por Compaixão.

\begin{abstract}
Psychosocial risks among health workers have been the subject of national and international research. In this sense, we turn to oncopediatric intensive care workers, who constantly deal with extreme situations making them vulnerable to emotional exhaustion and consequently looking for possible coping mechanisms. Objective: To identify productions that aim the value the quality of life of oncopediatric intensive care workers, through successful interventions. Method: Integrative review conducted in August 2019 through the search for original and available articles, published in the last 5 years with the theme of the valorization of the quality of life of the health workers with high emotional demand, in the oncopediatric intensive care environment. Online research conducted on the VHL portal, databases: LILACS, PUBMED, MEDLINE and CAPES. Results: The sample resulted in 09 publications of which only one evaluates
\end{abstract}

the occupational risk suffered in pediatric intensive care, while the others report the presence of feelings of negative emotional load and coping mechanisms adopted by health professionals. Numerous strategies are highlighted involving spirituality, resilience, individual and collective support techniques. Conclusion: Continuous assistance to those who are suffering gives rise to feelings that influence the lives of professionals in general, making them vulnerable to psychosocial risks. Improving the worker's ability to deal with situations of suffering with high emotional impact with equanimity and compassion is an initiative that not only promotes mental health but also favors effective care.

\section{Keywords:}

Education, Continuing; Intensive Care Units, Pediatric; Occupational Health; Compassion fatigue. 


\section{INTRODUÇÃO}

Na Terapia Intensiva, a labilidade do paciente crítico exige do enfermeiro atenção e habilidade. A expertise em lidar com equipamentos de alta tecnologia e procedimentos invasivos exige dedicação na busca do conhecimento em constante avanço, além da consciência de se trabalhar com a finitude e temores que circundam essa atividade. A Unidade de Terapia Intensiva (UTI) é entendida, culturalmente, como um local de mal prognóstico, sofrimento e dor (Barros \& Honório, 2015).

No setor de Terapia Intensiva, é possível perceber a construção do conhecimento de forma contínua por se tratar de um ambiente em transformação a partir do avanço acelerado da tecnologia em busca da cura. Um cuidado humanizado e eficaz promove um ambiente harmonioso e qualidade de vida para todos os envolvidos. Dessa forma, a Educação Permanente deve ser reconhecida como parte integrante deste dia a dia.

Articular humanização com os avanços tecnológicos tem sido um grande desafio em Terapia Intensiva, visto que tal ambiente já é reconhecido como ideal para os cuidados em fim de vida. Apesar disso, ainda há uma carência significativa no preparo emocional da equipe atuante (Silveira et al., 2016).

Encarado como fatal há décadas, o câncer infantil tornou-se amplamente tratável na atualidade pelo uso das tecnologias duras. A necessidade de constantes internações no CTI e, até mesmo, a dependência de tecnológicas complexas para a sobrevida não é incomum. Contudo, é possível observar que $25 \%$ dos casos não respondem à terapia antineoplásica, culminando no tratamento paliativo no ambiente de Terapia Intensiva (Javorski, Bushatsky \& Viaro, 2015).

No âmbito da pediatria, cuidar de uma criança cronicamente doente não estabelece nenhuma harmonia com o vigor do crescimento infantil. Analogamente, o crescimento da criança e a evolução da doença crônica seguem em paralelo rumo ao processo de terminalidade em que o crescimento e o desenvolvimento a aproximam da morte e de suas marcas simbólicas (Santos \& Moreira, 2014).

A luta contra o câncer na infância é a sentença de um longo caminho marcado por situações traumáticas para as crianças, seus familiares e profissionais envolvidos. Mesmo contando com tantos recursos altamente tecnológicos e curativos, existindo ou não a possibilidade de cura, o sofrimento psicológico, social, espiritual e físico é certo no decorrer do tratamento em todos os casos (Sousa, Silva \& Paiva, 2019)

Entre os profissionais de saúde, o tema gera sensação de derrota, frustração, incapacidade, fracasso, culpa, negação, entre outros. Entende-se, então, a importância de se discutir a melhor forma de lidar com o processo de morte e morrer da criança, e identificar os reflexos desse momento na assistência e na vida dos trabalhadores (Souza \& Conceição, 2018).

Monteiro et al. (2013) relata que os sentimentos vivenciados pelos profissionais envolvidos no cuidado em Terapia Intensiva são: frustração e impotência diante da morte de pacientes, desvalorização pessoal, exaustão física e emocional, angústia não expressa, insatisfação e decepção com o trabalho e com a instituição, desmotivação, fragilidade emocional e tristeza, medo ao chegar no ambiente laboral e vergonha. Percebe-se, nesses sentimentos, o sofrimento psíquico vivenciado pelos trabalhadores e a necessidade de intervenções psicossociais. 
Nessa linha de pensamento, pode-se afirmar que o exercício dos profissionais de Terapia Intensiva leva a sentimentos variados e controversos. Em um cenário intenso, repleto de situações imprevistas e conflitantes, e com a peculiaridade do binômio criança-família como centro do cuidado durante todo o período, repercussões significativas na vida desses trabalhadores são inevitáveis. O trabalho, ainda que gerador de prazer pelo reconhecimento profissional na recuperação de uma criança e na satisfação em poder ajudar, por outro lado, gera sofrimento, acompanhado de desgaste físico e mental principalmente diante da terminalidade. (Vasconcelos et al., 2019).

Devido à conjuntura citada, o presente estudo evidencia a necessidade de reconhecer o trabalho como grande influenciador na qualidade de vida do profissional, pois ele é parte integrante na construção da identidade do trabalhador. Assim, é possível entender a importância da psicodinâmica do trabalho para promoção da saúde mental e consequente qualidade de vida dos profissionais e dos serviços por eles prestados (Vasconcelos et al., 2019).

Outrora, o ínfimo quantitativo de estudos indica a existência de uma significativa lacuna em relação à produção de conhecimento nessa temática em específico. Ao mesmo tempo, justifica este estudo com o propósito de reunir dados para melhor compreender a situação em que os profissionais da saúde se encontram.

Diante do exposto, foi desenvolvido o seguinte questionamento de pesquisa: O que se tem produzido, na literatura, sobre a forma de prestar cuidado humanizado no Centro de Terapia Intensiva (CTI) oncológico pediátrico e manter-se emocionalmente estável?

Por tais razões, este estudo tem o objetivo de identificar produções científicas que visam a melhoria da qualidade de vida do trabalhador com alta demanda emocional, especificamente no ambiente de Terapia Intensiva oncopediátrica, assim como propostas de intervenções psicossociais bem fundamentadas no meio científico.

\section{Método}

Para a presente pesquisa foi realizada uma Revisão Integrativa (RI) da literatura, um dos métodos utilizados na Prática Baseada em Evidências (PBE). A RI é entendida como um tipo de revisão de natureza complexa, que demanda métodos normatizados e sistemáticos para garantir o necessário rigor requerido na pesquisa científica e a legitimidade das evidências estabelecidas (Soares et al., 2014).

Pela RI é possível a inclusão de estudos experimentais e não experimentais para a análise profunda do tema de pesquisa de forma amplificada, sendo desenvolvida em seis etapas: 1 . a determinação da questão a ser pesquisada; 2 . a definição de critérios de inclusão e exclusão para a busca na literatura; 3. o estabelecimento de informações a serem extraídas dos estudos; 4. a análise dos estudos incluídos; 5. a interpretação dos resultados; 6. e a síntese de dados de relevância (Soares et al., 2014; Souza, Silva \& Carvalho, 2010).

Para a confecção de uma questão de pesquisa eficaz pelo bom uso da PBE, optou-se por um método voltado para a pesquisa clínica. Nessa perspectiva, são necessários elementos que favorecem a uma questão bem elaborada, que guiará o pesquisador ao conhecimento dos dados fundamentais e à resolução da problematização estudada. São quatro os elementos determinantes que configuram a estratégia PICO: Paciente/problema, Intervenção, Comparação (optativo) e Desfecho. 
Sendo assim, de acordo com a estratégia PICO, foram eleitos os descritores próprios que traduzem o $P$, I e $O$. É necessário salientar o não uso do $C$ pelo fato da pesquisa dispensar comparações entre os mecanismos de enfrentamento (Santos \& Galvão, 2014).

A primeira fase correspondeu à elaboração da questão da pesquisa de acordo com a estratégia PICO. Em um segundo momento, foram estabelecidos critérios de inclusão e exclusão, assim como a busca na literatura.

Foram considerados artigos originais disponíveis na íntegra de forma gratuita na língua inglesa, portuguesa e espanhola para os critérios de inclusão. O tema da pesquisa definido foi a valorização da qualidade de vida de trabalhadores com alta demanda emocional, especificamente no ambiente de Terapia Intensiva oncopediátrica e estratégias de promoção objetivando um cuidado humanizado e eficaz. Para o recorte temporal, fixou-se o período de 2015 a 2019. Por fim, excluíram-se artigos de validação de conteúdo, estudos de casos e a duplicidade de publicações, sendo mantido apenas o texto de uma das fontes.

Na primeira busca nas bases de dados PubMed, CAPES e na BVS, nenhum artigo foi encontrado em se tratando de ações preventivas a favor da saúde mental dos profissionais em CTI oncopediátrico devido à restrita especificidade do assunto.

As buscas foram ampliadas, incluindo a promoção à saúde mental dos trabalhadores em cuidados paliativos na oncologia pediátrica com o auxílio da estratégia PICO para responder ao questionamento: Como promover a saúde mental dos trabalhadores vulneráveis à fadiga por compaixão no ambiente de Terapia Intensiva oncológica pediátrica?

Atualizados os termos da busca, com o auxílio de consulta realizada aos descritores em Ciências da Saúde (DeCS) e ao Medical Subject Headings (MeSH), estes foram associados à operadores booleanos, e a pesquisa foi iniciada conforme demonstra a estratégia final do Quadro 1.

Quadro 1 - Descritores utilizados na estratégia PICO. Rio de Janeiro, RJ, Brasil, 2020.

\begin{tabular}{|c|c|c|}
\hline PICO & DeSC & MESH \\
\hline $\mathrm{P}$ & $\begin{array}{c}\text { Fadiga por Compaixão AND Saúde Mental AND } \\
\text { UTI Pediátrica AND Oncologia AND } \\
\text { Saúde do Trabalhador } \\
\text { OR }\end{array}$ & $\begin{array}{c}\text { Compassion Fatigue AND Mental } \\
\text { health AND } \\
\text { Intensive Care Units, Pediatric } \\
\text { AND } \\
\text { Medical Oncology AND } \\
\text { Occupational Health } \\
\text { OR }\end{array}$ \\
\hline I & $\begin{array}{c}\text { Educação Continuada } \\
\text { AND / OR } \\
\end{array}$ & $\begin{array}{c}\text { Continuing Education } \\
\text { AND /OR } \\
\end{array}$ \\
\hline $\mathrm{C}$ & Não se aplica & Não se aplica \\
\hline $\mathrm{O}$ & Satisfação por Compaixão & Compassion Satisfaction \\
\hline
\end{tabular}

Fonte: Elaborado pelas autoras, 2020.

Conforme este segundo momento de busca, 132 produções foram identificadas, das quais 63 apresentadas no portal BVS, 30, na base de dados PubMed e 39, no portal CAPES.

Para a seleção, realizou-se a leitura dos títulos e resumos de forma detalhada a fim de refinar a amostra em concordância com os critérios de inclusão e exclusão preestabelecidos. Foram 
excluídos 29 artigos por estarem indisponíveis na íntegra, 53, por terem mais de cinco anos de publicação e 33, por não corresponderem ao tema da pesquisa, o que propiciou a seleção de dezessete estudos que foram lidos na íntegra de forma criteriosa. Posteriormente, foram excluídos ainda: um artigo por se tratar de duplicidade de publicação, um de validação de instrumento e mais seis que não apresentavam estreita relação com o tema em pesquisa, resultando, como seleção final, nove publicações (Tabela 1).

Tabela 1 - Número de publicações obtidas na busca. Rio de Janeiro, RJ, Brasil, 2020.

\begin{tabular}{l|c|c|c|c|c|c|c}
\hline Fonte & Artigos & Artigos & Artigos & \multicolumn{2}{|c|}{ Artigos Excluídos após leitura } & Artigos \\
\cline { 5 - 7 } & Encontrados & Excluídos & Selecionados & Duplicidade & Validação & Tema & Analisados \\
\hline BVS & 63 & 56 & 07 & 01 & 00 & 02 & 04 \\
\hline PubMed & 30 & 28 & 02 & 00 & 01 & 00 & 01 \\
\hline CAPES & 39 & 31 & 08 & 00 & 00 & 04 & 04 \\
\hline TOTAL & 132 & 115 & 17 & 01 & 01 & 06 & 09 \\
\hline
\end{tabular}

Fonte: Elaborada pelas autoras, 2020

Posteriormente, tais informações foram apresentadas conforme o fluxograma de PRISMA com a estratégia de busca (Figura 1).

Figura 1 - Fluxograma de PRISMA. Rio de Janeiro, RJ, Brasil, 2020.

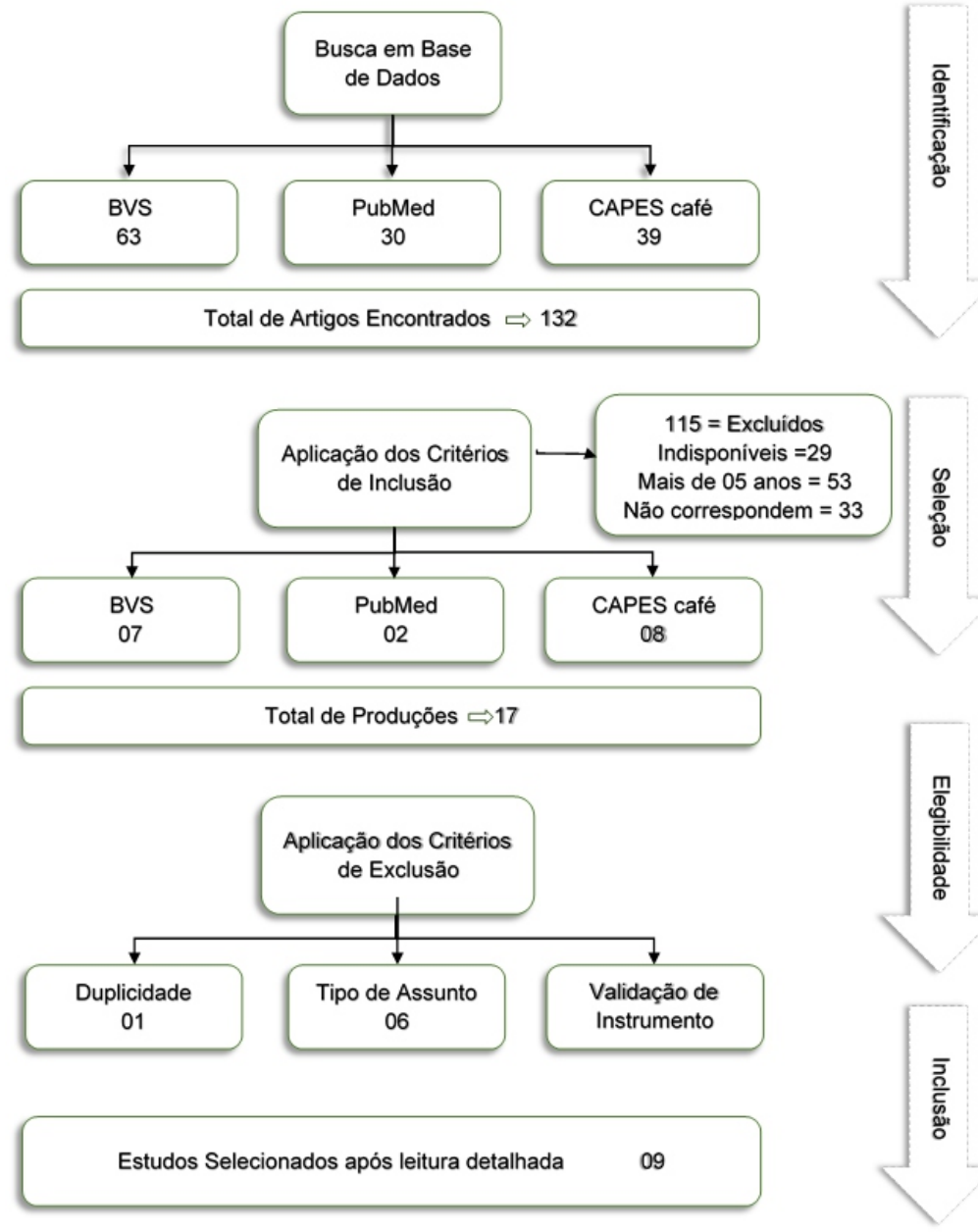

Fonte: Elaborada pelas autoras, 2020. 
A terceira etapa consistiu na formulação de um quadro e uma tabela objetivando extrair a totalidade de dados significativos dos artigos selecionados de modo a garantir uma análise crítica fidedigna das informações. O quadro 2 agrupa os seguintes dados: No, autor/ano de publicação, título, sistema de classificação de periódicos, Qualis e local de pesquisa.

Quadro 2 - Amostra segundo: autor(es)/ano, título, revista, Qualis e local de pesquisa. Rio de Janeiro, RJ, Brasil, 2020.

\begin{tabular}{|c|c|c|c|c|c|}
\hline $\mathrm{N}^{\mathrm{o}}$ & Autor/Ano & Título & Revista & Qualis & País \\
\hline 1 & $\begin{array}{c}\text { Barros; } \\
\text { Honório/2015 }\end{array}$ & $\begin{array}{l}\text { Risco de Adoecimento no } \\
\text { Trabalho de Médicos e } \\
\text { Enfermeiros em um Hospital } \\
\text { Regional do Mato-grossense }\end{array}$ & REGE, SP & A3 & Brasil \\
\hline 2 & $\begin{array}{c}\text { Santos; } \\
\text { Moreira/2014 }\end{array}$ & $\begin{array}{l}\text { Resiliência e morte: o profissional } \\
\text { de enfermagem frente ao cuidado } \\
\text { de crianças e adolescentes no } \\
\text { processo de finitude da vida }\end{array}$ & $\begin{array}{l}\text { Departamento } \\
\text { de Pediatria da } \\
\text { Fio Cruz }\end{array}$ & $\mathrm{A} 2$ & Brasil \\
\hline 3 & $\begin{array}{l}\text { Silveira et } \\
\text { al./2016 }\end{array}$ & $\begin{array}{l}\text { Cuidado paliativo e Enfermeiros } \\
\text { de Terapia Intensiva: Sentimentos } \\
\text { que ficam }\end{array}$ & REBEn & $\mathrm{A} 2$ & Brasil \\
\hline 4 & García/2017 & $\begin{array}{l}\text { Fatiga por compasión entre } \\
\text { profesionales sanitarios de } \\
\text { oncología y cuidados paliativos }\end{array}$ & Psicooncología & A3 & Espanha \\
\hline 5 & Jones/2017 & $\begin{array}{l}\text { Oncology Nurse Retreat A } \\
\text { strength-based approach to self- } \\
\text { care and personal resilience }\end{array}$ & $\begin{array}{l}\text { Clinical Journal } \\
\text { of Oncology } \\
\text { Nursing }\end{array}$ & A2 & USA \\
\hline 6 & $\begin{array}{c}\text { Souza e } \\
\text { Conceição/2018 }\end{array}$ & $\begin{array}{l}\text { Processo de Morrer em Unidade } \\
\text { de Terapia Intensiva Pediátrica }\end{array}$ & Bioética & $\mathrm{A} 2$ & Brasil \\
\hline 7 & $\begin{array}{l}\text { Sansó et } \\
\text { al. } / 2018\end{array}$ & $\begin{array}{l}\text { Evaluación de una Intervención } \\
\text { Mindfulness en Equipos de } \\
\text { Cuidados Paliativos }\end{array}$ & $\begin{array}{c}\text { Journals } \\
\text { Psychosocial } \\
\text { Intervention }\end{array}$ & A3 & Espanha \\
\hline 8 & $\begin{array}{l}\text { Sobral et } \\
\text { al. } / 2018\end{array}$ & $\begin{array}{l}\text { Burnout and work organization in } \\
\text { Nursing }\end{array}$ & $\begin{array}{l}\text { Ver. Bras Med } \\
\text { Trab }\end{array}$ & A3 & Brasil \\
\hline 9 & $\begin{array}{l}\text { Borges et } \\
\text { al. } / 2019\end{array}$ & $\begin{array}{l}\text { Fadiga por compaixão em } \\
\text { enfermeiros de urgência e } \\
\text { emergência hospitalar de adultos }\end{array}$ & $\begin{array}{l}\text { Revista Latino- } \\
\text { Americana de } \\
\text { Enfermagem }\end{array}$ & $\mathrm{A} 2$ & Portugal \\
\hline
\end{tabular}

Fonte: Elaborado pelas autoras, 2020. 


\section{Resultados}

Os estudos e literatura científica, em suas composições investigadas, conciliam que é cada vez mais urgente a necessidade de uma atenção especial à saúde mental dos trabalhadores de saúde que estão sob forte impacto emocional na ocupação do cuidar daqueles que estão em sofrimento.

Barros e Honório (2015) investigaram os riscos psicossociais de profissionais em uma grande emergência. Identificaram a necessidade da promoção da saúde do trabalhador de forma coletiva para um melhor enfrentamento dos riscos psicossociais por meio de um ambiente de trabalho harmonioso. Os participantes relataram experiências de satisfação por compaixão com relação ao exercício profissional, entretanto sofrem com a alta demanda associada à escassez de recursos. Sendo assim espiritualidade, isolamento, individualismo e inteligência astuciosa são os principais mecanismos de defesa diante do sofrimento a que são expostos.

Buscando estudos sobre o cuidado em pediatria oncológica no ambiente de Terapia Intensiva e, até mesmo, envolvendo o processo de finitude, pouco se pode encontrar. O estudo de Santos e Moreira (2014) aborda acerca da finitude na infância como um assunto complexo que ainda necessita de ampla discussão. Com os avanços na área tecnológica ambicionando a longevidade, a finitude passa a ser um processo institucionalizado. Todavia, os autores deixam claro a pouca dedicação quanto a capacitação dos profissionais de saúde para essa realidade em ascendência (Santos \& Moreira, 2014).

Desejando entender como os profissionais de saúde lidam com a morte de uma criança e o impacto causado na assistência prestada no ambiente de Terapia Intensiva, Souza e Conceição (2018) avaliam o discurso de uma equipe de Terapia Intensiva pediátrica. Como não poderia ser diferente, a morte de uma criança gera sentimentos conflituosos devido à consciência de se tratar de um processo antinatural. Por outro lado, pode também ser entendido como o fim de um sofrimento totalmente indébito. Frequentemente, essa incompreensão gera sentimentos negativos, apontando para a necessidade de discutir a melhor forma de lidar com a situação, e identificar seus reflexos na assistência prestada. A incapacidade de aceitação é reconhecida como compreensível, contudo, trata-se de uma carência de atributos psicológicos que merecem atenção profissional e requer busca da educação permanente em saúde promovendo o apoio devido (Souza \& Conceição, 2018).

De acordo com os artigos encontrados, os sentimentos experimentos pelos profissionais mostram a necessidade de intervenções que favoreçam apoio individual e coletivo (Silveira et al., 2016) na intenção de conhecer os sentimentos e emoções dos enfermeiros dedicados ao cuidado paliativo em Terapia Intensiva. No estudo intitulado Sentimentos que ficam, há evidências de que as representações sociais dos sentimentos gerados no cuidado paliativo em Terapia Intensiva são, em sua maioria, negativas, por serem concebidas durante a assistência prestada em ambiente fortemente obstinado pela cura. Tal conclusão aponta para o desafio de articular humanização e avanços tecnológicos.

García (2017) traz à tona o fenômeno fadiga por compaixão, que é a reposta ao contínuo contato com sofrimento e frequentes perdas por morte impactando o físico, o emocional, o social e o espiritual de quem exerce o cuidado. $\mathrm{O}$ autor identifica fatores individuais que predispõem a fadiga por compaixão entre trabalhadores de cuidados paliativos oncológicos. Seu estudo apresenta a enfermagem como a categoria mais acometida pelo fenômeno na equipe multidisciplinar. García (2017) fala, também, a respeito do alto risco de síndrome de Burnout, conceituando-a como o estresse em decorrência de circunstâncias psicossociais no trabalho, que permeia fortemente o profissional de enfermagem. Souza e Conceição (2018) corroboram que o impacto do processo de morte e morrer na continuidade da assistência reforça a enfermagem como a categoria mais atingida. 
Ademais, Sobral, Stephan, Zanatta e De Luca (2018) realizam sua pesquisa com o intuito de identificar os riscos psicossociais preditores do sofrimento mental e a Síndrome de Burnout em trabalhadores de enfermagem. A síndrome de Burnout é um conjunto de sintomas consequentes do estresse interpessoal no trabalho. Reconhecida como uma questão de saúde pública, os autores relatam preocupação internacional com o tema, defendendo que a mesma conduta seja cultivada no Brasil. De forma clara, o estudo reforça a necessidade de um olhar amplo quanto as causas da síndrome de Burnout e do sofrimento mental que assumem prevalência significativa entre os profissionais de enfermagem como consequência da função do cuidado aos que estão em sofrimento.

Borges et al. (2019), procurando mensurar o nível de fadiga por compaixão em enfermeiros, comprovam que grande parte desses profissionais expressam sinais relacionados ao fenômeno, além de elevados índices de síndrome de Burnout e estresse traumático secundário. De acordo como os autores, fatores individuais determinam a fadiga por compaixão e, entre tais fatores, está a proporção de tempo dedicado às atividades de lazer. Borges et al. (2019) entendem como fundamental o investimento em novas pesquisas que envolvam o tema com o intuito de dar prioridade ao planejamento de estratégias que visem a promoção da saúde do trabalhador.

Sansó et al. (2018) buscaram avaliar o impacto de um programa Mindfulness sobre os níveis de atenção plena, autopiedade e qualidade de vida profissional de um grupo de trabalhadores em cuidados paliativos. Como resultado, alcançou queda significativa quanto ao desgaste físico e emocional no grupo participante. Os estudiosos observaram o desenvolvimento da empatia, níveis de ansiedade em queda progressiva, a construção da resiliência e, dessa forma, a prevenção da síndrome de Burnout. A prática de atenção plena propicia a autoconsciência guiando a satisfação da compaixão e a manutenção da estabilidade emocional por apresentar evidências na diminuição da carga emocional negativa. A autoconsciência promove, ainda, o autocuidado, favorecendo o processo empático junto ao ser cuidado, minimizando o risco de sofrer estresse pela contínua assistência aos que sofrem.

Na visão de García (2017), é inegável o déficit de autocuidado, cuidado emocional e espiritual, além de desequilíbrio entre a vida profissional e pessoal nos profissionais vulneráveis à fadiga por compaixão. Desse modo, o autor ressalta a importância de saber lidar com a morte e o reconhecimento de sinais de fadiga por compaixão entre os profissionais.

Conscientização e autocuidado estão intimamente ligados com a capacidade do profissional em conviver com a morte sem que tal enfrentamento gere grandes riscos psicossociais, sendo o autocuidado uma prioridade. García (2017) conclui ressaltando acerca da escassez de programas de educação da enfermagem em fim de vida, que contribuem muito como alternativa de apoio.

Entre tantas intervenções de promoção à saúde do trabalhador, foram destacados espaços de apoio coletivo e individual, retiros com foco na construção do autocuidado e atenção plena, além do desenvolvimento e internalização da resiliência.

Analisando a resiliência na equipe de enfermagem que cuida de crianças cronicamente adoecidas e em processo de finitude, Santos e Moreira (2014) descrevem que o referido cuidado leva a mecanismos de defesa intimamente ligados a essa capacidade de resiliência tal como a busca pelo apoio religioso e psicológico e o apoio coletivo incipiente. Os autores registram, ainda, a ocorrência do sofrimento experimentado solitariamente que, mesmo não sendo incomum, trata-se de uma opção pouco eficaz. 
Santos e Moreira (2014) enfatizam que situações-limites trazem, como consequência, transformações na vida dos profissionais, dando lugar à capacidade de resiliência, fortalecendo e construindo uma melhor competência para o cuidar. Os autores concluem destacando a importância de priorizar estudos voltados para a resiliência e estratégias coletivas que estimulem o compartilhamento de experiências de esgotamento físico e emocional, instituindo espaços de apoio aos profissionais de saúde.

Jones (2017) descreve um retiro como intervenção eficaz junto a um grupo de enfermeiros da área de oncologia. Como resultado, o autocuidado e a resiliência foram trabalhados, atingindo melhora significativa da qualidade de vida de enfermeiros oncológicos paliativistas. $\mathrm{O}$ autor se refere à atividade de cuidar do paciente que trava a luta contra o câncer como tarefa gratificante e inspiradora, porém que requer força física, mental e emocional que, não sendo devidamente trabalhada, podem favorecer ao adoecimento. Sofrimento contínuo, diagnósticos terminais, luto, perdas e morte são parte da realidade do paliar e, por isso, é importante um canal de compartilhamento de histórias, em sua maioria sobrepostas e interiorizadas pelos profissionais do cuidado. O autor ressalta a importância de dar voz aos trabalhadores como uma forma eficaz de promoção e autocuidado, e como sustentação de força para quem cuida. O retiro mostrou-se uma alternativa de promoção de qualidade de vida coletiva e individual eficaz.

\section{Discussão}

Diante das evidências apresentadas pelos artigos encontrados, pôde-se identificar que os mecanismos de enfrentamento são denominados de padrões diretos quando estão relacionados ao uso de habilidades para solucionar problemas, envolvendo o indivíduo em alguma ação que afeta a demanda de alguma forma. E padrões indiretos quando incluem estratégias que não modificam as demandas na realidade, mas altera a forma pela qual a pessoa experimenta a demanda (enfrentamento paliativo) (Fernandes \& Inocente, 2011).

Nesse sentido, o estudo evidenciou e identificou, nos artigos, fatores relacionados ao desenvolvimento do trabalho como situações que podem desencadear estresse.

Por mais que as publicações reconheçam que esses fatores são inerentes ao cotidiano do trabalho na enfermagem e, assim, fazem parte de suas vidas diárias, os profissionais precisam aprender a lidar e saber desenvolver meios de enfrentamento, visando melhorar as condições gerais de trabalho.

Os artigos apontam a necessidade de propor ações conjuntas entre o trabalhador e o seu ambiente de trabalho para que possa estar fortalecido, e para que tais estratégias o auxiliem na criação de mecanismos de compensação.

Os resultados evidenciam a necessidade de intervenção a fim de se oferecer um maior suporte para estes trabalhadores de modo a melhorar as condições de trabalho deste profissional cujas atividades visam à promoção e à recuperação da saúde de outrem.

Urge ressaltar a relevância do tema, pois o estresse, por vezes, pode ser benéfico e servir como um impulso durante diversas situações da vida destes profissionais. Contudo, quando os níveis ultrapassam o limite do aceitável, de acordo com as características individuais de cada indivíduo, pode se tornar nocivo, e gerar agravos e danos à saúde. 
É fundamental a elaboração de mecanismos de enfrentamento via estratégias organizacionais e individuais de intervenção que envolvam treinamento, capacitação e supervisão dos profissionais. Além disso, contemplar a inserção de novas práticas que aumentem a qualidade de vida dos profissionais, tais como: hábitos alimentares mais saudáveis, cuidados com a qualidade do sono, prática de exercícios físicos regulares, busca pela qualidade nas relações interpessoais, reorganização do tempo, e estabelecimento de prioridades, minimizando os danos à saúde, melhorando a qualidade de vida no trabalho, e refletindo na qualidade dos serviços prestados (Ferreira et al., 2017).

Biazzi (2013) sugere algumas medidas nesse sentido, a serem aplicadas nos ambientes de trabalho: 1) conscientização e compreensão do problema, ou seja, observar os sinais de sintomas apresentados pelos trabalhadores, que podem ser: a rotatividade, as faltas recorrentes, erros, conflitos, entre outros; 2) Monitoramento das ameaças através da identificação das causas que geram estresse ao trabalhador. Esse monitoramento pode ser executado por meio de pesquisas internas na instituição (questionários, testes etc.); 3) Preparação das pessoas para lidarem corretamente com os agentes estressores, ou seja, trata-se de estratégias preventivas, bem como de estratégias para superar o estresse. Possibilita ao trabalhador ampliar suas ações em níveis comportamentais e emocionais; 4) Tratamento das consequências do estresse, envolvendo, assim, gestores e organizações para assumirem responsabilidades e dar suporte ao trabalhador e familiares, e possibilitando formas de tratamentos eficazes (Biazzi, 2013).

\section{Conclusão}

Os mecanismos de enfrentamento se caracterizam por padrões diretos quando estão relacionados ao uso de habilidades para solucionar problemas, envolvendo o indivíduo em ações que afetam, de alguma forma, a demanda. Denominam, ainda, os padrões indiretos quando incluem estratégias que não modificam as demandas reais, mas alteram a forma pela qual o profissional experimenta a demanda, ou seja, trata-se do enfrentamento paliativo (Fernandes \& Inocente, 2011).

Sugerimos estudos futuros no conhecimento das percepções das práticas de enfrentamento em apoio à saúde mental dos profissionais de saúde. 


\section{REFERÊNCIAS}

Barros, N.G.C. \& Honório, L.C. (2015). Risco de Adoecimento no Trabalho de Médicos e Enfermeiros em um Hospital Regional do Mato-grossense. Rege, 22(1), 21-39.

Biazzi, S. (2013). Estresse, Burnout e estratégias de enfrentamento: Um estudo com professores de uma instituição educacional provada de São Paulo.

Borges, E. N. et al. (2019). Fadiga por compaixão em enfermeiros de urgência e emergência hospitalar de adultos. Rev. Latino-Am. Enfermagem, 27(e3175), 1-6.

Fernandes, G. \& Inocente, N. J. (2011). Estratégias para enfrentamento (coping): um levantamento bibliográfico. XIV INIC/XEPG, 1-5.

Ferreira, J. S.; Ribeiro, K. V.; Caramuru, P. S. et al. (2017). Estresse e estratégias de enfrentamento em trabalhadores de enfermagem de uma unidade de saúde da família. Rev Fund Care Online. 9(3), 818-823.

García, M. C. H. (2017). Fatiga por compasión entre profesionales sanitarios de oncología y cuidados paliativos. Psicooncología, 14(1), 53-70.

Jones, A. K. (2017). Oncology Nurse Retreat A strength-based approach to self-care and personal resilienc. Clinical Journal of Oncology Nursing, 21(2), 259-262.

Lorenceti, A. \& Simonetti, J. P. (2005). As estratégias de enfrentamento de pacientes durante o tratamento de radioterapia. Rev Latino-am Enfermagem, 13(6):944-50.

Monteiro, J. K. et al. (2013). Adoecimento psíquico de trabalhadores de unidades de terapia intensiva. Psicol. cienc. prof., 33(2), 366-379.

Javorski, A. R.; Bushatsky, M. \& Viaro, W. D. (2015). Palliative care in children with cancer: integrative review. Revista de Enfermagem, 9(2), 718-730.

Sansó, N; Galianab, L., Oliverb, A., Cuestac, P., Sánchezd, C. \& Benitoe, E. (2018). Evaluación de una Intervención Mindfulness en Equipos de Cuidados Paliativos. Psychosocial Intervention, 27(2), 81-88.

Santos, R. A. \& Moreira, M. C. N. (2014). Resiliência e morte: o profissional de enfermagem frente ao cuidado de crianças e adolescentes no processo de finitude da vida. Ciênc. saúde coletiva, 19(12), 4869-4878.

Santos, M. A. R. C. \& Galvão, M. G. A. (2014). A elaboração da pergunta adequada de pesquisa. Introduçao à Metodologia Científica, 4(2), 53-56.

Silveira, N. R. et al. (2016). Cuidado paliativo e enfermeiros de terapia intensiva: sentimentos que ficam. Rev. Bras. Enferm., 69(6), 1074-1081.

Soares, C. B., Hoga, L. A., Peduzzi, M., Sangaleti, C., Yonekura, T., \& Silva, D. R. (2014). Integrative review: Concepts and methods used in Nursing. Revista da Escola de Enfermagem USP, 48(2), 335-345.

Sobral, R. C.; Stephan, C.; Zanatta, A. B. \& De Luca S. R. (2018). Burnout and work organization in Nursing. Rev. Brasileira de Medicina do Trabalho, 16(1), 44-52.

Sousa, A. D. R. S.; Silva, L. F. \& Paiva; E. D. (2019). Intervenções de enfermagem nos cuidados paliativos em Oncologia Pediátrica: revisão integrativa. Rev Bras Enferm, 72(2), 556-566.

Souza, P. S. N. \& Conceição, A. O. F. (2018). Processo de morrer em unidade de terapia intensiva. Pediátrica. Revista Bioética, 26(1), 127-134.

Souza, M. T.; Silva, M. D. \& Carvalho, R. (2010). Revisão integrativa: o que é e como fazer. Einstein, 8(1), 102-106.

Vasconcelos, L. S.; Camponogara, S.; Dias, G. L.; Bonfada, M. S.; Beck, C. L. C. \& Rodrigues, I. L. (2019). Prazer e sofrimento notrabalho de enfermagem em unidade de terapia intensiva pediátrica. Rev Min Enferm. 23(e-1165), 1-6. 
NARRATIVA DOS IMPACTOS E REPERCUSSÕES DA

PANDEMIA DA COVID-19 NA PERSPECTIVA DO ENFERMEIRO

EMERGENCISTA: A ÓTICA NÃO ROMÂNTICA DA

LINHA DE FRENTE DO CUIDADO

Denilson da Silva Evangelista

Universidade Iguaçu - denilsonevan@gmail.com

Thiago Valentim de Oliveira Marins

Universidade Iguaçu - thiagovalentim1@hotmail.com

Cristiano Gomes Crispim

Universidade Iguaçu - christianogomys@hotmail.com

Keila do Carmo Neves

Universidade Iguaçu -keila_arcanjo@hotmail.com

Bruna Porath Azevedo Fassarella

Universidade Iguaçu - brunaporath@gmail.com

Wanderson Alves Ribeiro

Universidade Federal Fluminense - nursing_war@hotmail.com
Jully Camara Guinancio

Universidade Iguaçu - guinancioju@gmail.com

Júlio Gabriel Mendonça de Sousa

Universidade Federal do Rio de Janeiro - juliogabriel33@gmail.com

Bianca Lemos de Carvalho

Universidade Iguaçu - biancalemos.carvalho@hotmail.com

Ana Beatriz Teodoro de Souza

Universidade Iguaçu - beasouzateo@gmail.com

Amanda de Araujo Franco

Universidade Iguaçu - amanda.af3@gmail.com

Amanda de Almeida Floriano

Universidade Iguaçu - enf.amandafloriano@gmail.com

\section{RESUMO}

Trata-se de um estudo descritivo que busca descrever determinados fenômenos ou ações. Com a opção da abordagem qualitativa, a pesquisa encontrou no relato de experiência, uma oportunidade de conhecer práticas integrativas e complementares para o bem-estar social. A partir do relato, foi possível realizar uma reflexão acerca de elementos relevantes a serem considerados. Durante o processo assistencial, especialmente na atuação durante a pandemia, o enfermeiro pode ser submetido a um nível de estresse que causará danos físicos e psíquicos. Neste sentido, o presente estudo tem por objetivo identificar e analisar os fatores estressores vivenciados pelo profissional da saúde na linha de frente do combate à COVID-19. Para a análise do discurso, apresentamos as seguintes categorias: Sentimentos vivenciados frente à pandemia na perspectiva do profissional de saúde; Preocupação quanto à manutenção da saúde mental e 0 impacto das condições de trabalho e perda de colegas. Conclui-se que se faz necessário que atuações de intervenção sejam realizadas visando o comprometimento da gestão garantindo a segurança do profissional atuante com o fornecimento de equipamentos de proteção individual e também assistência voltada à saúde mental do indivíduo.

\section{Palavras-chave:}

Coronavírus; Estresse ocupacional; Enfermagem; Pandemia.adolescência.

\begin{abstract}
This is a descriptive study that seeks to describe certain phenomena or actions. With the option of a qualitative approach, the research found in the experience report, an opportunity to learn about integrative and complementary practices for social well-being. From the report, it was possible to reflect on relevant elements to be considered. During the care process, especially when working during a pandemic, the nurse may be subjected to a level of stress that will cause physical and psychological damage. In this sense, the present study aims to identify and analyze the stressors experienced by health professionals on the front lines of the fight against COVID-19. For discourse analysis, we present the following categories: Feelings experienced in the face of
\end{abstract}

the pandemic from the perspective of the health professional; Concern about maintaining mental health and the impact of working conditions and loss of colleagues. It is concluded that it is necessary that intervention actions are carried out aiming at the commitment of the management, guaranteeing the safety of the working professional with the supply of personal protective equipment and also assistance aimed at the individual's mental health.

\section{Keywords:}

Coronavirus; Occupational Stress; Nursing; Pandemic. 


\section{INTRODUÇÃO}

A pandemia da doença causada pelo novo coronavírus 2019 (COVID-19) tornou- se um dos grandes desafios do século XXI. Trata-se de um vírus isolado pela primeira vez em 1937 e em 1965 foi descrito como coronavírus, em virtude de seu perfil na microscopia, semelhante a uma coroa. Entre 2002 e 2003, a OMS notificou 774 mortes devido à síndrome respiratória aguda grave, o coronavírus denominado SARS-CoV-2 e, em 2012, foram confirmadas 858 mortes causadas pela síndrome respiratória do oriente médio (Mers-CoV), na Arábia Saudita, ambas as complicações ocasionadas por membros da família do coronavírus (Chanh; Yan; Wang, 2020; Oliveira; Lucas; Iquiapaza, 2020).

No Brasil, o registro do primeiro caso ocorreu em 26 de fevereiro de 2020 no estado de São Paulo e hoje já está disseminado por todo país. A pneumonia é a manifestação mais frequente e mais grave da infecção. Em geral, o paciente cursa com febre, tosse, dispneia e infiltrados bilaterais, nem sempre detectados no Raio X, muitas vezes necessitando de tomografia computadorizada para serem melhor visualizados. Os sinais e sintomas não diferem clinicamente da gripe sazonal, tornando mais um desafio no processo assistencial. (Araújo et al., 2020). O atual cenário não é satisfatório e surge a adoção de medidas de saúde pública pelos gestores a níveis federais, estaduais e municipais, com o objetivo de mitigar as taxas de morbimortalidade e erradicar a doença (BRASIL, 2020).

O insuficiente conhecimento científico sobre o novo coronavírus, sua alta velocidade de disseminação e capacidade de provocar mortes em populações vulneráveis geram incertezas quanto à escolha das melhores estratégias a serem utilizadas para o enfrentamento da pandemia. Os hospitais estão sobrecarregados com o atendimento aos pacientes infectados pelo vírus, resultando em maiores demandas dos profissionais atuantes na linha de frente e sendo possível fonte geradora de estresse. Nesse contexto, a enfermagem brasileira está enfrentando grandes desafios, sem precedentes históricos em sua atuação, nos diversos cenários da assistência à saúde, sendo convocada a revisar a sua prática e a elaborar novas estratégias para minimizar os impactos, como o estresse, gerados pela pandemia no atendimento aos pacientes com COVID-19 (RAMOS, 2020).

A exposição prolongada a fatores estressores, resulta no estresse ocupacional, que por sua vez contribui com o aumento da exaustão emocional e da despersonalização, assim como com a baixa realização profissional. Devido ao trabalho exaustivo e tenso, os profissionais de enfermagem estão mais propensos a desenvolver o estresse ocupacional (ABDO et al., 2016) que com o tempo pode desencadear diversos transtornos mentais (BIANCHI et al., 2015). Tal realidade, vivida no ambiente de trabalho atual, provoca desgastes, resultando em uma baixa qualidade de vida para os trabalhadores, e, consequentemente, pode gerar alterações na saúde física e mental do profissional de enfermagem, contribuindo diretamente para o crescimento do absenteísmo no trabalho, afastamentos, exigência de readaptação de funções, queda da produtividade e possível perda da qualidade dos serviços prestados (KOGIEN, 2014).

Atualmente a palavra estresse tem sido muito recorrida, associada a sensações de desconforto, sendo cada vez maior o número de pessoas que se definem como estressadas ou relacionam a outros 
indivíduos na mesma situação. O trabalho árduo e prolongado pode interferir negativamente na saúde, aparecendo como fonte de estresse e expondo o trabalhador ao estresse ocupacional (SANTOS et al., 2017). Essa condição oferece sintomas físicos ou mentais, em consequência de acontecimentos do ambiente de trabalho e/ou suas atividades, destacando os profissionais de saúde atuasse na linha de frente da COVID-19. Além de poder estar relacionado ao ambiente e sobrecargas de trabalho, esse tipo de estresse pode estar associado às situações que desestruturam esse profissional (UENO et al., 2017).

Nessa situação, destaca-se o profissional enfermeiro, que, durante o processo assistencial, pode ser submetido a um nível de estresse que causará danos físicos e psíquicos (MACHADO et al., 2018). Relacionado ao estresse, surgem outros fatores que auxiliam no desgaste físico e mental, como por exemplo, condições de trabalho precárias, altas jornadas e sobrecarga de trabalho, exposição a fatores de riscos, desmotivação profissional, baixa remuneração e dupla jornada de serviços, o que resulta em reflexos negativos na qualidade de vida desse profissional. O elevado nível de estresse comum ao setor de trabalho, acarreta em riscos de falhas durante o processo assistencial, o que reflete diretamente na segurança do cuidado prestado (ABDO et al., 2016).

O estresse ocupacional é resultante da forma como a pessoa lida com as necessidades do trabalho e do modo como realiza o seu enfrentamento. Diversas são as fontes geradoras de estresse, e essas podem interferir no nível de estresse individual apresentado pelo profissional de enfermagem (UENO et al., 2017). Nesse sentido, para suportar situações estressantes, podem ser utilizadas diversas estratégias de enfrentamento, de modo a permitir vivenciá-las melhor, evitando condições patológicas (ANDOLHE et al., 2015). É importante que o profissional de enfermagem reconheça, portanto, os fatores estressores do ambiente de trabalho, principalmente diante de uma situação atípica como a atual pandemia (Oliveira et al., 2017).

Neste sentido, o presente estudo tem por objetivo identificar e analisar os fatores estressores vivenciados pelo profissional da saúde na linha de frente do combate à COVID-19.

\section{METODOLOGIA}

Com relação aos aspectos metodológicos, o estudo caracteriza-se como descritivo que, segundo Gil (2014) é o estudo que busca descrever determinados fenômenos ou ações. Com a opção da abordagem qualitativa, a pesquisa encontrou no relato de experiência, uma oportunidade de conhecer práticas integrativas e complementares para o bem-estar social. Nesse sentido, Minayo (2013) corrobora que a pesquisa qualitativa se aprofunda no mundo dos significados, das essências, das relações humanas, das atitudes, das crenças e dos valores, explorando, assim, uma realidade que não pode ser captada pelos dados quantitativos.

A coleta das informações se deu com um enfermeiro, residente do Estado do Rio de Janeiro, que exerce atividade laborativa no setor de emergência, na linha de frente de um hospital de grande porte, situado na Baixada Fluminense, no mês de maio de 2020, especificamente, 45 dias após o início da quarentena.

Nesse sentido, a coleta de dados foi por meio de entrevista estruturada, com duas questões abertas, previamente agendada, e realizada após plantão de 24 horas do profissional, com duração média de uma hora e vinte e cinco minutos. Os pesquisadores abordaram o enfermeiro por via chamada de vídeo, realizado por aplicativo de celular, cumprindo a assim o isolamento social, evitando o deslocamento e a aproximação do participante e dos pesquisadores. 
Cabe mencionar que a coleta foi realizada por três dos pesquisadores, todos em ambiente reservados, sem a presença de terceiros, com o objetivo de garantir o mínimo de interferências, pois, de acordo com Neto (2003) a entrevista deve ser caracterizada por um ambiente afável, de modo que a pessoa possa responder as arguições sem nenhum constrangimento. Por sua vez, o participante também se manteve sozinho durante a entrevista.

A entrevista foi gravada e transcrita pelos três pesquisadores, de forma individual, com o objetivo de não eliminar nenhuma informação que resultasse na perda do sentido na fala do entrevistado, para tornar o conteúdo familiar, facilitando a percepção dos conteúdos dos depoimentos. Utilizou-se o recurso de gravação do aplicativo do telefone portátil, registrando a entrevista de forma integral.

Optou-se por este tipo de entrevista, pois conforme Minayo (2013) a entrevista semiestruturada permitir maior flexibilidade nas conversas, com possibilidade de absorver novos temas e questões trazidas pelo interlocutor entrevistado. Assim, neste estudo elaborou-se um roteiro de entrevista composto por duas perguntas. A primeira arguia o participante sobre os principais fatores estressores advindos da atuação na linha de frente, em assistência aos pacientes com COVID-19 no setor de emergência. A segunda, questionou o paciente sobre as possíveis estratégias de enfrentamento dos fatores estressores, resultado da advindos da atuação na linha de frente, em assistência aos pacientes com COVID-19 no setor de emergência.

A escolha do pesquisado se deu de forma intencional (MINAYO, 2013), com o consentimento em relatar sua experiência de vida. Na análise dos dados, proposta por Bardin, (2016), optou-se pela análise de conteúdo temática, cuja operacionalidade se distingue em três etapas: a pré-análise; a exploração do material; e o tratamento dos resultados, com a inferência e as interpretações.

Os dados foram coletados após a aprovação do Comitê de Ética em Pesquisa da Universidade Iguaçu, número do Parecer: 3.380.665, com Certificado de Apresentação para Apreciação Ética (CAAE) de número 13532719.2.0000.8044 e mediante a assinatura do Termo de Consentimento Livre e Esclarecido (TCLE) pela participante, através de formulário online. Apoiou-se ainda, nas orientaçõese disposições da Resolução no 466/12, do Conselho Nacional de Saúde, que descrevem as diretrizes e normas que regulamentam os processos investigativos envolvendo seres humanos, sendo atendidas as recomendações em todas as fases da pesquisa.

\section{RESULTADO}

O relato: "A pandemia já me preocupava por meados de janeiro, uma doença nova assusta qualquer um. E ainda mais se espalhando e disseminando de uma forma agressiva e tão rápida. Eu estava feliz na época, tinha acabado de entrar em um emprego novo, hospital que sempre tive vontade de trabalhar, desde que tinha feito a primeira visita técnica na época da faculdade em 2004 e 15 anos depois consegui!“

O crescimento da doença assustava o mundo inteiro, ainda mais depois que a mesma ganhou a Europa, e de longe nós assistíamos a nossos colegas de trabalho mundo a fora sucumbindo e perdendo a vida por enfrentar na linha de frente tal doença. E cada vez mais eu ficava assustado, por conhecer a realidade da nossa saúde. Como profissionais da saúde estão morrendo com todos aqueles aparatos tecnológicos em Equipamentos de Proteção Individuais?

Chegaram os primeiros casos suspeitos e isolados no Brasil! E governantes fingindo não saberem 
dos casos para não afetarem o carnaval! Também com todo dinheiro que o carnaval trás para as mãos do governo, era só um sonho mesmo pensar no cancelamento.

No início de março já se começa a preocupação de mais amigos e colegas de profissão, pois as notícias na Europa não eram das melhores, cada vez mais e mais pessoas morriam e com elas profissionais da saúde também. Enquanto isso aqui no Brasil os casos suspeitos com pessoas apresentando os sintomas aumentava substancialmente e então a minha preocupação só aumentava, trabalho na emergência de um hospital estadual, e nós sabemos como nos faltam tudo a anos. Leitos, leitos de centros de tratamentos intensivos/unidades de tratamentos intensivos e vários medicamentos, materiais de limpeza, equipamentos de proteção individual para nós profissionais da saúde. Era só o começo de tudo.

Então você a cada plantão vai vendo pacientes sendo remanejados para outros setores, outros serviços sendo fechados, tudo para tentar se preparar para recebermos algo que não estamos prontos para lidar, o pavor só cresce dentro de cada um de nós, até que começam a chegar, durante dia e noite, pacientes e mais pacientes apresentando sintomas predominantes do SARS-COV-2.

Então você começa a enxergar plantão após plantão que seus colegas começam a se afastar, pois os mesmos passaram a ter os sintomas. E dentro de você só cresce a angústia, o medo, o pavor, pois você tem família, uma esposa, enteados e uma bebê que acabara de completar 8 meses. Como ficam a sua saúde mental? Eu não sei dizer. Apenas que a minha maior vontade é de não voltar para casa, mas e aí, pra onde você vai? Sua mãe também é hipertensa, idosa.

Já no início de abril, começamos a ver nossos colegas de profissão aqui, do nosso lado, a também ficarem pelo caminho na luta direta contra essa tormenta mundial, e você além de se sentir impotente também se pergunta: será que eu serei o próximo? Ainda mais quando você acabará de assistir uma notícia no jornal de que uma colega de trabalho que contraiu o COVID-19 em seu local de trabalho e mesmo assim ela não conseguiu atendimento onde trabalhava, e foi mandada pra casa e após alguns dias teve piora do quadro e após transferência para hospital no interior do estado, não resiste, desesperador! Ansiedade toma conta, sua família em quarentena a quase 60 dias e eles também estão à flor da pele, todos engordando, outros bebendo para tentar se distrair, outros se auto medicando com medicações pesadas, mas continuamos seguindo em frente, apesar de todo o terror!

Final de abril e início de maio, já não há respiradores suficientes, então você já começa a perceber que estão usando a escolha de Sofia e é nesse momento que você sabe que o caos já está instalado completamente.

Promessas de governantes sobre hospitais de campanha não cumpridas, a população em sua maioria não contribuindo com o isolamento social! E você com toda certeza de anos de experiência, sabe que todas essas combinações somadas só irá contribuir para cada vez mais pessoas infectadas.

\section{DISCUSSÃO}

O relato de experiência supracitado, permite a reflexão acerca de elementos relevantes a serem considerados. Para a análise do discurso, apresentamos as seguintes categorias: 


\section{Sentimentos vivenciados frente à pandemia na perspectiva do profissional de saúde}

Existem aproximadamente 59 milhões de profissionais de saúde no mundo (Joseph, 2015). No Brasil, cerca de 3,5 milhões de trabalhadores são da área da saúde (IBGE, 2018). No momento, a maioria deles atua ativamente no combate à COVID-19. Esses profissionais estão sendo vistos pela população não como solução para resolver a pandemia, mas sim como foco de contaminação da doença (United Nations, 2020). Profissionais de saúde, que já vinham sofrendo com atos de violência dentro dos locais de trabalho (SILVA et al., 2019), após o surgimento da COVID-19 passaram a ser vítimas também de agressões extramuros (WHO, 2020). É possível através de noticiários, internet e mídias sociais ter acesso às informações sobre atos de violência e discriminação contra profissionais de saúde. Agressões essas que podem ser verbais e até físicas (ALMEIDA, 2020).

Os atos de discriminação e humilhação vão desde xingamentos até expulsão de transportes públicos (JUNIOR, 2020) e hotéis (BISKIN, 2020). Todas essas ocorrências vêm sendo observadas em diversos países como Turquia, México, Filipinas, Estados Unidos, Índia, Reino Unido e Brasil (PUNZALAN et al., 2020). Organizações mostram- se preocupadas com a situação e pedem que as autoridades tenham tolerância zero ao assédio verbal, físico e psicológico deferido aos profissionais de saúde (WHO, 2020).

Em linhas gerais, na vigência de pandemias, a saúde física das pessoas e o combate ao agente patogênico são os focos primários de atenção de gestores e profissionais da saúde, de modo que as implicações sobre a saúde mental tendem a ser negligenciadas ou subestimadas (ORNELL et al., 2020). Contudo, medidas adotadas para reduzir os impactos psicológicos da pandemia não podem ser desprezadas nesse momento (BROOKS et al., 2020; XIAO, 2020). Se isso ocorre, geram-se lacunas importantes no enfrentamento dos desdobramentos negativos associados à doença, o que não é desejável, sobretudo porque os impactos psicológicos podem ser mais duradouros e prevalentes que o próprio acometimento pela COVID-19 (ORNELL et al., 2020).

Estudos têm sugerido que o medo de ser infectado por um vírus potencialmente fatal, de rápida disseminação, cujas origens, natureza e curso ainda são pouco conhecidos, acaba por afetar o bemestar psicológico de muitas pessoas (ASMUNDSON; TAYLOR, 2020; CARVALHO et al., 2020). Sintomas de depressão, ansiedade e estresse diante da pandemia têm sido identificados na população geral (WANG et al., 2020) e, em particular, nos profissionais da saúde (ZHANG et al., 2020). Ademais, casos de suicídio potencialmente ligados aos impactos psicológicos da COVID-19 também já foram reportados em alguns países (JUNG; JUN, 2020; GOYAL et al., 2020).

Contudo, muitos profissionais da saúde no Brasil não têm experiência de atuação em emergências de grande porte, como é o caso da COVID-19, o que representa um estressor adicional (BARROSDELBEN et al., 2020). Logo, sugere-se a realização de intervenções voltadas à orientação sobre sintomas psicológicos que profissionais da saúde podem apresentar nesse contexto (ex., estresse, depressão, ansiedade e insônia; Zhang et al., 2020), bem como estratégias de enfrentamento e autocuidado (TAYLOR, 2019).

Complementarmente, considerando relatos de profissionais da saúde sobre preocupações e sentimento de isolamento pelo afastamento da família e dos amigos (TAYLOR, 2019), psicólogos podem contribuir para o fortalecimento da rede de apoio, ao incentivá-los à manutenção de contato frequente, por meio de telefonemas, mensagens de texto, áudio e vídeo, durante os intervalos no trabalho (CHEN et al., 2020). Isso tende a beneficiar também a saúde mental das pessoas da rede 
de apoio dos profissionais da saúde, pois mantê-las informadas pode reduzir as emoções negativas, como o medo (BANERJEE, 2020).

Sobre os sentimentos vivenciados pelos profissionais da saúde em relação às intervenções psicológicas, destaca-se a possibilidade de baixa adesão, em função da falta de tempo e do cansaço pela sobrecarga de trabalho, em particular para aqueles que estão na linha de frente (LI ET AL., 2020a). Ademais, no Brasil, é possível que profissionais da saúde venham a se preocupar com questões como escassez de equipamentos de proteção individual, e venham a considerar as intervenções psicológicas como secundárias ou sem prioridade. Assim, para psicólogos que atuam em hospitais e outros serviços de saúde, sugere-se a realização de visitas à área de descanso para escutar os desafios vivenciados pelos profissionais e acolhê-los (CHEN et al., 2020), ou mesmo para sensibilizá-los ou estimulá-los a buscar auxílio psicológico, se necessário.

\section{Preocupação quanto à manutenção da saúde mental}

Estudos sobre impactos na saúde mental em decorrência da pandemia do novocoronavírus ainda são escassos, por se tratar de fenômeno recente, mas apontam para repercussões negativas importantes. Além disso, pesquisas anteriores sobre outros surtos infecciosos revelaram desdobramentos desadaptativos, em curto, médio e longo prazo, para a população geral e para os profissionais da saúde (JIANG et al., 2020; TAYLOR, 2019).

Na epidemia de Ebola de 1995, por exemplo, os sobreviventes relataram principalmente medo de morrer, de infectar outras pessoas, de se afastar ou sofrer abandono nas relações com familiares e amigos, bem como estigmatização social; os profissionais da saúde, por outro lado, reportaram sobretudo medo de contrair a doença e, ainda, transmiti-la a seus familiares, sofrimento por estarem afastados de seus lares, estresse, sensação de perda de controle e de desvalorização, além de preocupação com o tempo de duração da epidemia (HALL, HALL, CHAPMAN, 2008).

Situação semelhante ocorreu em 2003, durante a epidemia de Síndrome Respiratória Aguda Grave (Severe Acute Respiratory Syndrome Coronavirus-SARS), um outro tipo decoronavírus, quando os impactos psicológicos decorrentes da doença foram maiores que os impactos médicos, em termos de número de pessoas afetadas e tempo de duração em que elas foram afetadas (TAYLOR, 2019).

Sobre a COVID-19, em particular, os desafios enfrentados pelos profissionais da saúde podem ser um gatilho para o desencadeamento ou a intensificação de sintomas de ansiedade, depressão e estresse (BAO et al., 2020), especialmente quando se trata daqueles que trabalham na chamada "linha defrente", ou seja, em contato direto com pessoas que foram infectadas pelo vírus (LI ET AL., 2020b).

Para esses profissionais da saúde que experienciam níveis de sofrimento mais severos relacionados à pandemia, intervenções psicológicas mais intensivas tendem a ser necessárias (TAYLOR, 2019). Esses casos frequentemente incluem profissionais com suspeita ou diagnóstico confirmado e seus familiares (SHOJAEI; MASOUMI, 2020), profissionais e familiares hospitalizados ou que passaram pela experiência de hospitalização (DUAN; ZHU, 2020), profissionais vivenciando o processo de terminalidade ou a morte de familiares (LI ET AL., 2020a), em particular aqueles que não puderam se despedir presencialmente ou acompanhar o falecido em função da pandemia (BARROS-DELBEN et al., 2020). 
As demandas psicológicas tendem a se modificar de acordo com a progressão da doença ou da ocorrência dos fatos relacionados a ela, o que se alinha a intervenções psicológicas dinâmicas (ZHANG et al., 2020). Sempre que necessário, deve-se fazer encaminhamentos a outros profissionais ou serviços de saúde (TAYLOR, 2019). Nesse sentido, em 23 de março de 2020, o CFP enviou um ofício circular a gestores públicos, empregadores de psicólogos e usuários de serviços. Por meio desse documento, recomendou-se a suspensão das atividades de psicólogos na modalidade presencial em todo o país, com exceção daquelas comprovadamente emergenciais, ocasião em que devem ser ofertadas condições adequadas de prevenção e proteção contra o novo coronavírus, incluindo máscaras e álcool 70\% (CFP, 2020b).

Dadas as rigorosas medidas que os serviços de saúde adotam para contenção da infecção, o contato direto entre o psicólogo e as pessoas que têm COVID-19 costuma ser raro (Jiang et al., 2020). Assim, profissionais da saúde que trabalham na linha de frente, como enfermeirose médicos, serão aqueles que predominantemente escutarão queixas e oferecerão apoio psicológico às pessoas que buscam os serviços de saúde ou que estão hospitalizadas (DUAN; ZHU, 2020).

Portanto, psicólogos podem contribuir para promoção da saúde mental e prevenção de impactos psicológicos negativos aos profissionais da saúde, ao oferecer a eles suporte e orientação sobre como manejar algumas situações. Isso parece importante, pois dentre os desafios relatados por profissionais da saúde, destaca-se atender pessoas que testaram positivo para o novo coronavírus e que não compreendem as recomendações ou se recusam a aderir ao tratamento (CHEN ET AL., 2020), bem como lidar com a frustração por não conseguir salvar vidas, apesar de todos os esforços (TAYLOR, 2019).

\section{O impacto das condições de trabalho e perda de colegas}

Os profissionais da saúde costumam experienciar estressores no contexto de pandemias, como: risco aumentado de ser infectado, adoecer e morrer; possibilidade de inadvertidamente infectar outras pessoas; sobrecarga e fadiga; exposição a mortes em larga escala; frustração por não conseguir salvar vidas, apesar dos esforços; ameaças e agressões propriamente ditas, perpetradas por pessoas que buscam atendimento e não podem ser acolhidas pela limitação de recursos; afastamento da família e dos amigos; e, a perda dos colegas da equipe (TAYLOR, 2019).

Em geral, esses profissionais vêm sendo desencorajados a interagir de maneira próxima com outras pessoas, o que tende a aumentar o sentimento de isolamento; têm lidado com mudanças frequentes nos protocolos de atendimento, em decorrência de novas descobertas sobre a COVID-19; e, ainda, costumam despender um tempo significativo do seu dia para colocar e remover os equipamentos de proteção individual, o que aumenta a exaustão relacionada ao trabalho (ZHANG et al., 2020). Nesse sentido, na China, equipes de saúde mental passaram a observar sinais de sofrimento psicológico, irritabilidade aumentada e recusa a momentos de descanso por parte de profissionais da saúde que trabalhavam na linha de frente (CHEN et al., 2020).

Muitos profissionais da saúde que atuam na linha de frente, expostos ao vírus diariamente, destacando os profissionais de Enfermagem, foram infectados em todo o mundo; na Itália, esse número chegou a $20 \%$ no final do mês de março de 2020, de forma que o acesso a equipamentos de proteção individual para profissionais da saúde é preocupação central (The Lancet, 2020). No Brasil, a imprensa tem divulgado a escassez de equipamentos de proteção individual e o maior índice de 
licenças médicas a profissionais da saúde, como parece ser o caso de servidores municipais de São Paulo, na comparação entre a primeira e a segunda quinzena de março de 2020 (Folha de São Paulo, 2020b).

Ainda quando não atuam na linha de frente ou mesmo quando precisam se afastar dessa atuação temporariamente, profissionais da saúde podem apresentar sofrimento psicológico em contextos de emergências de saúde (BROOKS et al., 2020; LI et al., 2020b). Nesse sentido, destaca-se o fenômeno de "traumatização vicária"(também denominado "traumatização secundária"), em que pessoas que não sofreram diretamente um trauma (ex., desastre ou situação cruel) são afetadas e passam a apresentar sintomas psicológicos decorrentes da empatia por quem sofreu diretamente um trauma (Ll et al., 2020b).

Em estudo realizado na China, LI et al. (2020b) investigaram a traumatização vicária relacionada à COVID-19 junto a uma amostra composta por 214 pessoas da população geral, 234 enfermeiros que trabalhavam na linha de frente e 292 enfermeiros que não trabalhavam na linha de frente ( $\mathrm{n}=$ 740). Os achados evidenciaram níveis significativamente maiores de traumatização vicária em enfermeiros que não trabalhavam na linha de frente em comparação a enfermeiros que trabalhavam na linha de frente. Segundo os autores, uma das possíveis explicações para esse resultadoé a de que a traumatização vicária em enfermeiros que trabalham na linha de frente é derivada da empatia pelas pessoas que têm COVID-19, ao passo que enfermeiros que não trabalham na linha de frente mostram empatia pelas pessoas que têm COVID-19, mas também empatia e preocupação com os colegas da "linha de frente". Além disso, enfermeiros que trabalham na linha de frente podem ter maior preparo e habilidades psicológicas para lidar com emergências de saúde em comparação a enfermeiros que não trabalham na linha de frente (LI et al., 2020b).

Assim, mesmo quando precisam se afastar das funções laborais (ex., quando a quarentena é necessária), profissionais da saúde tendem a reportar culpa, raiva, frustração e tristeza (BROOKS et al., 2020), o que sugere a importância da atenção psicológica a essa população no contexto de pandemias. Intervenções psicológicas voltadas aos profissionais da saúde desempenham um papel central para lidar com os impactos na saúde mental em decorrência da pandemia do novo coronavírus (BAO et al., 2020; SHOJAEI; MASOUMI, 2020; ZHOU, 2020). Autoridades sanitárias, organizações ligadas à saúde e cientistas em diferentes países têm divulgado orientações para práticas alinhadas às demandas do atual contexto (APA, 2020; CFP, 2020a; JUNG; JUN, 2020; OMS, 2020b).

Em geral, recomenda-se que as intervenções psicológicas face a face sejam restritas ao mínimo possível (ex., atendimento a profissionais da saúde que trabalham na linha de frente e não foram infectados), para minimizar o risco de propagação do vírus(Jiang et al., 2020). Assim, serviços psicológicos realizados por meios de tecnologia da informação e da comunicação, incluindo internet, telefone e carta, têm sido sugeridos (JIANG et al., 2020; WANG et al., 2020; XIAO, 2020). Em outras epidemias, como a SARS, o atendimento psicológico remoto se tornou rapidamente um mecanismo importante para acolhimento àa queixas relativas à saúde mental (DUAN; ZHU, 2020). No Brasil, em 26 de março de 2020, foi publicada a Resolução CFP $n$ ㅇ 4/2020, que permite a prestação de serviços psicológicos por meios de tecnologia da informação e da comunicação após realização do "Cadastro e-Psi", embora não seja necessário aguardara emissão de parecer para iniciar o trabalho remoto. A Resolução CFP no 4/2020 suspende, durante o período de pandemia do novo coronavírus, os Art. 3으, Art. 4으, Art. 6으, Art. 7으 e Art. 8ㅇ da Resolução CFP no 11/2018. Portanto, passa a ser 
autorizada a prestação de serviços psicológicos por meios de tecnologia da informação e da comunicação a pessoas e grupos em situação de urgência, emergência e desastre, bem como de violação de direitos ou violência, buscando minimizar os impactos psicológicos diante da COVID-19 (CFP, 2020a).

Devido a crescente demanda relacionada à saúde mental nesse período, a escassez de profissionais capacitados para acolhê-la, bem como a necessidade de respostas rápidas e eficientes, algumas localidades têm proposto uma classificação de pessoas e grupos afetados pelo novo coronavnírus, a ser considerada na priorização para oferta das intervenções. A Comissão Nacional de Saúde da China, por exemplo, propôs uma classificação em quatro níveis: (1) Casos mais vulneráveis a problemas de saúde mental, como pessoas hospitalizadas com infecção confirmada e profissionais da saúde que trabalhem ou não na linha de frente; (2) Pessoas isoladas com sintomas leves, suspeitas de infecção ou em contato próximo com casos confirmados; pessoas com sintomas como febre; (3) Pessoas em contato próximo com casos descritos nos níveis 1 e 2, ou seja, familiares, amigos e colegas; equipes de resgate que participem de ações de resposta à COVID-19; (4) Pessoas afetadas pelas medidas de prevenção e controle, grupos suscetíveis e população geral (DUAN; ZHU, 2020; JIANG et al., 2020; LI et al., 2020a). Sistemas semelhantes de classificação também foram propostos na Coreia do Sul (JUNG; JUN, 2020) e no Irã (SHOJAEl; MASOUMI, 2020).

Sobre as temáticas de saúde mental relacionadas aos profissionais da saúde, destacam-se: informações sobre reações esperadas no contexto de pandemia, como sintomas de ansiedade e estresse, além de emoções negativas, como tristeza, medo, solidão e raiva (WEIDE et al., 2020); estratégias para promoção de bem-estar psicológico, a exemplo de medidas para organização da rotina de atividades diárias sob condições seguras, cuidado com o sono, prática de atividades físicas e de técnicas de relaxamento (BANERJEE, 2020); cuidado com a exposição em excesso a informações, incluindo noticiários na televisão e em outras mídias (BARROS-DELBEN et al., 2020); e, importância da checagem da veracidade de informações (BAO et al., 2020).

\section{CONCLUSÃO}

Os profissionais de saúde que participam da assistência ao paciente portador e acometido grave por COVID-19, demonstram a incansável busca pelo saber e a melhor forma assistencial voltada ao paciente. A equipe de enfermagem, se faz fundamental e demostra o quanto a dinâmica da assistência faz-se importante para o bom prognóstico do doente assistido. Diante desta, é possível observar a exigência inconsciente da equipe de enfermagem atuante frente a este cenário, visando de caráter integral a excelência, levando à sentimentos reflexivos de exaustão, cansaço e frustração quando esta não é alcançada.

Se faz necessário que atuações de intervenção sejam realizadas visando o comprometimento da gestão garantindo a segurança do profissional atuante com o fornecimento de equipamentos de proteção individual e também assistência voltada a saúde mental do indivíduo, garantindo assim, que este tenha as suas inquietações amparadas, articulando a saúde mental do profissional com a qualidade de assistência que este está disposto a oferecer ao seu paciente. 


\section{REFERÊNCIAS}

ABDO SA, El-SALLAMY RM, EI-SHEBINY AA, KABBASH IA. Burnout among physicians and nursing staff working in the emergency hospital of Tanta University, Egypt. East Mediterr Health J. 2016;21(12):906-15.

Almeida A. Em protesto em Brasília, enfermeiros são agredidos por apoiadores de Bolsonaro. O Globo [Internet]. 2020[acesso em 2020 maio 05]. Disponível em: https://oglobo.globo.com/sociedade/ coronavirus/em-protestoem-brasiliaenfermeiros-sao-agredidos-porapoiadores-de-bolsonaro-24406003

American Psychological Association. (2020). Pandemics. Retrieved from https://www.apa.org/practice/ programs/dmhi/research-information/pandemics

ANDOLHE R, BAR RLBOSA, OLIVEIRA EM, COSTA ALS, PADILHA KG. Stress, coping and burnout among Intensive Care Unit nursing staff: associated factors. Rev Esc Enferm USP. 2015;49(spe):57-63. doi: 10.1590/S0080623420150000700009.

ARAÚJO, C, S, F, L; STRINA, A; GRASSI, G, R, F, M; TEIXEIRA, G, M. Aspectos clínicos e terapêuticos da infecção da COVID-19. 2020 Acessado em: https://www.arca.fiocruz.br/handle/icict/40662; 14/04/2020, 10:40.

Asmundson, G. J. G., \& Taylor, S. (2020). Coronaphobia: fear and the 2019-nCoV outbreak. Journal of Anxiety Disorders, 70, 102196. http://dx.doi.org/10.1016/j.janxdis.2020.102196

Banerjee, D. (2020). The COVID-19 outbreak: crucial role the psychiatrists can play. Asian Journal of Psychiatry, 50, 102014. http://dx.doi.org/10.1016/j.ajp.2020.102014

Bao, Y., Sun, Y., Meng, S., Shi, J., \& Lu, L. (2020). 2019-nCoV epidemic: address mental health care to empower society. The Lancet, 395(10224), e37-e38. http://dx.doi.org/10.1016/S0140-6736(20)30309-3

BARDIN, L. Content Analysis. Lisboa (PT): Edições 70; 2016.

Barros-Delben, P., Cruz, R. M., Trevisan, K. R. R., Gai, M. J. P., Carvalho, R. V. C., Carlotto, R. A. C., ... MalloyDiniz, L. F. (2020). Saúde mental em situação de emergência: COVID-19 [Ahead of print]. Revista Debates in Psychiatry, 10, 2-12. Recuperado de https://d494f813-3c95-463a-898c-ea1519530871.filesusr.com/ugd/c37608_ e2757d5503104506b30e50caa 6fa6aa7.pdf

BIANCHI R, SCHONDELF IS, LAURENT E. Is burnout separable from depression in cluster analysis? a longitudinal study . Soc Psychiatry Psychiatr Epidemiol. 2015;50(6):1005-11.

Biskin H. Saglik çalisanlari konakladiklari otelden kovuldu. GazeteDuvar [Internet]. 2020[cited 2020 Apr 28]. Available from: https://www.gazeteduvar.com.tr/gun dem/2020/04/13/saglik-calisanlarikonakladiklariotelden-kovuldu/

Brooks, S. K., Webster, R. K., Smith, L. E., Woodland, L., Wessely, S., Greenberg, N., \& Rubin, G. J. (2020). The psychological impact of quarantine and how to reduce it: rapid review of the evidence. The Lancet, 395(10227), 912-920. http:// dx.doi.org/10.1016/S0140-6736(20)30460-8

Carvalho, P. M. M., Moreira, M. M., Oliveira, M. N. A., Landim, J. M. M., \& Rolim Neto, M. L. (2020). The psychiatric impact of the novel coronavirus outbreak. Psychiatry Research, 286(112902), 1-2. http://dx.doi.org/10.1016/j. psychres.2020.112902

CHANH L.E; YAN, Y, WANG, L. Coronavirus disease 2019: Coronaviruses and blood safety. Transfus Med Rev. 2020 Feb 21.

Chen, Q., Liang, M., Li, Y., Guo, J., Fei, D., Wang, L., ... Zhang, Z. (2020). Mental health care for medical staff in China during the COVID-19 outbreak. The Lancet, 7(4), 15-16. http://dx.doi.org/10.1016/S2215-0366(20)30078-X

Cluver, L., Lachman, J. M., Sherr, L., Wessels, I., Krug, E., Rakotomalala, S., ... McDonald, K. (2020). Parenting in a time of COVID-19. The Lancet, 395, e64. http://dx.doi.org/10.1016/S0140-6736(20)30736-4 
Consejo General de la Psicología de España. (2020, 3 de octubre). Recursos de ayuda psicológica para afrontar el Covid-19. Recuperado el http://www.infocop.es/view_article.asp?id=8670\&cat=44

Conselho Federal de Psicologia. (2020a). Resolução do exercício profissional no4, de 26 de março de 2020. Dispõe sobre regulamentação de serviços psicológico prestados por meio de Tecnologia da Informação e da Comunicação durante a pandemia do COVID19. Recuperado de https://atosoficiais.com.br/cfp/resolucao-doexercicio-profissional-n-42020-dispoe-sobre-regulamentacao-de-servicos-psicologicos-prestados-por-meio-detecnologia-da-informacao-e-dacomunicacao-durante-a-pandemia-do-covid19?origin=instituicao

Conselho Federal de Psicologia. (2020b). Ofício-Circular no 40/2020/GTec/CG-CFP. Recuperado de https://site.cfp.org. br/wp-content/uploads/2020/03/SEI_CFP-0214041-Of\%C3\%ADcio-Circular_.pdf

DUAN, L., \& ZHU, G. (2020). Psychological interventions for people affected by the COVID-19 epidemic. The Lancet Psychiatry, 7(4), 300-302.

Duan, L., \& Zhu, G. (2020). Psychological interventions for people affected by the COVID-19 epidemic. The Lancet Psychiatry, 7(4), 300-302. http://dx.doi.org/10.1016/\$2215-0366(20)30073-0

Ferguson, N., Laydon, D., Nedjati Gilani, G., Imai, N., Ainslie, K., Baguelin, M., ... Ghani, A. (2020). Report 9: impact of non-pharmaceutical interventions (NPIs) to reduce COVID19 mortality and healthcare demand. http://dx.doi. org/10.25561/77482

GIL, A. C. Como elaborar projetos de pesquisa. 6 ed. São Paulo: Atlas, 2014.

Goyal, K., Chauhan, P., Chhikara, K., Gupta, P., \& Singh, M. P. (2020). Fear of COVID 2019: first suicidal case in India. Asian Journal of Psychiatry, 49(101989). http://dx.doi.org/10.1016/j.ajp.2020.101989

Hall, R. C. W., Hall, R., \& Chapman, M. J. (2008). The 1995 Kikwit Ebola outbreak: lessons hospitals and physicians can apply to future viral epidemics. General Hospital Psychiatry, 30(5), 446-452. http://dx.doi.org/10.1016/j. genhosppsych.2008.05.003

Instituto Brasileiro de Geografia e Estatística (IBGE). Síntese de indicadores sociais: uma análise das condições de vida da população brasileira: 2018[Internet]. Rio de Janeiro: IBGE; 2018[acesso em 2020 abr 28]. Disponível em: https://biblioteca.ibge.gov.br/visuali zacao/livros/liv101629.pdf

JOSEPH, JOSEPH M. The health of the healthcare workers. Indian j. occup. environ. med. [Internet]. 2016[cited 2020 Apr 28];20(2):71-2. Available from: https://www.ncbi.nlm.nih.gov/pmc/a rticles/PMC5299814/

Jung, S. J., \& Jun, J. Y. (2020). Mental health and psychological intervention amid COVID-19 Outbreak: perspectives from South Korea. Yonsei Medical Journal, 61(4), 271-272. http://dx.doi.org/10.3349/ymj.2020.61.4.271

Junior G. Profissionais de saúde são hostilizados em trens: 'Sai do vagão, seu doente'. Estadão [Internet]. 2020 [acesso em 2020 abr 28]. Disponível em: https://saude.estadao.com.br/noticia s/geral,profissionais-de-saudesaohostilizados-em-trens-sai-do-vagaoseu-doente,70003246731

KOGIEN M, CEDARO JJ. Public emergency department: the psychosocial impact on the physical domain of quality of life of nursing professionals. Rev Latino-Am Enferm, 2014.

Li, W., Yang, Y., Liu, Z. H., Zhao, Y. J., Zhang, Q., Zhang, L., ... Xiang, Y. T. (2020b). Progression of mental health services during the COVID-19 outbreak in China. International Journal of Biological Sciences, 16(10), 1732-1738. http://dx.doi. org/10.7150/ijbs. 45120

Li, Z., Ge, J., Yang, M., Feng, J., Qiao, M., Jiang, R., ... Yang, C. (2020a). Vicarious traumatization in the general public, members, and non-members of medical teams aiding in COVID-19 control. Brain, Behavior, and Immunity. http:// dx.doi.org/10.1016/j.bbi.2020.03.007

MACHADO DA, FIGUEIREDO NMA, VELASQUES LS, BENTO CAM, MACHADO WCA, VIANNA LAM. Cognitive changes in nurses working in intensive care units. Rev Bras Enferm. 2018;71(1):73-9. doi: 10.1590/0034-71672016-0513.

Matos, H. J. (2018). A próxima pandemia: estamos preparados? Revista Pan-Amazônica de Saúde, 9(3), 9-11. http://dx.doi.org/10.5123/S2176-62232018000300001 
MINAYO, M. C. S. O desafio do conhecimento: pesquisa qualitativa em saúde. 13 ed. São Paulo: Hucitec, 2013.

MINISTÉRIO DA SAÚDE (BR). Painel de casos de doença pelo coronavírus 2019 (COVID-19) no Brasil pelo Ministério da Saúde. Brasília: Ministério da Saúde; 2020[acesso 15 abril 2020]. Disponível em: https://covid.saude.gov.br

Ministério da Saúde. (2020a). Painel de casos de doença pelo coronavírus 2019 (COVID-19). Recuperado de https:// covid.saude.gov.br/

Ministério da Saúde. (2020b). Portaria no 639, de 31 de março de 2020. Dispõe sobre a Ação Estratégica "O Brasil Conta Comigo - Profissionais da Saúde", voltada à capacitação e ao cadastramento de profissionais da área de saúde, para o enfrentamento à pandemia do coronavírus (COVID-19). Diário Oficial da União. Brasília: Autor. Recuperado de http:// www.in.gov.br/en/web/dou/-/portaria-n-639-de-31-de-marco-de-2020-250847738

NETO, O.C. O trabalho de campo como descoberta e criação. In: MINAYO, M. C. S; Pesquisa social: teoria, método e criatividade. 22. ed. Petrópolis, RJ: Vozes, 2003.

OLIVEIRA EB, GALLASH CH, JUNIOR PPAS, OLIVEIRA AVR, VALÉRIO RL, DIAS LBS. Occupational stress and burnout in nurses of an emergency service: the organization of work. Rev Enferm UERJ. 2017;25:e28842. doi: 10.12957/reuerj.2017.28842.

OLIVEIRA, Adriana Cristina de; LUCAS, Thabata Coaglio; IQUIAPAZA, Robert Aldo. O que a pandemia da covid-19 tem nos ensinado sobre adoção de medidas de precaução?. Texto \& Contexto-Enfermagem, v. 29, 2020.

Ornell, F., Schuch, J. B., Sordi, A. O., \& Kessler, F. H. P. (2020). "Pandemic fear" and COVID-19: mental health burden and strategies. Brazilian Journal of Psychiatry. Retrieved from https://www.rbppsychiatry.org.br/ details/943/en-US/pandemic-fear--and-covid-19--mental-health-burden-and-strategies

Owen, L. (2020, March 8). Coronavirus: five ways virus upheaval is hitting women in Asia. BBC News. Retrieved from https://www.bbc.com/news/world-asia-51705199

Pautasso, M. (2020). The structure and conduct of a narrative literature review. In R. S. Tubbs, S. M. Buerger, M. M. Shoja, A. Arynchyna \& M. Karl (Eds.), A guide to the scientific career: virtues, communication, research, and academic writing (pp.299-310). Hoboken: Wiley Blackwell.

Punzalan J. Ambulance driver hurt after getting shot over parking row in Quezon. ABS-CBN News [Internet]. 2020[cited 2020 Apr 28]. Available from: https://news.abscbn.com/news/04/03/20/ambulancedriver-hurtafter-getting-shot-overparking-row-in-quezon

RAMOS, R.S. A Enfermagem Oncológica no Enfrentamento da Pandemia de Covid-19: Reflexões e Recomendações para a Prática de Cuidado em Oncologia. 2020. [acesso24abril2020]. Disponívelem:file:///C:/Users/wbar/Downloads/1007Texto\%20do\%20artigo-6130-1-10-20200430\%20(1).pdf

Rodrigues, A. (2020, 31 de março). Afastamentos por suspeitas de coronavírus explodem entre profissionais da saúde. Folha de S. Paulo. Recuperado de https://www1.folha.uol.com.br/equilibrioesaude/2020/03/com-altado-coronaviruslicencas-medicas-de-servidores-da-saude-aumentam-57-em-sp.shtml

Rothe, D., Gallinetti, J., Lagaay, M., \& Campbell, L. (2015). Ebola: beyond the health emergency. Retrieved from https:// plan-international.org/publications/ebola-beyond-health\%C2\%A0emergency

Russell, T. W., Hellewell, J., Abbott, S., Jarvis, C. I., van Zandvoort, K., CMMID nCov working group, Flasche, S., ... Kucharski, A. J. (2020). Using a delay-adjusted case fatality ratio to estimate under-reporting. Retrieved from https://cmmid.github.io/topics/covid19/severity/global_cfr_estimates.html

SANTOS NAR, SANTOS J, SILVA VR, PASSOS JP. Occupational stress in palliative care in oncology. Cogitare Enferm. 2017;22(4):e50686. doi: 10.5380/ce.v22i4 2.

Schmidt, B., Crepaldi, M. A., Bolze, S. D. A., Neiva-Silva, L., \& Demenech, L. M. (2020). Impactos na Saúde Mental e Intervenções Psicológicas Diante da Pandemia do Novo Coronavírus (COVID-19). Scielo Preprints. Versão 1. http://dx.doi.org/10.1590/SciELOPreprints.58

Shimizu, K. (2020). 2019-nCoV, fake news, and racism. The Lancet, 395(10225), 685-686. http://dx.doi.org/10.1016/S0140-6736(20)30357-3 
Shojaei, S. F., \& Masoumi, R. (2020). The importance of mental health training for psychologists in COVID-19 outbreak. Middle East Journal of Rehabilitation and Health Studies, 7(2), e102846. http://dx.doi.org/10.5812/mejrh.102846

Silva BDM, Martins JT, Moreira AAO. Violência laboral contra a equipe de enfermagem: revisão integrativa. Revista de saúde pública do paraná [Internet]. 2019[acesso em 2020 maio05];2(2):125-35.Disponível em: http://revista.escoladesaude.pr.gov.br/index.php/rspp/article/view/287/1 04

Taylor, S. (2019). The psychology of pandemics: preparing for the next global outbreak of infectious disease. Newcastle upon Tyne: Cambridge Scholars Publishing.

The Lancet (2020). COVID-19: protecting health-care workers (Editorial). The Lancet, 395(10228), 922. http://dx.doi. org/10.1016/S0140-6736(20)30644-9.

United Nations (UN). COVID-19 highlights nurses' vulnerability as backbone to health services worldwide 2020 [Internet]. 2020[cited 2020 Apr 28]. Available from: https://news.un.org/en/story/2020/0 4/1061232

Villela, D. A. M. (2020). The value of mitigating epidemic peaks of COVID-19 for more effective public health responses. Revista da Sociedade Brasileira de Medicina Tropical, 53, e20200135. http://dx.doi.org/10.1590/0037-8682-0135-2020

Wang, C., Pan, R., Wan, X., Tan, Y., Xu, L., Ho, C. S., \& Ho, R. C. (2020). Immediate psychological responses and associated factors during the initial stage of the 2019 coronavirus disease (COVID-19) epidemic among the general population in china. International Journal of Environmental Research and Public Health, 17(5), 1729. http://dx.doi. org/10.3390/ijerph17051729

Weide, J. N., Vicentini, E. C. C., Araujo, M. F., Machado,W. L., \& Enumo, S. R. F. (2020). Cartilha para enfrentamento do estresse em tempos de pandemia. Porto Alegre: PUCRS/PUC-Campinas.

XIAO, Chaolin et al. Clinical features of patients infected with 2019 novel coronavirus in Wuhan, China. The lancet, v. 395, n. 10223, p. 497-506, 2020.

ZHANG, Jin-jin et al. Clinical characteristics of 140 patients infected with SARS-CoV-2 in Wuhan, China. Allergy, v. 75, n. 7, p. 1730-1741, 2020.

ZHOU, Peng et al. A pneumonia outbreak associated with a new coronavirus of probable bat origin. nature, v. 579, n. 7798, p. 270-273, 2020. 


\title{
INTER-RELAÇÃO: MICROBIOTA ORAL E \\ DOENÇAS SISTÊMICAS, COM FOCO À ABORDAGEM MULTIDISCIPLINAR EM ODONTOLOGIA
}

\author{
Natália Franco Brum \\ Universidade Federal de Santa Maria - UFSM/RS \\ Patrícia Kolling Marquezan \\ Universidade Federal de Santa Maria - UFSM/RS \\ patimarquezan@hotmail.com
}

\section{RESUMO}

Partindo da abordagem do poeta inglês, Joseph Addison (1672-1719); “O que o sol é para as flores, os sorrisos são para a humanidade" (), percebe-se que os seres vivos como as plantas dependem do sol para viver (crescer, desenvolver e produzir flores), assim como as pessoas, visto que há necessidade de uma boa saúde oral para que realizem as suas atividades fisiológicas (através da mastigação e deglutição). A manutenção de uma condição oral satisfatória proporcionará sorrisos mais radiantes e bonitos, condizentes à saúde corpórea, como um todo. Com essa perspectiva, depreende-se que diversas doenças sistêmicas, como: Artrite Reumatoide (AR), Cânceres bucais (Carcinoma Epidermóide Bucal), Diabetes mellitus 1, Endocardite Bacteriana e Infecções Respiratórias, além de partos prematuros, são relacionadas à negligência dos cuidados bucais, os quais contribuem para o desenvolvimento de biofilmes dentários patogênicos e liberação de mediadores de virulência bacterianos (OLIVEIRA et al., 2017). Estes, ao serem secretados nos tecidos do hospedeiro, ativam o Sistema Imunológico, o qual libera citocinas inflamatórias visando à apoptose dos antígenos. Porém, pelo sistema de defesa apresentar-se debilitado, as suas células imunológicas acabam sendo utilizadas como uma forma de agregação de partículas nocivas e posteriormente, repercussões corpóreas (OLIVEIRA et al., 2017). Assim, o presente capítulo tem como objetivo demonstrar as interrelações entre a microbiota oral e algumas patologias sistêmicas, com foco à abordagem multidisciplinar (Anatomia, Estomatologia, Imunologia, Fisiologia, Histologia, Microbiologia e Patologia) e ressaltar a importância da cavidade oral em diversos contextos, tanto como forma de irradiação de doenças bucais, como de diagnósticos das patologias corpóreas. Concluindo-se que a manutenção da cavidade oral saudável é equivalente ao sol para as plantas (corroborando com o pensamento de Joseph Addison), ou seja, algo imprescindível à realização dos processos vitais.

\section{Palavras-chave:}

Odontologia; Microbiota oral; Doenças sistêmicas.

\section{ABSTRACT}

Ibased on the approach of the English poet, Joseph Addison (1672-1719); "What the sun is for flowers, smiles are for humanity" (), it is clear that living beings like plants depend on the sun to live (grow, develop and produce flowers), as well as people, since that there is a need for good oral health to perform their physiological activities (through chewing and swallowing). Maintaining a satisfactory oral condition will provide more radiant and beautiful smiles, consistent with bodily health, as a whole. With this perspective, it appears that several systemic diseases, such as: Rheumatoid Arthritis (RA), Oral cancers (Oral Squamous Cell Carcinoma), Diabetes mellitus 1, Bacterial Endocarditis and Respiratory Infections, in addition to premature births, are related to the neglect of oral care, which contribute to the development of pathogenic dental biofilms and release of bacterial virulence mediators (OLIVEIRA et al., 2017). These, when secreted in the host's tissues, activate the Immune System, which releases inflammatory cytokines aiming at the apoptosis of antigens. However, because the defense system is weakened, its immune cells end up being used as a form of aggregation of harmful particles and later, bodily repercussions (OLIVEIRA et al., 2017). Thus, this chapter aims to demonstrate the interrelationships between the oral microbiota and some systemic pathologies, focusing on the multidisciplinary approach (Anatomy, Stomatology, Immunology, Physiology, Histology, Microbiology and Pathology) and highlight the importance of the oral cavity in different contexts, both as a form of irradiation of oral diseases and diagnoses of bodily pathologies. In conclusion, the maintenance of a healthy oral cavity is equivalent to the sun for plants (corroborating the thought of Joseph Addison), that is, something essential to the

\section{Keywords:}

Dentistry; Oral microbiota; Systemic diseases. 


\section{INTRODUÇÃO}

O contexto histórico de valorização bucal abrange muitos milênios, visto que desde o século XVII a.C, aproximadamente, os grupos étnicos, como gregos, hebreus e romanos acreditavam que "dentes fortes" simbolizavam não só uma boa condição higiênica bucal, como também refletiam o bom estado salutar corpóreo e por consequência expressavam uma forma de prevenção às doenças sistêmicas (LINDHE \& LANG, 2018). Contudo, esse período ainda não continha os aparatos necessários para realização de testes e descobertas científicas, sendo atribuídas às "sepses orais" (atualmente, infecções focais), o fator etiológico à progressão de patologias. No século XX, entretanto, através de estudos, como aqueles realizados pelo médico e anatomista escocês, Willian Hunter, confirmou-se que uma área doente (como a bucal) poderia acarretar diversos impactos à superfície corpórea, como um todo (LINDHE \& LANG, 2018).

Tendo em vista tais comprovações, com o decorrer do tempo, buscaram-se relações entre doenças bucais e doenças sistêmicas, justamente pela perspectiva multidisciplinar ocorrida aos cursos da saúde, uma vez que a cavidade oral apresenta-se em constante dinamismo e evolução, fazendo-se necessários estudos constantes desta.

A Odontologia, antigamente e até mesmo em nossos dias, muitas vezes é analisada como uma profissão restrita à cavidade bucal. Entretanto, esta é mais ampla, visto que a cavidade oral representa um reservatório de microrganismos, os quais atravessam o tecido externo e a penetram (RIBEIRO et al., 2012). Sendo assim, tal microbiota pode sofrer alterações, pela disbiose e produzir bacteremias (evadir à corrente sanguínea), alcançando múltiplos órgãos e direções (RIBEIRO et al., 2012), como as válvulas cardíacas, embolizando partículas e formando coágulos, os quais proporcionam doenças sistêmicas, como a Endocardite Bacteriana. Ademais, as associações (microflora oral e cavidades corpóreas) ocorrem em ambas direções (a cavidade bucal pode manifestar impactos da doença sistêmica, como também, pode irradiar patologias bucais a todo corpo) (RIBEIRO et al., 2012).

Inquestionavelmente, a integridade da saúde oral vai além da estética do órgão bucal, pois além de evitarem prejuízos dentários, previne a manifestação e o agravamento de diversas doenças, por meio da realização de diagnósticos precoces (geralmente, os primeiros sintomas são manifestados na cavidade oral, além de ser a partir desta, o desenvolvimento de certas patologias) (RIBEIRO et al., 2012).

Em suma, torna-se imprescindível os cursos da área da saúde conterem conhecimento, acerca da relação entre doenças bucais e sistêmicas. Quanto à Odontologia, busca-se uma nova postura dos cirurgiões-dentistas e da população (em geral), valorizando a boca em todos os contextos profissionais, sendo eles, saúde e educação. 


\section{Cavidade Oral e Biofilme Dentário}

A cavidade oral apresenta características únicas, que a torna um local favorável à proliferação microbiana, tais como os fatores exógenos e endógenos: $\mathrm{PH}$, temperatura, aspectos nutritivos (advindos da dieta) e até mesmo, as suas superfícies (Fluido Crevicular Gengival, língua, mucosa especializada, órgão dentário e saliva) (MARSH \& MARTIN, 2005). Nesse sentido, torna-se uma área extremamente importante, englobando cerca de $10^{14}$ células e 700 espécies de microrganismos convivendo harmoniosamente com tal superfície corpórea, ao fornecerem defesa (MARSH \& MARTIN, 2005). Porém, por alguns aspectos, como a não escovação dentária, tais cepas que já se apresentam em uma comunidade embebida em uma matriz extracelular de polissacarídeos, trocando metabólitos e nutrientes (chamado Biofilme dentário), tornam-se patogênicas e resistentes a ação do meio externo, como atuação de antibióticos (MARSH \& MARTIN, 2005). Dessa forma, ao acumular-se na superfície dental por algum tempo sem a sua remoção, contribui para o desenvolvimento de doenças típicas orais como a doença cárie e periodontal. Além disso, o biofilme acumulado contribui para o aparecimento de bactérias oportunistas, as quais são responsáveis por diversas doenças sistêmicas, como as infecciosas, através da liberação de mediadores inflamatórios que visam entrada à corrente sanguínea e circulação corpórea (LINDHE \& LANG, 2018).

Tal processo de admissão bacteriana à corrente sanguínea é denominado bacteremia e pode ser ocasionada através de dois mecanismos: diariamente, por meio da bacteremia transitória (realização da escovação e uso do fio dental), ocorrida sob mesmo ponto, em meios fisiológicos (como a mastigação), bem como a bacteremia induzida (advinda dos procedimentos dentários invasivos ou não) (WILSON et al., 2008). Contudo, o problema encontra-se nas bacteremias transitórias, visto serem de fácil ocorrência e responsáveis por muitas doenças sistêmicas (WILSON et al., 2008).

A partir desta perspectiva, entende-se a importância do controle do biofilme dentário, através da correta higienização e explicação aos pacientes de como realizá-la (qual o melhor método, respeitando os aspectos fisiológicos destes). Além disso, busca-se maior relevância da saúde oral ao contexto profissional de todas as áreas salutares (multidisciplinaridade) (RIBEIRO et al., 2012).

\section{Inter-relação: Microbiota Oral e doenças sistêmicas}

\subsection{Inter-relação: Microbiota Oral e Artrite Reumatoide (AR)}

A doença Artrite Reumatoide é definida como sendo autoimune (Sistema Imunológico a reconhece como não-própria do organismo e desencadeia uma R.I destrutiva contra ele próprio) e multissistêmica (diversos sintomas), acometendo indivíduos de todas as idades, entretanto, a incidência geralmente ocorre entre 30-40 anos (LIMA, 2010). Assim, apresenta-se em formato de inflamações crônicas e bilaterais (simétricas), das superfícies articulares, tanto superiores quanto inferiores, principalmente mãos e pés (LIMA, 2010).

Do ponto de vista anatômico, atinge as articulações sinoviais, por serem aquelas, nas quais um osso se movimenta sobre o outro, sendo estes recobertos em suas extremidades pelas cartilagens e ao seu redor, pela cápsula articular, revestida pela membrana sinovial (SILVA, 2010). Essa reveste e, consequentemente, protege a articulação, além de produzir o líquido sinovial, o qual é responsável por nutrir a cartilagem e lubrificar os ossos para que os movimentos normais sejam realizados (como abdução, estiramento e flexão) (SILVA, 2010), juntamente à atuação dos tecidos fibrosos, presentes 
nos ligamentos. Entretanto, quando tal membrana inflama, se torna mais espessa e há liberação de substâncias inflamatórias, através de seu líquido, o qual será superproduzido (SILVA, 2010). Dessa forma, tais compostos visarão à posterior destruição da cartilagem sub-condral, manifestando-se inicialmente dor e inchaço nas articulações, analisadas através da Ressonância Magnética e Ultrassonografias, uma vez que as inflamações, caso não sejam tratadas, estimularão à inflamação da membrana (sinovite) ocasionando erosões em outras articulações, além de deformidades ósseas, com perdas funcionais (através do rompimento dos ligamentos, há perda de alinhamento dos ossos, portanto o enfermo não consegue realizar os movimentos) (LIMA, 2010).

A problemática é multifatorial, embora saiba-se que há estímulos etiológicos ao seu desenvolvimento, como ambiente compartilhado, hábitos (tabagismo), sendo o mais preponderante a hereditariedade, por meio dos marcadores genéticos de Classe II, no Antígeno Leucocitário Humano (HLA) (LIMA, 2010). Contudo, a associação entre bactérias presentes na cavidade oral, como as gramnegativas (as quais participam de doenças periodontais): Prevotella intermedia, Porphyromonas gingivalis e Tannerella Forsythia também é considerada um mecanismo etiológico visto que estas, quando presentes em Doenças Periodontais, secretam muitos fatores de virulência $(P$. gingivalis é considerada "espécie-chave", ao induzir à liberação de endotoxinas para apoptose, além de conter fímbrias e liberar lipopolissacarídeos), os quais impulsionam a R.I (MARSH \& MARTIN, 2018).

Para que ocorra a ativação do S.I e posterior desenvolvimento da R.I, inicialmente, o marcador inflamatório "Proteína C Reativa" (PCR) reconhecerá o antígeno (caso seja bacteriano), iniciando-se a Resposta Imunológica Inata (Primeira linha de defesa do organismo) (SILVA, 2010). Este é capturado pela célula apresentadora de antígeno (APC), a qual ativará as células imunológicas, como os Linfócitos auxiliares/Helpers (TCD4), que secretarão citocinas, como Fator Necrose Tumoral $\alpha$ (TNF- $\alpha$ ) e as Interleucinas (IL-1 e IL6), de forma parácrina (longe dos antígenos), sendo que a IL- 6 irá estimular a Resposta Imunológica Adaptativa (secundária) (SILVA, 2010). Por sua vez, estes mediadores super produzirão os Linfócitos T, aumentando as células B (responsáveis pela "memória"), ocasionando a vasodilatação e posteriormente, produzindo-se anticorpos de maneira exacerbada (SILVA, 2010).

Dessa maneira, as articulações atingidas pela A.R conterão muitas células de defesa (citocinas pró e anti-inflamatórias, células B, macrófagos, neutrófilos, TCD4 e TCD8), as quais buscarão a apoptose de tais antígenos (SILVA, 2010). Entretanto, tal acúmulo sinovial extravasará e permanecerá por dias, com angiogênese, portanto será considerado crônico, tendo grandes repercussões funcionais, além dos sinais básicos de inflamação (calor, dor, edema e rubor), como erosão e destruição da cartilagem de tal osso sub-condral (LIMA, 2010) (justamente, pelas células buscarem a destruição dos antígenos extravasados do espaço normal, do líquido sinovial).

Nesse sentido, estuda-se na área Odontológica, a relação entre A.R e D.P, com os antígenos sendo bactérias (Prevotella intermedia, Porphyromonas gingivalis e Tannerella forsythia), visto estarem presentes em pacientes que retratam D.P (MARSH \& MARTIN, 2018). Tal patologia (D. P) é provinda do inicial acúmulo bacteriano patogênico em formato de biofilme dentário, além da coroa clínica, o qual se não for removido, transforma-se em patogênico e contribui aos processos inflamatórios, inicialmente (gengivite) e posteriormente, periodontite (impulsionada por diversos fatores, como estilo de vida), visando à perda de inserção periodontal e à reabsorção do osso alveolar (OLIVEIRA et al., 2017), auxiliando às bacteremias.

Com esta perspectiva, a cepa Porphyromonas gingivalis (em especial), presente em pacientes com D.P, possui a enzima Peptidil-Arginina Deaminase (PAD) em sua membrana externa ou a secreta, 
desaminando a Arginina em Citrulina (Citrulina é um aminoácido alterado na pós-tradução genética do aminoácido básico e essencial a todos, Arginina) (MARSH \& MARTIN, 2018). Essa reação é feita pela PAD, ocasionando mudanças conformacionais e funcionais em tal proteína, a qual, após a citrulinização proteica, é identificada como auto antígeno (fragmento que desencadeia R.I) da A.R (MARSH \& MARTIN, 2018). Como consequência, forma-se Amônia, alteram-se as condições (como o $\mathrm{PH}$ e a temperatura), favorecendo microrganismos adaptados a estas e gera-se uma inflamação crônica extra-sinovial, com novos antígenos, favorecendo a disseminação de mediadores inflamatórios que contribuem à resposta auto-imune e à A.R (afetando órgãos distantes), associando, desse jeito, a A.R com a D.P (MARSH \& MARTIN, 2018).

Quanto às manifestações da A.R, a mais comum decorre no complexo oral e maxilofacial, como dores na ATM (a serem percebidas através de sinais ou evidências radiográficas) e má oclusão, mordida em Classe II, as quais favorecem a rigidez muscular, o trismo e o bruxismo (LIMA, 2010).

O tratamento para tal doença envolve múltiplos profissionais e formas, como educação higiênica, fármacos sistêmicos e injeção de corticosteróides (LIMA, 2010). No entanto, uma descoberta clínica interessante ocorrida em 15 de julho de 2020, pelo investigador Robert Darnell, mostrou que algumas células (encontradas somente nos ossos, cartilagens e músculos) aumentam o RNA e aparecem no sangue na semana anterior aos sintomas, em grandes proporções, sendo chamadas de células PRIME, ativadas por meio das células do S.I (como as células B). Dessa maneira, tal descoberta auxiliará à prevenção e novas formulações de tratamentos, tendo como alvo interromper o surto de A.R antes de ocorrer.

Embora haja grandes casos de tal patologia na população, o cirurgião-dentista ainda não está familiarizado e necessita obter maiores conhecimentos, até mesmo buscando compreender como ocorre a R.I e os motivos do S.I (citocinas) não conseguirem agir de maneira eficaz, com o fito de controlar e/ou reduzir tal problemática (SILVA. 2010). Além disso, o profissional necessita compreender a semelhança da patobiologia de ambas, que inclui o processo de reabsorção óssea por meio da ativação do receptor ativador do fator nuclear kB e o uso de medicamentos da AR que têm efeito imunossupressor, o que torna os pacientes com AR predispostos à DP.

Entretanto, embora existam inúmeros estudos transversais e longitudinais que relatam a relação da DP com AR (KARATAS et al., 2020; JUNG et al., 2019), ainda não há evidências convincentes que sugiram que o tratamento periodontal leve ao controle da AR. A revisão sistemática de Kaur et al. (2013) mostrou que o tratamento periodontal não cirúrgico em indivíduos com periodontite e AR apresenta melhorias nos marcadores de atividade da doença AR. Entretanto todos os estudos tiveram um baixo número de participantes com períodos de intervenção não superiores a 6 meses não sendo confiáveis. Assim, estudos em maior escala são necessários para examinar a melhor relação entre as duas doenças e os efeitos de estudos de intervenção (MARSH \& MARTIN, 2018).

\subsection{Inter-relação: Microbiota Oral e Carcinoma Epidermóide Bucal}

O Câncer bucal é decorrido em função da anormal proliferação celular devido a danos no ciclo celular (mutações) e embora seja multifatorial, existem alguns fatores de risco pré-estabelecidos, como: exposição extrema à radiação solar, ingestão excessiva de álcool, tabagismo e mascar noz de batel (fruta típica dos países da Ásia), tendo também o grupo de não-fumantes (WONG \& WIESENFELD, 2018). A patologia é a causa de altas taxas de mortalidade e morbidade (LINDHE \& LANG, 2018). 
Além disso, o carcinoma de células escamosas oral (OSCC), uma neoplasia epitelial invasiva com diferentes graus de diferenciação, é responsável por cerca de $90 \%$ dos cânceres bucais. As áreas de alto risco são o assoalho da boca e a língua ventrolateral, enquanto as regiões de baixo risco estão na mucosa palatina e no dorso da língua. Ademais, atualmente, as relações bacterianas vem sendo estudadas como fatores favoráveis ao seu desenvolvimento, em mesma proporção que o fumo (Agente carcinogênico, classe I), como a Helicobacter Pylori (FERLAY et al., 2012).

Tendo em vista a composição da microbiota (como $\mathrm{pH}$, temperatura e nutrientes adequados), que confere equilíbrio ao corpo, sabe-se que ao não ser realizada a correta higienização dental pode ocorrer a disbiose, alterando-se o equilíbrio bucal e juntamente com fatores como o uso excessivo de álcool e tabaco, contribui como indicadores de risco ao câncer bucal (CIESIELSKI et al., 2010).

Neste viés, as bactérias tornam-se patogênicas e liberam fortes fatores de virulência, os quais se transformarão em mecanismos bacterianos de carcinogênese, podendo provocar o crescimento celular exacerbado e evadir do S.I, suprimindo as possibilidades de apoptose (caso tais seres sobrevivam de forma imunossupressora) (CIESIELSKI et al., 2010). Assim, quando o S.I descobre o antígeno, liberam-se mediadores inflamatórios (citocinas pró e anti-inflamatórias), que visam destruir tal patógeno, mas este os utilizam de forma a elevar a carcinogênese, como a Helicobacter pylori, a qual está associada fortemente à gastrite que, ao provocar mucosa inflamada, pode conduzir ao adenocarcinoma, através de alterações no DNA e expressão/supressão de genes (CIESIELSKI et al., 2010). Além disso, essa cepa causa indução da glicoproteína Cicloxigenase (COX-2), com o fito de invadir tecidos, por meio dos neutrófilos e produzir citocinas pró-inflamatórias (CIESIELSKI et al., 2010).

Em outra abordagem, a bactéria Porphyromonas gingivalis (presente em pacientes com D.P) induz à COX-2 e aumenta as Interleucinas: IL-1, IL-6 e IL8, para que atuem como pró-carcinogênicos químicos, visando à destruição tecidual (CIESIELSKI et al., 2010). Outroassim, estes podem ser ativados através de enzimas xenobióticas-metabolizantes (como a Álcool Desidrogenase), presente em periodontopatógenos (CIESIELSKI et al., 2010). Tais cepas, mesmo em anaerobiose produzem energia, pela fermentação da Glicose e em conjunto ao uso do álcool e/ou tabaco, formam Álcool endógeno, como o Acetaldeído, (primeiro metabólito do etanol), através de reações entre a enzima ADH (Álcool Desidrogenase) dos microrganismos, metabolizando Etanol em Acetaldeído (CIESIELSKI et al., 2010). Com isso, alteram-se as condições locais $(\mathrm{pH})$, favorece a existência de espécies bacterianas tolerantes a tal ambiente, influindo ao metabolismo do hospedeiro, já que tal composto funciona como carcinogênico (tóxico) e produz inflamações crônicas, ao interferir no ciclo celular normal (CIESIELSKI et al., 2010).

Além dos mecanismos bacterianos carcinogênicos, o uso do tabaco funciona de forma análoga ao Acetaldeído, uma vez que a Nicotina induz à modificação populacional e pode auxiliar à existência de algumas bactérias específicas, como as prevalentes em D. P, já que decorrem-se mudanças fisiológicas e funcionais, aumentando-se a virulência bacteriana (liberação de toxinas) e desregulando o S. I (CIESIELSKI et al., 2010). Não apenas isso, os componentes do cigarro interagem às toxinas dos periodontopatógenos (Agreggatibacter actinomycetemcomitans, Porphyromonas gingivalis e Tannerella forsythia) e funcionam como forma de agregação bacteriana ao trato respiratório, bem como representam maiores riscos às doenças infecciosas deste ambiente (maiores níveis de Streptococcus mutans, pela fumaça do cigarro) (CIESIELSKI et al., 2010). Sob a mesma visão, encontraram-se em tumores bucais, cepas de Fusobacterium spp., Porphyromonas spp e Porphyromonas gingivalis, sendo que a apresentação da última demonstra grande risco ao desenvolvimento de cânceres (CIESIELSKI et al., 2010). 
Em síntese, quando a microbiota oral é desestabilizada, se torna patogênica, os microrganismos competem pelos sítios de ligação (adesinas) e dependem das respostas do hospedeiro, para que a microflora seja reorganizada às condições expostas (LINDHE \& LANG, 2018).

Quanto às principais formas de diagnóstico, profilaxia e tratamento, são respectivamente: exame clínico (realizado pelo cirurgião-dentista) e biópsia (dependendo dos resultados); consultas regulares ao cirurgião-dentista, anamnese antes de procedimentos dentários, controle do biofilme dentário e procurar não fumar e/ou beber; cirurgia oncológica e/ou radioterapia (conforme as necessidades do paciente) (MINISTÉRIO DASAÚDE, 2006).

Diante de todas as informações sobre a inter-relação entre o câncer bucal e a Odontologia, depreende-se que o primeiro é uma doença ocasionada por mutações gênicas, a qual pode acometer qualquer indivíduo, porém tem-se fatores preponderantes ao seu desenvolvimento, os quais podem ser suprimidos, através de hábitos de vida saudáveis e práticas de higiene bucal, obtidas por meio de consultas regulares ao cirurgião-dentista.

Várias pesquisas são realizadas a fim de aprimorar essa área. Um recente estudo (ZHANG et al., 2020) avaliou as evidências disponíveis para determinar a relação entre os diferentes tipos de câncer e o microbiota, concentrando-se no papel das bactérias bucais na proliferação celular, angiogênese, apoptose, facilitando a invasão e metástase além de auxiliar as células tronco cancerosas.

Houve diferenças na composição bacteriana entre pacientes com câncer e indivíduos normais e pacientes pré-câncer. Bactérias patogênicas periodontais e suas substâncias pró-inflamatórias como LPS foram associadas a um maior risco de carcinoma: principalmente a Fusobacterium (que houve aumento significativo em pacientes estágio 4 , sugerindo ser parte essencial pois possui a capacidade de se coaderir com outras espécies e formar uma rede de co-associação), Peptostreptococcus, Parvimonas, Campylobacter Filifactor, Capnocytophaga. Pseudomonas não foram associadas ao câncer ainda, mas possui fatores de virulência que desempenham papéis na carcinogênese, neutralizando as defesas do hospedeiro e causando dano direto aos tecidos do hospedeiro. Outras bactérias como Firmicutes e Actinobacteria foram confirmados como tendo uma correlação negativa com pré-câncer oral, sugerindo que podem ser alterados no início do desenvolvimento do câncer (ZHANG et al., 2020).

Os resultados de pesquisas mais recentes de 10 anos relataram alterações nas bactérias orais no carcinoma (KAKABADZE et al., 2020). No entanto, um consenso completo não foi alcançado. Diferentes tipos de espécimes, controles e métodos podem ter contribuído para a falta de consenso. Além desses fatores, estágios díspares do carcinoma estudados também podem contribuir para os resultados inconsistentes. Na progressão do tecido epitelial normal para canceroso, a proporção de bactérias orais muda e as bactérias que se adaptam tornam-se dominantes. Modelo de "passageiros de passeio" para explicar este fenômeno. Os "drivers" são definidos como bactérias orais com características pró-carcinogênicas, como a produção de compostos que danificam o DNA que podem iniciar o câncer oral, como $P$. gingivalis (ocorre mais no estágio inicial do carcinoma). Os passageiros seriam inibidos em um estado oral saudável, mas quando ocorrer disbiose, como em um estado relacionado ao câncer, os passageiros terão uma vantagem competitiva no microambiente tumoral. Esse tipo de bactéria participa da progressão e promoção de tumores (KAKABADZE et al., 2020).

Assim, durante o desenvolvimento do carcinoma, abundância e variedade de bactérias orais muda, necessitando de mais estudos que possam identificar métodos potenciais para o diagnóstico precoce e tratamentos mais eficazes. Logo, o conhecimento do papel da microbiota oral e a relação com carcinoma é indispensável para o dentista para maiores conhecimentos sobre a etiologia bacteriana oral e sua aplicação, na prática. 


\subsection{Inter-relação: Microbiota Oral e Diabetes tipo I}

Diabetes é uma síndrome (conjunto de distúrbios) metabólica ocasionada pelo desequilíbrio endócrino do hormônio Insulina, na síntese de gorduras, carboidratos e proteínas (DALBOSCO \& $\mathrm{RECH}, 2013)$. Desse modo, tem capacidade de afetar a cavidade oral (bem como, o fluxo salivar), sendo um fator de risco à D.P (e inversamente) (DALBOSCO \& RECH, 2013; MARSH \& MARTIN, 2018).

O nível glicêmico pode ser observado, através de exames laboratoriais de Glicemia em jejum, pósprandial, Teste Oral de Tolerância à Glicose (TOTG) e Hemoglobina glicada, sendo os dois primeiros realizados em estado momentâneo, podendo sofrer interferência por fatores, como dieta e medicamentos,enquanto a Hemoglobina glicada é por meio da reação irreversível da glicose sanguínea e a hemoglobina, gerando substâncias a serem analisadas (mede a glicemia média dos últimos 3 meses, equivalente a um teste de rastreio de diabetes) (DALBOSCO \& RECH, 2013).

Para melhor compreendimento, acerca da Diabetes mellitus 1, esta pode ser dividida em Diabetes mellitus 1, tipo IA ou tipo IB, sendo imprescindível o entendimento da principal diferença entre as células alfa e células beta.

No fígado, há as llhotas de Langerhans, as quais apresentam ambas as células, a primeira secreta o hormônio Glucacon (age oposto à Insulina), eleva a glicose sanguínea, por outro lado, a segunda produz e sintetiza os compostos (exemplos: carboidratos e proteínas), contendo a glicemia e promovendo a entrada de glicose na célula (OLIVEIRA et al., 2017). Dessa maneira, Diabetes mellitus tipo $1 \mathrm{~A}$ é caracterizada pela ativação da alta imunidade corpórea e consequentemente, liberação de anticorpos que visam à destruição das células beta, compactuando à produção insuficiente de Insulina (OLIVEIRA et al., 2017), tendo como principal fator, a suscetibilidade gênica (herança dos alelos HLA). Geralmente apresenta-se em crianças e adolescentes de maneira súbita, já em adultos é indiciosa, sem destruição massiva (forma latente), em contrapartida, Diabetes mellitus tipo 1B é apresentada contendo defeitos na ação da Insulina e por isso, seu principal fator preponderante é a idade avançada.

A Doença Periodontal envolve vários eventos inflamatórios e imunopatológicos, como a genética e doenças sistêmicas (nesse caso), com destaque a Diabetes, sendo iniciada pelo acúmulo de biofilme na margem gengival e posteriores inflamações, desse modo, suas formas mais graves (diabetes) estão associadas à D.P (DALBOSCO \& RECH, 2013). Além disso, conforme a American Dental Association, pelo aumento de glicose sanguínea, há maior acúmulo de "açúcar" pelo corpo, sendo um ambiente propício às bactérias cariogênicas (dependendo de outros fatores do hospedeiro), sendo mais suscetível à cárie dentária. Desde 2009, protocolos da American Diabetes Association recomendam especificamente que o médico encaminhe o paciente com DM para o cirurgião-dentista para a realização de um exame periodontal e dental criterioso.

Através da progressão da D.P, a qual necessita de um ambiente favorável, com microrganismos gramnegativos e PH alcalino, há acúmulo de biofilme calcificado e posteriores inflamações, além da formação de bolsas periodontais, com mobilidade dentária (pela destruição bacteriana), assim com maior perda de inserção, ocorrendo reabsorção óssea, sangramento e hipossalivação (DALBOSCO \& RECH, 2013).

No que tange aos aspectos imunológicos, as bactérias periodontopatógenas (como Porphyromonas gingivalis) liberam mediadores inflamatórios (endotoxinas), enquanto o S.I libera citocinas próinflamatórias (IL-1ß e TNF- $\alpha$ ) para combatê-las, juntamente à IL-1fÀ (induz à reabsorção óssea e destruição do tecido mole) sendo que quando tais endotoxinas estiverem presentes na circulação 
sanguínea dificultarão o metabolismo da glicose, levando à resistência insulínica ( por isso, quem tem Diabetes, tem dificuldade em controlar a glicemia, assim como apresenta menor capacidade de defesa e reparo tecidual) (DALBOSCO \& RECH, 2013). Demonstrando-se, que o enfermo que apresenta Diabetes mellitus 1 contém controle metabólico ruim, relacionado aos elevados níveis de secreção de IL-1fÀ e TNF- $\alpha$ e, detém, aproximadamente, o dobro de probabilidade de ocasionar Periodondite, sendo a atuação conjunta do tabagismo também impactante, visto aumentar a perda óssea e formar bolsas profundas (DALBOSCO \& RECH, 2013).

Tendo isso em vista, a terapia periodontal surge como forma de não só reduzir sinais e sintomas produzidos pela Diabetes, como também auxiliar ao controle glicêmico, visto que as infecções contribuem à resistência insulínica (DALBOSCO \& RECH, 2013).

Como forma de manifestação, os primeiros sinais e sintomas são: fome, fadiga, sede e náuseas, sendo que segundo as projeções feitas pela Organização Mundial da Saúde, essa patologia é associada ao favorecimento de doenças renais crônicas (observadas pela baixa taxa de filtração glomerular e perda dos glóbulos renais), como a doença renal intersticial, a qual retém compostos tóxicos excretados pelos rins, além, de anemias, distúrbios nos eletrólitos sanguíneos e hipertensão (LINDHE \& LANG, 2018).

Um achado clínico interessante é quanto à realização da anestesia local (bloqueio reversível na condução nervosa, com perda sensorial, mas sem alterar a consciência), percebendo-se que não é recomendável o uso de epinefrina (adrenalina), posto que ao apresentar-se como vasoconstritor, exerce efeito oposto ao da Insulina (aumenta a glicemia), sendo em quadros de diabetes descompensado, não recomendável até que haja controle glicêmico (CARVALHO et al., 2013).

O cirurgião-dentista deve estar atento, que 1/3 das pessoas com Diabetes não demonstra diagnóstico clínico, então faz-se necessário ter conhecimento acerca desta doença, trabalhando de forma integrada, já que a terapia periodontal influi de forma positiva a esta patologia e consegue reduzir citocinas inflamatórias responsáveis, tendo em vista que a D. P não tratada atua de forma agressiva, piorando o controle metabólico, por muitas citocinas pró-inflamatórias serem liberadas à corrente sanguínea, levando até mesmo a apoptose das células beta de Langerhans e receptores de insulina (DALBOSCO \& RECH, 2013; LINDHE \& LANG, 2018).

Há na literatura vários estudos longitudinais, transversais e de intervenção que analisam a relação entre doença periodontal e a diabetes. Nenhuma conclusão unânime pode ser tirada sobre a terapia periodontal e controle metabólico. Duas revisões sistemáticas que combinaram estudos de intervenção concluíram que há efeito estatisticamente significativo da terapia periodontal sobre níveis de $\mathrm{HbA} 1 \mathrm{c}$ (hemoglobina glicada). Ainda faltam estudos para confirmar a validade dos achados assim como esclarecer questões como: 1-o efeito da terapia periodontal sobre controle metabólico de pacientes diabetes mellitus tipo 1, 2- o quão responsáveis são os antibióticos adjuntos pela melhora observada do controle glicêmico, 3- se o efeito difere de acordo com os níveis de pretratamento do controle metabólico e/ou pré-tratamento da gravidade de periodontite e outras comorbidades (LINDHE \& LANG, 2018).

\subsection{Inter-relação: Microbiota Oral e Doenças Respiratórias (D. R)}

As Doenças Respiratórias são aquelas relacionadas à dificuldade de respiração, principalmente, devido à cavidade oral estar conectada à orofaringe e ao trato respiratório inferior (MARSH \& MARTIN, 2018). Assim, caso a situação oral esteja debilitada, poderá haver influência às funções 
pulmonares, desenvolvendo, por exemplo, pneumonia bacteriana através da aspiração de secreções contendo bactérias de origem orofaríngea e eliminação inadequada de algumas saudáveis, pelo S.I (LINDHE \& LANG, 2018).

A microbiota oral apresenta-se dinâmica e é modificada por comportamentos, como mudanças alimentares, hábitos (fumo e álcool), além das práticas de higiene dentária, assim, quando o biofilme dentário torna-se patogênico, contendo bactérias, como Prevotella spp., Fusobacterium e Streptococcus, desenvolve-se a D.P, agindo como um fator de risco às D. R, bem como a pneumonia nasocomial (triplica a possibilidade, quando há presença destas bactérias) (MARSH \& MARTIN, 2018). Assim, as D.R representam uma grande problemática, visto que os hábitos do hospedeiro sofrem modificações a cada instante, fazendo com que a microflora mostre-se diversa e sofra impactos por estes ou que o hospedeiro as apresentem (D.R) de forma latente (cerca de 1/3 da população a contém dessa forma) (MARSH \& MARTIN, 2018). Os grupos de alto risco para aquisição de pneumonias de origem bacteriana oral são os residentes em instituições de longa permanência, indivíduos hospitalizados, pacientes com ventilação mecânica devido a insuficiência respiratória (LINDHE \& LANG, 2018).

Tem-se muitas D. R, como as infecções respiratórias associadas às bactérias advindas da cavidade oral, como a bronquite, enfisema, pneumonia e sinusite(aguda, aguda recorrente, subaguda ou exacerbadamente aguda), sendo destacada aqui a Tuberculose, a qual acomete cerca de 1, 5 milhões de mortes e 9 milhões casos/ano, sendo seu agente etiológico a Mycobacterium e as suas cepas como M. tuberculosis (75\%), M.bovis e M. africanum, as quais apresentam como nicho ecológico, a cavidade oral (MARSH \& MARTIN, 2018).

A Tuberculose é desenvolvida a partir da ingestão de tais bacilos, os quais percorrem direções ao linfonodo, acessando a corrente sanguínea e afetando, assim, diversas regiões corpóreas (SILVA et al., 2018). Dessa maneira, há a ativação da R.I do hospedeiro, através da liberação de macrófagos alveolares (nos quais, os bacilos se replicam e ocasionam as suas apoptoses) e células inflamatórias (SILVA et al., 2018). Entretanto, estas são utilizadas pelos patógenos como forma de agregação de partículas e elevação da nocividade, (SILVA et al., 2018) desenvolvendo pneumonias. Geralmente, a dita infecção viabiliza-se de maneira latente, em que o S.I reprime a replicação bacilar antes dos sintomas aparecem (pode durar anos), mas com o decorrer do tempo e por esses estarem se locomovendo pelo corpo, acabam se transformando em granulomas e dessa maneira, manifestam os sintomas de maneira grave (febre, falta de ar e tosse seca), os quais podem ser analisados por meio de gotículas do escarro, análise de lesões na cavidade bucal, biópsia, teste tuberculínico, radiografia do tórax e o principal teste; coloração de Ziehl-Neelsen, percebendo-se a inflamação granulomatosa (SILVA et al., 2018).

A apresentação da Tuberculose pode ser na cavidade oral, observada em formato de úlcera irregular crônica, na superfície dorsal da língua (contudo, pode ser em qualquer local), tendo as sãs bordas levantadas (semelhante às infecções fúngicas) (MARSH \& MARTIN, 2018).

Tem-se como opção de tratamento a terapia antibiótica (Rifampicina e Etambutol), entretanto sabese que as cepas estão muito resistentes aos fármacos e buscam-se formas mais naturais de tratá-las, por isso a importância de manter consultas regulares ao cirurgião-dentista, realizar o controle do biofilme dentário, procurar não fumar e adquirir hábitos saudáveis, sendo que como forma mais eficiente de profilaxia, tem-se a vacinação (quando existente), como a BCG (tem em vista prevenir a Tuberculose) (MARSH \& MARTIN, 2018).

Atualmente a associação entre doença periodontal e infecções pulmonares é plausível, além disso a patogenicidade é aumentada nos inóculos polimicrobianos quando comparada às monoinfecções. Há 
evidências científicas da relação entre D.R e D.P., como estudos prospectivos, ensaios clínicos (intervenção antimicrobiana oral reduz a incidência de infecção pulmonar), que embora não tenham sido uniformemente bem sucedidos em reduzir a incidência dos desfechos, os dados são apoio para noção que intervenções antibacterianas orais são valiosas no controle de infecção pulmonar (LINDHE \& LANG, 2018).

\subsection{Inter-relação: Microbiota Oral e Endocardite Bacteriana (E.B)}

A Endocardite Bacteriana (EB) apresenta-se, como uma problemática mundial, por ser uma doença infecciosa, ocasionada por bacteremias de origem bucal, acometendo, principalmente, pessoas com doenças cardíacas pré-existentes (BARROSO et al., 2014). A doença é caracterizada por uma infecção no endocárdio coronário, devido a múltiplos fatores, que possibilitam bactérias bucais alcançarem a corrente sanguínea e irem em direção às válvulas cardíacas, formando vegetações e podendo levar o indivíduo a óbito (BARROSO et al., 2014).

Com o decorrer do tempo, houve modificações no sexo e na epidemiologia pelo uso exacerbado dos antibióticos, tendo maior prevalência de Staphylococcus e Enterococcus (WILSON et al., 2008).

A partir das 3 bacteremias existentes, a que afeta em maior número os pacientes é a bacteremia transitória (hábitos diários), dando destaque à necessidade de reduzir a disseminação bacteriana, advinda das ações diárias, por meio da manutenção de uma boa higienização dentária (WILSON et al., 2008).

Com a mesma abordagem, a maioria dos enfermos com EB apresentam problemas dentários e não realizam consultas odontológicas regulares, então a Odontologia urge como uma importante área de estudo, já que os microrganismos apresentam como habitat natural a cavidade oral, tendo-se que levar em consideração, além das características epidemiológicas e fisiológicas do paciente (como idade avançada, uso de drogas injetáveis ou pré-disposição à doenças cardíacas), os aspectos higiênicos bucais, por contribuírem para a bacteremia transitória.

Sabe-se que o coração apresenta 2 átrios e 2 ventrículos (tetracavitário), sendo revestidos por pericárdio pseroso e fibroso, miocárdio e endocárdio, sendo um órgão extremamente vascularizado e essencial à vitalidade do homem (BARROSO et al., 2014). Dessa forma, a camada mais interna, denominada endocárdio, faz-se composta por Epitélio Pavimentoso Simples e Conjuntivo, o qual contribui à irrigação sanguínea, envolvendo átrios e ventrículos (BARROSO et al., 2014).

Quanto ao desenvolvimento da enfermidade, a cavidade bucal possui nichos de colonização diverso, favorecendo o desenvolvimento de uma microbiota típica necessária para a manutenção da saúde bucal, visto algumas bactérias presentes nessa terem o poder de se aderirem a superfícies não descamativas (como os dentes), através das adesinas, por exemplo, e se organizarem em biofilmes dentários (LOCKHART et al., 2009).

O biofilme se constitui em bactérias envoltas de uma matriz de polissacarídeos (exopolissacarídeos) e substância de reserva que fazem a sustentação e aumentam a patogenicidade. Tal organização se apresenta como uma forma de proteção das bactérias, tornando-as mais resistentes a antibióticos e funcionando como um fator de virulência (WERDAN et al., 2014). Nessa ocasião, as bactérias acessam a superfície do endocárdio valvar, através de vários mecanismos, se acumulam e proliferam, depositando material trombótico, agregando plaquetas, estreitando orifícios valvares e criando vegetações (WILSON et al., 2008). Em indivíduos normais, o sistema imunológico desenvolverá resposta frente aos desequilíbrios, mas aqueles grupos ditos de risco, o sistema de defesa irá desenvolver uma resposta que elevará a patogenicidade, desencadeando a doença (WILSON et al., 2008).

A partir do momento em que instaurou-se uma infecção devido ao acúmulo de biofilme patogênico, 
como acontece nas doenças periodontais, as bactérias ao atingirem a corrente sanguínea liberam substâncias pró-inflamatórias, visando à invasão e à persistência no local (WERDAN et al., 2014). Há um aumento na fibronectina, por exemplo, cuja função é englobar o patógeno, e destruir os tecidos agravando a doença E.B silenciosamente (WERDAN et al., 2014). Além disso, a presença de prófagos estimula a diversidade bacteriana e posteriormente destrói o tecido endocárdio. Tendo o sistema imunológico do hospedeiro atacado, possibilita-se a entrada de microrganismos sem controle, ampliando destruição tecidual pelos patógenos (WERDAN et al., 2014).

Nesse contexto podem se movimentar pelo endotélio valvar, formando um coágulo com fibrinogênio, proliferando a vegetação e embolizando partículas. Nesse sentido, com o estímulo da resposta imunológica humoral e celular possibilita que as células endoteliais respondam à inflamação, expressem integrinas $\beta$ de família $\beta 1$ (antígenos tardios), presentes na superfície endotelial, que contribuem para a adesão bacteriana, principalmente das espécies Streptococcus e Staphylococcus, as quais contém tais adesinas (WERDAN et al., 2014).

O principal patógeno, Staphylococcus aureus, apresenta dois métodos de adesão e colonização valvar à $E . B$, que funcionam de forma diferente: Proteínas ligadas covalentemente aos peptídeos da parede (MSCRAMMs), sendo o principal fator de aglomeração A (ClfA), ligando-se rapidamente ao fibrinogênio do hospedeiro (WERDAN et al., 2014). Além de FnBPs que conectam-se diretamente ao hospedeiro, ativando plaquetas e proteínas secretadas, aderindo com Repertório Expandido Secretável que Adere Moléculas Essenciais (SERAMs), responsáveis pela ligação e agregação plaquetária, mas também podem ser ativadas pelas FimA (proteínas fímbrias) (WERDAN et al., 2014).

Caso ambos os métodos forem ativados, o $S$. aureus produzirá vários fatores de virulência, os quais irão ativar as células endoteliais. A partir de um destes métodos, o coco liga-se à protrombina humana, induzindo à agregação plaquetária (mesmo em repouso) (WERDAN et al., 2014).

Após a maturação, ocorre a inflamação e destruição das células do hospedeiro, através dos múltiplos mecanismos de virulência, com a liberação de mediadores inflamatórios, como toxinas e enzimas, alfa-hemolisina e modulinas, as quais se fixam às válvulas cardíacas (superfície com colágeno) e aos biofilmes, formando um nicho ecológico, com aspectos ambientais, de temperatura e pH que favorecem a expansão bacteriana, ativando o endotélio, abrindo junções celulares e contribuindo à morte celular (WERDAN et al., 2014).

Conclui-se que para a ocorrência a E.B, faz-se necessária uma lesão cardíaca pré-existente, a qual possibilita a interação patógeno-hospedeiro à colonização valvar das bactérias advindas da cavidade oral, em péssimas condições. As bacteremias transitórias de origem bucal permitem a entrada das bactérias na corrente sanguínea levando a colonização de coágulos e posterior ativação do sistema imune. Com isso, há a liberação de integrinas que estimulam o depósito da fibronectina que promoverá a maior agregação bacteriana em localizações intracelulares, produzindo-se coágulos da E.B em locais de difícil acesso, os quais persistirão por meio de outros mediadores, proporcionando a disseminação hematogênica.

Tendo em vista este processo, destaca-se a necessidade dos saberes sobre o desdobramento das espécies bacterianas e os seus mecanismos para a notoriedade da Odontologia, buscando a percepção precoce dos pacientes com risco ao desenvolvimento da E.B e até mesmo a formulação de novos medicamentos preventivos mais naturais, que atuem na desestruturação dos mecanismos bacterianos patogênicos. 
Recentemente, foram documentadas associações entre microrganismos bucais e outras formas de doença cardiovascular, particularmente a Aterosclerose. A aterosclerose está ligada a inflamação crônica de baixo grau. As interações celulares relacionadas à aterosclerose são similares a doenças inflamatórias crônicas e doenças fibroproliferativas, além de apresentarem respostas celulares específicas que podem ser mais bem descritas como doença inflamatória (ROSS, 1993,1999, LINDHE \& LANG, 2018).

Parece haver uma associação consistente entre a aterosclerose e a doença periodontal em estudos epidemiológicos que não é explicada por fatores de risco em comum como diabetes, tabagismo e hereditariedade. Os ensaios de intervenção conduzidos até o momento foram, em grande parte, limitados ao estudo dos efeitos da terapia periodontal sobre os marcadores de risco, devido a evolução lenta da doença vascular, e considerações éticas. Ainda faltam evidências com estudos maiores controlando fatores confundidores a fim de elucidar a relação causa-efeito direta ou o exato papel da infecção periodontal na patogênese do aterosclerose (HERRERA, 2020).

\subsection{Microbiota Oral e Período Gestacional}

O nascimento prematuro é a causa mais comum de morbidade e mortalidade infantil nos países desenvolvidos, sendo que 11 a 12,5 \% destes causam problemas, como alterações agudas e crônicas (baixo peso, cardiopatias, cegueiras, deficiências de aprendizado, epilepsia, paralisia cerebral e síndrome da angústia respiratória) (LINDHE \& LANG, 2018).

Ao contexto histórico, em 1980, determinou-se que as infecções maternas, como as bucais, influem negativamente ao nascimento, bem como são fatores ao desenvolvimento de bebês prematuros, visto que a cavidade oral, estando em péssimas condições, apresenta bactérias patogênicas, como Eikenella corrodens, Bergeyellam, Fusobacterium e Porphyromonas gingivalis (LINDHE \& LANG, 2018).

Estas, com seus métodos de virulência (fímbrias e pili) conseguem se aderir às células epiteliais e endoteliais, pela via intercelular e intracelular, estimulando respostas inflamatórias (bacteremias transitórias) (LINDHE \& LANG, 2018). E quando há D. P, os microrganismos conseguem penetrar à corrente sanguínea e liberar mediadores inflamatórios por todo o corpo, até mesmo ao tecido placentário, induzindo assim à ativação do S.I, o qual libera Linfócitos para possível destruição dos antígenos, mas estes (pelas endotoxinas) acarretam a apoptose de Linfócitos (realizariam a proteção e coagregação de patógenos) e ímpeto inflamatório em trabalhos de parto (LINDHE \& LANG, 2018). Além disso, em pesquisas, mostrou-se que algumas culturas contendo líquido amniótico de mulheres apresentavam bactérias orais do periodonto, como a Porphyromonas gingivalis, a qual libera IL-1 13 e Prostaglandinas, visando à destruição, sendo uma ameaça corioamniótica (LINDHE \& LANG, 2018).

Em resumo, percebe-se a relevância da saúde oral e a necessidade de tratamentos dentários (prénatal odontológico), visto que as bactérias orais podem tornar-se patogênicas e evadir à corrente sanguínea, indo em direção ao tecido placentário, ocasionando infecções entre o feto e a gestante. Assim, visando eliminar possíveis riscos à saúde da mãe e do feto, recomenda-se realizar uma boa higienização oral, mantendo consultas regulares ao cirurgião-dentista, principalmente, no terceiro trimestre (antes do 3ㅇ) .

Foram realizados vários estudos de associação e caso-controle entre os desfechos adversos na gravidez e condições periodontais debilitadas mostrando associação positiva entre eles. Contudo, uma revisão de literatura em 2013 (BOUTIN et al., 2013) que avaliou todos os tipos de estudo concluiu que a periodontite materna está modestamente associado ao baixo peso ao nascer, entretanto a 
heterogeneidade dos estudo foi alta, outra revisão de caso-controle de 2016 (TECHOME et al., 2016) relata que a DP pode ser fator de risco para parto prematuro.

Apesar do relato dos estudos acima e do mecanismo de patogenicidade ser descrito, estudos de intervenção, na qual a condição periodontal materna é tratada na tentativa de reduzir o risco para o bebe, não mostraram de forma consistente algum efeito sobre o resultado no parto. $O$ nascimento prematuro é causa mais comum de morbidade e mortalidade infantil nos países em desenvolvimento e, portanto, merece mais estudos (MARSH \& MARTIN, 2018).

\begin{tabular}{|c|c|c|c|c|}
\hline Patologia: & Agente etiológico: & Sinais/Sintomas: & Transmissão: & Tratamento: \\
\hline $\begin{array}{l}\text { Acidente Vascular } \\
\text { Encefálico }\end{array}$ & Enterobacterium & $\begin{array}{l}\text { Pneumonia e perda do controle } \\
\text { muscular }\end{array}$ & $\begin{array}{l}\text { Má higienização e contato } \\
\text { oral }\end{array}$ & Anticoagulantes \\
\hline $\begin{array}{l}\text { Encefalopatia } \\
\text { Espongiforme } \\
\text { Transmissível }\end{array}$ & $\begin{array}{l}\text { Príons ( Moléculas menores } \\
\text { do que a partícula viral) }\end{array}$ & $\begin{array}{l}\text { Perda das funções autônomas e } \\
\text { voluntárias. }\end{array}$ & $\begin{array}{l}\text { Instrumentos contaminados } \\
\text { e cadeia alimentar. }\end{array}$ & $\begin{array}{l}\text { Terapia intensiva de } \\
\text { controle (manter a } \\
\text { calma). }\end{array}$ \\
\hline Gonorréia & Neisseria gonorrhoeae & $\begin{array}{l}\text { Mucosa genital (alterações } \\
\text { bucais, eritema, vesículas) }\end{array}$ & $\begin{array}{l}\text { Doença Sexualmente } \\
\text { Transmissível }\end{array}$ & $\begin{array}{l}\text { Uma dose de Penicilina } \\
\text { intramuscularl } \\
\text { Amoxicilina oral }\end{array}$ \\
\hline HIVIAIDS & $\begin{array}{l}\text { Vírus da Imunodeficiência } \\
\text { Humana }\end{array}$ & $\begin{array}{l}\text { Apresenta múltiplas } \\
\text { manifestações, como febre, } \\
\text { suores noturnos, fadiga e lesões } \\
\text { orais (Sarcoma de Kaposi) }\end{array}$ & $\begin{array}{l}\text { Doença Sexualmente } \\
\text { Transmissível }\end{array}$ & $\begin{array}{l}\text { Não há cura, porém seu } \\
\text { desenvolvimento pode } \\
\text { ser retardado através das } \\
\text { terapias antirretrovirais. }\end{array}$ \\
\hline Sífilis & Treponema pallidum & $\begin{array}{l}\text { Úlcera labial ou na mucosa, } \\
\text { podendo agravar-se até mesmo, } \\
\text { em leucoplasias. }\end{array}$ & $\begin{array}{l}\text { Doença Sexualmente } \\
\text { Transmissivel e a bactéria } \\
\text { consegue atravessar a } \\
\text { placenta. }\end{array}$ & $\begin{array}{l}\text { Antibióticos, como a } \\
\text { Penicilina (Benzetacil) }\end{array}$ \\
\hline
\end{tabular}

Tabela 1: Breve descrição de algumas doenças Negligenciadas Fonte: Adaptado de MARSH \& MARTIN (2018).

\section{Conclusão}

Conclui-se, a partir de todas as abordagens, a importância da multidisciplinaridade em saúde, visto que a saúde oral integra diversas áreas corpóreas e denota-se um local, tanto de manifestação de sintomas, como um local de irradiação de doenças. A Odontologia corrobora à prevenção de patologias e formas de diagnósticos precoces, sendo que o cuidado com a saúde oral através do simples controle do biofilme dentário e realização de consultas regulares ao cirurgião-dentista combate não só problemas bucais, como doenças que podem levar a óbito.

Confirmando-se que a cavidade oral em boas condições para as pessoas é equivalente ao sol para as flores, algo imprescindível à realização de processos vitais. 


\section{REFERÊNCIAS}

ADDISON JOSEPH. In: Citações e Frases Famosas, 2019. Disponível em: < https://citacoes.in/citacoes/578758joseph-addison-o-sol-e-para-as-flores-o-que-os-sorrisos-sao-para/>. Acesso em: 3 mar. 2019.

BARROSO, M. G.; et al. ENDOCARDITE BACTERIANA: DA BOCA AO CORAÇÃO. Revista Ciência e Estudos Acadêmicos de Medicina, n. 2, p. 47-57, 2014.

BOUTIN A, DEMERS S, ROBERGE S, ROY-MORENCY A, CHANDAD F, BUJOLD E. Treatment of periodontal disease and prevention of preterm birth: systematic review and meta-analysis. Am J Perinatol. 2013 Aug;30(7):537-44. doi: 10.1055/s-0032-1329687. Epub 2012 Dec 27. PMID: 23271387.

CARVALHO, B.; et al. O emprego dos anestésicos locais em Odontologia: Revisão de Literatura. Revista Brasileira de Odontologia, v. 70, n. 2, p. 178-181, 2013.

CIESIELSKI, F. I. N.; et al. Biofilmes orais como um possível fator de risco ao câncer bucal. ODONTO, v. 18, n. 36, p.127-138, 2010.

DALBOSCO \& RECH. Influência do tratamento periodontal no nível glicêmico de paciente diabético. J Oral Invest, v. 2, n. 2, p. 27-31, 2013.

FERLAY, J., SOERJOMATARAM, I., ERVIK, M., DIKSHIT, R., ESER, S., MATHERS, C. et al. GLOBOCAN 2012 v1.0, Cancer Incidence and Mortality Worldwide: IARC CancerBase No. 11. Lyon, France: International Agency for Research on Cancer; 2013 in: https://www.paho.org/bra/index.php?option=com_content\&view=article\&id=5588:folhainformativa-cancer\&Itemid=1094

HERRERA D, MOLINA A, BUHLIN K, KLINGE B. Periodontal diseases and association with atherosclerotic disease. Periodontol 2000. 2020 Jun;83(1):66-89. doi: 10.1111/prd.12302. PMID: 32385870.

JUNG ES, CHOI YY, LEE KH. Relationship between rheumatoid arthritis and periodontal disease in Korean adults: Data from the Sixth Korea National Health and Nutrition Examination Survey, 2013 to 2015. J Periodontol. 2019 Apr;90(4):350-357. doi: 10.1002/JPER.18-0290. Epub 2018 Nov 26. PMID: 30380152.

KAKABADZE MZ, PARESISHVILI T, KARALASHVILI L, CHAKHUNASHVILI D, KAKABADZE Z. Oral microbiota and oral cancer: Review. Oncol Rev. 2020 Jul 6;14(2):476. doi: 10.4081/oncol.2020.476. PMID: 32676172; PMCID: PMC7358985.

KARATAŞ E, KUL A, TEPECIK E. Association between Rheumatoid Arthritis and Apical Periodontitis: A Crosssectional Study. Eur Endod J. 2020 Jul 22;5(2):155-158. doi: 10.14744/eej.2019.52824. PMID: 32766528; PMCID: PMC7398985.

KAUR S, WHITE S, BARTOLD PM. Periodontal disease and rheumatoid arthritis: a systematic review. J Dent Res. 2013 May;92(5):399-408. doi: 10.1177/0022034513483142. Epub 2013 Mar 22. PMID: 23525531

LIMA, N. F. V. Manifestações Orais em Pacientes com Artrite Reumatoide: Porto, 2010.

LINDHE \& LANG. Tratado de Periodontia Clínica e Implantologia Oral: 6 a Ed. Editora Guanabara Koogan, 2018.

LOCKHART, P. B.; et al. Poor oral hygiene as a risk factor for infective endocarditis- related bacteremia. Journal of the American Dental Association, v. 140, n. 10, p. 1238-1244, 2009.

MARSH \& MARTIN. Microbiologia Oral: 6 ㅌed. Editora ELSEVIER, 2018.

MINISTÉRIO DA SAÚDE. Secretaria de Atenção à Saúde. Departamento de Atenção Básica. Saúde Bucal. (Cadernos de Atenção Básica, n. 17). Brasília: Ministério da Saúde. 2006:92p. Disponível em: http://189.28.128.100/dab/docs/publicacoes/cadernos_ab/abcad17.pdf 
OLIVEIRA, F. C.; et al. DOENÇA PERIODONTAL E DIABETES MELLITUS - REVISÃO DE LITERATURA. Revista Gestão \& Saúde, v.16, n.02, p.32-41,2017.

RIBEIRO, B. B.; et al. Importância do reconhecimento das manifestações bucais de doenças e de condições sistêmicas pelos profissionais de saúde com atribuição de diagnóstico. ODONTO, v. 20, n. 39, p. 61-70, 2012.

ROSS R. The pathogenesis of atherosclerosis: a perspective for the 1990s. Nature. 1993 Apr 29;362(6423):801-9. doi: 10.1038/362801a0. PMID: 8479518.

ROSS R. Atherosclerosis--an inflammatory disease. N Engl J Med. 1999 Jan 14;340(2):115-26. doi: 10.1056/NEJM199901143400207. PMID: 9887164.

SILVA, M. E. N.; et al. Aspectos gerais da tuberculose: uma atualização sobre o agente etiológico e o tratamento. Revista Brasileira de Análises Clínicas, v. 50, n. 3, 2018.

SILVA, M. L. F. Artrite reumatóide: o papel das moléculas pró- reumatóide: o papel das moléculas próinflamatórias e antiinflamatórias: Uberaba, 2010.

TESHOME A, YITAYEH A. Relationship between periodontal disease and preterm low birth weight: systematic review. Pan Afr Med J. 2016 Jul 12;24:215. doi: 10.11604/pamj.2016.24.215.8727. PMID: 27800070; PMCID: PMC5075444.

ZHANG L, LIU Y, ZHENG HJ, ZHANG CP. The Oral Microbiota May Have Influence on Oral Cancer. Front Cell Infect Microbiol. 2020 Jan 15;9:476. doi: 10.3389/fcimb.2019.00476. PMID: 32010645; PMCID: PMC6974454.

WERDAN, K. et al. Mechanisms of infective endocarditis: pathogen-host interaction and risk states. NATURE REVIEWS, v. 11, p. 35-50, 2014.

WILSON, W. et al. Prevention of infective endocarditis:Guidelines from the American Heart Association. Journal of the American Dental Association, v. 139, n.1, p. 3-24, 2008.

WONG \& WIESELFELD. Oral Cancer. Australian Dental Journal, v. 63, n. 1, p. 91-99, 2018. 


\title{
ATIVIDADE ANTIMICROBIANA E ANTIBIOFILME DA IMUNOGLOBULINA Y: UMA REVISÃO DE LITERATURA
}

\author{
Fernanda Haboski da Silva \\ Universidade Federal de Santa Maria - UFSM \\ haboskifernanda@gmail.com \\ Gabriela da Luz Machado \\ Universidade Federal de Santa Maria - UFSM \\ gmc.gabrielamachado@gmail.com \\ Patricia Kolling Marquezan \\ Universidade Federal de Santa Maria - UFSM \\ patimarquezan@hotmail.com
}

\section{RESUMO}

IA imunoglobulina Y (IgY), termo utilizado para referir-se ao principal anticorpo sérico em galinhas e presente em grande quantidade na gema do ovo, tem se mostrado altamente relevante no meio científico nas últimas décadas. Estudos recentes têm avançado ao estudar a relação da imunoglobulina com atuações antimicrobiana e antibiofilme. Sendo assim, o objetivo do presente estudo é analisar aspectos estruturais e funcionais da imunoglobulina $\mathrm{Y}$, bem como sua atividade antimicrobiana e antibiofilme. Para isso, foi realizada uma busca nas bases de dados PubMed/MEDLINE, Cochrane e EMBASE, utilizando os descritores MeSH/DeCS "Dental caries", "IgY" e seus derivados, associados entre si pelo operador booleano "AND" e adaptados para cada base de dados. Além disso, foi feita uma busca complementar no Google Acadêmico e nas referências dos artigos selecionados. Após uma leitura crítica de títulos e resumos, 10 estudos foram selecionados. A revisão incluiu estudos publicados nos últimos 20 anos. A imunoglobulina $Y$ além de apresentar um potencial uso em tratamentos odontológicos, mostrou-se eficiente quanto à redução de patógenos como a Salmonella spp e Pseudomonas aeruginosa. Na cavidade oral, a imunoglobulina apresentou atuação seletiva para com a bactéria Streptococcus mutans. Entretanto, não há um consenso na literatura sobre a ação da IgY na candidíase, doenças nutricionais e metabólicas, neoplasias, amigdalite e o resfriado comum. Assim sendo, a imunoglobulina $Y$ apresenta uma boa atuação antimicrobiana in vitro e in vivo em bactérias do biofilme, porém são necessários mais estudos a fim de elucidar sua ação contra outras bactérias e a aplicabilidade clínica da mesma.

\section{Palavras-chave:}

Agente Antiinfecciosos; Imunoglobulina Y; Odontologia.

\begin{abstract}
Immunoglobulin $Y(\lg Y)$, a term used to refer to the main serum antibody in chickens and present in large quantities in egg yolks, has been shown to be highly relevant in scientific circles in recent decades. Recent studies have advanced when studying the relationship of immunoglobulin with antimicrobial and antibiofilm actions. Therefore, the aim of the present study is to analyze structural and functional aspects of immunoglobulin $Y$ as well as its antimicrobial and antibiofilm activity. For this, a search was performed in the PubMed / MEDLINE, Cochrane and EMBASE databases, using the MeSH / DeCS descriptors "Dental caries", "IgY" and their derivates, associated with each other by the Boolean operator "AND" and adapted for each data base. In addition, a complementary search was made on Google Scholar and on the references of selected articles. After a critical reading of titles and abstracts, 10
\end{abstract}

studies were selected. The review includes studies published in the past 20 years. In addition to having a potential use in dental treatments, immunoglobulin $Y$ was shown to be efficient in reducing pathogens such as Salmonella spp and Pseudomonas aeruginosa. In the oral cavity, immunoglobulin showed a selective action of bacteria Streptococcus mutans. However, there is no consensus in the literature about the action of $\lg Y$ in candidiasis, nutritional and metabolic diseases. Therefore, immunoglobulin $Y$ has a good antimicrobial action in vitro and in vivo in biofilm bacteria, but further studies are needed in order to elucidate its action against other bacteria and its clinical applicability.

\section{Keywords:}

Agents Antiinfective; Immunoglobulin Y; Dentistry. 


\section{INTRODUÇÃO}

A imunoglobulina Y, também conhecida como IgY ou, simplesmente, anticorpos da gema de ovo, foi nomeada pela primeira vez em 1969 na Flórida, Estados Unidos (Leslie and Clem 1969; Leiva et al. 2020). O termo, utilizado para se referir a anticorpos produzidos por aves, foi proposto pelos autores a fim de corrigir o equívoco até então cometido pelos pesquisadores que a chamavam de IgG, mudança justificada pela significativa diferença estrutural quando comparada à sua contraparte mamífera (Leiva et al. 2020).

Também produzida por répteis, anfíbios (Zhang et al. 2017; Constantin et al. 2020) e ornitorrincos (Zhang et al. 2017), a lgY é o principal anticorpo sérico em galinhas (Gallus gallus domesticus), sendo produzida através da sensibilização do hospedeiro por bactérias específicas. Os anticorpos específicos resultantes no soro são passados ao embrião como parte da imunidade materna, podendo, então, ser coletados em grande quantidade (100-150 mg por ovo) (Mine \& Kovacs-Nolan, 2002) sem que haja sofrimento por parte do animal (Leiva et al., 2020), uma vez que não há coleta de sangue. Assim, a imunoglobulina $Y$ tem se mostrado um forte concorrente a tratamentos que utilizem a imunoterapia passiva.

A doença cárie é altamente prevalente em todo o mundo (Bernabe et al., 2020), e se apresenta como uma doença multifatorial (Fejerskov et al., 2017) cuja progressão normalmente se dá de forma lenta. A etiologia da cárie dentária se constitui na associação entre a formação e manutenção de um biofilme microbiano patogênico sobre a superfície dos dentes aliados a fatores intrínsecos e extrínsecos (Hofling \& Gonçalves, 2007). Tais processos sofrem interferência de diversos mecanismos dos sistemas imunes inato e adaptativo, podendo-se destacar elementos como as glicoproteínas, proteínas, peptídeos e as imunoglobulinas (Spolidorio \& Duque et al., 2013), sendo as últimas diferenciadas em várias classes conforme suas características estruturais e funcionais, constituindo, então, a expressão da imunidade adaptativa.

Segundo Nguyen e colaboradores (2011), a estratégia da imunização passiva, ou seja, aquela que se dá através da introdução de anticorpos exógenos na cavidade oral, apresenta riscos muito menores quando comparados àqueles que podem vir a ocorrer em um tratamento que utilize de mecanismos de imunização ativa. Apesar de terem se mostrado efetivas em modelo de desenvolvimento de lesões cariosas em animais, as vacinas anticárie até então desenvolvidas e estudadas ainda não estão disponíveis para uso humano dado o grande investimento e regulação necessários para desenvolver este tipo de medicamento (Bachtiar \& Imanina, et al. 2019). Portanto, o objetivo do presente estudo é, com base na literatura, analisar aspectos estruturais e funcionais da imunoglobulina $Y$, relacionando-os à sua atividade antimicrobiana e antibiofilme visando o tratamento da doença cárie.

\section{Metodologia}

A revisão de literatura seguiu os preceitos do estudo descritivo de caráter qualitativo por meio de uma pesquisa bibliográfica em livros e artigos científicos. O método qualitativo foi utilizado pelos 
pesquisadores pois possibilita a interpretação e emissão de suas opiniões sobre o que é estudado (Pereira et al., 2018). Buscou-se sintetizar o conhecimento sobre a atividade antimicrobiana e antibiofilme da imunoglobulina $Y$ (IgY) por meio de um levantamento em três bases de dados distintas, sendo incluídos artigos dos últimos 20 anos e que abordassem propriedades antibiofilme e antimicrobiana da IgY. Foram excluídas revisões de literatura e relatos de caso, além de estudos que não contemplassem o espaço temporal proposto nem a temática do presente trabalho. Todas as buscas foram realizadas no período de setembro de 2020.

Na base de dados PubMed/MEDLINE e Cochrane Library foram realizadas as primeiras pesquisas, sendo combinados os descritores cadastrados no MeSH "Dental caries", "IgY" e seus derivados. Todas as palavras-chave foram unidas pelo operador booleano "AND". No total foram encontrados 19 e 4 artigos em cada base, respectivamente, sendo selecionados apenas 11 da primeira base após leitura de títulos e resumo de acordo com os critérios estabelecidos.

Quanto à base EMBASE, foram buscadas as mesmas palavras-chaves sem restrição de idioma. Obtevese, por fim, um total 28 resultados, sendo incluídos 20 dentre estes que atendiam os critérios de inclusão estabelecidos. Inicialmente foram selecionados através da leitura de títulos e resumos e depois novamente após a leitura na íntegra dos estudos. Por fim, a última busca complementar foi realizada no Google Acadêmico e referências dos artigos selecionados, encontrando outros artigos para complementação do estudo.

O fluxograma (Figura 1) apresentado descreve o número de artigos encontrados, quantos excluídos pelos critérios de exclusão (fuga do tema, duplicata ou trabalhos com mais de 20 anos) até chegar aos artigos incluídos na revisão de literatura. A seleção segundo critérios foi fundamental para a melhor confiabilidade e poder de generalização das conclusões desse estudo.

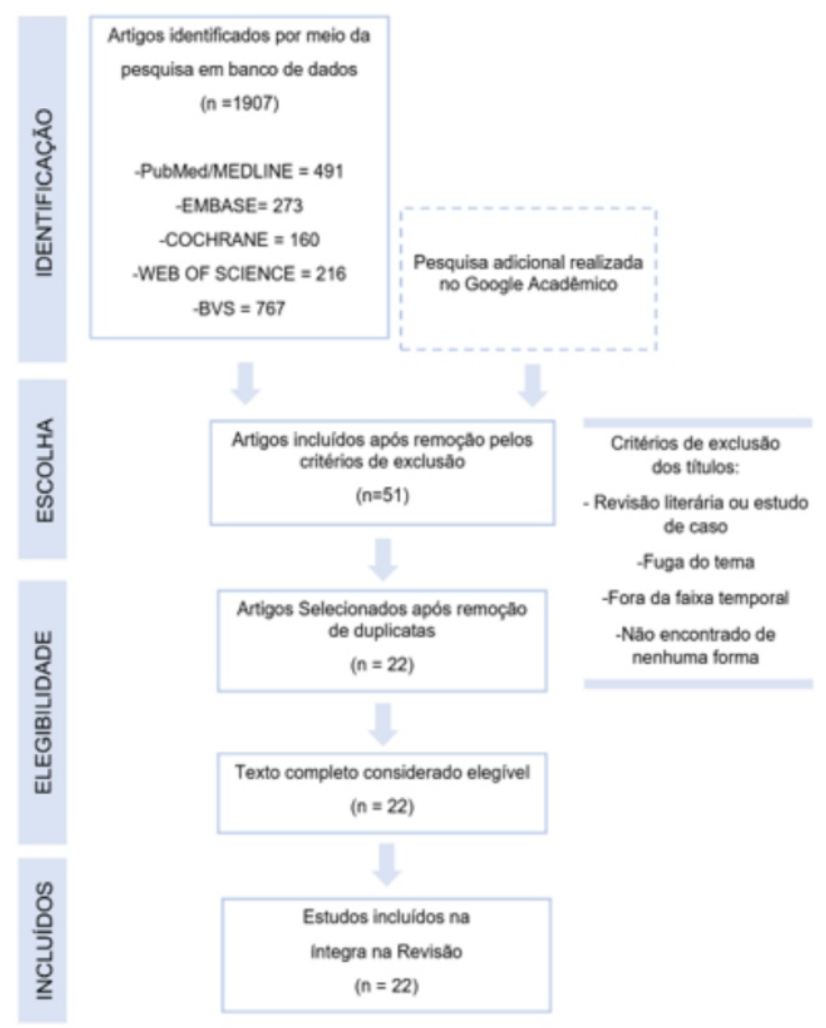

Figura 1: Fluxograma do estudo

Fonte: Autoria própria, 2020. 


\section{Resultados}

Após uma leitura crítica de títulos e resumos, além da aplicação dos critérios de elegibilidade foram selecionados 10 artigos para a revisão de literatura. As características dos estudos selecionados são apresentadas no Quadro 1, que mostra um alto número de publicações nas Revistas Internacionais e dentre os títulos selecionados, quatro caracterizam-se como estudos em animais, quatro in vivo enquanto os dois restantes enquadram-se como estudos in vitro.

Quadro 1: Análise detalhada das publicações quanto ao autor, ano de publicação, título, revista publicada, tipo de estudo, metodologia e resultados.

\begin{tabular}{|c|c|c|c|c|c|}
\hline $\mathrm{N}^{0}$ & Autor/Ano & Titulo & $\begin{array}{l}\text { Tipo de } \\
\text { estudo }\end{array}$ & Metodologia & Resultados \\
\hline 1 & $\begin{array}{l}\text { D. Carlander, } \\
\text { H. Kollberg and A. Larsson } \\
\text { (2002) }\end{array}$ & $\begin{array}{l}\text { Retention of Specific Yolk } \\
\text { IgY in the Human } \\
\text { Oral Cavity }\end{array}$ & In vivo & $\begin{array}{l}\text { Após escovar os dentes à noite e executar um } \\
\text { enxágue bucal com dois ou três tubos de solução } \\
\text { tampão e coletá-la no tubo "sl", os individuos } \\
\text { foram instruidos a fazer um gargarejo com } \\
\text { anticorpo. A amostra "s2" foi coletada no primeiro } \\
\text { e segundo experimentos } 8 \text { horas após o bochecho, } \\
\text { enquanto a amostra "s3" foi coletada no segundo } \\
\text { experimento após } 24 \text { horas. }\end{array}$ & $\begin{array}{l}\text { Um maior número de IgY especificos contra a } P \text {. aeruginosa } \\
\text { pôde ser observado na amostra s } 2 \text {, quando comparada ao controle } \\
\text { negativo, padrão que também foi observado na amostra s3, } \\
\text { demonstrando que os anticorpos ainda estão presentes na } \\
\text { cavidade oral após } 24 \text { horas. }\end{array}$ \\
\hline 2 & C. Krüger et al (2004) & $\begin{array}{l}\text { The Effects of Egg-Derived } \\
\text { Antibodies to } \\
\text { Glucosyltransferases on } \\
\text { Dental Caries in Rats }\end{array}$ & $\begin{array}{l}\text { Estudo } \\
\text { em } \\
\text { animais }\end{array}$ & $\begin{array}{l}\text { Os animais foram infectados com S. mutans } \\
\text { MT8148R e tratados com anticorpos provenientes } \\
\text { de gema do ovo de galinha anti-CA-Gtf (IgY) ou } \\
\text { pó de gema de ovo não imune. }\end{array}$ & $\begin{array}{l}\text { Os animais que receberam IgY desenvolveram lesões de cárie } \\
\text { menos extensas, demonstrando que os anticorpos anti-CA-Gtf } \\
\text { não apenas preveniram o inicio de cáries, mas também reduziram } \\
\text { o progresso da doença. A cárie de sulcos e fissuras também foi } \\
\text { reduzida e de menor gravidade. }\end{array}$ \\
\hline 3 & Sa V. Nguyen et al (2011) & $\begin{array}{l}\text { Anti-cell-associa-ted } \\
\text { glucosyltrans- ferase } \\
\text { immuno- globulin Y } \\
\text { suppression of salivary } \\
\text { mutans streptococci in } \\
\text { healthy young adults }\end{array}$ & In vivo & $\begin{array}{l}\text { Após a produção da IgY anti-CA-gtf foi em forma } \\
\text { de pastilhas. Foram realizados testes in vitro a fim } \\
\text { de analisar a reatividade da IgY contra vários } \\
\text { sorotipos de S.mutans bem como se a } \\
\text { imunoglobulina poderia } \\
\text { bacteriana. }\end{array}$ & $\begin{array}{l}\text { A IgY anti-CA-gtf reagiu com } S \text {. mutans, mas não com } S \text {. } \\
\text { cricetuls, } S \text {. rattus ou } S \text {. downei. Apesar de os valores médios de } \\
\text { S. mutans antes do experimento não serem significativamente } \\
\text { diferentes entre os três grupos, os escores diminuiram } \\
\text { significativamente após o estudo no grupo de tratamento. }\end{array}$ \\
\hline 4 & $\begin{array}{l}\text { D.J.Smith; W.F. King; AND } \\
\text { R. Godiska. } \\
\text { (2011) }\end{array}$ & $\begin{array}{l}\text { Passive Transfer of IgY } \\
\text { Antibody to Streptococcus } \\
\text { mutans Glucan Binding } \\
\text { Protein B Can Confer } \\
\text { Protection against } \\
\text { Experimental Dental Caries }\end{array}$ & $\begin{array}{c}\text { Estudo } \\
\text { em } \\
\text { animais }\end{array}$ & $\begin{array}{l}\text { Uma dieta suplementada com a imunoglobulina Y } \\
\text { pré-imune foi oferecida ao grupo controle durante } \\
9 \text { dias e } 24 \text { dias. Durante o estudo, amostras da } \\
\text { microbiota estreptocócica dos ratos foram feitas, } \\
\text { sendo posteriormente comparadas a fim de } \\
\text { identificar a eficácia do tratamento. }\end{array}$ & $\begin{array}{l}\text { A porcentagem média de S.mutans em relação à flora } \\
\text { estreptocócica total mostrou-se maior no grupo controle. Os } \\
\text { escores médios de cáries dos ratos alimentados com a GBP-IgY } \\
\text { representaram um valor equivalente à metade dos observa- dos } \\
\text { dentre o grupo controle. }\end{array}$ \\
\hline 5 & $\begin{array}{l}\text { E.W.Bachiar; } \\
\text { R.D.Soejoedono; B. } \\
\text { M.Bachtiar; A.Henrietta } \\
\text { N. Fahana.; M. Yuniastuti } \\
\text { (2015) }\end{array}$ & $\begin{array}{l}\text { Effects of soybean milk, } \\
\text { chitosan, and anti- } \\
\text { Streptococcus mutans IgY in } \\
\text { malnourished rats' dental } \\
\text { biofilm and the IgY } \\
\text { persistency in saliva }\end{array}$ & $\begin{array}{l}\text { Estudo } \\
\text { em } \\
\text { animais }\end{array}$ & $\begin{array}{l}20 \text { ratos experimentais foram desnutridos no } \\
\text { periodo pré e pós-natal, e infectados com } S \text {. } \\
\text { mutans. Após, foram divididos em } 5 \text { grupos. Após } \\
15 \text { dias de alimentação, foi avaliado o } S \text {. mutans no } \\
\text { biofilme dentário, além do nivel de persistência do } \\
\text { IgY anti-S. mutans. }\end{array}$ & $\begin{array}{l}\text { O grupo de ratos que recebeu leite de soja enriquecido com IgY } \\
\text { anti- } S \text {. mutans e quitosana, apresentou a menor contagem de } S \text {. } \\
\text { mutans no biofilme dentário sendo doze vezes menor que no } \\
\text { grupo controle. IgY anti-S. mutans foi detectado na saliva dos } \\
\text { grupos que receberam Igy com ou sem quitosana, após } 15 \text { dias de } \\
\text { alimentação. }\end{array}$ \\
\hline 6 & $\begin{array}{l}\text { E.W. Bachtiar; B.M. } \\
\text { Bachtiar; R.D. Soejoedono; } \\
\text { I.W. Wibawan A. Afdhal } \\
\text { (2016) }\end{array}$ & $\begin{array}{l}\text { Biological and } \\
\text { Immunogenicity Property of } \\
\text { IgY Anti S. mutans ComD }\end{array}$ & In vitro & $\begin{array}{l}\text { Após a produção da IgY através da imunização de } \\
\text { galinhas com uma vacina contendo DNA do } \\
\text { receptor ComD, o efeito do anticorpo na formação } \\
\text { de biofilme por } S \text {. mutans isolados de individuos } \\
\text { com ou sem cárie ativa foi avaliado. }\end{array}$ & $\begin{array}{l}\text { IgY anti-ComD apresentou propriedades de imunorreatividade } \\
\text { contra ambos os isolados de } S \text {. mutans de individuos com e sem } \\
\text { cárie dentária, inibindo a formação de seu biofilme. Quanto ao } \\
\text { perfil proteico, a expressão de algumas bandas de proteinas foi } \\
\text { afetada após a exposição ao anticorpo. }\end{array}$ \\
\hline 7 & $\begin{array}{l}\text { E.W.Bachtiar; A.Afdhal; } \\
\text { R.Meidyawati; } \\
\text { R.D. Soejoedono; } \\
\text { E.Poerwaningsih } \\
\quad(2016)\end{array}$ & $\begin{array}{l}\text { Effect of topical anti- } \\
\text { Streptococcus mutans IgY } \\
\text { gel on quantity of S. mutans } \\
\text { on rats' tooth surface }\end{array}$ & $\begin{array}{l}\text { Estudos } \\
\text { em } \\
\text { animais }\end{array}$ & $\begin{array}{l}24 \text { ratos tiveram a cavidade oral exposta ao } S \text {. } \\
\text { mutans e a uma dieta cariogênica. Foram coletadas } \\
\text { amostras de placa dos dentes anteriores e de saliva, } \\
\text { a fim de quantificar a colônia de } S \text {. mutans e medir } \\
\text { a imunorreatividade. }\end{array}$ & $\begin{array}{l}\text { Redução mais significativa na contagem de } S \text {. mutans foi } \\
\text { observada no grupo que apresentou o maior periodo de aplicação } \\
\text { do gel.. Esses resultados mostraram que a aplicação de gel nas } \\
\text { superficies dos dentes forneceu proteção ao biofilme, reduzindo } \\
\text { a formação de colônias de } S \text {. mutans. }\end{array}$ \\
\hline 8 & $\begin{array}{l}\text { J. Handajani, D. H.Narissi, } \\
\text { M. Azis and A.S. Rahmawati } \\
\text { (2016) }\end{array}$ & $\begin{array}{c}\text { Effects of immunoglobulin } \\
\text { Y (IgY) serum against } \\
\text { plaque } \\
\text { bacteria }\end{array}$ & In vitro & $\begin{array}{l}\text { Após a imunização das galinhas e coleta da IgY } \\
\text { especifica contra o } S \text {. mutans, foi realizado um } \\
\text { teste de disco-difusão a fim de analisar a inibição } \\
\text { da IgY contra o } \quad \text { S. mutans, S. alpha e } \\
\text { Staphylococcus aureus. }\end{array}$ & $\begin{array}{l}\text { A IgY especifica contra a espécie somente apresentou atividade } \\
\text { antibacteriana contra o } \mathrm{S} \text {. mutans, não inibindo o } \mathrm{S} \text {. aureus e } \mathrm{S} \text {. } \\
\text { alpha. }\end{array}$ \\
\hline 9 & $\begin{array}{l}\text { E.W.Bachtiar; D.Apritantia; } \\
\text { A.T.Sarwono; B.M.Bachtiar; } \\
\text { R.D. Soejoedono; } \\
\text { I.W.T.Wibawan } \\
\quad \text { (2019) }\end{array}$ & $\begin{array}{l}\text { The effect of mouthwash } \\
\text { combination of } \\
\text { immunoglobulin-Y anti- } \\
\text { COMD Streptococcus } \\
\text { mutans and chitosan on the } \\
\text { formation of Streptococcus } \\
\text { mutans biofilm }\end{array}$ & In vivo & $\begin{array}{l}\text { Individuos, divididos em } 2 \text { grupos, o enxaguante } \\
\text { contendo IgY anti-ComD foi administrado a } \\
\text { pessoas com e sem cárie ativa, respectivamente - } \\
\text { foram instruidos a fazer o bochecho com o } \\
\text { enxaguante duas vezes ao dia, utilizando, durante } \\
\text { o periodo de seis dias. Após a coleta de amostras } \\
\text { de superficie, a formação de biofilme foi avaliada }\end{array}$ & $\begin{array}{l}\text { Ao analisar os resultados da amostra dos individuos componentes } \\
\text { do Grupo } 4 \text {, concluiu-se que, após o tratamento, houve um au- } \\
\text { mento na formação de biofilme. } \\
\text { Por outro lado, nos grupos } 1 \text { e } 2 \text {, aos quais foi administrado o } \\
\text { enxaguante contendo somente a IgY anti-ComD, apresentaram } \\
\text { uma diminuição do biofilme, no entanto, não possuindo } \\
\text { relevância estatistica. }\end{array}$ \\
\hline 10 & $\begin{array}{l}\text { E.W. Bachtiar; } \\
\text { A.N.Imanina; } \\
\text { R.D Soejoedono; } \\
\text { I.W.T. Wibawan; } \\
\quad(2019)\end{array}$ & $\begin{array}{l}\text { Effect of mouthrinse } \\
\text { containing immunoglobulin- } \\
\text { y anti-comd Streptococcus } \\
\text { mutans + chitosan on } \\
\text { quantity of salivar } S \text {. } \\
\text { mutans in caries and caries- } \\
\text { free subjects }\end{array}$ & In vivo & $\begin{array}{l}24 \text { alunos com e sem cárie foram divididos em dois } \\
\text { grupos que receberam enxaguante bucal contendo } \\
\text { IgY anti-ComD). Foram instruidos a enxaguar } 2 \\
\text { vezes ao dia por } 30 \text { segundos, durante } 6 \text { dias. Após } \\
\text { o periodo de tratamento, amostras de saliva foram } \\
\text { coletadas novamente. Colônias bacterianas de } S \text {. } \\
\text { mutans foram calculados manualmente. }\end{array}$ & $\begin{array}{l}\text { A diminuição nas colônias de } S \text {. mutans ocorreu em ambos os } \\
\text { grupos após o tratamento. Os resultados não mostraram nenhuma } \\
\text { diferença significativa na diminuição do número de } S \text {. mutans em } \\
\text { individuos que usaram enxaguatório bucal com e sem quitosana. } \\
\text { Este estudo demonstrou que o enxaguatório bucal contendo IgY } \\
\text { anti-ComD } S \text {. mutans + quitosana tem o potencial de diminuir a } \\
\text { quantidade de } S \text {. mutans salivar, embora não significativamente. }\end{array}$ \\
\hline
\end{tabular}

Fonte: Autoria própria, 2020. 


\section{Revisão de literatura e Discussão}

A cavidade oral é colonizada por uma flora diversificada e complexa, composta por inúmeras espécies, dentre as quais aproximadamente 350 já foram identificadas (Juni et al., 2016). Os microrganismos constituintes da flora oral vivem em homeostase até que ocorra uma desequilíbrio desta microbiota que, por sua vez, resulta no desenvolvimento de doenças como cárie, doença periodontal, candidíase oral entre outras (Marsh \& Martin, 2005; Fejerskov, 2017).

O sistema imune oral é insuficiente frente a disbiose microbiana bucal, pois fora desenvolvido para a manutenção da homeostasia entre membros comensais, sem a eliminação destes (Hofling \& Gonçalves, 2007). Sendo assim, diversos tratamentos que auxiliem ou se relacionem com o sistema imunológico vêm sendo desenvolvidos para atuar no combate ou no controle do biofilme e outras bactérias patogênicas a fim de reduzir a prevalência de condições orais prejudiciais na população (Mercenes et al., 2013).

O sistema imune inato e adaptativo são preceitos que medeiam a defesa contra patógenos na cavidade oral, portando elementos como glicoproteínas, peptídeos, enzimas, linfócitos e imunoglobulinas. O sistema imune não específico detém vários figurantes enzimáticos e protéticos que visam a atividade antimicrobiana sem destinar-se a um patógeno em específico, além de não apresentar memória imunológica. Dentre tais componentes, estão as lisozimas, lactoferrinas, peroxidases salivares, mieloperoxidases, fibronectinas, mucinas, histatinas, prolinas, aglutininas salivares, $\beta 2$-microglobulina e fibronectina. Estas, mesmo não apresentando especificidade, podem interagir com componentes específicos, uma vez que podem amplificar a atividade das imunoglobulinas. Além destas, outros agentes celulares específicos que podem ser destacados são os linfócitos $\mathrm{T}$ e B, elementos capazes de responder a diversos microrganismos bacterianos, sendo recrutados pelo acúmulo bacteriano na porção subgengival (Hofling \& Gonçalves,2007).

As respostas específicas aos antígenos são mediadas pelas imunoglobulinas, proteínas globulares formadas após exposição prévia ao patógeno, com destaque à $\lg \mathrm{A}, \lg \mathrm{g}$ e $\lg \mathrm{M}$. Dentre estas, a IgA é a mais predominante, sendo responsável por cerca de $80 \%$ das imunoglobulinas presentes na cavidade oral (Hofling \& Gonçalves, 2007); sintetizadas na lâmina própria das glândulas salivares maiores e menores (Spolidorio \& Duque, 2017), a imunoglobulina A (IgA) subdivide-se em duas formas diferindo estruturalmente entre si. A IgA secretória possui uma cadeia polipeptídica extra, que a confere resistência às enzimas proteolíticas e relativa adaptação funcional em ambientes hostis da boca (Hofling \& Gonçalves, 2007). Esta classe de anticorpos se vê presente na cavidade oral dentro de poucas semanas de vida, mantendo níveis constantes de IgA contra S. mutans durante toda a vida. Dentre os componentes que conferem patogenicidade a esta bactéria, e que estão associados à ação funcional da IgA, pode-se destacar o antígeno I/II, as glucosiltransferases e a proteína ligante de glucano B (GbpB) (Spolidorio \& Duque, 2017). Assim, a ação antibiofilme da imunoglobulina A, se dá pelo bloqueio das adesinas da superfície bacteriana, promovendo a aglutinação bacteriana e facilitando a posterior remoção do patógeno no ambiente oral (Hofling \& Gonçalves,2007), como também, a inativação das enzimas glucosiltransferases, essenciais à síntese de glucano e manutenção estrutural do biofilme (Spolidorio \& Duque, 2017).

As imunoglobulinas IgG e IgM também são componentes da imunologia oral, entretanto, estão em concentrações menores quando comparadas à IgA. $O$ anticorpo $\lg G$, semelhante à IgA, atua inibindo a aderência bacteriana e a ação da glucosiltransferase, como também, na placa subgengival, pode agir ativando o sistema complemento e formando imunocomplexos, os quais agem como opsonina, 
facilitando a morte e a fagocitose bacteriana (Hofling \& Gonçalves, 2007). É pela transferência plaquetária que ocorre a aquisição inicial de imunoglobulinas IgG, refletindo a experiência materna com determinados microrganismos (Spolidorio \& Duque, 2017). No fluido crevicular gengival, podem ser detectados anticorpos IgG contra S. mutans, e, durante processos inflamatórios, níveis elevados de IgG são detectados nessa região. A imunoglobulina IgM, por sua vez, não aparece estar ligada diretamente a imunologia da cárie, entretanto, em casos em que há deficiência seletiva de IgA, são encontrados IgM contra S. mutans, apresentando mecanismos complementares contra a cárie dentária (Hofling \& Gonçalves, 2007).

O sistema imune oral é insuficiente frente a uma disbiose da microbiota bucal, uma vez que, segundo Hofling e Gonçalves, desenvolveu-se a fim de manter a homeostasia entre os membros da microbiota comensal, sem destinar-se à eliminação destes, portanto, vê-se necessário o desenvolvimento de abordagens terapêuticas a fim de remediar tal situação.

Segundo Rahman e colaboradores (2013), com o aumento da prevalência de bactérias resistentes a antibióticos, é importante que, a fim de tratar de doenças orais, sejam desenvolvidos novos fármacos como uma alternativa ao uso de antibióticos. Preliminarmente, os esforços dos pesquisadores que objetivavam a prevenção da cárie dentária, fez-se com base na imunização ativa, ou seja, através da inoculação de uma célula de Streptococcus mutans modificada. No entanto, além de exigir grande investimento, a técnica tem como consequência uma reação cruzada com o tecido do músculo cardíaco fazendo com que, portanto, o interesse de tais profissionais fosse realocado no campo da imunização passiva (a.Bachtiar, et al. 2019), ainda que a ação desta tenha curta duração no organismo (Rahman et al. 2013).

A imunoterapia oral, utilizando de anticorpos específicos como a IgG humana, anticorpos monoclonais e policlonais, colostro bovino e anticorpos da gema do ovo, tem sido buscada e testada efetivamente ao longo das últimas décadas (Carlander et al., 2000). No entanto, apesar da ampla gama de possibilidades a serem exploradas, recursos como os anticorpos policlonais mostraram-se inviáveis uma vez que estes não podem ser obtidos em grande escala por requerer coleta de sangue. Em contrapartida, anticorpos monoclonais podem ser produzidos em larga escala através de hibridomas, mas possuem alto custo, inviabilizando seu uso em tratamentos (Mine \& Kovacs-Nolan 2002). Assim, para um possível recurso terapêutico imunológico, é necessário encontrar um método de produção que não somente possua um bom custo-benefício e permita que a imunoglobulina seja produzida em grande quantidade, mas que tal elemento, também, não leve a reações-cruzadas com o organismo humano, podendo-se citar, portanto, como excepcional candidata, a imunoglobulina Y.

Uma intervenção que se utilize da IgY, quando comparada à vacinação, por exemplo, além das vantagens citadas previamente, apresenta prós tais quais uma rápida ação local (Zhang et al., 2017), alta especificidade quanto à sua ação, aplicabilidade a uma ampla gama de pacientes, sua não toxicidade, uma vez que faz parte da dieta humana (Rahman et al., 2013) e a possibilidade de ser produzida em grande quantidade, dado que em aproximadamente $15 \mathrm{ml}$ de gema de ovo há mais de $100 \mathrm{mg}$ de lgY (Carlander, Kollberg \& Larsson 2002); tal concentração permite que, em um ano, uma galinha imunizada produza mais de $40 \mathrm{~g}$ da imunoglobulina, sendo este valor equivalente à quantidade produzida por 40 coelhos (Mine and Kovacs-Nolan, 2002). A imunoglobulina Y, graças às diferenças evolucionárias, também apresenta maior reatividade aos epítopos de um antígeno de um mamífero, levando, portanto, a um aumento de sinalização. Apesar de se fazer necessária a consideração quanto a uma possível alergia antes de se dar início ao uso de algum fármaco que tenha a lgY como princípio ativo (Carlander et al., 
2000), o risco associado a uma possível reação alérgica é consideravelmente menor quando a via de administração é a oral (Carlander, Kollberg \& Larsson, 2002).

A imunoglobulina Y, a principal dentre as três diferentes classes de imunoglobulinas em pássaros - IgA, IgM e IgY (Mine \& Kovacs-Nolan, 2002), segundo Müller e colaboradores (2015), é um elemento que sustenta a imunidade passiva do filhote dado que, através da transferência dos anticorpos presentes no serum materno à corrente sanguínea embrionária, os pintos, ainda que imuno-incompetentes, podem resistir a várias doenças. Tal transferência é mediada por um receptor e se dá no decurso dos dias finais do desenvolvimento embrionário, de forma que a presença das IgY já pode ser observada na gema do ovo entre 4 e 6 dias após a inoculação do patógeno na galinha (Müller et al. 2015).

Constituída de duas cadeias pesadas $(\mathrm{H})$ e duas cadeias leves (L) unidas por ligassões dissulfeto (Müller et al. 2015), e de maior peso molecular quando comparado ao da lgG humana; segundo Mine \& Kovacs-Nolan (2002), o maior obstáculo quanto ao isolamento da IgY é separar esta das lipoproteínas que se encontram em emulsão na gema do ovo a fim de, então, poder purificá-la. Foram desenvolvidas, então, diversos métodos de purificação que se utilizam da estratégia da separação das lipoproteínas e da imunoglobulina alvo; podendo-se destacar a ultracentrifugação, a delipidação através de solventes orgânicos, bem como precipitação por polietilenoglicol, dextran de sulfato de sódio (DSS) e alginato de sódio, bem como a ultrafiltração (Mine and Kovacs-Nolan 2002). A cromatografia de troca iônica, também conhecida como IEC ou IEX, segundo os autores, constitui uma etapa final do processo de purificação.

A diferença existente entre a IgY e IgG de mamíferos não se limita a pesos moleculares distintos, mas abarca diversos fatores que têm de ser considerados a fim de proporcionar condições ideais para um tratamento que se utilize da imunoglobulina do ovo. Apesar da estabilidade de ambas as moléculas se mostrarem semelhantes quando em um ambiente alcalino, quando estas são submetidas a um pH inferior, a atividade da IgY diminuiu consideravelmente a um $\mathrm{pH}$ de 3-5 e a perdeu completamente quando colocada em um meio de $\mathrm{pH}$ equivalente a 3-0, mostrando-se, portanto, mais propensa à desnaturação ácida (Mine \& Kovacs-Nolan, 2002).

Quanto à sua atividade em condições alcalinas, esta manteve-se inalterada até que se atingisse um $\mathrm{pH}$ equivalente a 12 ou superior, tendo seu funcionamento, então, reduzido (a.Bachtiar et al., 2015). A sensibilidade à temperatura também é um importante elemento a ser considerado, uma vez que, as imunoterapias até então proposta, que possuem a IgY como princípio ativo são de uso tópico, fazendo, portanto, com que a molécula seja sujeita à temperatura corporal humana; e, mais importantemente, que esta deva suportar a energia necessária para que passe pelos processos de produção do fármaco.

Após serem submetidas a diversos testes, estudos concluíram que a resistência imunoglobulina Y a temperaturas mais elevadas é notavelmente menor quando está fora comparada à da molécula de IgG de coelhos; tendo seu desempenho quanto à sua ligadura ao antígeno reduzido quando aquecida por 15 minutos à temperatura de $65^{\circ} \mathrm{C}$ ou mais, podendo sofrer uma desnaturação quando submetida a temperaturas superiores a $75^{\circ} \mathrm{C}$ (Mine \& Kovacs-Nolan, 2002, a.Bachtiar et al., 2015).

Em vista de tais propriedades, a imunoglobulina $Y$ fora estudada para diversos fins terapêuticos. IgY antiPseudomonas aeruginosa mostrou-se efetiva na redução da colonização do patógeno no ambiente pulmonar de pacientes com fibrose cística (Carlander et al., 2000; Kollberg et al., 2003; Thomsen et al., 2016); tal qual quando atuante como adjunto profilático ao antibiótico (Thomsen et al., 2016), uma vez que esse patógeno se encontra relacionado à resistência a antibióticos (Constantin et al., 2020). 
A imunoglobulina também teve sua ação estudada quanto ao tratamento de patologias gastrointestinais, como gastrite (Rahman et al., 2013; Leiva et al., 2020), gastroenterite em bebês (Rahman et al., 2013) e doenças infecciosas entéricas e disbiose no ambiente gástrico (Leiva et al., 2020); apresentando também eficiência na redução de patógenos gastrointestinais tal como a Salmonella typhimurium e a Salmonella enteritidis (Constantin et al., 2020).

A imunoglobulina também teve sua ação estudada quanto ao tratamento de patologias gastrointestinais, como gastrite (Rahman et al., 2013; Leiva et al., 2020), gastroenterite em bebês (Rahman et al., 2013) e doenças infecciosas entéricas e disbiose no ambiente gástrico (Leiva et al., 2020); apresentando também eficiência na redução de patógenos gastrointestinais tal como a Salmonella typhimurium e a Salmonella enteritidis (Constantin et al., 2020).

Bachtiar e colaboradores, em 2016, através de um estudo in vitro, estudaram a eficácia da IgY ao desservir o sistema de comunicação celular (quorum sensing), tendo, portanto, como finalidade reduzir a interação microbiana, fator essencial para a adesão, formação e manutenção do biofilme cariogênico. Assim, foi produzido IgY anti-ComD, moléculas pertencentes ao sistema de comunicação da bactéria S. mutans, um dos principais patógenos relacionados à doença cárie. Os resultados obtidos identificaram que a IgY reduziu o potencial do $S$. mutans em formar biofilme e minimizou a interação com outras bactérias comumente encontradas na superfície dentária, tal qual a Actinomyces viscosus e Lactobacillus spp. (Bachtiar et al., 2016).

Outro estudo in vitro do mesmo ano estudou a atuação da IgY anti-S. mutans (Juni et al., 2016), onde, após a obtenção do respectivo anticorpo, foi analisada a eficácia do IgY em inibir a colonização de S. mutans, S. alpha e Staphylococcus aureus. Ao final do estudo, os autores concluíram que houve um efeito inibidor sobre S. mutans, sem haver, no entanto, reatividade com as demais bactérias, podendo-se explicar essa ocorrência pela capacidade do IgY específico em se ligar à bactéria patogênica e mudar a superfície desta, resultando em enfraquecimento da capacidade de aderência, evitando, portanto, a replicação bacteriana (Bachtiar et al., 2016; Juni et al., 2016).

A imunoglobulina $Y$ também apresenta como mecanismo de ação, a supressão das glicosiltransferases, enzimas que, através de vários sorotipos, sintetizam os glucanos essenciais à formação e manutenção do biofilme cariogênico. Essas proteínas enzimáticas estão relacionadas aos principais microrganismos relacionados à cárie dentária, com notoriedade ao Streptoccocus mutans (Smith et al., 2001).

Em 2004, Krüger e colaboradores analisaram a atividade da imunoglobulina $Y$ anti-CA-gtb (inibidora da glicosiltransferase), através de um estudo em animais, em que ratos foram infectados por $\mathrm{S}$. mutans e tratados com anticorpos IgY anti-CA-gtb ou pó de gema de ovo não imune. Os resultados demonstraram que, pela exposição à respectiva IgY, tanto em solução como também na superfície de hidroxiapatita houve redução nas atividades das glicosiltransferases do tipo B (GtbB) e C (GtbC), as quais sintetizam glucanos insolúveis em água a partir da sacarose, como também a GtbC sintetiza glucanos solúveis. Apesar das diferenças estatísticas não significativas, observou-se que a IgY anti-CAgtb não somente preveniu apenas o surgimento da cárie, mas também reduziu o progresso da doença, uma vez que foi identificada uma redução na extensão e gravidade de lesões (Krüger et al., 2004).

Em 2001, Smith e colaboradores apresentaram um estudo realizado com animais, que, por sua vez, tiveram a dieta suplementada com IgY anti-GBP-B (proteínas de ligação ao glucano) a fim de analisar a possível redução na colonização de $S$. mutans e, consequentemente, redução da cárie dentária. No experimento 1, os animais foram suplementados durante 9 dias, e no experimento 2, a 
suplementação durou 24 dias. Apesar de a maioria dos ratos estarem fortemente infectados por $S$. mutans ao final do experimento (dia 78), a prevalência de lesões foi metade do que apresentou o grupo controle. Pelo menos seis dessas proteínas GBP foram identificadas na bactéria $S$. mutans, no entanto, neste estudo, foi analisada apenas a GBP-B, demonstrando que a IgY anti-GBP-B parece ter o potencial de modular a patogenicidade do S. mutans (Smith et al., 2001).

Em outro estudo com animais, Bachtiar e colaboradores (2015), 20 ratos foram infectados com S. mutans e divididos em 5 grupos (grupo 1-controle, 2- alimentado com leite de soja, 3- leite de soja enriquecido com quitosana, 4-IgY anti S. mutans, 5- IgY anti S. mutans e leite de soja com quitosana). Na análise do biofilme, realizada após 15 dias de alimentação, percebeu-se que houve maior número de achados bacterianos no grupo alimentado apenas por leite de soja. $O$ grupo de ratos que recebeu leite de soja enriquecido com IgY anti-S. mutans e quitosana apresentou a menor contagem de $S$. mutans no biofilme dental (Bachtiar et al., 2015).

Seguindo a mesma linha de pesquisa, Bachtiar e colaboradores, em 2016, realizaram um estudo, onde 24 ratos tiveram a cavidade oral exposta ao $S$. mutans e a uma dieta cariogênica, sendo estes também alocados em quatro grupos. As contagens de colônias de S. mutans diminuíram nos ratos dos grupos que receberam gel contendo IgY, com redução mais significativa no grupo que apresentou o maior período de aplicação do gel. Já nos ratos de outro grupo, o anticorpo apresentou, após uma semana de uso, efeito curativo das lesões presentes, uma vez que este grupo começou a receber o gel apenas quando manchas brancas começaram a aparecer. Quando analisadas as amostras salivares, observou-se que o IgY não foi detectado após o experimento, no entanto, percebeu-se também maiores volumes de saliva nos grupos com IgY, podendo-se inferir, portanto, que o gel contendo IgY tenha aumentado a produção de saliva, resultando em uma maior defesa química e imunológica, o que reduziu o risco da ocorrência da cárie. Este estudo também mostrou que menores concentrações de IgY, necessárias para reduzir as colônias de S. mutans, são empregues quando géis são usados, apresentando imunorreatividade tão estável quando a IgY pura (Bachtiar et al., 2016).

Além disso, estudos in vivo também foram desenvolvidos, como o de Carlander e colaboradores (2002), que analisaram a especificidade da imunoglobulina $Y$, utilizando como aparato um enxaguante bucal contendo IgY anti-Pseudomonas aeruginosa. Primeiramente, os participantes foram instruídos que após escovar os dentes, realizassem um enxágue bucal com solução salivar tamponada com fosfato e, posteriormente, coletar este bochecho no tubo denominado "s1". Depois, foram instruídos a fazer um bochecho com solução contendo IgY anti-P.aeruginosa, por 1 ou 2 minutos, e após, a solução era então engolida. A amostra "s2" foi obtida após 8 horas do bochecho com IgY, e a amostra "s3", após 24 horas. Após análise dos achados coletados, percebeu-se que maiores concentrações do anticorpo estavam nas amostras "s2" e "s3", demonstrando a presença deste anticorpo na cavidade oral, mesmo sem repetir o uso do enxaguante contendo IgY (Carlander et al., 2002).

Nguyen e colaboradores, em 2011, realizaram um estudo in vivo através da produção de duas pastilhas orais, uma contendo IgY anti-CA-gtf (células associadas às glicosiltransferases) e a outra contendo placebo, a fim de analisar a ação da imunoglobulina e a possível capacidade desta de inibir a adesão bacteriana. Como resultado, identificou-se que as pastilhas contendo IgY inibiram a adesão de S. mutans em porcentagens muito maiores que no grupo placebo, todavia, a imunoglobulina não interagiu com outras espécies do Grupo mutans, como S. cricetus, S. rattus e S. downei (Nguyen et al., 2011).

Os estudos mais recentes (Bachtiar et al., 2019) in vivo avaliaram o potencial da IgY anti-ComD, utilizando-se, entretanto, de enxaguantes bucais contendo quitosana, um derivado da quitina com 
propriedades de conservante natural da imunoglobulina Y. Os resultados obtidos identificaram a redução do biofilme oral nos indivíduos que utilizaram o enxaguante contendo IgY anti-ComD sem quitosana, não apresentando diferenças estatisticamente significantes entre indivíduos com ou sem cárie ativa. Mediante os testes realizados, os autores puderam constatar o potencial do enxaguante quanto a sua atuação referente ao aumento do $\mathrm{pH}$ oral, prevenindo assim a desmineralização da superfície dentária (Bachtiar et al., 2019). Levando em consideração tais resultados obtidos com as pesquisas, uma vacina contendo a região de codificação da molécula ComD de S. mutans foi desenvolvida por Endang Winiati Bachtiar (anúncio de patente número 0492779.7) (Bachtiar et al., 2019).

Em suma, os estudos in vitro demonstraram uma ótima atividade da IgY contra a bactéria S.mutans através da desestruturação do quorum sensing e inibição da adesão da bactéria (Bachtiar et al., 2016; Juni et al., 2016). Estudos com animais demonstraram a atuação da Imunoglobulina $Y$ quanto as glicosiltransferases (Smith, 2001; Krüger et al., 2004) e, ao pesquisarem influência da IgY em dietas controladas, percebeu-se a redução de S.mutans no biofilme dental e efeito curativo do gel de IgY, reduzindo lesões cariosas instaladas (Bachtiar et al., 2015; Bachtiar et al., 2016). Nos estudos in vivo (Carlander, 2002; Nguyen et al., 2011, Bachtiar et al., 2019), houve uma progressão no pensamento e evolução da ação da imunoglobulina, culminando na vacina criada por Endang Winiati Bachtiar (anúncio de patente número 0492779.7) (Bachtiar et al., 2019).

\section{Conclusão}

Deste modo, os estudos expostos na revisão demonstram que, além de seu potencial uso odontológico, a imunoglobulina Y tem atuação em bactérias causadoras de doenças sistêmicas, como a redução da Pseudomonas aeruginosa em pacientes com fibrose cística (Carlander et al., 2000; Kollberg et al., 2003; Thomsen et al., 2016); e nas bactérias Salmonella typhimurium e a Salmonella enteritidis (Constantin et al., 2020), sendo estudada quanto ao tratamento de patologias gastrointestinais (Rahman et al., 2013; Leiva et al., 2020).

Em relação a doenças da cavidade oral, vários estudos encontraram resultados significativos na Periodontite (Yokoyama et al., 2007), Gengivite (Leiva et al., 2020) e Cárie Dentária (Nguyen et al., 2011). Frente aos diversos estudos realizados, o conhecimento sobre a atuação e mecanismos da imunoglobulina $Y$ contra a bactéria S.mutans apresentaram uma evolução ao longo do tempo, culminando no desenvolvimento de uma vacina que age sobre a glicosiltransferase da S. mutans.

Assim sendo, a IgY apresenta uma boa atuação antimicrobiana seletiva à bactéria Streptococcus mutans, atividade que, por sua vez, culmina na interferência do biofilme como um todo. Ademais, vários estudos recentes sugerem que a IgY tem ação no diagnóstico do vírus influenza (Constantin et al., 2020); candidíase (Rahman et al., 2013), doenças nutricionais e metabólicas, neoplasias, doenças crônicas (Leiva et al., 2020), amigdalite e o resfriado comum (Carlander et al., 2000), sendo necessárias, portanto, mais pesquisas que consigam avaliar a real atuação nessas doenças bem como em outras bactérias patogênicas da cavidade bucal, visando que, no futuro, a lgY possa ser usada para fins médicos e odontológicos. 


\section{REFERÊNCIAS}

Bachtiar, E.W., et al. (2016). Effect of Topical Anti-Streptococcus Mutans IgY Gel on Quantity of S. Mutans on Rats' Tooth Surface. Acta Microbiologica et Immunologica Hungarica 63 (2): 159-69. https://doi.org/10.1556/030.63.2016.2.2.

Bachtiar, E.W., et al. (2015). "Effects of Soybean Milk, Chitosan, and Anti-Streptococcus Mutans IgY in Malnourished Rats' Dental Biofilm and the IgY Persistency in Saliva." Interventional Medicine and Applied Science $7(3): 118-23$.

a. Bachtiar, E.W. et al. (2019). The Effect of Mouthwash Combination of Immunoglobulin-y Anti-Comd Streptococcus Mutans and Chitosan on the Formation of Streptococcus Mutans Biofilm. International Journal of Applied Pharmaceutics 11(4): 110-13.

b. Bachtiar, E.W., et al (2019). Effect of Mouthrinse Containing Immunoglobulin-y Anti-Comd Streptococcus Mutans + Chitosan on Quantity of Salivary Streptococcus Mutans in Caries and Caries-Free Subjects. International Journal of Applied Pharmaceutics 11 (4): 120-22.

Bernabe.B. (2020). Global, Regional, and National Levels and Trends in Burden of Oral Conditions from 1990 to 2017:A Systematic Analysis for the Global Burden of Disease 2017 Study. Journal of Dental Research. 99(4) 258 362-373

Carlander, D., Kollberg H., Larsson A. (2002). Retention of Specific Yolk IgY in the Human Oral Cavity. BioDrugs 16 (6): 433-37.

Carlander, D. et al. (2000). Peroral Immunotheraphy with Yolk Antibodies for the Prevention and Treatment of Enteric Infections. Immunologic Research 21 (1): 1-6.

Constantin, C., et al (2020). IgY - Turning the Page toward Passive Immunization in COVID-19 Infection (Review). Experimental and Therapeutic Medicine 20 (1): 151-58.

Fejerskov et al. Carie Dentária. A doença e seu tratamento clínico. 2017,2ed; Rio de Janeiro, Elsievier

Hofling, J.F., Gonçalves, R. Imunologia para Odontologia. 2007. 1. ed. Porto Alegre: Artmed

Juni, H. et al (2016). Effects of Immunoglobulin Y (IgY) Serum against Plaque Bacteria.African Journal of Microbiology Research 10 (39): 1668-74.

Kollberg, H., et al.(2003). Oral Administration of Specific Yolk Antibodies (IgY) May Prevent Pseudomonas Aeruginosa Infections in Patients with Cystic Fibrosis: A Phase I Feasibility Study. Pediatric Pulmonology 35 (6): 433-40.

Krüger, C., et al. (2004). The Effects of Egg-Derived Antibodies Glucosyltransferases on Dental Caries in Rats. Caries Research 38 (1): 9-14.

Leiva, C.L., et al. (2020). IgY-Technology (Egg Yolk Antibodies) in Human Medicine: A Review of Patents and Clinical Trials. International Immunopharmacology. Elsevier B.V. 81:106269.

Leslie, G. A., Clem L.W. (1969). Phylogen of Immunoglobulin Structure and Function. 3. Immunoglobulins of the Chicken. The Journal of Experimental Medicine 130 (6): 1337-52.

Marcenes, W., Kassebaum, N.J., Bernabe, E. (2013). Global burden of oral conditions in 1990-2010: a systematic analysis. Journal of Dental Research. 92(7), 592-597

Marsh, P., Martin, M.V.(2005). Microbiologia oral. São Paulo: Editora Santos.

Mine, Y, Kovacs-Nolan J. (2002). Chicken Egg Yolk Antibodies as Therapeutics in Enteric Infectious Disease: A Review. Journal of Medicinal Food. Mary Ann Liebert Inc. 5(3):159-69. 
Nguyen, SV., et al. (2011). Anti-Cell-Associated Glucosyltransferase Immunoglobulin Y Suppression of Salivary Mutans Streptococci in Healthy Young Adults. Journal of the American Dental Association 142 (8): 943-49.

Pereira A.S. et al. (2018). Metodologia da pesquisa científica. [e-book]. Santa Maria. Ed. UAB/NTE/UFSM

Rahman, S, et al. (2013). Oral Passive IgY-Based Immunotherapeutics: A Novel Solution for Prevention and Treatment of Alimentary Tract Diseases. Human Vaccines and Immunotherapeutics. 9(5):1039-48

Smith, D. J., W. F. King W.F., Godiska R. (2001). Passive Transfer of Immunoglobulin Y Antibody to Streptococcus Mutans Glucan Binding Protein B Can Confer Protection against Experimental Dental Caries.Infection and Immunity 69 (5): 3135-42.

Spolidorio \& Duque. Microbiologia e Imunologia Geral e Odontológica. 2017.Vol.2, Série Abeno

Thomsen, K., et al. (2016). Anti-Pseudomonas Aeruginosa IgY Antibodies Augment Bacterial Clearance in a Murine Pneumonia Model. Journal of Cystic Fibrosis 15 (2): 171-78.

Yokoyama, K., et al. (2007). Effects of Egg Yolk Antibody against Porphyromonas Gingivalis Gingipains in Periodontitis Patients.Journal of Oral Science 49 (3): 201-6.

Zhang, X., Rosaleen A. Calvert, B.J.S, Katy A. D. (2017). IgY: A Key Isotype in Antibody Evolution. Biological Reviews 92 (4): 2144-56. 


\section{PANDEMIC METAPHORS: BIBLIOMETRIC STUDY OF THE COVID-19 (CO)LLATERAL EFFECTS}

\author{
Priscilla Chantal Duarte Silva \\ Universidade Federal de Itajubá - Brasil \\ priscillachantal@unifei.edu.br
}

\begin{abstract}
The current COVID-19 pandemic, that stopped the world, brought with it major consequences for humanity. Seen as the great villain, the new coronavirus brought changes in lifestyle, hygiene and consumption, confinement, and new ways of thinking, working and, managing human relationships. This has generated stress on humanity because, in many ways, there was no preparation for these social changes. Exposing the health system to its greatest risk, the need to cope with COVID-19 brought transformations in all areas, many of which had a negative impact. The objective of this study is to analyze the (co) side effects of the pandemic in a general aspect, showing positive and negative effects. However, highlighting marked changes to the environment, given the time when the emission of carbon dioxide into the atmosphere received a mandatory reduction as a result of social confinement. The methodological basis used is a systematic literature review, consulted in impact databases by the scientific community. We chose to search the Web of Sscience, Science Direct and PubMed databases. The search keys were: pandemic, COVID-19, new coronavirus, effects of COVID-19. In addition, to analyze the presence of conceptual metaphors, opinion articles published in the world media, and published on the web during thea pandemic were selected. The
\end{abstract}

choice of texts is based on the theme of the new coronavirus and its impacts. The theoretical bias of Lakoff (1987; 2006) is adopted to explain metaphor on the cognitive plane, as a natural process of the human mind, that is, a way of thinking. This research is characterized in qualitative, bibliographic and analysis of content. The results show that the conceptual metaphors reveal an image of COVID-19 as the "savior" of the environment, for having forced man to stop as a need for carbon. It was concluded that the conceptual metaphors, being of a cognitive nature, appear in the form discourse, showing COVID-19 as agents of positive effects on the environment and business for the other areas of society.

\section{Keywords:}

COVID-19; Pandemic. Conceptual metaphors;

Social and environmental effects of COVID-19. 


\section{INTRODUÇÃO}

The virus that stopped the world in 2020 is called the New Coronavirus or COVID-19. It is an RNA virus of the order Nidovirales of the family Coronaviridae. The SARS-CoV, MERS-CoV, and 2019-nCoV viruses are from the subfamily Betacoronavirus that infect only mammals (MINISTRY OF HEALTH, 2020). COVID-19 is known to be part of the family of coronaviruses, common in animals. The name Coronavirus was assigned because of the viral surface that shapes the appearance of a crown under electron microscopy. They are positive RNA, with a diameter between $60 \mathrm{~nm}$ and 140nm (Richman, Whitley; Hayden, 2016). "The clinical spectrum of coronavirus infection is very broad, ranging from a simple cold to severe pneumonia" (MINISTRY OF HEALTH, 2020). Symptoms by the infectious pathogen - such as sneezing, coughing, bleeding - spread to the next replicating host, or "RO" of a pathogen. Imperial College London estimated the R0 of the new coronavirus from 1.5 to 3.5 (Walsh, 2020).

Studies indicate that Coronaviruses can rarely infect people and subsequently reproduce in humans, as happened with MERS-CoV and SARS-CoV. However, the origin of the New Coronavirus is still a mystery. Walsh (2020) highlights that Covid-19 marks the return of an old - and familiar - "enemy" virus. Similar metaphors began to circulate in the international media involving COVID-19. Therefore, we aimed to understand how these metaphors, both from the semantic field of enmity and of friendship, were being produced, and what are their correlation with human cognition.

For Walsh (2020), throughout history, nothing has killed more human beings than the viruses, bacteria, and parasites that cause disease, which demonstrates human fragility in the face of biological issues. In principle, epidemics have turned into massacres on a scale that we cannot imagine today - even at the time of the coronavirus. When a virus - like the new coronavirus - infects a host, it becomes a cell "factory" which creates more viruses (Walsh, 2020), revealing metaphors well known in the scientific world: CELL IS FACTORY. VIRUS IS A LIVING BEING. VIRUSES ARE INVADERS. VIRUSES ARE ENEMIES. In this sense, one can observe the presence of the metaphor.

The use of metaphors to explain Science is not new. For Brown (2008), this linguistic resource is used to understand the world. Many concepts have been determined by scientists using metaphors to explain abstract concepts. Terms such as time, quantity, and energy are understood through embodied experiences. "ENERGY IS A SURFACE", "TIME IS A LINEAR DIMENSION" as highlighted by Brown (2008, p.160), and "the mitochondria are THE CELL OVEN or PLANT" due to the fact that they produce energy for cells, and behave similarly to an oven in terms of energy-generating transformations and, as argued by Gentner \& Maravilla (2018), they are examples of how metaphors became familiar with the field of Sciences. In the study in question, metaphors are associated with the virus.

The treatment protocol for COVID-19 of the Ministry of Health of Brazil (2020) states that, at the beginning of virus propagation, some people with outbreaks of respiratory diseases caused by 2019nCov in China, were assumed to have some connection to the fruit market as highlighted by Duarte (2020) and to live animals, as it was thought that the transmissiontransmition first happened from animals to people. On the other hand, there is also an indication that the spread has occurred from person to person, by those who have not had exposure to animals. 
According to UN Environment Program (2020), COVID-19 can be a response of the environment in relation to its degradation by the action of man. Once suffering the loss and deterioration of habitat due to deforestation or other actions that damage the environment, man is having more direct contact with wild animals, which may have caused the spread of a series of viruses to humanity.

COVID-19 is a reminder that human health is linked to the health of the planet. Coronaviruses are zoonotic diseases, which means that they are transmitted between animals and humans. These diseases represent about 75\% of all emerging infectious diseases. To prevent future outbreaks, we must address threats to ecosystems and wildlife, including habitat loss, illegal trade, pollution and climate change (UN Environment Programme, 2020).

The representations of COVI-19 in the media, at a global level, reflect the urgent need to build discursive scenarios around a disease classified as a pandemic, and, as such, highly dangerous to human health, easily transmitted socially, and whose contagion mechanisms are still poorly understood. It is not surprising that the referred discursive scenarios constitute selective representation processes, as postulated by Fernandez (2012, p. 72): "the construction of the discourse takes place through a selective process capable of projecting a representation of the world [...] the speeches and social uses of the language reflect the representation of the speaker's world, group or community".

Thus, the speeches portray representations of how the world is understood. In this context, analyzing the discourses on COVID-19 may help us understand how the virus is interpreted, as well as the actions taken because of it while facing the pandemic. Thus, the objective of this study is to verify, in the scientific discourses on COVID-19, what are the (co) side effects of the pandemic in a more general scope, as well as those of a more positive character, that is, which portray the positive side of the pandemic, especially concerning the description of the environment through metaphors.

\section{Global effects of COVID-19}

COVID-19, the first pandemic in human history caused by coronavirus, brought with it several side effects in addition to the disease that spread throughout the world The term "Collateral" Co + lateral; from Latin collateralis, from Latin Com, alongside and Lateralis (Dicimedico, 2020), to the side has a connotation, according to Priberam (2020), referring to parallel, which happens indirectly. However, in medical vocabulary, this term usually refers to something bad, unpleasant or harmful (Dicio, 2020). In this study, the objective is to discuss both the harmful effects of the pandemic and those of a lateral order, positive for the environment. After all, many effects happened due to the quarantine period during the pandemic.

"The COVID-19 pandemic has enormous impacts on most aspects of human activities, as well as on the economy and health systems" (Zowalaty, Young, Järhult, 2020). With the quarantine, a period of seclusion of individuals to contain the spread of a disease according to the incubation period, humanity has seen negative effects of living with the pandemic. Quarantine is a known risk factor for psychological and psychiatric disorders (Parodi et al. 2020). In the quarantine of COVID-19, the authors highlight cases of depression and anxiety due to isolation. However, there are also other pandemic impact factors. 
Despite the negative impacts such as psychological stress, fear, severe global economic losses, health system overload, and general societal disruption (Zowalaty, Young, Järhult, 2020), lifestyle changes in response to outbreak resistance, according to the authors can also bring positive changes to the environment, health to humans, animals and the ecosystem.

The guidelines adopted by governments regarding social distance led companies to reformulate their means and work routine, adoption to the home office, travel restrictions, which resulted in less oil use, consequently reducing emissions of gases generated by oil. If COVID-19 is a causal factor for an improvement in the global pollution situation, on the other hand, pollution may be the consequence or contributing factor for the advancement of COVID-19. According to Zhu et al. (2020), the scientific literature suggests that air pollutants are risk factors for respiratory infection, capable of transporting microorganisms to make pathogens more invasive, compromising immunity, which means that the less pollution, the better for health.

Paital (2020) defends the idea that although COVID-19 has brought serious side effects to humanity, as the economy has been drastically affected by human losses and the closure of businesses, nothing compares to the environmental gain during the COVID- pandemic period. 19. For Lal et al. (2020), the pandemic just caused great suffering and economic losses, interruptions in global supply chains, business, commodities, tourism, increased anxiety in general, etc.

However, nature is rejuvenating under social distance and lockdown policies (Specktor, 2020). "Mother Nature was waiting for a transformation process to revive her individual ecosystems. It seems that the social blockade in the fight against COVID-19 gave it a long-awaited break for selfregeneration" (Paital, 2020, p.3). In this sense, the effect was (co) lateral, that is, a positive result for the environment. The metaphor "Mother nature" can be seen, in the perspective of the Conceptual Metaphor Theory, as a mental way to understand that NATURE IS A MOTHER, in the sense that mankind depends on her to survive, just as a son depends on his mother.

With the confinement and activities interrupted, "[...] important environmental indices, such as NO2 reduction, $\mathrm{CO} 2$ emissions, water pollution and increased air quality in many polluted cities were observed" (Paital et al., 2020). The COVID-19 pandemic has a severe negative impact on humans, as well as on health and the world economy. However, it results in a significant reduction in pollution, due to the limitations of social and economic activities (Dutheil et al., 2020; Sulaman and Salman, 2020).

CBS News (2020) also confirms the positive effects of the pandemic. As human beings remain in their homes due to the pandemic, the Earth is slowly recovering. Wild animals have started to roam the streets, the clear waters have returned to the Venice canals, and the world is shaking less. According to Lewis' report (2020) on CBS News, many cities have seen changes in the visual and climatic aspects of the western and eastern world, after the confinement period, compared to previous years. It is visible how the air is less polluted.

Sulaman and Salman (2020) point out that NO2 (nitrogen dioxide) is a highly reactive pollutant emitted by the combustion of fossil fuels. According to He et al., 2020a, 2020b apud Sulaman and Salman, 2020), traffic pollution is considered the main source of NO2 emissions, which are highly lethal for human health. Sulaman and Salman (2020) highlight, through NASA satellite images, how the NO2 emission reduced significantly after lockdown. According to the authors, it is a "Blessing in disguise", "camouflaged blessing" or "disguised blessing" in the sense that everyone believes it is a tragedy, but it also brings something good. At the same time, although the positive effects are seen as a "blessing", it hides behind its real destructive function. 


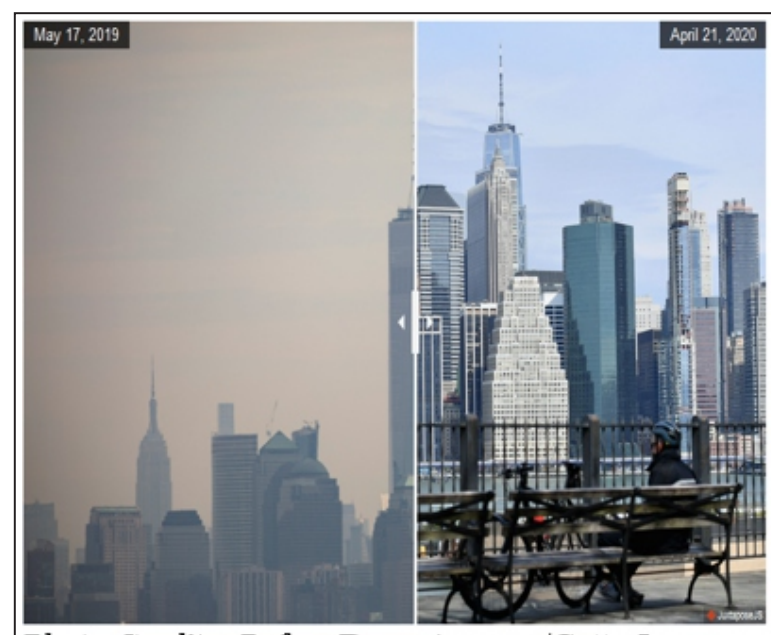

Photo Credits: Before Drew Angerer/Getty Images After ANGELA WEISS/AFP via Getty Images

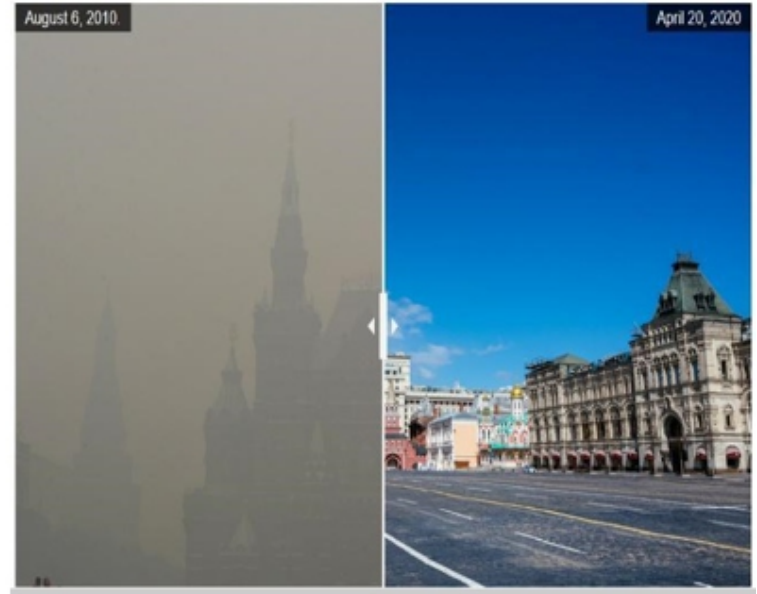

Photo Credits: Before NATALIA KOLESNIKOVA/AFP via Getty Images After NIKLAS HALLE'N/AFP via Getty Images

Figure 1 - Comparative image of New York 2019-2020 and Moscow 2010-2020 Source: Lewis (2020)

This English idiom also brings with it the metaphor that COVID-19 IS CAMOUFLAGE. "COVID-19 is a global pandemic and a serious threat to human health that paralyzes economic activities, but it is also considered a "Blessing in Disguise". However, the authors emphasize that the change, while positive, is temporary and that it will serve for governments and people, in general, to learn how to reduce pollution in the world.

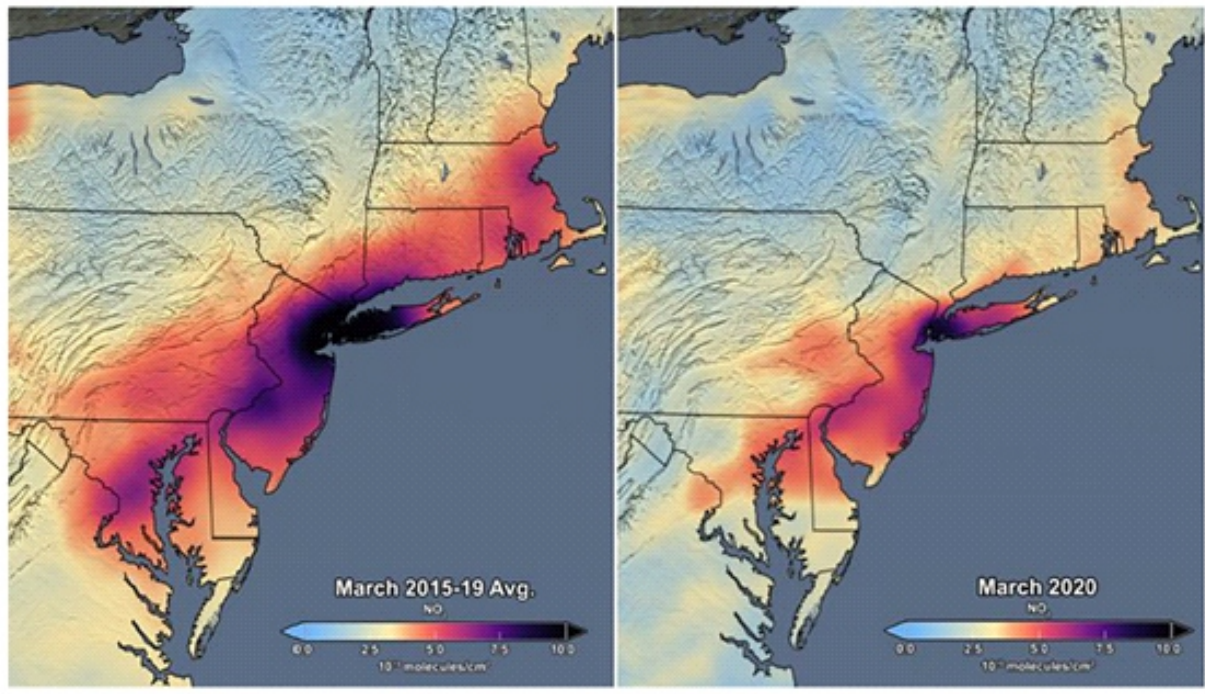

Figure. 2 - NO2 emissions in the northeastern USA before and after the lockdown. Source: (NASA, 2020, apud Sulaman and Salman, 2020)

In addition to the effects on pollutant emissions, the research by Monserrate et al. (2020) also highlights the association between contingency measures and improved air quality, clean beaches, and reduced environmental noise. On the other hand, there is also a reduction in recycling and an increase in waste, due to greater indoor consumption. This, according to the authors, can put the contamination of physical spaces at an increased risk. Also, some countries have stopped with 
recycling programs in some cities for fear of spreading the virus in these centers. Waste management was also restricted. Disposables have been revoked because plastic can harbor viruses and bacteria.

The effects of COVID-19 also have their social and psychological effects. Li et al. (2020) argue, through research, that there was an increase in negative emotions such as: anxiety, depression and indignation, greater sensitivity to social risks, and a decrease in positive emotions after the declaration of the pandemic in China. Besides, other effects have been observed in several segments. In education, for example, the changes were too sudden in some sectors. Both students and teachers had to adapt to remote education, often without adequate preparation. Dealing with the "new normal", a name popularly recognized as a paradigm shift followed by new health and hygiene care in establishments, has also had an impact on society.

On the other hand, as (co) side effects in education, there was an increase in combined learning, collaborative work, and availability of learning material (Misra, 2020). Teachers started to have greater experience with technology, transforming traditional classes into new forms of learning; reformulation of the way of thinking about distance learning. It was also an opportunity for students to deal with new technologies and forms of teaching as well as greater preparation for changes and adversities. There was also an opportunity to develop learning management systems for use in universities.

For Currie (2020), the "new normal" is likely to have an effect on organizations with more flexible work hours for staff and remote tasks, where this kind of activity is more practical and convenient. Also, new practices that are currently adopted to contain the spread of the virus may be implemented as conventional practices. For example, similar to patient screening, pre-service research or on-site monitoring is likely to persist beyond the recovery of COVID-19, as a general precaution for infectious diseases. Therefore, the "new normal" metaphor includes a series of procedures, attitudes, and behaviors that affect society.

\section{Cognitive Linguistics and Conceptual Metaphors}

With a revolution in neural studies on the functioning of the mind and brain, ways of thinking were also the target of analysis and understanding. As Lakoff (2008) points out, discoveries about neural computing and brain sciences contributed to the understanding of how conceptual metaphors work as components of human thought. According to the author, all body actions are controlled by the brain, and thinking is physical. Ideas and concepts are computed by brain structures. Brown (2008, p. 31) states that many entities used to think about things and talk about them, such as love, time, or meanings of scientific observations, which are all abstract concepts.

Everything that the human being possibly thinks stems from cognitive processing. Thus, the processing of metaphor, as a phenomenon that people observe linguistically, is anchored in mental operations. For Lakoff (2008), the metaphor does not reside in words, but in ideas. It is present in people's daily lives, not only in language but fundamentally in human thought and actions. For him, it is not a simple figure of speech. Charteris-Black (2004) believes that metaphor cannot be defined by a simple criterion that can be applied in all circumstances, but it is necessary to follow linguistic, pragmatic, and cognitive criteria. The author defends the idea that the metaphor must be understood taking into account the specific communication context, while its cognitive characteristics should not be treated without observing the persuasive function of the metaphor in the discourse. 
The conceptual system in terms of what one thinks and acts is of metaphorical nature. In this way, the concepts about all things in the world are structured, according to the Theory of Conceptual Metaphor (TMC) from physical and social experiences. Literature maintains that the essence of metaphor consists of understanding and experiencing a type of thing in terms of another. TMC explains that this process is structured based on certain experiences. In this way, abstract concepts can only be understood as metaphorical mappings of domains of origin based on direct physical and social experiences (Brown, 2008). According to Lakoff and Johnson (1980), the conceptual metaphor involves a relationship between source and target domains. In these domains, metaphorical correspondences are considered mappings. Coulson (2008), also argues that the understanding of metaphor involves the construction of cognitive models involving mappings or correspondences between represented objects and relations.

In Lakoff and Jonhson's (1980) theory, these relationships occur through conceptual domains. Thus, the domain over which metaphorical expressions are extracted to understand the other domain is called the source domain. Consequently, the conceptual domain that is interpreted with those particular characteristics is the target domain. Thus, in the metaphorical expression LIFE IS A JOURNEY, for example, the target domain is life because this term will be interpreted under the aspects that contemplate the JOURNEY domain. In this sense, the conceptual apparatus will interpret by building conceptual and analog relations to create the effect of meaning.

The conventional way of representing a certain phenomenon, for example, presupposes a metaphor that is often elaborated without the person being aware of it. In this conception, everyday language is full of metaphors without awareness of its metaphorical character (BROWN, 2008, p.32). Lakoff (1980) refers to the metaphor ARGUMENT IS WAR, in which, relating to the term "ARGUMENT", the target domain is mapped in the light of the source domain of WAR. For him, actions are in accordance with the way people conceive things and act according to the way they conceive them. Thus, thought processing is metaphorical, conceptual, and systematic. In this way, metaphorical concepts can be recognized underlying the metaphorical term because they use expressions from one domain to explain another. For Lakoff (1993), the place of metaphor is not in the language itself, but in the way in which one mental domain is conceptualized in terms of another. A conceptual metaphor consists of a set of mappings between two domains of experience (Kovecses, 2017).

In ARGUMENT as WAR, for example, it is possible to find several expressions that lead to this metaphor, such as ideas of attack, defense, strategy, etc. Likewise, in TIME IS MONEY it is common to find expressions such as "you are spending my time", or "there is still no time to give", etc. It is worth highlighting the reason why TIME is represented in the light of MONEY, given that in capitalist societies the working time is allocated in a certain monetary value. Therefore, as with money, we can spend, lose, invest time, or even save some time to perform a certain action.

In this way, an abstract term can be represented from another, and this mapping is necessarily partial, that is, it is based only on some characteristics of the element in the source domain. The author stresses that the understanding of the metaphorical concept is partial, considering what it communicates. It is understood that TIME is represented as MONEY, once spending time on something that is not possible to get back, much less give someone time, and get that person the same time as a return.

In this sense, Lakoff (1980) postulates that through linguistic expressions or forms, it is possible to discover what is the type of metaphorical concept involved, that is, what is behind the linguistic use, in 
terms of a way of thinking the world. Lakoff (1980) highlights that, through linguistic expressions, it is possible to study the nature of metaphorical concepts, and thus understand the metaphorical nature of human activities.

\section{Protective discourses in a cognitive analysis and socio-environmental effects of COVID-19}

Regarding the context related to the pandemic, there is a use of metaphorical mappings aimed at the source domains WAR, ENMITY OR FRIENDSHIP, in the sense of combating the harmful agent in the first two and subversion in the last regarding the positive effects of the pandemic, especially concerning to the benefits to the environment. After understanding the panorama of what COVID-19 is, as well as the (co)llateral effects, of the disease at global levels, which are fundamental to understand the context in which metaphors are located, this section starts with the understanding of the reason why these metaphors were being formulated mainly within the semantic field of enmity and friendship.

Some studies have pointed to the figure of COVID-19 as an ENEMY, leading to the direction of the metaphorical mapping of the WAR domain. As Charteris-Black (2004), Hidalgo-Downing \& KarljevicMujic (2009) developed a quantitative study on the metaphors of immunity, involving a corpus of 60 articles from the journal Scientific American. This study highlights the pragmatic functions of metaphor in the discourse, focusing on discursive intentionality and temporality of metaphorical representations, in conjunction with its persuasive function, as pointed out by the studies by Charteris-Black (2004).

The results of the quantitative study revealed that most of the metaphorical images referring to the immunity of the human body to various viruses were, for the most part, conventionalized based on the source domains WAR, TRAVEL, or PERSONIFICATION. Personification refers to something that is inanimate using a word or phrase that within another context refers to something animated (CHARTERIS-BLACK, 2004). In this context, the virus is personified by being assigned to act, invade, threaten, etc.

This personification can be seen in the following excerpt, the title of an opinion article on Science and Health, from the Portuguese media. It is noted in the excerpt that the title brings to the population's attention an unexpected controversy: COVID-19 as FRIEND OF THE ENVIRONMENT. The conceptual metaphor used to deconstruct and demystify that all harm brings harm is strategically chosen to expose how the pandemic, due to the absence of large circulation of people and the subsequent reduction on the emission of polluting gases, brought to the environment the possibility of BREATHING BETTER, in the sense of decreasing ofhaving fewer pollutants.

It is worth remembering that the term "breathe better" brings in the context of the article the idea of a personification, both of the environment that is capable of breathing, and of a virus, although being an acellular living being, it has the competence to have the quality of friend. The other terms such as contribute and bring improvement, even if not metaphorical, join the semantics of explaining why COVID-19 is considered a FRIEND OF THE ENVIRONMENT. Metaphorically the term is associated in the context of the FRIENDSHIP domain. Thus, the subject conceptually interprets certain characteristics that are part of what is considered as a friend: the one who helps, as well as the one who contributes 
to some state of improvement. This scenario of measures to combat a virus, whose forms of dissemination are partially unknown, elects as a primary combat measure the permanence of people in confinement in their homes, depriving them of social or professional coexistence in person.

COVID-19: enemy of Man, friend of the environment: Data from the European Environment Agency show that the quarantine caused by the coronavirus is indirectly contributing to the improvement of the state of our planet, allowing it to "breathe" better.

Table 1 - ENVIROMENT FRIEND

Source:https://www.juponline.pt/ciencia-saude/artigo/34883/covid-19-inimigo-do-homem-amigo-doambiente.aspx

On the other hand, a questioning survey was found in the international media questioning if the COVID-19 is a friend or an enemy of the climate. In the excerpt below, the title raises a paradoxical reflection. The text, however, suggests that, although there is a benefit to the environment due to the reduction of polluting gases, there is also a predominant opinion that the pandemic may focus society's attention on the economic crisis, and no longer on the environmental crisis.

Climate friend or foe? The COVID-19 pandemic has had a dramatic impact on carbon emissions - more than that of the financial crisis, World War II or the Spanish flu. But will it help or hurt the green agenda in the long run?

Table 2 - COVID-19 FRIEND or ENEMY of the climate?

Source: NORDEA (2020)

Due to the lack of control over the pandemic outbreak, representations of the virus proliferate as NATURAL CATASTROPHES, namely tsunamis, hurricanes, or other equally overwhelming natural phenomena that are beyond human control. The catastrophe is semantically associated with calamity, with something disastrous. Thus, the conceptual metaphor COVID-19 IS CATASTROPHE is observed in the table below. Although the metaphor is not explicitly marked in the linguistic expression of the sentence, it is possible to arrive at the conceptual metaphor by looking at the semantic domains involved.

"Covid-19 pandemic is one of the most complex catastrophes of all time", says economist José Pio Martins.

Table 3 - COVID-19 IS CATASTROPHE

Source: HEALTH DEBATE (2020)

In principle, it is commonly noted the use of metaphors in forms of media discourse, although some scientific articles may also present metaphorical mappings, especially relating to howthe ways in which the virus acts and spreads, as well as the measures to be taken. As Brown (2008) states, human language is full of metaphors that people use without being aware of its metaphorical character. In order to explain 
how the virus works, many metaphors have emerged correlating the effects of the pandemic with the representations that people have about it. On the other hand, Lakoff (1980) refers to metaphor as a conceptualization process, even though one can observe the representations involved in the metaphorization of the pandemic, it must also be considered that it is a matter of thought.

Since COVID-19 is a virus that invades the human body and establishes itself in a host cell, it is expected that it will necessarily request a response from your immune system in order to fight it. In this sense, the individual's immune system will respond in an attempt to eliminate the invading agent. In terms of metaphorical mapping, it is inevitable that the source domain of WAR will inevitably be predominant in the metaphorical elaborations conveyed by the international press, as illustrated in the excerpt below:

"Covid-19: a biological war - the role of the Armed Forces: Portugal is not prepared for an attack with these proportions. Each day it is learning, adapting and trying to respond".

Table 4 - Biological warfare

Source:https://sol.sapo.pt/artigo/689906/covid-19-uma-guerra-biologica-o-papel-das-forcas-armadas

Considering a larger context and, observing other parts of the text, the source domain WAR can be observed taking into account other terms, such as those highlighted in the table 5: attack, combat, war, threat, enemy and weapon. These terms comprise the war context emphasizing the idea of the title of treating COVID-19 as an enemy and agent of biological war. It can be observed, in this case, that the war refers to something that is intended to fight, in which there are opponents in a fight.

The conceptual metaphor is then constructed in this context by the fact that COVID-19 has emerged as something bad, difficult to control and to eliminate. In a way, humanity was not prepared to deal with such a biological agent. In this regard, it became helpless in the face of the virus's actions. The term "attack" refers to the type of invasion of the virus itself, which attacks the cell and makes it produce copies of the virus. The adjective "biological" that accompanies the noun "war" in the title leads to the interpretation of the type of war that involves the COVID-19 virus as a theme. Many lexicons that people use to describe abstract concepts are full of metaphors (Glucksberg, 2001).

The "fight", in this context, is the virus versus the human being who is trying to find a solution to the pandemic. It is a constant "threat" because it is an invisible unknown ENEMY, which makes it hard to be avoided. Thus, the terms converge for all semantic traits belonging to the context of war, reinforcing the understanding of the reason for the semantic and conceptual relationship, at a metaphorical level, between "war" and COVID-19. Likewise, the term "weapon" refers to the tools it has in an attempt to win the "war".

Sabucedo, Alzate, and Hur (2020) believe that metaphor is a good rhetorical resource capable of associating the new to an image of a family situation. For the authors, metaphors, in the light of Lakoff and Johnson (1980), consist of conceptual structures for interpreting reality, and this interpretation is based on the perception of reality. The way the subject perceives the reality of the world influences the way he responds to that reality. In other words, the war metaphor is very present in the pandemic because it evokes images, in the authors' opinion, of confrontation, obedience, while the enemy 
metaphor denotes conflict. In a way, metaphor, in this sense, comprises a form of representation of the world. For the authors, the war metaphor in this context can bring negative consequences, both for the management of the crisis and for the socio-political dynamics, because it evokes even more negative emotions. This can lead to a "save whomever we can" belief or thought, as it incites war behavior.

Indeed, as described by Charteris-Black (2004), the metaphor consists of a communicative resource by which users of language can increase the expressiveness of their message. After all, it is possible to understand how the conceptual system works, and how human beings establish relations of similarity of meanings, cognitive and semantic domains. "The metaphor is a kind of linguistic representation that results from a change in the use of a word or phrase in the context or domain in which it is expected to occur [...]" (Charteris-Black, 2004, p.21).

The covid-19 pandemic behaves as if it were a biological attack. The agent used - the SARSCoV-2 coronavirus - contaminates hundreds of thousands of people worldwide and has already caused thousands of deaths. As in other countries in the world, the situation in Portugal is worrying. Faced with the threat to National Security, the Armed Forces, as a component of the National Security and Defense system, can and must play an important role in combating this crisis. We have a widespread biological agent with relevant contagion capacity that causes a disease. As a consequence, the community was socially and economically shaken, becoming fragile. A biological war is like that. The only difference is that the threat is not an identified state or force. The enemy is the agent itself and there is (so far) no weapon capable of eliminating or neutralizing it. The consequences of the covid-19 pandemic are already effective in Portugal, with the number of sick and dead in progress and the severe impact on the economy and society. We are facing a serious threat to national security.

Table 5 - Covid-19: a biological war - the role of the Armed Forces

Source:https://sol.sapo.pt/artigo/689906/covid-19-uma-guerra-biologica-o-papel-das-forcas-armadas

The following table highlights other terms related to the WAR domain, which are widely used in communications, and in articles that portray COVID-19. The terms tactic, strategic thinking, war, threat and front line can be found widely in the media. The tactic is related to the ability to deploy and employ troops for war, who work strategically to fight the enemy. In this context, the author of this opinion article exposes the terms of war by placing analogical associations on the agents who are acting more directly in dealing with COVID-19, pointing out that it is necessary to act cautiously and strategically, with organization and discipline, to achieve success against the virus.

Health professionals, being in direct contact with patients, deal directly with the virus, which allowed the comparison with the term "front line", as they are the ones who face the enemy first. Indeed, it can be inferred that the use of conceptual metaphors confirms the notion of how the conceptual system consists of attributing concepts through a semantic network of other terms that contemplate some similarity. The metaphor is a cognitive process that acts on the structures of language. According to Lakoff $(2008$, p. 18), thinking is physical. Ideas and concepts are physically computed by brain structures. In the conception of Lakoff and Johnson (1980), the conceptual metaphor represents the interaction of two cognitive structures or domains. 
This is a biological war for which there areis adequate doctrine and tactics. The Portuguese Armed Forces can and should be engaged in other dimensions. They have strategic thinking, organization and discipline, training and capacity in the face of biological threats and have operational means prepared and available. In this war, health professionals have been at the forefront, often without the right conditions.

Table 6 - Terms of war

Source:https://sol.sapo.pt/artigo/689906/covid-19-uma-guerra-biologica-

o-papel-das-forcas-armadas

Other terms from the WAR source domain appear in the argumentation of the text in the following excerpt, as terms such as soldiers, struggle, battle and troops traditionally show up in the context of war. In the text, there are soldiers like health professionals: doctors, nurses, and assistants who deal directly with patients infected with COVID-19, so they face the risk of becoming infected too. Thus, the source domain is WAR, in the sense of generalizing and understanding several terms related to war and its target, the COVID-19.

However, considering internally, that is, within each expression or phrase, we have, in this case, the source domain as SOLDIERS and target domain as health professionals, in the conceptual metaphor: HEALTH PROFESSIONALS ARE SOLDIERS. In this way, the interpretation of the conceptual metaphor can start from the metaphorical expression and be understood more broadly when one perceives the larger domain, which in this case is WAR.

Troops are equated with teams that work together for something. In this case, the medical team usually works with many people. They are nurses, technicians, speech therapists, doctors, etc., who are part of the team that takes care of the patient. Therefore, one can observe the conceptual metaphor MEDICAL TEAM IS WAR TROOP, as they face the "enemy" (virus) in constant activity. Thus, the struggle and the battle are related to the effort, in an attempt to eradicate the disease, and to the difficulty, given of the lack of protective equipment, medicine. However, despite all their efforts, they do not obtain a response from the patient. The fight is also related to their continuous exposure to danger. For this reason, some professionals end up isolating themselves to avoid further contagion (Caires, 2020).

The soldiers in this fight are our health care professionals. It's the doctors, it's the nurses, it's the people who are working in the hospitals, it's the aids. They are the soldiers who are fighting this battle for us. You know the expression, "Save our troops", troops. In this battle, the troops are healthcare professionals. Those are the troops who are fighting this battle for us. We need to recruit more healthcare workers. We need to share healthcare professionals within this state and within this country.

Table 7 - Terms of war

Source: REV (2020)

The same conceptual metaphor is recognized by the United Nations when they publish on the world wide web that "We are at war with a virus - and we have not beaten it". Looking at the context of the publication, it was noted that if humanity is at war with the virus, it leads to the understanding that COVID-19 is an ENEMY. After all, in a war, there is a confrontation between enemies, and there can be a 
winner and a loser. In this case, the war concerns efforts to eliminate the virus, and "we did not win" because there are still many cases of COVID-19 in the world.

We are at war with a virus - and not winning it.

Table 8 - Viruses and War

Source: UNITED NATIONS (2020)

COVID-19 was also found metaphorized as a THIEF. In the table below, the conceptual metaphor is observed: COVID-19 is INVISIBLE THIEF. The term thief refers to the fact that COVID-19 appeared unexpectedly and invisibly because it is so small. The world was not prepared for this pandemic. Thus the association with a thief who suddenly appears, without warning and with a treacherous side. COVID-19 "steals" not only people's health but also their freedom. Also, with the confinement, a series of side effects were observed.

'Invisible mugger': how Boris Johnson's language hints at his thinking

Table 9 - Invisible thief

Source: The Guardian (2020)

Still considering the condition of the confinement, the discourse of health officials, given that there is no vaccine that can effectively fight the disease, is to appeal to the need to control the pandemic outbreak by using confinement, as well as ways of social detachment. Therefore, the control of the pandemic is built, discursively, based on the metonymies of CONFINEMENT and SOCIAL DISTANCING which refer, respectively, to the image schemes of the CONTAINER, specifically the residences. Another prominent metonymy is the (NEAR) -FAR relationship to maintain a safe distance from other human beings. In this regard, it is worth remembering that the method of SOCIAL BARRIER was also recommended, which metonymically comprises social distance. The same occurs with the use of masks. After all, they consist of protective equipment, a physical barrier to prevent the spread of the virus through the respiratory tract, based on the BARRIER image scheme. The following table shows an example of how the term has been used by the media to speak about protective masks.

A physical barrier against the coronavirus

Experiment conducted in China indicates that surgical masks can reduce the transmission of agents that cause respiratory diseases

Table 10 - MASK IS BARRIER

Source: FAPESP (2020)

The actions and measures to combat the pandemic have been in force as a topic widely discussed in the media. Thus, new metaphorical representations have emerged with the evolution of the control of the pandemic outbreak. According to Johnson (1987), cognition is a form of embodied action, allocated to the interactions between organism and environment. In the following example, 
there is a humorous criticism of the metonymic expression CHINESE VIRUS. The term circulates during the pandemic to demonstrate the origin or "homeland" of COVID-19 - China - as the place where it was discovered. However, in the text, the author criticizes this possible nationality of the virus. In the field of conceptual metaphor, it is possible to observe that, in this context, the virus having a nationality would also have a human characteristic, since only humans regularly have nationality, which leads to understanding the personification of metaphoric fields, as highlighted by Johnson (1987).

\begin{abstract}
People who make a point of referring to the coronavirus as "the Chinese virus" deserve my recognition [...] Knowing the virus from a scientific point of view is important, but taking a look at your passport is also helpful. I imagine that these people, after being run over, communicate to the doctor, on arrival at the hospital, the brand of the vehicle that ran over them, so that he knows if they were victims of a French, Swedish or German run over, and can determine the appropriate treatment. The identification of the nationality of the virus fills a gap that has been causing great discomfort for a long time: we never have the information about the country from which the viruses originate - and, what also disturbs, the germs in general. You never hear about the Hungarian bacteria, the Norwegian fungus or the German protozoan. They are always bacteria, fungi and protozoa, without reference to nationality, affiliation and, by the way, any other data on the citizen card of the germ in question.
\end{abstract}

Table 11 - Chinese virus

Source: Pereira (2020)

As Flusberg, Matlock and Thibodeau (2018) explain, metaphors can help you talk and think about the problem by simplifying it, highlighting certain aspects and reducing the emphasis on others. It can be said that the same extends to metonymies. By using them, the subject simplifies and highlights aspects of one object in the other. To name COVID-19 as a Chinese virus is to attribute to it all the stereotyped semantic load that is often found in Chinese products, in addition, of course, to the possibility of highlighting a certain Chinese "culpability", attributed by the media, about the origin of the virus. Therefore, the expression "Chinese virus" carries with it a negative stereotype linked to most people'speople low opinions about Chinese products. Gibbs (1999) states that both metaphor and metonymy work with mappings. In the metaphor, there are two domains, where one is understood in terms of the other, while metonymy involves only one conceptual domain.

However, another form of personification in the scope of fiction, is the relationship between COVID-19 and a monster. In the table below, it is possible to observe the conceptual metaphor COVID-19 IS MONSTER. It is important to understand the use of this metaphor within the context of the pandemic, as well as its effects on society. It is known that there are countless effects involving the appearance of COVID-19. The semantic field of the term "monster" contemplates the notion of being bad, evil, cruel and capable of having certain "powers" of an evil character. Hence, the term "terrible spell" is a metaphor that is pertinent to the condition that COVID-19 has an ability to spread evil as well. In this context, it is hardly related to the disease that COVID-19 causes in humans. That said, it is clear that the interpretation of the conceptual metaphor requires semantic integration between the terms and between the domains involved. 
Trump reflects on "the terrible spell" of the "monster" Covid-19 and speaks in the past:

"We were fine".

Table 12 - Monster COVID-19

Source: Observador (2020)

The relationship between COVID-19 and religion was also found in the media, contemplating the conceptual metaphor COVID-19 IS PUNISHMENT; COVID-19 IS PURPOSE. The article entitled "Covid: punish the purpose", in the table below, discusses the possibility that God has punished men with COVID-19. Like a "plague", the pandemic is equated to something bad for humanity. On the other hand, the purpose is raised by questioning whether COVID-19 is a divine plan, perhaps to adjust and correct humanity. Comparatively, to the metaphorical scenario of COVID-19 and the environment, it is noted that, in focus, there will be two different points of view of environmentalists about COVID-19. There is a group of environmentalists who design a "storyline" based on a chain of cause-and-effect metonymies between the environment and this pandemic outbreak. In his view, the environmental crimes committed by humanity for decades will be at the origin of the pandemic outbreak. Therefore, the "storyline" chooses PUNISHMENT as the source domain for metaphorical mappings. This scenario is inspired intertextually in the biblical frame of the plagues of Egypt, configured metaphorically as a divine punishment for the sinful conduct of the leaders of the Egyptian nation.

The Coronavirus in the world has caused havoc, the effects of a punishment or God's purpose?

Table 13 - COVID IS PUNISHMENT. COVID-19 IS PURPOSE

Source: El Verbo (2020)

\section{METHODOLOGY}

The work uses research methods qualitative and quantitative analyze bibliometric approaches to scientific production about metaphor and COVID-19. bibliometric analysis is a methodology for counting bibliographic content. The identification of the number of times in which terms are found can indicate the level of research activity on the topic (Vidican; Woon \& Madnick, 2009; Porter, A., 2007).

The methodological basis used is the systematic review of the literature, in the first moment of the research, searched, in impact databases by the scientific community, the correlation between COVID-19 and the environment and COVID-19 and possible effects. We chose to search the Web of Sscience, Science Direct and PubMed databases. The search keys were: pandemic, COVID-19, new coronavirus, effects of COVID-19. The objective was to identify the effects of COVID-19 in the literature, and then analyze them as positive or negative. In this phase of the study, a bibliometric analysis was carried out, in which the scientific articles found in the Science Direct database were published between 2015 and 2020 (last 5 years, from the beginning of the year 2015 to the month of August of the year of 2020). Its choice of PubMed and Clarivate Web of Science is justified because both are relevant and huge databases, with widespread and wide use for all areas of science. 
In a second step, to analyze the presence of conceptual metaphors, the articles selected in the bibliometric study were analyzed, as well as opinion articles published in the world media during the pandemic. The search keys were those of the bibliometric study, and also COVID-19 and ENEMY, COVID-19 and friend, in order to find possible metaphorical mappings of this semantic field to contrast with the effects of COVID-19 in several aspects.

The choice of texts is based on the theme of the new coronavirus and its impacts. The basic theoretical bias focuses on the postulations of Lakoff $(1987 ; 2006)$, whose orientation is the study of metaphor on the cognitive plane, as a natural process of the human mind, something pertinent to the cognitive apparatus. Finally, a mixed methodological profile is designed for the present study, which aims to identify the recurrent source domains of metaphorical mappings representing the disease as a phenomenon, unknown, overwhelming and highly dangerous to human health, and also, in a character qualitative approach under the principles of Lakoff and Johnson (1980), and Charteris-Black (2004) to analyze the metaphorical construction about COVID-19 that gave rise to the representation of the virus as FRIEND and ENEMY.

\section{RESULTS AND DISCUSSIONS}

From the bibliometric analysis, there was an evolution in the number of articles published over the years, which were inserted in the database of Pubmed and Clarivate Web of Science and Science Direct around the theme COVID / COVID-19. The search keys for the research arewere as shown in table 14. There was a greater number of articles involving the effects of COVID-19 in the Web of Science and Science Direct database. Research papers involving the effects of COVID-19 were more frequent on PubMed, which suggests a greater number of effects on COVID-19 inand health.

When it comes to the positive or negative effects of COVID-19, it is observed that there is a greater number of research papers about the negative effects. However, it is noteworthy that among the research papers on positive effects, these are related to the environment. There is a greater number of research papers about environment and COVID-19 more focused on health aspects, which also include studies on how the environment changed during the pandemic.

\begin{tabular}{|c|c|c|c|}
\hline 2015-2020 & \multirow{2}{*}{ Web of science } & \multirow{2}{*}{ PubMed } & \multirow{2}{*}{ Science Direct } \\
\hline Chaves de busca & & & \\
\hline COVID & 29537 & 48235 & 20279 \\
\hline COVID-19 & 29236 & 53905 & 20174 \\
\hline EFFECTS OF COVID & 2797 & 19633 & 7506 \\
\hline EFFECTS OF COVID-19 & 2808 & 22589 & 7482 \\
\hline "COVID" + "POSITIVE EFFECTS OF COVID" & 7 & 0 & 10 \\
\hline "COVID" + "NEGATIVE EFFECTS OF COVID" & 1 & 0 & 12 \\
\hline "COVID-19" + "POSITIVE EFFECTS OF COVID-19" & 7 & 0 & 10 \\
\hline "COVID-19" + "NEGATIVE EFFECTS OF COVID-19" & 1 & 0 & 12 \\
\hline COVID + ENVIRONMENT & 752 & 10435 & 4812 \\
\hline "COVID-19" + ENVIRONMENT & 743 & 10616 & 4774 \\
\hline "COVID" + "METAPHOR" & 13 & 196 & 66 \\
\hline "COVID-19" + METAPHOR" & 13 & 196 & 66 \\
\hline
\end{tabular}

Table 14 - Bibliometric Research

Source: author data 
In this study, the objective was to show the side effects of COVID-19 and, later, to verify the conceptual metaphors present in the selected texts, therefore, the bibliometric survey helped in the understanding of these effects, especially with regard to the understanding about the relationship between COVID and friendship, present in texts whose theme involves COVID-19, and positive effects of COVID-19. Compared to other topics involving COVID-19, research on the effects of the pandemic is still growing. It is believed that other studies may be in the process of publication. With the search key involving metaphors and COVID / COVID-19, few results were found compared to others related to studies on Science, which indicates originality regarding the studies on this correlation. The largest number (196 articles) was found in PubMed, which suggests a greater use of metaphors and COVID-19 related to Health and Environment.

Throughout the semantic analyzes carried out, based on the interpretation of metaphors found with this semantic bias, there were many other effects here named by the author of this study as (co) lateral, given the harmful and positive character of COVID-19 in various aspects. However, what really stands out as a positive effect of COVID-19 is the benefit to the environment during the quarantine period, when the circulation of people is limited.

In terms of positive and negative effects there was a greater number of metaphors with the source domain related to negative effects such as: WAR and ENEMY. When it comes to the positive effects of COVID-19, metaphors were found whose source domain is FRIENDSHIP. The results show that there is a greater presence of (explicit) metaphors in opinion articles, compared to scientific articles, which suggests greater freedom of writing in journalistic genres. The metaphors found in scientific articles tend to be more implicit, focused on the argument itself, and revolving around the concepts of scientific terms, often to explain them, such as the studies by Brown (2003).

Furthermore, it can be seen, as argued by Lakoff (1980) and Glucksberg (2001), that the metaphor transcends linguistic manifestations as it deals with something in the conceptual apparatus itself. The language for Lakoff (1980) is secondary and the mapping is primary, because, before it is manifested as a phenomenon, there is a cognitive conceptualization process.

Initially, it was defined that the type of search selected would be summaries limiting the results to the last 5 years, and the search language for the researched scientific articles was English. For opinion articles, the search language has also been expanded to Portuguese and Spanish. A refinement was made in the search and the keywords were expanded to better filter the articles. With these filters, it was observed that most of the articles, involving the COVID-19 theme are from 2020.

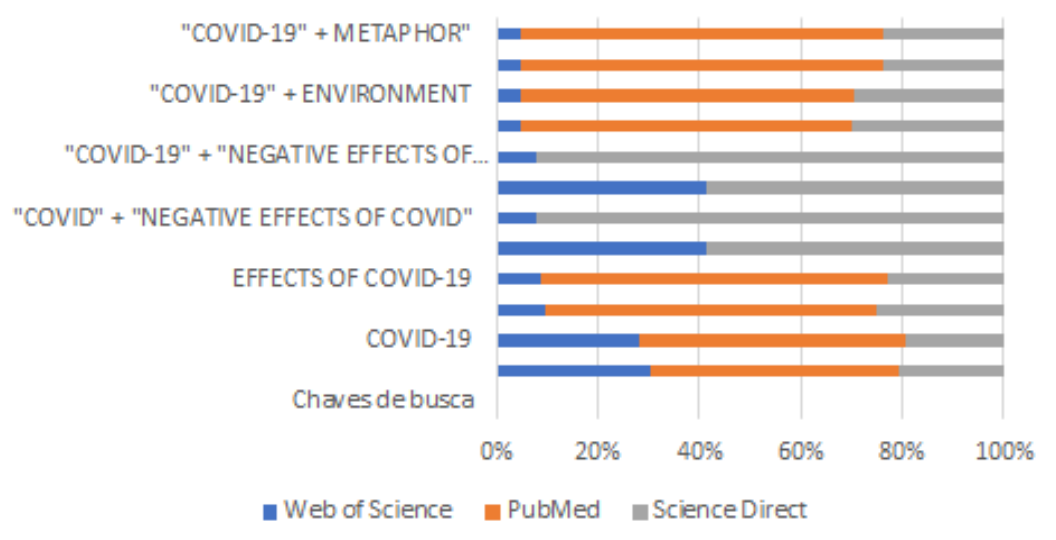

Graph 1 - Results of bibliometric research

Source: author data 


\section{CONCLUSION}

It was concluded that COVID-19, in terms of metaphorical object, is usually understood in the media and scientific texts as ENEMY, considering the sphere of the semantic field virus, and its invader role regarding the human organism. Therefore, most of the metaphorical terms and expressions will contain semantic features that bring a semantic correlation to the universe or domain of WAR. War source domain is the most found due to its association withto the negative effects of COVID-19 for humanity. After all, the current scenario presents favorable conditions for this semantic correlation, since the entire socioeconomic, cultural and health spheres of society are in a critical situation, on the path to a world crisis of dimensions that are still incalculable, in some aspects.Therefore, the metaphor expression COVID-19 IS FRIEND is found when the author's news talks about climate change during the pandemic period. More negative than positive metaphors were found related to COVID-19

The construction of the conceptual metaphor COVID-19 IS ENEMY is widely adopted during the pandemic, which suggests that, in fact, the human cognitive apparatus involves metaphorical formulations, since the association was easily disseminated. The enemy (the virus) has been identified and a strategy is needed, such as measures to contain and spread the virus, the need to "flatten the curve" to avoid further damage, and still "save the economy."

However, COVID-19 appears as a subversion of the negative circumstances of the pandemic, very much focused on an evil that brought something positive to humanity despite all the harmful trail to men. It is observed that the use of metaphors in this pandemic context not only brings to the fore the awareness that man thinks through metaphors, but also reveals a certain argumentative appeal to encourage the relation of the condition of the pandemic to something serious and harmful to humanity, such as a world war. 


\section{REFERÊNCIAS}

Brown, T. L. (2003). Making truth: metaphor in Science. University of Illinois Press.

Bruno, C. (2020). Trump reflete sobre "o feitiço terrível" do "monstro" Covid-19 e já fala no passado: "Estivemos bem". Observador. Saúde/Coronavírus, 10 abr. 2020. Retrieved from: https://observador.pt/2020/04/10/trump-reflete-sobre-o-feitico-terrivel-do-monstro-covid-19-e-ja-falano-passado-estivemos-bem/.

Caires, L. (2020) O cotidiano dos profissionais de saúde na linha de frente da COVID-19. Jornal da USP, 22 mai 2020. Retrieved from: https://pfarma.com.br/coronavirus/5522-cotidiano-profissional-saude.html.

Coulson, S. (2008). Metaphor Comprehension and the brain. In: GIBBS, R.W. Metaphor and thought. New York: Cambridge University Press, 2008, .177-194.

Currie, G.M. (2020).A Lens on the Post-COVID-19 "New Normal" for Imaging Departments. Journal of Medical Imaging and Radiation Sciences,2020, p 1-3.

Dicimedico. Dicionário de etimologia médico. (2020). Retrieved from: https://dicimedico.com/colateral/.

Dicio. Dicionário Online de Português. (2020). Retrieved from: https://www.dicio.com.br/colateral/.

DOWNING, L.; MUJIC, B.K. Infectious diseases are sleeping monsters:Conventionaland culturally adapted new metaphors in a corpus of abstracts on immunology. Ibéria, 17, 2009, p. 61-82.

Duarte, P. M. (2020). COVID-19: Origem do novo coronavírus. Braz. J. Hea. Rev., Curitiba, v. 3, n. 2, p.35853590, mar./apr. 2020.

Dutheil, F., Baker, S.J.; Navel, V. (2020). COVID-19 as a factor influencing air pollution? Environ. Pollut. Retrieved from: https://doi.org/10.1016/j.envpol.2020.114466.

Fapesp. (2020). Uma barreira física contra o coronavírus: Experimento realizado na China indica que máscaras cirúrgicas podem reduzir a transmissão de agentes causadores de doenças respiratórias. Pesquisa FAPESP. Saúde Pública. Retrieved from: https://revistapesquisa.fapesp.br/uma-barreira-fisica-contra-o-coronavirus/.

Fe-nix. (2020). COVID: castigo o proposito. El Coronavirus en el mundo ha causado estragos, ¿efectos de un castigo o propósito de Dios? El Verbo, 18 mai 2020. Disponível em:https://elverbo.org/castigo-o-proposito/. Acesso em:05 set. 2020.

Flusberg, S.; Matlock, T.; Thibodeau, P. War metaphors in public discourse. Metaphor and Symbol, 33(1):118, 2018. Retrieved from: DOI: 10.1080/10926488.2018.1407992

Gibbs JR, R.W.(1999). Researching metaphor. In: CAMERON, L.; LOW, G. Researching and applying metaphor. New York: Cambridge University Press, pp.29-47.

Gentner, D.; Maravilha, F. (2018). Analogical reasoning. L. J. Ball \& V. A. Thompson (eds.). International Handbook of Thinking \& Reasoning. NY, NY: Psychology Press, pp. 186-203.

Glucksberg, S. (2001). Understanding figurative language: from metaphor to idioms. New York: Oxford University Press, 2001.

He, M.Z., Kinney, P.L., Li, T., Chen, C., Sun, Q., Ban, J., Wang, J., Liu, S., Goldsmith, J. Kioumourtzoglou, M.A., 2020a. Short- and intermediate-term exposure to NO2 and mortality: a multi-county analysis in China. Environ Pollut. 
He, L., Zhang, S., Hu, J., Li, Z., Zheng, X., Cao, Y., Xu, G., Yan, M., Wu, Y., 2020b. On-road emission measurements of reactive nitrogen compounds from heavy-duty diesel trucks in China. Environ. Pollut. Retrieved from: https://doi.org/10.1016/j.envpol.2020.114280.

Johnson, M. (1987). The body in the mind: the bodily basis of meaning, imagination and reason. Chicago: The University of Chicago Press, 1987.

Lakoff, G. (2008). The neural theory of metaphor. In: Gibbs, R.W. Metaphor and thought. New York: Cambridge University Press, pp.17-38.

Lal, A. P; Kumar, A.; Kumar, S.; Kumari, S.; Saikia, P.; Dayanandan, A.; Adhiakari D.; Khan, M.L. (2020). The dark cloud with a silver lining: Assessing the impact of the SARS COVID-19 pandemic on the global environment. Science of the Total Environment, 732 (2020) 139297.

Lewis, S. (2020). Before-and-after photos show dramatic decline in air pollution around the world during coronavirus lockdown. CBS News, april 22, 2020 . Retrieved from: https://www.cbsnews.com/news/coronavirus-photos-decline-air-pollution-lockdown/.

Li, S.; Wang, Y.; Xue, J.; Zhao, N.; Zhu, T. (2020). The Impact of COVID-19 Epidemic Declaration on Psychological Consequences: A Study on Active Weibo Users. Int. J. Environ. Res. Public Health, 17(6), 2032. Retrieved from: https://doi.org/10.3390/ijerph17062032

Martins, M.T. (2020). Covid-19: inimigo do homem, amigo do ambiente. JUP, Ciência e Saúde, 27 Mar 2020. Retrieved from: https://www.juponline.pt/ciencia-saude/artigo/34883/covid-19-inimigo-do-homemamigo-do-ambiente.aspx.

Misra, K. Covid-19: 4 negative impacts and 4 opportunities created for education: The Covid-19 pandemic has had a major impact on education - both negative and positive. What exactly are the risks and opportunities brought about by Coronavirus? Indiatoday, 12 may 2020. Retrieved from: https://www.indiatoday.in/education-today/featurephilia/story/covid-19-4-negative-impacts-and-4opportunities-created-for-education-1677206-2020-05-12.

Ministério Da NASA, 2020. NASA (2020). Retrieved from: https://earthobservatory.nasa.gov/images.

Monserrate, M.A.; Ruanob, M.A.; Sanchez-Alcalde, L. Indirect effects of COVID-19 on the environment. Science of the Total Environment, 728 (2020) 138813.

Nordea. Climate. Covid-19: Climate friend or foe?. Retrieved from: https://insights.nordea.com/en/sustainable-finance/covid-19-climate/. 2020. Acesso em: 05 set. 2020.

Paital, B. B., Das, K., Parida, S.K., 2020. Internation social lockdown versus medical care against CO VID-19, a mild environmental insight with special reference to India. Sci. Total Environ. 138914 PII S00489697(20)32431-1.

Paital, B. Nurture to nature via COVID-19, a self-regenerating environmental strategy of environment in global context. Science of the Total Environment, 729 (2020) 139088.

Parodi, I.C.; Poetal, M.G.; Assinil, A.; Schirinzil, E. Sete, P.D. (2020). Impact of quarantine due to COVID infection on migraine: a survey in Genova, Italy. Neurological Sciences, 2020, 41:2025-2027. Retrieved from: DOI: https://doi.org/10.1007/s10072-020-04543-x.

Pereira, R. A. (2020). A nacionalidade do coronavírus. Opinião boca do inferno, 01 mai. 2020. Retrieved from: https://visao.sapo.pt/opiniao/cronicas/boca-do-inferno/2020-05-01-a-nacionalidade-do-coronavirus/. 
Priberam Dicionário. Dicionário de Língua Portuguesa online. Retrieved from: https://dicionario.priberam.org/colateral.

Protocolo de tratamento do Novo Coronavírus (2019-nCoV). Secretaria de Atenção Especializada à Saúde. Departamento de Atenção Hospitalar, Urgência e Domiciliar. Brasília - DF, 2020. Retrieved from: http://das.prodegesp.ufsc.br/files/2020/02/protocolo-tratamento_coronavirus-individ-1-1.pdf

Rev. Governor Andrew Cuomo New York COVID-19. Press Conference Transcript March 30, 30 mar 2020. Retrieved from: https://www.rev.com/blog/transcripts/governor-andrew-cuomo-new-york-covid-19press-conference-transcript-march-30.

Richman, D.D; Whitley, R.J; Hayden, F.G. (2016). Clinical Virology, 4.ed.Washington: ASM Press.

Sabucedo, J.M.; Alzate, M.; Hur, D. (2020). COVID-19 and the metaphor of war (COVID-19 y la metáfora de la guerra. International. Journal of Social Psychology, 35:3, 618-624, 2020. Retrieved from: DOI: $10.1080 / 02134748.2020 .178 .3840$

Saude Debate. Notícias. (2020). "Pandemia da Covid-19 é uma das mais complexas catástrofes de todos os tempos", diz economista José Pio Martins..2020. Retrieved https://saudedebate.com.br/noticias/pandemia-da-covid-19-e-uma-das-mais-complexas-catastrofes-detodos-os-tempos-economista-jose-pio-martins.

Sulaman, M.; Long, X.; Salman, M. (2020). COVID-19 pandemic and environmental pollution: A blessing in disguise?. Science of the Total Environment, 728 (2020) 138820. Retrieved from: https://doi.org/10.1016/j.scitotenv.2020.138820

Specktor, B. (2020). Starving Monkey 'Gangs' Battle in Thailand as Coronavirus Keeps Tourist Away. Retrieved from: https://www.livescience.com/macaque-fight-thailand-temple-coronavirus.html.

Un environment programme. Trabalhar com o meio ambiente para proteger as pessoas: resposta do PNUMA à COVID-19. 14 de maio de 2020. Retrieved from: https://www.unenvironment.org/pt$\mathrm{br} /$ resources/trabalhar-com-o-meio-ambiente-para-proteger-pessoas-resposta-do-pnuma-covid-19.

United Nations. (2020). COVID-19 Response. This war needs a war-time plan to fight it. 26 mar. 2020. Retrieved from: https://www.un.org/en/coronavirus/war-needs-war-time-plan-fight-it.

Vidican, G., Woon, W.L. \& Madnick, S. (2009). Measuring innovation using bibliometric techiques: The case of solar photovoltaic industry. Sloan School of Management, MIT.

Walsh, B. (2020). Covid-19: The history of pandemics. BBC, 25 março 2020. Retrieved from: https://www.bbc.com/future/article/20200325-covid-19-the-history-of-pandemics.

Zowalaty, M. E.E.; Young, S.G.; Järhult, J. D. (2020). Environmental impact of the COVID-19 pandemic - a lesson for the future. Infection Ecology \& Epidemiology, 2020, vol. 10, 17680023. Retrieved from: DOI: https://doi.org/10.1080/20008686.2020.1768023.

Zhu, Y.; Xie, J.; Huang, F.; Cao, L. (2020). Association between short-term exposure to air pollution and COVID19. Science of the Total Environment, 727, 138704. 


\section{Sobre a Organizadora}

\section{Maria Emília de Abreu Chaves}

Graduada em Fisioterapia (PUC-MG), Especialista em Fisioterapia aplicada a Ortopedia e Esportes (UFMG), Mestre e Doutora em Bioengenharia (UFMG). Docente no Centro Universitário UNA e na Faculdade FACEMG. Pesquisadora do Laboratório de Bioengenharia (LABBIO) nos projetos de desenvolvimento de tecnologias e inovação.

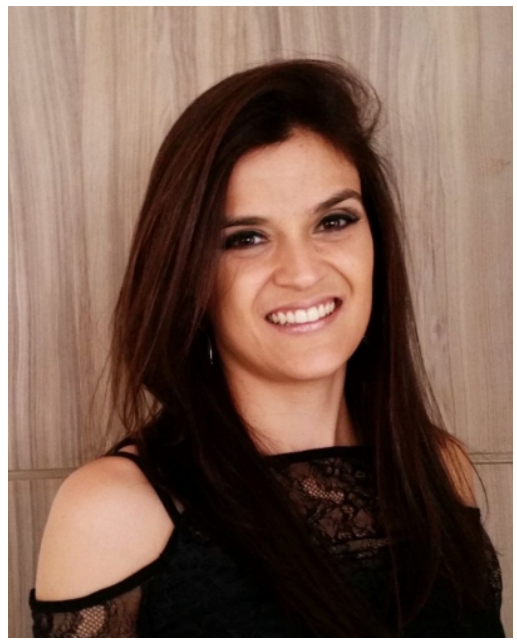



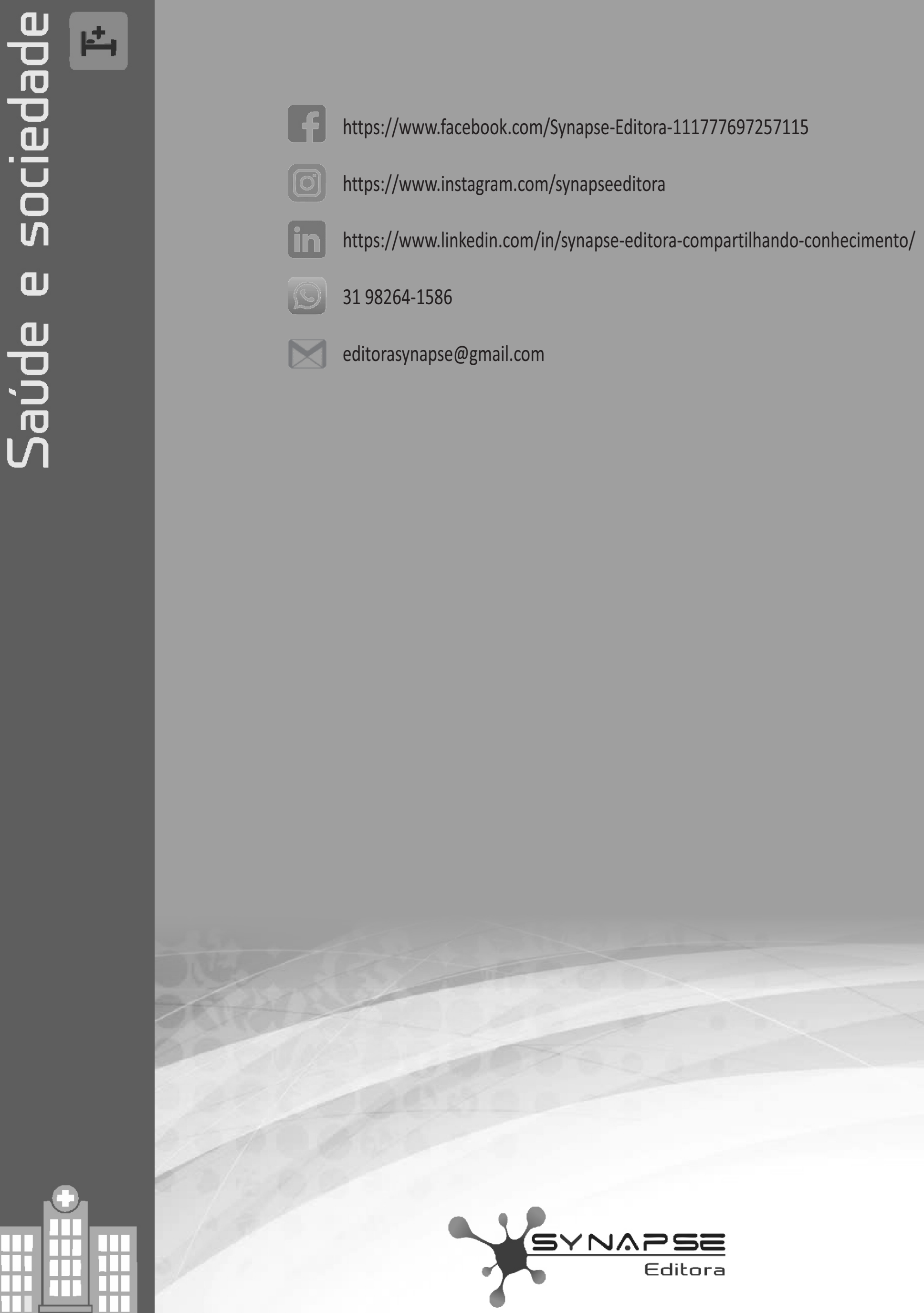

Compartilhando conhecimento 